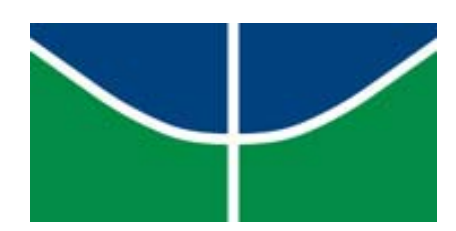

Universidade de Brasília

Instituto de Psicologia

Programa de Pós-Graduação em Psicologia Social, do Trabalho e das Organizações

Tese de Doutorado

\title{
ANTECEDENTES E CONSEQUENTES DE EXPECTATIVAS DE CARREIRA E DE FUTURO ORGANIZACIONAL
}

Vinicius Carvalho de Vasconcellos

Brasília, março de 2015 


\section{ANTECEDENTES E CONSEQUENTES DE EXPECTATIVAS DE CARREIRA E DE FUTURO ORGANIZACIONAL}

\section{ANTECEDENTS AND CONSEQUENTS OF CAREER AND ORGANIZATIONAL FUTURE EXPECTATIONS}

Vinicius Carvalho de Vasconcellos

Tese de doutorado apresentada ao Programa de Pós-Graduação em Psicologia Social, do Trabalho e das Organizações, do Instituto de Psicologia da Universidade de Brasília, como parte dos requisitos para obtenção do título de Doutor em Psicologia Social, do Trabalho e das Organizações.

Orientadora: Prof ${ }^{\mathrm{a}}$. Dra. Elaine Rabelo Neiva 


\title{
ANTECEDENTES E CONSEQUENTES DE EXPECTATIVAS DE CARREIRA E DE FUTURO ORGANIZACIONAL
}

\section{Esta tese foi avaliada pela seguinte comissão examinadora:}

\author{
Prof. ${ }^{a}$ Dra. Gardênia da Silva Abbad (Presidente) \\ Programa de Pós-Graduação em Psicologia Social, do Trabalho e das Organizações \\ Universidade de Brasília - UnB
}
Prof. Dr. Mauro de Oliveira Magalhães (Membro titular)
Programa de Pós-Graduação em Psicologia
Universidade Federal da Bahia - UFBA

Prof. a Dra. Tatiane Paschoal (Membro titular)

Departamento de Administração

Universidade de Brasília - UnB

\section{Prof. Dr. Pedro Paulo Murce Meneses (Membro titular) \\ Programa de Pós-Graduação em Administração \\ Universidade de Brasília - UnB}

Prof. Dr. Jairo Eduardo Borges-Andrade (Membro titular)

Programa de Pós-Graduação em Psicologia Social, do Trabalho e das Organizações

Universidade de Brasília - UnB

Prof. ${ }^{\text {a }}$ Dra. Gisela Demo (Membro suplente)

Programa de Pós-Graduação em Administração

Universidade de Brasília - UnB 


\section{AGRADECIMENTOS}

Agradeço, sobretudo, aos participantes da pesquisa que dedicaram seu tempo para responder aos questionários e aos profissionais de recursos humanos que abriram as portas de suas organizações para a coleta de dados. Sem tal colaboração, a pesquisa não passaria do estágio de projeto.

Sou grato pelo sólido apoio de minha família e por sua compreensão diante dos momentos de ausência. Foi por uma boa causa.

Agradeço à Elaine Neiva, orientadora desta tese, por acolher este carioca na Universidade de Brasília (UnB) e por seus apontamentos em todo o transcurso da pesquisa. Acessível e presente, contribuiu muito para encurtar a distância de 1100 quilômetros que separam o Rio de Janeiro de Brasília.

Ressalto a importância das ponderações dos membros da banca de qualificação, Maria Cristina Ferreira, Gisela Demo e Jairo Eduardo Borges-Andrade. O formato final da tese foi assaz influenciado por estes professores. Envio também meu muito obrigado aos solícitos e cordiais funcionários do Departamento de Psicologia Social e do Trabalho da UnB.

Expresso igualmente minha gratidão diante do suporte fornecido por Eduardo Medrado, Regina Valle, Dennis Russo e Cláudia Nunes, profissionais que possibilitaram a conciliação do doutorado com meu trabalho na Petrobras.

Por fim, sou grato também pelo companheirismo inquebrantável de Raquel Vasques, compreensiva, carinhosa e solidária mesmo quando nossas horas de convívio eram subtraídas em função do doutorado. Registro aqui o pedido oficial: quer casar comigo? 


\section{RESUMO}

A relação dos profissionais com o futuro constitui tema pouco explorado em comportamento organizacional, embora existam evidências de sua relevância para a vida laboral. Partindo dessa lacuna e valorizando o caráter intertemporal do trabalho, esta tese investigou variáveis que influenciam expectativas sobre o futuro na carreira e sobre o futuro da organização, assim como analisou os efeitos dessas expectativas em outras variáveis no contexto organizacional. A tese está organizada em sete manuscritos concatenados. Os Manuscritos $1 \mathrm{e}$ 2 descortinam revisões de literatura sobre futuro na carreira e futuro organizacional, examinando possibilidades de investigação acadêmica e sumariando pesquisas empíricas sobre os tópicos. Os Manuscritos 3 e 4 apresentam, respectivamente, o desenvolvimento da Escala de Expectativas de Carreira na Organização e da Escala de Expectativas de Futuro Organizacional. As duas escalas foram validadas por análise fatorial confirmatória e exibiram boas qualidades psicométricas. O Manuscrito 5 analisa, por meio de três amostras distintas, os efeitos de variáveis relativas à atual situação de carreira do profissional nas suas expectativas de carreira na organização. Os dados, combinados em meta-análise de pequeno porte, apontaram o efeito significativo do cargo ocupado e da obtenção de conquistas profissionais recentes, o que não ocorreu nas variáveis estágio de carreira e tempo de carreira na organização. A pesquisa relatada no Manuscrito 6 testa, em amostra de uma autarquia federal, modelo estrutural com antecedentes de expectativas de carreira e de futuro organizacional. Os dados sinalizaram o impacto positivo de percepções de políticas e práticas de $\mathrm{RH}$ e bem-estar no trabalho nas expectativas e o papel moderador de tempo de organização nessa relação. Por derradeiro, o Manuscrito 7 reporta estudo que testou, em amostra de profissionais de múltiplas organizações, um modelo estrutural de consequentes de expectativas de carreira e de futuro organizacional. Estas exibiram efeitos significativos em comprometimento organizacional afetivo e intenção de rotatividade. Tipo de organização e orientação para o futuro dos respondentes moderaram a relação das expectativas de carreira com as variáveis consequentes. Em conjunto, os manuscritos produziram conhecimentos novos sobre a relação dos indivíduos com o futuro no contexto organizacional e forneceram instrumentos úteis para a academia e as organizações. A seção de considerações finais discute implicações e limitações da tese, assim como possíveis pesquisas futuras.

Palavras-chave: carreira, expectativas, futuro profissional, futuro organizacional 


\begin{abstract}
The relationship between professionals and the future is rarely explored in organizational behavior area, although there is evidence of its relevance to working life. Considering this gap and the intertemporal nature of the work, this doctoral dissertation investigated variables that influence expectations about future career and future of the organization, and analyzed the effects of these expectations on other variables in the organizational context. The dissertation is organized in seven concatenated manuscripts. Manuscripts 1 and 2 present literature reviews on projections about future career and future of the organization, examining research possibilities and summarizing empirical research on the topics. Manuscripts 3 and 4 show, respectively, the development of Career Expectations in the Organization Scale and of Organizational Future Expectations Scale. Both scales were validated by confirmatory factor analysis and showed good psychometric properties. The Manuscript 5 analyzes, with three different samples, the effects of variables related to current career situation on the career expectations in the organization. The data, combined into small meta-analysis, indicated the significant effect of the professionals' career position and of the recent career achievements, pattern that was not present in other variables like career stage and organizational tenure. The research in Manuscript 6 tests, in a sample of a government agency, a structural model with antecedents of career and organizational future expectations. The data signaled the positive impact of perceptions of human resources policies/practices and of well-being at work on expectations, and the moderating role of organizational tenure on this relationship. The research in Manuscript 7 tests, in a sample of professionals from multiple organizations, a structural model with consequents of career and organizational future expectations. The expectations showed significant effects on affective organizational commitment and turnover intention. Organization's sector and future time perspective of the respondents moderate the effects of career expectations on the consequents. Together, the manuscripts produced new knowledge about the relationship between individuals and the future in the organizational context and provided useful tools for the academy and organizations. The implications and limitations of the dissertation are discussed in the final section, which also points out future research possibilities.
\end{abstract}

Keywords: career, expectations, professional future, organizational future 


\section{SUMÁRIO}

Apresentação.

Manuscrito 1 - Futuro na Carreira no Contexto Organizacional: Possibilidades e

Tendências na Literatura.

Resumo/Abstract 20

Introdução. 21

Trajetórias de Carreira no Cenário Contemporâneo.

Futuro na Carreira: Possibilidades de Investigação no Contexto Organizacional.

Expectativas e Percepções sobre Futuro na Carreira: Definições, Instrumentos e Variáveis Relacionadas.

Futuro na Carreira no Contexto Organizacional: Síntese e Reflexões sobre a Literatura.. 34

Considerações Finais. 38

Referências

Manuscrito 2 - Futuro Organizacional na Perspectiva Individual: Possibilidades e Tendências na Literatura

Resumo/Abstract. 48

Introdução. 49

Futuro no Nível Macro-Organizacional: Planejamento, Cenários, Desenvolvimento e Mudanças

Futuro Organizacional: Possibilidades de Investigação na Perspectiva Individual.

Futuro Organizacional na Perspectiva Individual: Síntese e Tendências na Literatura... 66

Considerações Finais. 70

Referências.

Manuscrito 3 - Escala de Expectativas de Carreira na Organização: Desenvolvimento e Evidências de Validade.

Resumo/Abstract 80

Introdução. 81

Estudo 1. 89

Estudo 2. 95

Discussão Geral 100

Referências.

Manuscrito 4 - Escala de Expectativas de Futuro Organizacional: Desenvolvimento e Evidências de Validade.

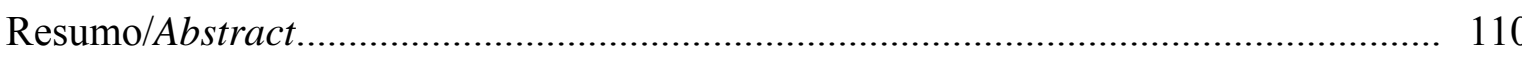

Introdução 


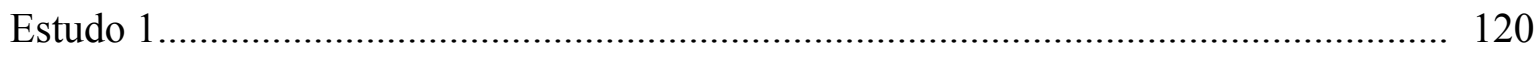

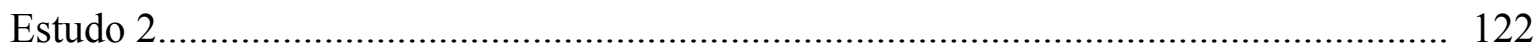

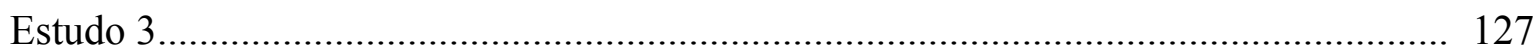

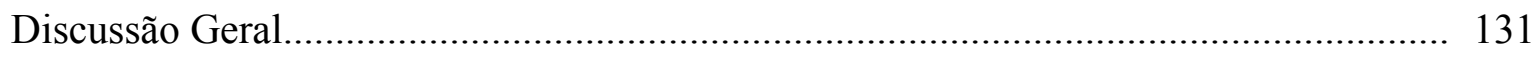

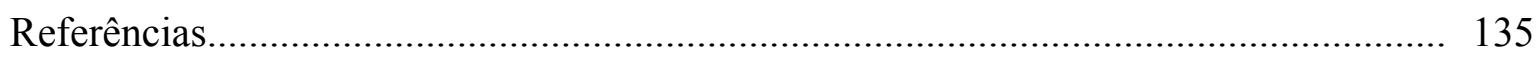

Manuscrito 5 - Situação de Carreira e Expectativas de Futuro na Organização............ 139

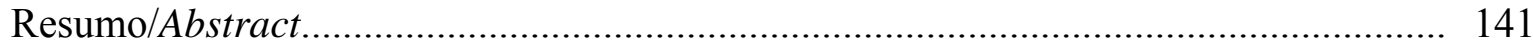

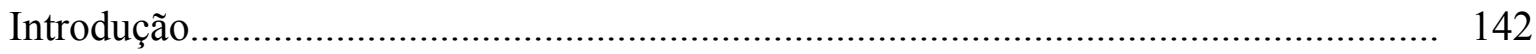

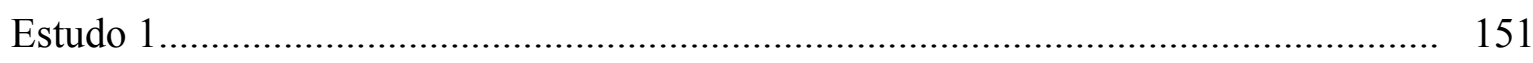

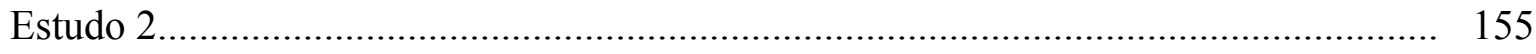

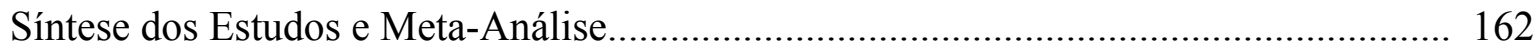

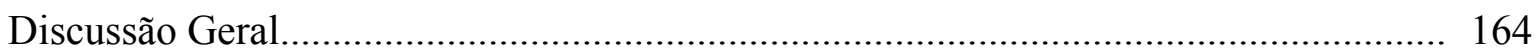

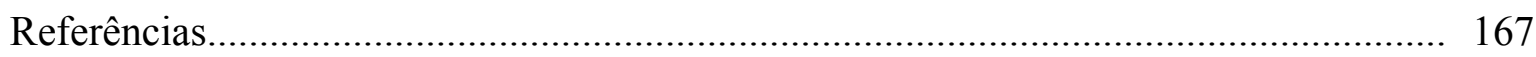

Manuscrito 6 - Como Será o Amanhã? Examinando Antecedentes de Expectativas de

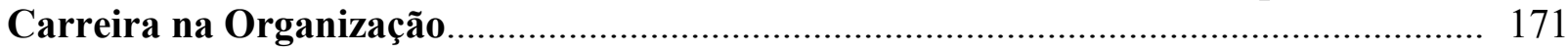

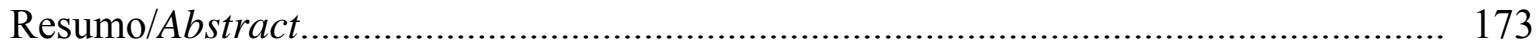

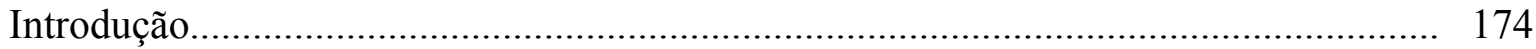

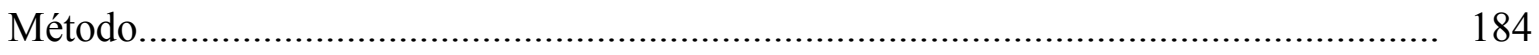

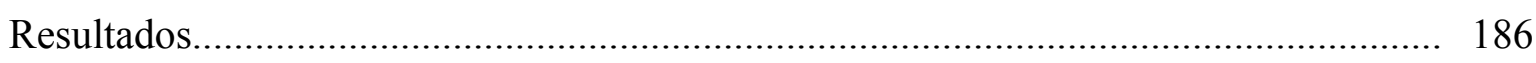

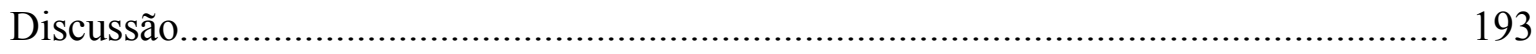

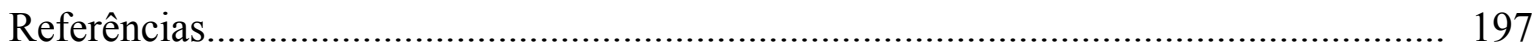

Manuscrito 7 - Efeitos de Expectativas de Futuro em Comprometimento

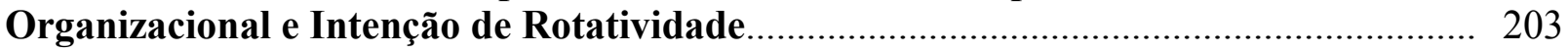

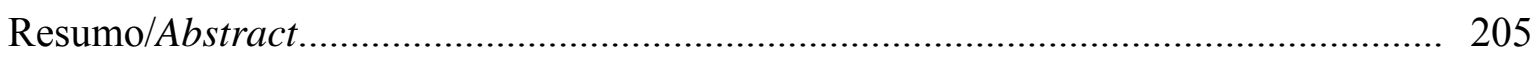

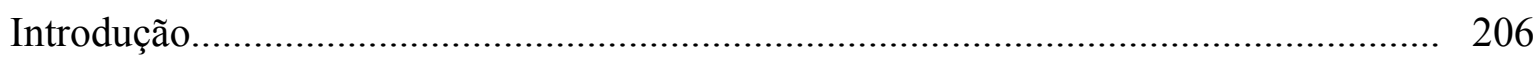

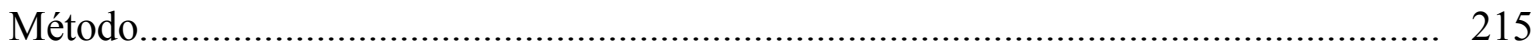

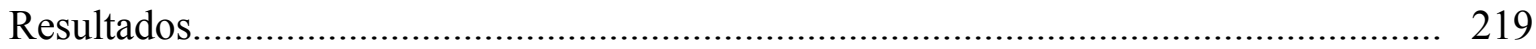

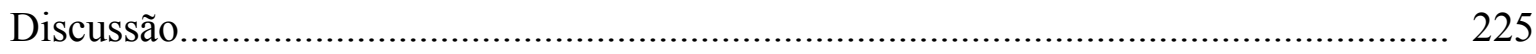

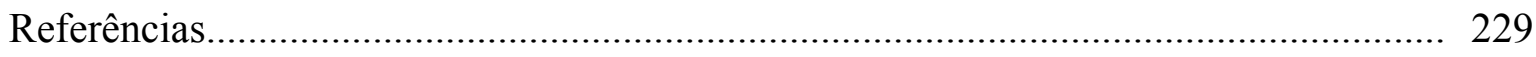

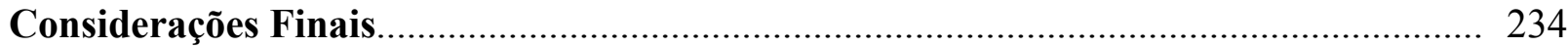




\section{LISTA DE FIGURAS}

\section{Apresentação}

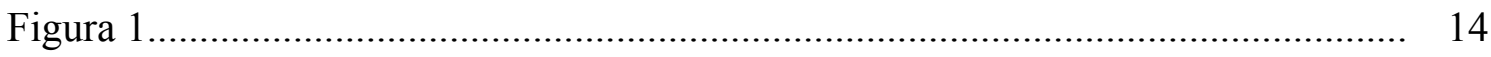

\section{Manuscrito 1}

Figura 1

\section{Manuscrito 2}

Figura 1

\section{Manuscrito 4}

Figura 1.

Manuscrito 5

Figura 1

Figura 2. 163

Figura 3.

Manuscrito 6

Figura 1. 176

Figura 2 .. 189

Figura 3.

\section{Manuscrito 7}

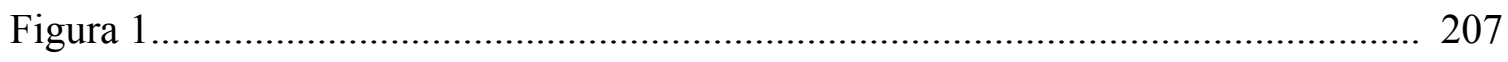

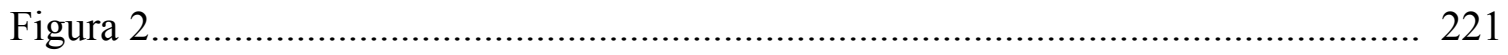




\section{LISTA DE TABELAS}

\section{Manuscrito 1}

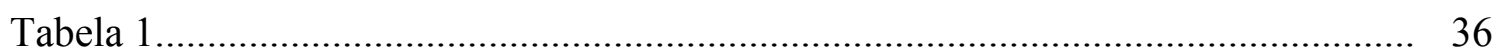

\section{Manuscrito 2}

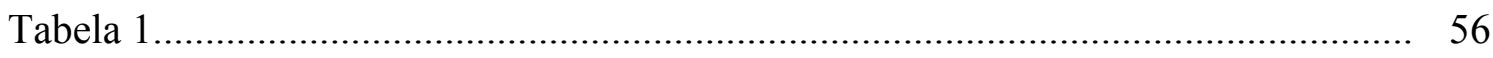

Manuscrito 3

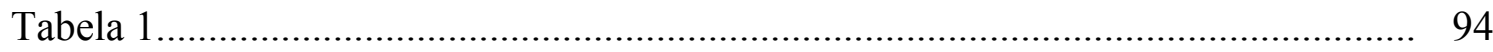

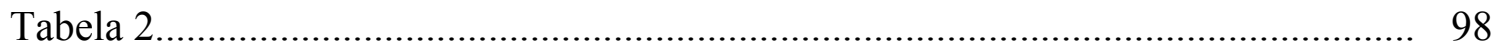

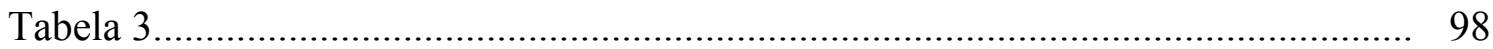

Manuscrito 4

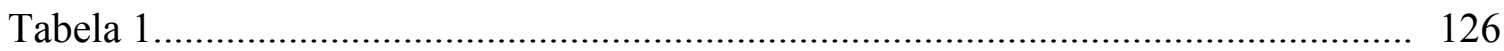

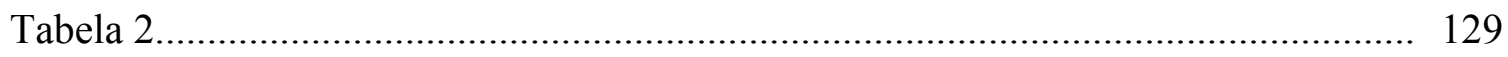

Manuscrito 5

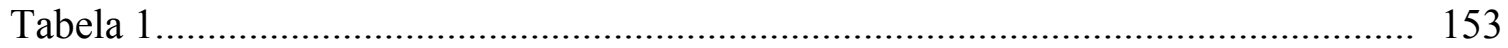

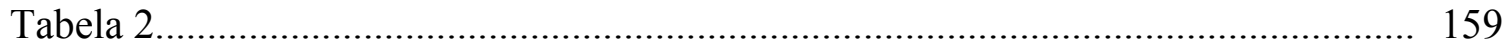

Manuscrito 6

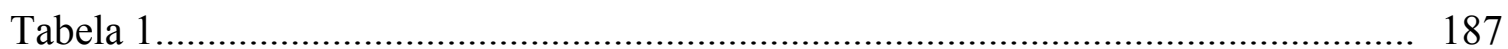

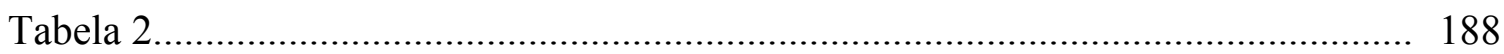

Manuscrito 7

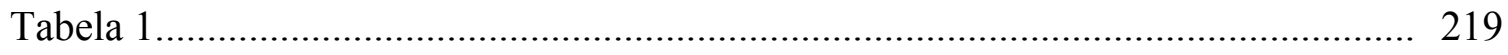

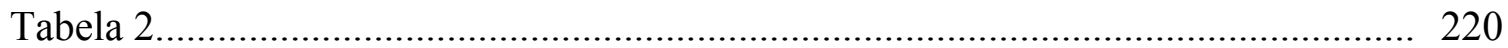




\section{APRESENTAÇÃO}

Como seria a vida dos indivíduos sem a percepção de passado, presente e futuro? Como seriam seus pensamentos, afetos e comportamentos sem o lastro interpretativo das experiências pregressas e memórias? E como seria o dia a dia sem a possibilidade de projetar eventos que ainda não se consumaram e sem a perspectiva do amanhã? A dificuldade em responder tais indagações denuncia como a vida psíquica e social é modulada pela experiência temporal, fenômeno sutil e ubíquo que opera como pedra angular que sustenta e orienta os indivíduos ao longo de sua existência.

A experiência temporal deriva da percepção de que o mundo e os próprios indivíduos passam por constantes mudanças. A percepção de mudança pode ser compreendida por meio dos conceitos de sucessão - percepção de que dois ou mais eventos são diferentes e organizados sequencialmente - e de duração, que remete à apreensão da existência de um intervalo entre eventos sucessivos (Fraisse, 1984). Embora as vivências de sucessão e duração permeiem de forma bastante natural o cotidiano dos indivíduos, a rigor, não há caminho único para examinar a temática, sendo a própria concepção de tempo suscetível a mudanças no decurso da história. Por exemplo, no campo da física, a visão newtoniana de um tempo absoluto e regular cedeu lugar, a partir da teoria da relatividade de Einstein, para o entendimento de que o tempo transcorre de forma diferente a depender da velocidade do observador (Butler, 1995; Lee \& Liebenau, 1999).

As ciências humanas e sociais, por seu turno, reconhecem a existência do tempo objetivo e do tempo subjetivo, distinção frequentemente simbolizada pelo contraste entre o tempo do relógio e o tempo social (Orlikowski \& Yates, 2002). A primeira concepção, predominante nas sociedades ocidentais contemporâneas, apreende o tempo como entidade homogênea, absoluta, linear e independente dos eventos. A segunda acolhe-o como fenômeno subjetivo e compartilhado socialmente, surgindo de forma heterogênea, dinâmica e 
descontínua ao sabor das convenções e práticas sociais (Bluedorn \& Denhardt, 1988; Lee \& Liebenau, 1999; Orlikowski \& Yates, 2002).

Esta investigação filia-se à tradição de estudos sobre o tempo subjetivo ocupando-se, sobretudo, da capacidade humana de se relacionar com eventos do futuro. Com efeito, a experiência temporal relacionada ao futuro figura em formulações teóricas de grande monta na psicologia, entre as quais a teoria de campo e a teoria do espaço vital (Lewin, 1939, 1951) e o conceito de autoeficácia (Bandura, 1977). No fundo, a relação com o futuro influencia a vida de todas as pessoas (Lewin, 1939) e se manifesta em diversos fenômenos da vida psíquica, incluindo cognições, emoções e comportamentos (Aspinwall, 2005).

A relação dos indivíduos com futuro permeia os mais diversos domínios do campo social, tais como, trabalho, educação, lazer, família e relacionamentos amorosos. Esta tese debruça-se especificamente sobre o campo do trabalho e das organizações. De modo surpreendente, diversos pesquisadores reconhecem que a temporalidade (incluindo a relação dos indivíduos com o futuro) é em larga escala ignorada ou tratada de forma implícita/inadequada na administração, na psicologia organizacional e do trabalho e no comportamento organizacional (Bluedorn \& Denhardt, 1988; Butler, 1995; George \& Jones, 2000; Lee \& Liebenau, 1999).

Assim, por um lado, a relação dos indivíduos com o futuro condiciona sua subjetividade e anima sua vida psíquica. Por outro, o conhecimento sobre esse fenômeno no campo organizacional ainda compõe ponto frágil na literatura. Reconhecendo a relevância e, concomitantemente, a carência de estudos sobre o fenômeno nesse campo, a tese investiga dois tipos de expectativas de futuro: expectativas de carreira na organização e expectativas sobre o próprio futuro da organização. Expectativas tratam de crenças sobre a probabilidade de ocorrência de um evento/situação no futuro (Oettingen \& Mayer, 2002). Trata-se de uma das variáveis utilizadas pela literatura para compreender a relação dos indivíduos com o 
futuro, ao lado das aspirações, planos, preocupações e esperança, entre outras possibilidades (Aspinwall, 2005). Ao analisar expectativas no contexto laboral, esta tese centra-se nas crenças de profissionais já empregados sobre a provável situação futura de suas carreiras e de suas organizações.

Nessa linha, o objetivo geral da tese foi investigar variáveis que influenciam expectativas sobre a carreira na organização e sobre o futuro da própria organização (futuro organizacional), assim como identificar os efeitos dessas mesmas expectativas sobre outras variáveis no contexto organizacional. Esse objetivo geral foi destrinchado em objetivos específicos. O primeiro foi revisar a literatura que trata de variáveis relativas ao futuro na carreira na organização e ao futuro organizacional, considerando o ponto de vista dos profissionais. O segundo foi desenvolver e fornecer evidências de validade de dois instrumentos que aferem, respectivamente, expectativas de carreira na organização e expectativas de futuro organizacional. O terceiro foi testar o efeito de variáveis que representam a atual situação de carreira do profissional em suas expectativas de carreira na organização. Testar um modelo no qual as percepções de políticas e práticas de recursos humanos $(\mathrm{RH})$ e bem-estar no trabalho atuavam como antecedentes dos dois tipos de expectativas constituiu o quarto objetivo. O quinto objetivo foi testar um modelo no qual os dois tipos de expectativas atuavam como antecedentes de comprometimento organizacional afetivo e intenção de rotatividade.

Esses objetivos foram alcançados por meio de sete manuscritos redigidos conforme as normas da American Psychological Association (2010). Embora cada manuscrito seja em si mesmo uma pesquisa, todos estão concatenados, de modo que os primeiros textos municiam os subsequentes. Destarte, a tese pode ser representada por uma teia de manuscritos, conforme expõe a Figura 1. 


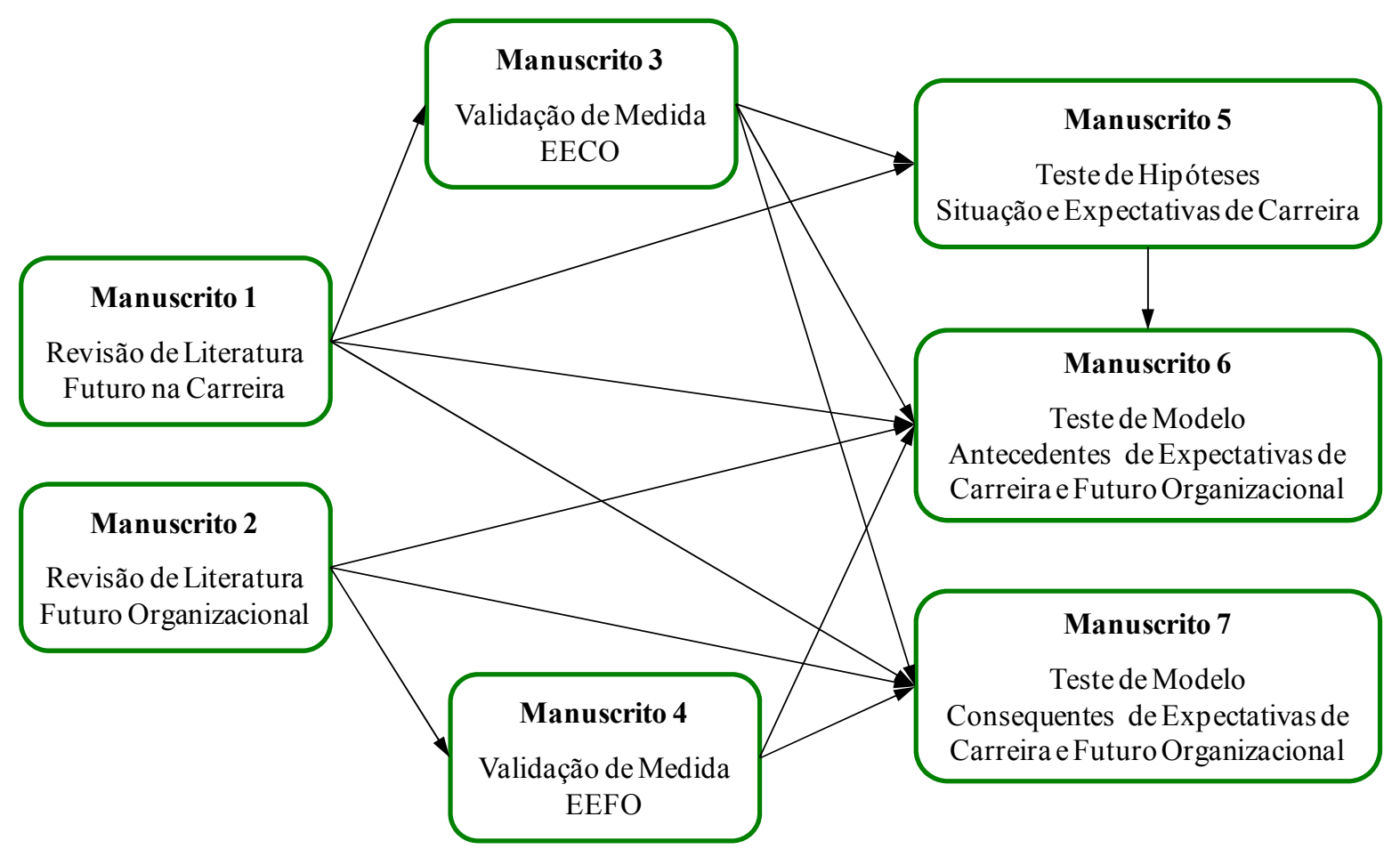

Figura 1. Teia de manuscritos da tese.

EECO=Escala de Expectativas de Carreira na Organização. EEFO=Escala de Expectativas de Futuro Organizacional.

Os dois primeiros manuscritos revisam pesquisas que investigaram variáveis relativas ao futuro na carreira na organização e ao futuro organizacional (sob a ótica dos profissionais). Ambos discutem as possibilidades e tendências da literatura, caracterizam os construtos, variáveis e instrumentos que lidam com esses temas, evidenciam a relação dessas variáveis com outras variáveis de comportamento organizacional e propõem agendas de pesquisa.

Em especial, tais manuscritos ajudam a organizar esses fragmentados campos de estudos, clarificando as diferentes abordagens da literatura diante de tais fenômenos. Por exemplo, o Manuscrito 1 distingue expectativas de carreira (crenças sobre como a carreira provavelmente se desenvolverá no futuro) de aspirações de carreira (que se referem a preferências e objetivos). Similarmente, o Manuscrito 2 discerne expectativas de futuro organizacional (crenças dos profissionais sobre como provavelmente será o futuro da organização) de conceitos de nível macro-organizacional (planejamento, cenários e visão da organização). 
Esses dois manuscritos de revisão, a rigor, funcionam como sustentáculos para toda a tese, suportando os manuscritos subsequentes. Nessa linha, o Manuscrito 1, ao expor o estágio inicial dos estudos na temática do futuro na carreira, inspirou a redação do Manuscrito 3. Este propõe o construto expectativas de carreira na organização e descreve o desenvolvimento da Escala de Expectativas de Carreira na Organização (EECO), fornecendo evidências de sua validade. Este manuscrito conta com dois estudos, sendo que o primeiro relata a análise fatorial exploratória da medida ao passo que o segundo trata da análise fatorial confirmatória. A revisão de variáveis/instrumentos perpetrada no Manuscrito 1 serviu de base para a construção da EECO.

Por sua vez, o Manuscrito 4 propõe o construto expectativas de futuro organizacional e retrata o desenvolvimento da Escala de Expectativas de Futuro Organizacional (EEFO). Os três estudos deste manuscrito incluem os resultados de uma pesquisa exploratória sobre o tema, assim como a análise fatorial exploratória e a análise fatorial confirmatória do instrumento. O processo de desenvolvimento foi fundamentado na revisão sobre futuro organizacional empreendida no Manuscrito 2.

O Manuscrito 5 analisa em que medida a atual situação de carreira dos profissionais influencia as expectativas de carreira em sua organização. A situação de carreira foi operacionalizada por variáveis como estágio de carreira, tempo de carreira na organização, cargo ocupado, participação em programas de desenvolvimento de carreira, entre outras variáveis. Os dados foram obtidos por meio de três amostras, o que permitiu a realização de uma meta-análise de pequeno porte. Esse manuscrito aproveitou os estudos revisados pelo Manuscrito 1 para derivar suas hipóteses. Para aferir as expectativas de carreira na organização foi utilizado o instrumento desenvolvido no Manuscrito 3.

O Manuscrito 6 busca identificar variáveis que influenciam as expectativas de carreira na organização e de futuro organizacional. O manuscrito descreve o teste de um modelo no 
qual as percepções de políticas e práticas de RH e bem-estar no trabalho atuam como antecedentes dessas variáveis. Este manuscrito integra, no mesmo modelo, as expectativas de carreira e de futuro organizacional e aproveita insumos dos manuscritos anteriores, incluindo as revisões de literatura (Manuscritos 1 e 2), as validações de instrumento (Manuscritos 3 e 4 ) e a pesquisa empírica anterior (Manuscrito 5).

A pesquisa detalhada no Manuscrito 7, por sua vez, visa a compreender como as expectativas de carreira na organização e de futuro organizacional influenciam outras variáveis relevantes no contexto organizacional. O manuscrito relata o teste de um modelo no qual tais expectativas atuam como antecedentes de comprometimento organizacional afetivo e intenção de rotatividade. Assim como o Manuscrito 6, o Manuscrito 7 também articula os dois tipos de expectativas e utiliza subsídios dos manuscritos anteriores. Cabe ainda sublinhar que as análises desses dois últimos manuscritos são enriquecidas pelo teste de moderadores nos seus respectivos modelos.

Os manuscritos da tese, seja por meio das revisões executadas, dos instrumentos desenvolvidos ou dos resultados empíricos detectados, almejam contribuir tanto para a academia quanto para as organizações e seus profissionais. A seção de considerações finais compila essas contribuições, além de apontar as limitações da pesquisa e sugerir estudos futuros. 


\section{Referências}

American Psychological Association. (2010). Publication Manual of the American Psychological Association (6th edition). Washington, DC: Author.

Aspinwall, L. G. (2005). The Psychology of Future-Oriented Thinking: From Achievement to Proactive Coping, Adaptation, and Aging. Motivation and Emotion, 29, 203-235.

Bandura, A. (1977). Self-efficacy: Toward a unifying theory of behavioral change. Psychological Review, 84, 191-215.

Bluedorn, A.C. \& Denhardt, R.B. (1988). Time and Organisations. Journal of Management, 14, 299-320.

Butler, R. (1995). Time in organizations: its experience, explanations and effects. Organization Studies, 16, 925-950.

Fraisse, P. (1984). Perception and estimation of time. Annual Review of Psychology, 35, 1-36. George, J.M. \& Jones, G.R. (2000). The role of time in theory and theory building. Journal of Management, 26, 657-684.

Lee, H. \& Liebenau, J. (1999). Time in organizational studies: towards a new research direction. Organization Studies, 20, 1035-1058.

Lewin, K. (1939). Field Theory and Experiment in Social Psychology: Concepts and Methods. American Journal of Sociology, 44, 868-896.

Lewin, K. (1951). Field Theory in Social Science: Selected Theoretical Papers. New York: Harper and Bros.

Oettingen, G. \& Mayer, D. (2002). The Motivating Function of Thinking About the Future: Expectations Versus Fantasies. Journal of Personality and Social Psychology, 83, 11981212.

Orlikowski, W. \& Yates, J. (2002). It's About Time: An Enacted View of Time in Organizations. Organization Science, 13, 684-700. 


\section{MANUSCRITO 1}

O primeiro manuscrito traz uma revisão de literatura cujo objetivo principal é explicitar as diferentes formas de se estudar a relação dos indivíduos com o futuro na carreira no contexto organizacional, sistematizando e organizando o heterogêneo conjunto de pesquisas sobre o tópico. O manuscrito revela ainda como tal literatura está longe de obter um acordo terminológico e conceitual mínimo, além de carecer de instrumentos abrangentes e bem fundamentados, cenário que motivou o desenvolvimento de um novo instrumento (Manuscrito 3). O Manuscrito 1 sintetiza também evidências empíricas da relação das variáveis que investigam futuro na carreira na organização com outras variáveis de comportamento organizacional, contribuição que facilitou o estabelecimento das hipóteses testadas nos manuscritos posteriores. 


\section{MANUSCRITO 1}

Futuro na Carreira no Contexto Organizacional:

Possibilidades e Tendências na Literatura

Future Career in Organizational Context:

Possibilities and Trends in the Literature

Vinicius Carvalho de Vasconcellos

Universidade de Brasília 


\title{
Resumo
}

As perspectivas de desenvolvimento e crescimento no futuro da carreira estão entre elementos mais valorizados por profissionais em organizações. Nesse sentido, o objetivo deste artigo foi discutir possibilidades e tendências de investigação acadêmica sobre a relação de trabalhadores em organizações com o futuro de suas carreiras. Para contextualizar o tema, expõem-se inicialmente as transformações nas trajetórias de carreira no mundo contemporâneo. O artigo então discorre sobre as distintas formas usadas pela literatura para tratar do futuro na carreira, apontando inicialmente como as pesquisas se diferenciam quanto ao tipo de variável empregada (aspirações/objetivos, expectativas/percepções e afetos relativos ao futuro) e às referências de ambiente organizacional fornecidas (intraorganizacional, interorganizacional e inespecífica). Em seguida, a discussão aprofundase nas pesquisas empíricas sobre expectativas e percepções sobre o futuro na carreira, destacando os conceitos e os instrumentos empregados, além das variáveis relacionadas. Por fim, realiza-se uma síntese da literatura sobre o tópico (enfatizando notadamente suas tendências e limitações) e se propõe uma agenda de investigação.

Palavras-chave: carreira, expectativas, aspirações profissionais, revisão de literatura

\begin{abstract}
The career prospects are one of the most important elements in professional life inside organizations. In this way, the objective of this article is to discuss academic possibilities and research trends about the relationship of professionals with their future career in the organizational context. To contextualize the theme, the changes in career paths in the contemporary world are exposed in the beginning of the article. Then, the article discusses the different forms used in the literature to address the future career, highlighting how research differ in the type of variable (aspirations/goals, expectations/perceptions and affections related to the future) and in the organizational environment references (intraorganizational, inter-organizational and nonspecific). Next, the article analyzes the empirical research on perceptions and expectations about the future career, highlighting the concepts, instruments and the related variables used by the scholars. Finally, the article offers a literature overview of the topic (emphasizing trends and limitations) and proposes a research agenda.
\end{abstract}

Keywords: career, expectations, professional aspirations, literature review 
Uma das características marcantes das sociedades ocidentais atuais é sua orientação para o futuro (Giddens, 1991). Tal orientação cresce especialmente com o advento da Modernidade, época na qual o futuro, menos atrelado ao fatalismo imposto pela religião/tradição, passa a ser representado como projeto aberto que exige constante monitoramento de possibilidades, oportunidades e riscos (Giddens, 1991; Leccardi, 2005).

A relação dos indivíduos com o futuro está presente em diversos domínios sociais, inclusive no trabalho. Neste último domínio, o exercício de projetar o futuro profissional ganha papel de destaque, uma vez que existem evidências de que a perspectiva de crescimento na carreira surge rotineiramente entre as características mais valorizadas por trabalhadores em organizações (Tolfo, 2002). De fato, publicações no contexto organizacional sugerem o elo entre expectativas/percepção de oportunidades futuras de carreira e variáveis relevantes para a gestão, como atitudes no trabalho e intenções de desligamento (Chay \& Aryee, 1999; Chen, Ployhart, Cooper-Thomas, Anderson \& Bliese, 2011; Prince, 2003; Stroh \& Reilly, 1997).

Partindo desses elementos, este artigo objetivou discutir as possibilidades de investigação acadêmica sobre a relação dos trabalhadores em organizações com o futuro de suas carreiras. Especificamente, o interesse foi identificar e analisar as variáveis, conceitos e instrumentos utilizados pela literatura nacional e internacional, bem como apontar as principais tendências e lacunas nessa vereda de pesquisa.

Para contextualizar o tema, expõem-se inicialmente as transformações nas trajetórias de carreira contemporâneas. Depois, o artigo traça um quadro de possibilidades de pesquisa sobre o futuro na carreira em organizações, com especial atenção às variáveis utilizadas para investigar o futuro na carreira na ótica dos profissionais (suas aspirações/objetivos, expectativas/percepções e afetos associados ao futuro) e à referência de ambiente organizacional (intraorganizacional, interorganizacional ou inespecífica) adotada nos estudos. 
A seção seguinte aprofunda-se em estudos sobre expectativas e percepções de futuro na carreira, abordagem predominante na literatura. Neste caso, são analisados os conceitos e os instrumentos utilizados, assim como as variáveis relacionadas testadas. Por fim, realiza-se uma síntese da literatura e se propõe uma agenda de investigação sobre o tópico.

\section{Trajetórias de Carreira no Cenário Contemporâneo}

Até as últimas décadas do século XX, o desenvolvimento das carreiras ocorria em meio a um ambiente econômico no qual floresciam organizações altamente hierarquizadas e predominavam a normatividade e a estabilidade do modelo taylorista-fordista (Chanlat, 1995; Tolfo, 2002). Tal cenário favorecia trajetórias relativamente previsíveis para a maioria dos trabalhadores, porquanto estavam assentadas na segurança do emprego, nos vínculos de longo prazo e na progressão hierárquica, processo este controlado mormente pelas organizações (Chanlat, 1995).

Essa configuração sofreu substanciais mudanças no fim do século passado. O esgotamento do modelo taylorista-fordista ensejou a emergência de sistemas de produção mais flexíveis e enxutos, resultado da crescente competitividade e da necessidade de adaptação das organizações. Concomitantemente, o mundo do trabalho assistiu à globalização da economia, à aceleração dos avanços tecnológicos e à proliferação de terceirizações, contratos temporários, reestruturações, fusões e aquisições.

$\mathrm{Na}$ esteira da maior flexibilidade na gestão e do achatamento das estruturas hierárquicas, as empresas não podiam mais assegurar carreiras para toda vida, tampouco garantir facilmente oportunidades de crescimento vertical, fragilizando assim o vínculo empregatício (Arthur \& Rousseau, 1996; Prince, 2003). Por outro lado, profissionais com elevada qualificação tornaram-se mais propensos a buscar, de modo ativo, oportunidades mais consoantes com seus desejos/aspirações. Em última instância, seja por iniciativa própria ou em função de pressões organizacionais/mercadológicas, os contratos psicológicos 
tornaram-se mais transacionais (Arthur \& Rousseau, 1996). O efeito dessa conjuntura foi o incremento na mobilidade na carreira, entendida como o conjunto de mudanças de atividade/função, organização ou ocupação dos indivíduos (Feldman \& Ng, 2007).

Tal cenário estimulou a literatura a propor novos padrões/modelos de trajetória profissional, tais como os modelos de carreira proteana e sem fronteiras. Carreira proteana refere-se a uma trajetória profissional autogerenciada, isto é, eminentemente guiada pelo indivíduo, por seus valores pessoais e por seus ideais de felicidade/realização (Hall, 2004). Nesse contexto, o papel da organização em conduzir a carreira encontra-se reduzido e os indivíduos atuam com maior autonomia e liberdade. Por sua vez, o modelo de carreira sem fronteiras expressa caminho profissional que não se confina a um empregador nem a um plano pré-determinado de avanço hierárquico, sendo inclusive condicionado por elementos extra-organizacionais como relações familiares (Arthur, 1994). A ênfase aqui recai sobre a mobilidade e as possibilidades de transição experimentadas pelos profissionais.

Nos últimos anos, estudos sobre esses modelos emergentes de carreira ganharam força na literatura. Todavia, alguns autores questionam sua generalização e relativizam sua potência. Chanlat (1995), por exemplo, sinalizou a coexistência de modelos emergentes com o modelo tradicional (caracterizado por promoções lineares e vínculo longo/estável com a organização). Na mesma linha, outros autores atestam que muitas organizações ainda operam no modelo tradicional e que grande parte dos profissionais prefere carreiras com esse padrão de desenvolvimento (Baruch, 2006; Elchardus \& Smits, 2008).

Investigações empíricas evidenciaram a presença de atitudes proteanas e sem fronteiras em profissionais brasileiros, contudo, estas parecem ser mais fortes na iniciativa privada do que no funcionalismo público (Oliveira et al., 2010; Oliveira \& Gomes, 2014), o que sugere a impossibilidade de generalização. Também em pesquisa empírica, Wilkoszynski e Vieira (2013) reportam que aspectos emergentes e tradicionais de carreira mesclam-se na realidade 
nacional: por um lado, os profissionais assumem um discurso próprio ao modelo emergente; por outro, tal discurso ainda não se traduz em ações efetivas de gestão de carreira.

Mesmo que seja impossível generalizar os modelos emergentes de carreira, as trajetórias profissionais parecem emolduradas por novo cenário. Tanto a instabilidade das organizações quanto a busca ativa dos indivíduos por seus ideais de trabalho tendem a transformar o futuro da carreira em um projeto aberto para muitos profissionais. E, uma vez que as trajetórias futuras não estão fixadas e que cresce o autogerenciamento da carreira, os rumos a seguir tornam-se uma questão para os profissionais. Nesse sentido, os riscos e as oportunidades no futuro tendem cada vez mais a capturar a atenção dos trabalhadores.

Os pontos levantados indicam como a relação dos indivíduos com o futuro na carreira granjeou notável relevância no contexto atual. Considerando tal relevância, a próxima seção sumaria as principais possibilidades de investigação sobre a temática no âmbito organizacional. Tal procedimento mostra-se útil, sobretudo, haja vista o pequeno grau de sistematização e a considerável fragmentação da literatura nesse campo, como será possível apreender a seguir.

\section{Futuro na Carreira: Possibilidades de Investigação no Contexto Organizacional}

A relação dos indivíduos com o futuro desabrocha em diversos fenômenos da vida psíquica e inclui ampla gama de cognições, afetos e comportamentos (Aspinwall, 2005). Da mesma forma, ao lidar especificamente com seu futuro na carreira, os indivíduos podem experimentar afetos, cultivar preferências/desejos ou expressar expectativas, percepções ou crenças sobre o porvir, sendo todos esses elementos passíveis de exploração acadêmica.

Ao tratar do futuro na carreira, a literatura diferencia, em primeiro lugar, aspirações de expectativas (Metz, Fouad \& Ihle-Helledy, 2009). As primeiras refletem preferências, desejos e/ou objetivos de carreira, ao passo que as últimas expressam projeções sobre o que ocorrerá no futuro profissional (baseadas, portanto, no cenário mais provável e realista). Com efeito, 
há evidências empíricas que apoiam a distinção entre projeções relativas à carreira ideal, desejada ou preferida e projeções concernentes às trajetórias profissionais concebidas como as mais prováveis e realistas (Pisarik \& Shoffner, 2009).

Tal distinção, comum em pesquisas com estudantes, também é observada em estudos em organizações. Entre as investigações centradas em aspirações/objetivos, uma proposta de investigação que adquiriu espaço na literatura recente trata do construto Future Work Selves, definido como a representação do indivíduo sobre si mesmo no futuro com base em suas aspirações/esperanças em relação ao trabalho (Strauss, Griffin \& Parker, 2012). Outra linha de pesquisa importante neste campo refere-se às aspirações e objetivos de carreira de mulheres em organizações, analisados principalmente a luz da busca pelo equilíbrio entre vida pessoal/familiar e o trabalho (Hite \& McDonald, 2003; Walsh, 2012). No Brasil, a expressão projeto profissional, malgrado sua conotação flexível, costuma ser empregada em pesquisas sobre objetivos/aspirações de carreira. Neste enquadre, há estudos sobre processos identitários que, ao percorrer todos os quadros temporais da trajetória laboral, averiguam os projetos de carreira dos profissionais (Coutinho, 2009; Graf \& Coutinho, 2010).

De sua parte, investigações sobre expectativas remetem essencialmente às crenças dos respondentes sobre como sua carreira provavelmente será no futuro. No fundo, essas projeções mais realistas e pautadas na avaliação das circunstâncias e do contexto adquirem outros rótulos na literatura, tais como prospectos, perspectivas e percepções de oportunidades futuras. A despeito da terminologia, pesquisas com esse teor (Burke, 2001; Carr, Pearson, Vest \& Boyar, 2006; Chen et al., 2011; O’Neill, Stanley \& O’Reilly, 2011; Prince, 2003; Zacher \& Frese, 2011) surgem como campo majoritário de investigação do futuro na carreira em organizações e serão discutidas mais detidamente na próxima seção.

Aspirações/objetivos e expectativas, discutidas anteriormente, são duas formas de se estudar o futuro na carreira. Outra forma de lidar com o fenômeno refere-se aos estudos 
centrados nos afetos vinculados ao futuro na carreira, embora estes sejam relativamente raros na literatura. Contudo, um exemplo pode ser encontrado no artigo de Bolanowski (2005), que analisou a ansiedade sentida por jovens médicos diante do futuro profissional. Os dados desvelaram que o baixo nível de autoavaliação de habilidades influencia a ocorrência de tal afeto. Em outra ilustração, Stahl, Miller e Tung (2002) examinaram as preocupações com o desenvolvimento futuro da carreira de profissionais expatriados e encontraram níveis consideráveis de preocupação com a repatriação, notadamente no tocante à possibilidade de redução de autonomia e responsabilidade no trabalho.

Além do tipo de variável (aspirações/objetivos, expectativas/percepções e afetos), as investigações sobre futuro na carreira diferenciam-se quanto à especificação de um determinado ambiente organizacional. Sendo assim, há pesquisas na perspectiva intraorganizacional (isto é, indagam sobre o futuro dentro da atual organização), outras na perspectiva interorganizacional (que convida os participantes a pensar sobre como seria o futuro em outras organizações) e, ainda, aquelas que não concedem referência clara ao respondente (sendo, portanto, inespecíficas).

Sobre esse tópico, observa-se certa preeminência da perspectiva intraorganizacional, visto que a atual organização do respondente é usualmente oferecida como referência (Stroh \& Reilly, 1997; Treadway, Breland, Adams, Duke \& Willians, 2010). De outra parte, a perspectiva interorganizacional parece ser mais escassa na literatura, sendo possível ilustrar esse direcionamento por intermédio do estudo de Pearce e Randel (2004) acerca das expectativas dos indivíduos em mudar de empregador. Já as investigações sem referência organizacional podem ser exemplificadas nas pesquisas baseadas no construto foco em oportunidades, definido como as crenças dos indivíduos acerca das novas opções e possibilidades existentes em seu futuro ocupacional (Schmitt, Zacher \& Lange, 2013; Zacher \& Frese, 2011). Essas últimas pesquisas são aplicadas em organizações, contudo, não há 
especificação se o respondente deve se remeter ao futuro em geral ou ao futuro em sua atual organização.

Ao se analisar o ambiente organizacional de referência, a marcante presença da perspectiva intraorganizacional pode gerar estranheza, dada a emergência dos modelos de carreira sem fronteiras e proteana. Cumpre frisar, contudo, que a perspectiva intraorganizacional fornece um horizonte mais concreto para se projetar o futuro, elemento possivelmente valorizado pelos pesquisadores em seus instrumentos. Ademais, ao privilegiar o vínculo indivíduo-organização e gerar insumos mais concretos para a gestão, a referência intraorganizacional talvez seja mais atraente para as organizações, propiciando a realização de mais estudos. Por fim, frisa-se que os modelos sem fronteiras e proteano são estudados prioritariamente como atitudes/orientação de carreira (Enache, Sallan, Simo \& Fernandez, 2011; Gubler, Arnold \& Coombs, 2014; Oliveira et al., 2010), variáveis que são centradas no presente e não no futuro.

Baseada nos pontos discutidos, a Figura 1 compila as principais possibilidades de investigação sobre futuro na carreira no contexto organizacional. Nesse sentido, contempla os tipos de variáveis de futuro na carreira e os ambientes de referência, indicando exemplos de pesquisas. 


\begin{tabular}{|c|c|c|c|}
\hline & Categoria & Descrição & $\begin{array}{l}\text { Exemplos de } \\
\text { Pesquisas }\end{array}$ \\
\hline & $\begin{array}{l}\text { Aspirações e } \\
\text { Objetivos }\end{array}$ & $\begin{array}{l}\text { Variáveis que refletem o futuro na } \\
\text { carreira desejado, preferido ou ideal }\end{array}$ & $\begin{array}{l}\text { Hite e McDonald (2003) } \\
\text { Strauss et al. (2012) } \\
\text { Walsh (2012) }\end{array}$ \\
\hline \multirow[t]{3}{*}{$\begin{array}{c}\text { Tipo de } \\
\text { variável de } \\
\text { futuro na } \\
\text { carreira }\end{array}$} & $\begin{array}{l}\text { Expectativas e } \\
\text { Percepções }\end{array}$ & $\begin{array}{l}\text { Variáveis que refletem o futuro na } \\
\text { carreira mais provável ou percebido } \\
\text { como possível dadas as circunstâncias }\end{array}$ & $\begin{array}{l}\text { Chen et al. (2011) } \\
\text { Prince (2003) } \\
\text { Zacher e Frese (2011) }\end{array}$ \\
\hline & Afeto & $\begin{array}{l}\text { Variáveis que abordam afetos } \\
\text { relacionados ao futuro na carreira } \\
\text { (ex: medo, ansiedade e preocupação) }\end{array}$ & $\begin{array}{l}\text { Bolanowski (2005) } \\
\text { Stahl, Miller e Tung ( } 2002\end{array}$ \\
\hline & Intraorganizacional & $\begin{array}{l}\text { Futuro na carreira na atual } \\
\text { organização }\end{array}$ & $\begin{array}{l}\text { Carr et al. (2006) } \\
\text { Stroh e Reilly (1997) } \\
\text { Treadway et al. (2010) }\end{array}$ \\
\hline \multirow{2}{*}{$\begin{array}{l}\text { Tipo de } \\
\text { ambiente de } \\
\text { referência }\end{array}$} & Interorganizacional & $\begin{array}{l}\text { Futuro na carreira em outras } \\
\text { organizações }\end{array}$ & Pearce e Randel (2004) \\
\hline & Inespecífico & $\begin{array}{l}\text { Futuro na carreira sem } \\
\text { referência organizacional clara }\end{array}$ & $\begin{array}{l}\text { Zacher e Frese (2011) } \\
\text { O'Neill et al. (2011) }\end{array}$ \\
\hline
\end{tabular}

Figura 1. Possibilidades de investigação sobre futuro na carreira no contexto organizacional.

Após esse panorama, a próxima seção aprofunda-se nos estudos empíricos ancorados em expectativas e percepções de futuro na carreira e que adotam os ambientes de referência intraorganizacional ou inespecífico, dado que esses delineamentos congregam a maioria dos estudos. Nesse recorte, abordam-se adiante as definições e instrumentos que caracterizam as variáveis de futuro na carreira, assim como as variáveis relacionadas analisadas nas pesquisas. Considerando a pluralidade de variáveis, especial atenção será dada aos instrumentos utilizados, visto que estes traduzem com maior precisão que tipo de fenômeno foi, de fato, aferido.

\section{Expectativas e Percepções sobre Futuro na Carreira: Definições, Instrumentos e Variáveis Relacionadas}

Ao analisar a produção acadêmica, constata-se que é relativamente comum os estudos indagarem sobre o futuro genericamente, isto é, sem menção explícita a atributos como salários, promoções ou realização profissional. Tal direcionamento materializa-se, na 
realidade nacional, em estudos qualitativos que introduzem, em entrevistas, questões gerais sobre as expectativas/perspectivas de carreira e de futuro profissional (Lima, Neto \& Tanure, 2012; Lopes \& Silva, 2009; Moreno Júnior, Cavazotte \& Farias, 2009). Em alguns desses estudos, os entrevistados sinalizaram restrições no futuro na carreira em função do risco de fusões/aquisições ou da presença de políticas/práticas de gestão que dificultam a ascensão profissional (Lima et al., 2012; Moreno Júnior et al., 2009). Em contraste, Lopes e Silva (2009) depararam-se com discursos heterogêneos sobre o futuro na carreira, de modo que os autores identificaram quatro perfis de expectativas: os desiludidos, os ambivalentes, os céticos e os crédulos.

Desenhos quantitativos também podem operar na mesma linha genérica de investigação. Por exemplo, Buckley, Fedor, Veres, Wiese e Carraher (1998) mediram expectativas de trabalho em recém-admitidos com uma escala de cinco itens (tais como "Este trabalho será ótimo" e "Ficarei satisfeito com esse trabalho"). Em última instância, ao responder itens tão abertos, os participantes poderiam pensar em promoções e aumento salarial, assim como na oportunidade de obter novos conhecimentos, vivenciar novas experiências laborais ou em qualquer outro tópico. Entre os resultados, os autores relatam que o grupo de tratamento (submetido a um seminário para rebaixar expectativas) apresentou expectativas e taxas de desligamento mais baixas do que o grupo de controle.

Utilizando igualmente uma amostra de recém-admitidos, Carr et al. (2006) pesquisaram expectativas dos indivíduos por meio de três itens, entre os quais, "Minhas expectativas para esse trabalho são elevadas" e "Espero que trabalhar nessa organização seja ótimo". Os resultados indicaram relação negativa entre as expectativas e o desligamento voluntário dos participantes. Stroh e Reilly (1997) também se alicerçam em uma visão inespecífica de futuro na organização ao trabalhar com a variável oportunidades de carreira, aferida por apenas um item ("Meu futuro nesta companhia parece brilhante"). Nessa pesquisa longitudinal, baixos 
escores em oportunidades de carreira influenciaram gerentes altamente comprometidos com suas carreiras a deixar suas organizações.

Citada anteriormente, a variável foco em oportunidades também não faz alusão a atributos particulares e seu instrumento inclui itens como "Meu futuro ocupacional é cheio de possibilidades" e "Muitas oportunidades esperam por mim no meu futuro ocupacional" (Zacher \& Frese, 2011). Estudos nesse enfoque desvelaram, por exemplo, a relação negativa dessa variável com a idade dos respondentes, sua associação positiva com engajamento e desempenho no trabalho e sua função mediadora na relação entre complexidade do trabalhodesempenho e na relação entre idade-desempenho (Schmitt et al., 2013; Zacher, Heusner, Schmitz, Zwierzanska \& Frese, 2010; Zacher \& Frese, 2011).

Por sua vez, Treadway et al. (2010) construíram escala semelhante à de Zacher e Frese (2011), porém, utilizando nitidamente a atual organização como referência ("Nesta organização, muitas oportunidades esperam por mim no futuro" ou "Essa organização me provê um futuro cheio de possibilidades"). A variável medida por essa escala foi denominada de perspectiva de tempo futuro organizacional e definida como as percepções dos profissionais sobre o tempo que lhes resta em seu papel organizacional. Treadway et al. (2010) constataram que indivíduos com elevados níveis de habilidade política e de perspectiva de tempo futuro engajavam-se mais em networking relacionado à carreira do que aqueles que também apresentavam habilidade política, mas que não vislumbravam grandes perspectivas de futuro na organização.

A valorização de objetivos profissionais concede ao futuro na carreira contorno um pouco mais específico. É o caso do construto oportunidades de carreira percebidas que trata da percepção da existência de oportunidades ocupacionais, dentro da atual organização, que sejam consoantes com os interesses/objetivos de carreira dos indivíduos (Kraimer, Seibert, Wayne, Liden \& Bravo, 2011). O instrumento validado pelos autores abarca três itens, entre 
os quais, "Esta organização oferece várias oportunidades de trabalho que combinam com meus objetivos de carreira" e "Existem oportunidades nesta organização atraentes para mim".

Impõe-se nesse ponto uma breve digressão sobre a utilização do termo oportunidade nesses estudos. Este, no fundo, pode simbolizar tanto projeções de futuro (Zacher \& Frese, 2011) quanto possibilidades no presente (Kraimer et al., 2011). Com efeito, os itens de Kraimer et al. (2011), ao empregar o presente como tempo verbal e não incluir referência clara ao futuro na redação dos itens, tendem a impelir o respondente a considerar a existência de possibilidades/oportunidades no momento atual.

O termo oportunidade também é empregado na literatura brasileira com as duas orientações temporais. Pesquisas na década de 1990, por exemplo, perscrutaram percepções de oportunidades de carreira no presente (Borges-Andrade, Cameschi \& Xavier, 1990; Brandão \& Bastos, 1993). Estudos mais recentes (Veloso et al., 2011; Veloso, Silva \& Dutra, 2012) trabalharam com um item sobre oportunidades de carreira voltado para o futuro (“Acredito que trabalhando nesta empresa terei oportunidade de fazer carreira e crescer"). Todavia, a escala desses dois últimos estudos, que visava a mensurar percepções de crescimento profissional, continha outros dois itens orientados para presente ("Considero justos os critérios de promoção e carreira adotados nesta empresa" e "Sei o que devo fazer para crescer profissionalmente nesta empresa"). Nesses quatro estudos brasileiros, os itens faziam parte de amplos questionários sobre práticas de gestão ou clima organizacional, ou seja, não almejavam aferir especificamente o futuro na carreira.

Voltando aos estudos manifestadamente direcionados ao futuro, a literatura registra também pesquisas que, ao invés de se endereçar a objetivos e oportunidades de carreira (opções que ainda trazem consigo um caráter relativamente aberto), concedem ênfase explícita à mobilidade na carreira. Por exemplo, De Souza (2002), em amostra de gerentes, revelou que o número de promoções recebidas no passado opera como preditor na 
formulação de expectativas de promoção, variável aferida a partir do número de vezes que o gerente esperava ser promovido nos cinco anos seguintes.

De modo similar, a mobilidade na carreira está no centro de estudos pautados na variável prospectos de carreira (Burke, 2001; Burke \& Macdermid, 1999). Apesar dos pesquisadores não conceituarem a variável, o instrumento (com três itens) versa sobre expectativas relacionadas à obtenção de promoções. Nessas pesquisas, prospectos de carreira relacionaram-se ao comportamento workaholic e à satisfação com o trabalho (Burke, 2001; Burke \& Macdermid, 1999). Também realçando promoções, Carmeli, Shalom e Weisberg (2007) testaram diversos preditores para a variável prospectos de promoção (aferida por item único no qual o gerente atribuía uma probabilidade de promoção ao seu subordinado). Desempenho no trabalho e tempo na organização mostraram-se preditores relevantes de prospectos de promoção, ao contrário de absenteísmo, atrasos, horas-extras e sexo do respondente.

Intimamente relacionado à mobilidade via promoções, expectativas salariais também são trazidas à baila neste contexto. Assim, em Gibson e Lawrence (2010), a variável expectativas de carreira foi medida como o nível salarial esperado pelos profissionais ao se aposentar/desligar da organização. Os resultados sublinharam a importância do nível (posição) de carreira dos chamados referentes de carreira (indivíduos vistos pelos respondentes como similares no desenvolvimento profissional) na formulação das expectativas. Nessa linha, indivíduos com referentes em níveis mais altos tendem a apresentar expectativas mais elevadas de salário. Ainda no campo da remuneração, O’Neill et al. (2011) mediram o quanto os indivíduos esperavam receber de salário no topo de suas carreiras e descobriram correlação positiva entre essas expectativas e afetos positivos. Diferente de Gibson e Lawrence (2010), a medida era inespecífica quanto ao ambiente organizacional de desenvolvimento de carreira. 
Por sua vez, Prince (2003) agrega à mobilidade via promoções outras formas de se pensar no futuro na carreira. O autor investe em duas variáveis: oportunidades de mobilidade e oportunidades de melhoria no papel. A primeira reflete expectativas dos indivíduos em trocar vertical ou horizontalmente de posição nos dois anos seguintes e, a segunda, expectativas de se obter atribuições mais complexas no atual cargo no mesmo período. A escala de oportunidades de mobilidade contém cinco itens (exemplo: "Nos próximos dois anos, terei a chance de assumir uma posição mais alta no meu cargo/ocupação”) e a de oportunidades de melhoria de papel é composta por sete itens (exemplo: "Nos próximos dois anos, minhas tarefas exigirão que eu aja de forma mais independente").

Mediante tal proposta, Prince (2003) abarca diversas possibilidades de futuro na carreira, como promoções, mudanças para cargos no mesmo nível hierárquico e alterações no conteúdo das atividades (papel) sem mudança de cargo. Os dados indicaram relação positiva entre os dois tipos de oportunidades e que a variável oportunidades de melhoria no papel prediz significativamente comprometimento organizacional e envolvimento com o trabalho, notadamente em trabalhadores com menor tempo de organização.

Enfatizando, igualmente, projeções de características/conteúdo de atividades, Eby, Allen e Brinley (2005) interessaram-se pela percepção de limitação nos desafios do trabalho no futuro, variável rotulada de platô de conteúdo do trabalho. Esta foi aferida por itens como “As tarefas e atividades do meu trabalho atual se tornarão rotina no futuro". De modo geral, a existência de práticas de gestão de carreira na organização e as variáveis demográficas nos modelos explicaram pequena parcela da variância de platô de conteúdo do trabalho.

Também com foco na realização de atividades, van Dam, van der Vorst e van der Heijden (2009) voltaram sua atenção para a percepção das futuras condições de trabalho. Esta variável foi operacionalizada por meio de duas escalas: antecipação da qualidade das condições de trabalho (envolvendo itens sobre a oportunidade de se desenvolver e o suporte 
dos colegas/supervisores) e antecipação da quantidade de trabalho (com itens sobre a possibilidade de se trabalhar menos horas ou de se reduzir a quantidade de trabalho pesado). Os autores sugerem que profissionais próximos à aposentadoria estão propensos a adiá-la quando antecipam qualidade nas condições de trabalho futuras.

É tempestivo finalizar essa seção com um estudo que consubstanciou diversos atributos já citados (mobilidade na carreira, salários e conteúdo/condições de trabalho). Nesse sentido, Chen et al. (2011) definiram expectativas de trabalho como as expectativas dos profissionais sobre as experiências e condições futuras de seu atual trabalho, aferindo-as com uma escala de 12 itens que abrangia projeções de salário, relação com pares, relação com supervisor, desenvolvimento de carreira, desafios no trabalho, entre outros tópicos. Os respondentes indicavam em que medida esses aspectos do trabalho mudariam nos meses seguintes (opções de resposta variando entre piorarão muito até melhorarão muito).

Nessa pesquisa longitudinal, foi corroborada a hipótese de que melhorias na satisfação com trabalho ao longo do tempo associavam-se positivamente às expectativas de trabalho (medidas apenas na última aplicação da pesquisa). Ademais, os resultados indicaram que as expectativas de trabalho mediaram parcialmente a relação negativa entre mudanças na satisfação com o trabalho e mudanças nas intenções de desligamento.

À luz das pesquisas precedentes, nota-se a existência de diferentes formas de examinar o futuro na carreira nas organizações. A próxima seção sintetiza a literatura e traz reflexões sobre as possibilidades, tendências e limitações que perpassam o estudo desse tópico.

\section{Futuro na Carreira no Contexto Organizacional: Síntese e Reflexões sobre a Literatura}

A seção anterior compilou estudos voltados para expectativas e percepções de futuro na carreira, abordagem predominante no ambiente organizacional. Porém, mesmo dentro das balizas dessa tendência majoritária, existe considerável pluralidade de construtos, variáveis e escalas e, até onde a revisão avançou, não foram localizados estudos que buscassem 
estabelecer fronteiras nítidas entre eles, tampouco discutir suas distinções. Essa pluralidade não se exprime apenas nos distintos termos que rotulam as variáveis, mas também nos atributos/domínios da vida laboral abordados.

Sobre os instrumentos, escalas mais simples geralmente não especificam atributos e contêm poucos itens, optando somente por indagar se o futuro na organização será ótimo/promissor/satisfatório (Buckley et al., 1998; Carr et al., 2006). Este delineamento encontra pelo menos duas limitações entrelaçadas: a) não permite distinguir eventuais diferenças entre os domínios que caracterizam a vida laboral e b) fornece pouca informação para as organizações aprimorarem suas práticas de gestão.

Estudos pautados por maior grau de especificidade em seus construtos/instrumentos podem ser divididos em dois grupos. O primeiro aprecia aspectos tradicionalmente vinculados ao sucesso na carreira, como a obtenção de promoções e a melhoria em remuneração (Burke, 2001; Carmeli et al., 2007; De Souza, 2002; Gibson \& Lawrence, 2010; O’Neill et al., 2011). O segundo, por outro lado, não se limita a esses aspectos e valoriza outros elementos, tais como projeções sobre características da atividade/papel, condições/ambiente de trabalho e mobilidade horizontal, assim como sobre o alinhamento entre as oportunidades e os objetivos de carreira dos indivíduos (Chen et al., 2011; Eby et al., 2005; Kraimer et al., 2011; Prince, 2003; van Dam et al., 2009).

O surgimento desse segundo grupo parece se vincular às transformações no desenvolvimento de carreira nos últimos decênios, mencionadas anteriormente. Em especial, recupera-se aqui a reformulação das trajetórias de carreira (cada vez menos lineares e verticais, dificultando as promoções) e a ascensão de novos critérios de sucesso na carreira (como realização profissional e equilíbrio entre vida pessoal e trabalho). No fundo, ganha espaço no trabalho contemporâneo o sucesso subjetivo/psicológico na carreira, isto é, aquele 
derivado do alcance de objetivos com sentido pessoal e que não coincide necessariamente com promoções e salários (Hall \& Chandler, 2004).

Considerando os estudos nesses dois grupos, a literatura detectou a relação de expectativas e percepções de futuro na carreira com variáveis típicas de comportamento organizacional. Nesse sentido, a Tabela 1 sumaria resultados das pesquisas empíricas citadas em seções anteriores. A variedade de instrumentos/construtos fragiliza a comparação direta entre as pesquisas, porém, há indícios do potencial de investigação do campo.

Tabela 1

Relação entre Variáveis de Comportamento Organizacional e de Futuro na Carreira

\begin{tabular}{|c|c|c|}
\hline $\begin{array}{l}\text { Variáveis de } \\
\text { Comportamento } \\
\text { Organizacional }\end{array}$ & $\begin{array}{c}\text { Variáveis de } \\
\text { Futuro na Carreira }\end{array}$ & Correlação \\
\hline $\begin{array}{l}\text { Satisfação com } \\
\text { o trabalho }\end{array}$ & $\begin{array}{l}\text { Expectativas de salários (O’Neill et al., 2011) } \\
\text { Expectativas de trabalho (Chen et al., 2011) } \\
\text { Prospectos de carreira (Burke \& Macdermid, 1999) }\end{array}$ & $\begin{array}{l}0,07 \\
0,29 \\
0,40\end{array}$ \\
\hline $\begin{array}{l}\text { Comprometimento } \\
\text { organizacional }\end{array}$ & $\begin{array}{l}\text { Oportunidades de crescimento na carreira (Chay \& Aryee, 1999) } \\
\text { Oportunidades de melhoria no papel (Prince, 2003) } \\
\text { Oportunidades de mobilidade (Prince, 2003) }\end{array}$ & $\begin{array}{c}0,46 \\
0,21 \\
-0,07\end{array}$ \\
\hline $\begin{array}{l}\text { Envolvimento } \\
\text { com o trabalho }\end{array}$ & $\begin{array}{l}\text { Oportunidades de crescimento na carreira (Chay \& Aryee, 1999) } \\
\text { Oportunidades de melhoria no papel (Prince, 2003) } \\
\text { Oportunidades de mobilidade (Prince, 2003) } \\
\text { Prospectos de carreira (Burke \& Macdermid, 1999) }\end{array}$ & $\begin{array}{l}0,41 \\
0,19 \\
0,07 \\
0,06\end{array}$ \\
\hline Afetos positivos ${ }^{\mathrm{a}}$ & $\begin{array}{l}\text { Expectativas de salários (O’Neill et al., 2011) } \\
\text { Foco em oportunidades (Zacher \& Frese, 2011) }\end{array}$ & $\begin{array}{r}0,26 \\
-0,03\end{array}$ \\
\hline $\begin{array}{l}\text { Desempenho no } \\
\text { trabalho avaliado } \\
\text { por pares/líder }\end{array}$ & $\begin{array}{l}\text { Foco em oportunidades (Zacher \& Frese, 2011) } \\
\text { Prospectos de promoção (Carmeli et al., 2007) }\end{array}$ & $\begin{array}{l}0,19 \\
0,56\end{array}$ \\
\hline
\end{tabular}

$\begin{array}{lll}\text { Intenções de } & \text { Expectativas de trabalho (Chen et al., 2011) } & -0,46 \\ \text { desligamento } & \text { Oportunidades de crescimento na carreira (Chay \& Aryee, 1999) } & -0,39 \\ & \text { Prospectos de carreira (Burke \& Macdermid, 1999) } & -0,10\end{array}$

${ }^{a}$ Afetos positivos na vida em geral, ou seja, não se trata especificamente de afetos no ambiente de trabalho. 
Não obstante esse potencial, duas importantes limitações na produção acadêmica (tanto nacional quanto internacional) podem ser aventadas. A primeira trata da dificuldade de interlocução entre as pesquisas, o que parece atrelado à própria multiplicidade de variáveis, construtos, instrumentos e domínios nessa literatura. Tal variedade não é problemática per se, contudo, torna-se contraproducente na medida em que as pesquisas pouco dialogam entre si, sendo particularmente escassas as referências cruzadas. Esta fragmentação obstaculiza a sistematização dos estudos e o acúmulo de evidências acerca da relação das variáveis de futuro na carreira com outras variáveis.

A segunda limitação refere-se à constatação de que nem todas as investigações denotam rigor na definição de seus objetos de pesquisa. Poucos estudos empreendem discussões teóricas e conceituais sobre o futuro na carreira, o que pode ser parcialmente explicado pelo papel secundário que normalmente essas variáveis assumem nas investigações. A definição dos construtos e a elaboração dos instrumentos dificilmente se alicerçam em elementos teóricos ou empíricos específicos da investigação de futuro na carreira. No caso dos instrumentos, rotineiramente faltam informações sobre as qualidades psicométricas e o processo de construção/validação.

Além dessas limitações, a literatura brasileira exibe ainda volume incipiente de produção. A recente revisão de Vasconcellos, Borges-Andrade, Porto e Fonseca (no prelo), sobre pesquisas brasileiras que investigaram carreira no âmbito do comportamento organizacional, sustenta tal asserção. Dos 60 artigos analisados, predominam a orientação para o presente (27 artigos) e para o presente/passado concomitantemente (nove artigos). As pesquisas que contemplam o futuro surgem depois, inseridas nas investigações orientadas para o presente/futuro (oito artigos) ou para os três quadros temporais simultaneamente (oito artigos). 
Nesse grupo de pesquisas que contempla o futuro na carreira, a maioria apenas tangencia a questão ao explorar qualitativamente expectativas ou aspirações no bojo de outras agendas de investigação, tais como sentidos do trabalho, terceirização, empregabilidade e convívio de gerações (Coutinho, 2009; Diogo, 2007; Graf \& Coutinho, 2010; Lima et al., 2012; Moreno Júnior et al., 2009). Pesquisas quantitativas recentes (Veloso et al., 2011; Veloso et al., 2012) avançaram nesse campo ao centrar suas análises no estudo das percepções de crescimento na carreira, contudo, o instrumento utilizado, oriundo de um questionário de clima organizacional, mescla itens sobre o presente e o futuro na carreira. Dessa forma, nota-se que o cenário brasileiro ainda carece de investigações mais específicas sobre o futuro na carreira em organizações.

\section{Considerações Finais}

Diante da volatilidade econômica, da flexibilidade organizacional e do protagonismo dos profissionais na condução da carreira, o futuro tende a se colocar cada vez mais como questão saliente para os indivíduos. De fato, várias pesquisas citadas aqui evidenciaram essa importância ao reportar a associação de expectativas e percepções sobre futuro na carreira com variáveis relevantes na vida organizacional, o que indica a pertinência de se investir nessa temática.

No entanto, este é um campo de investigação ainda em formação, caracterizado sobremodo por iniciativas isoladas e sem grande aprofundamento na formulação de construtos/instrumentos. Logo, a proposição de uma agenda positiva neste campo passa pela necessidade de maior desenvolvimento conceitual e metodológico. Sob o prisma conceitual, cumpre ancorar as definições em fundamentos teóricos mais sólidos e analisar diferenças com outros construtos já existentes na literatura, como satisfação com a carreira. Como ilustração, é perfeitamente possível o profissional estar insatisfeito com sua atual posição de carreira, 
mas vislumbrar um futuro favorável. Nesse rumo, a referência temporal de futuro deve ser claramente estabelecida, evitando ambiguidades.

A construção de instrumentos mais completos seria oportuna, pois favoreceria a emergência de uma proposta integradora para o campo. Nessa construção, parece promissor conciliar domínios tradicionais de carreira (promoções e salários) com as tendências mais contemporâneas, vinculadas ao sucesso subjetivo de carreira. Bons instrumentos tendem a ser amplamente utilizados e a facilitar a comparação, agregação e replicação de resultados.

A agenda do campo inclui ainda a necessidade de se aprofundar as análises sobre a relação das variáveis de futuro na carreira com variáveis que começaram a ser testadas internacionalmente (atitudes/desempenho no trabalho e intenções de desligamento), assim como de se desenvolver estudos com outras variáveis, como percepções de práticas de recursos humanos, expectativas sobre o futuro da organização e atitude/orientação de carreira. No Brasil, há amplo espectro de possibilidades, haja vista a escassez dos estudos.

Entre suas limitações, alerta-se que o presente estudo não contemplou igualmente todas as formas de se pesquisar o futuro na carreira no contexto organizacional. O foco recaiu nas expectativas e percepções em virtude de sua produção acadêmica mais robusta. Outra limitação versa sobre a dificuldade de apresentar evidências numerosas sobre a eventual associação das variáveis de futuro na carreira com outras variáveis, o que se explica, em parte, pela insuficiência e fragmentação da literatura.

Em termos de contribuições, este artigo esquadrinhou diversas opções de investigação e coligiu resultados que possivelmente ajudarão futuros pesquisadores a delimitar/fundamentar com maior precisão suas pesquisas. Para as organizações, a proposta foi ressaltar a importância das variáveis de futuro na carreira no nexo indivíduo-trabalho-organização. A forma como os indivíduos lidam com o futuro é parte constituinte da dinâmica social e organizacional; portanto, deve ser considerada na gestão de recursos humanos. 


\section{Referências}

Arthur, M. (1994). The boundaryless career: A new perspective for organizational inquiry. Journal of Organizational Behavior, 15, 295-306.

Arthur, M., \& Rousseau, D. (Eds.) (1996). The boundaryless career: A new employment principle for a new organizational era. New York: Oxford University.

Aspinwall, L. (2005). The Psychology of Future-Oriented Thinking: From Achievement to Proactive Coping, Adaptation, and Aging. Motivation and Emotion, 29, 203-235.

Baruch, Y. (2006). Career development in organizations and beyond: Balancing traditional and contemporary viewpoints. Human Resource Management Review, 16, 125-138.

Bolanowski, W. (2005). Anxiety about professional future among young doctors. International Journal of Occupational Medicine and Environmental Health, 18, 367-374.

Borges-Andrade, J., Cameschi, C. \& Xavier, O. (1990). Comprometimento organizacional em instituição de pesquisa: diferenças entre meio e fim. Revista de Administração, 25, 29-43.

Brandão, M. \& Bastos, A. V. (1993). Comprometimento organizacional em uma instituição universitária. Revista de Administração, 28, 50-61.

Buckley, M., Fedor, D., Veres, J., Wiese, D. \& Carraher, S. (1998). Investigating newcomer expectations and job-related outcomes. Journal of Applied Psychology, 83, 452-461.

Burke, R. (2001). Workaholism Components, Job Satisfaction, and Career Progress. Journal of Applied Social Psychology, 31, 239-235.

Burke, R. \& Macdermid, G. (1999). Are workaholics job satisfied and successful in their careers? Career Development International, 4, 277-282.

Carmeli, A., Shalom, R. \& Weisberg, J. (2007). Considerations in organizational career advancement: what really matters. Personnel Review, 36, 190-205. 
Carr, J., Pearson, A., Vest, M. \& Boyar, S. (2006). Prior Occupational Experience, Anticipatory Socialization, and Employee Retention. Journal of Management, 32, 1-17.

Chanlat, J.F. (1995). Quais carreiras e para qual sociedade? (I). Revista de Administração de Empresas, 35, 67-75.

Chay, Y. \& Aryee, S. (1999). Potential moderating influence of career growth opportunities on careerist orientation and work attitudes: Evidence of the protean career era in Singapore. Journal of Organizational Behavior, 20, 613-623.

Chen, G., Ployhart, R., Cooper-Thomas, H., Anderson, N., \& Bliese, P. (2011). The power of momentum: A new model of dynamic relationships between job satisfaction change and turnover intentions. Academy of Management Journal, 54, 159-181.

Coutinho, M. C. (2009). Sentidos do trabalho contemporâneo: as trajetórias identitárias como estratégia de investigação. Cadernos de Psicologia Social do Trabalho, 12, 189-202.

De Souza, G. (2002). A Study of the Influence of Promotions on Promotion Satisfaction and Expectations of Future Promotions among Managers. Human Resource Development Quaterly, 13, 325-340.

Diogo, M. F. (2007). Os sentidos do trabalho de limpeza e conservação. Psicologia em Estudo, 12, 483-492.

Eby, L. T., Allen, T. D., \& Brinley, A. (2005). A cross-level investigation of the relationship between career management practices and career-related attitudes. Group and Organization Management, 30, 565-596.

Elchardus, M., \& Smits, W. (2008). The vanishing flexible: ambition, self-realization and flexibility in the career perspectives of young Belgian adults. Work, Employment and Society, 22, 243-262. 
Enache, M., Sallan, J., Simo, P., \& Fernandez, V. (2011). Examining the impact of protean and boundaryless career attitudes upon subjective career success. Journal of Management \& Organization, 17, 459-473.

Feldman, D. \& Ng, T. (2007). Careers: Mobility, embeddedness, and success. Journal of Management, 33, 350-377.

Gibson, D. \& Lawrence, B. (2010). Women's and men's career referents: how gender composition and comparison level shape career expectations. Organization Science, 21, 1159-1175.

Giddens, A. (1991). As consequências da modernidade. São Paulo: Editora UNESP.

Graf, L. \& Coutinho, M. C. (2010). Trajetórias de mulheres atuantes em pequenos abatedouros de animais. Cadernos de Psicologia Social do Trabalho, 13, 119-132.

Gubler, M., Arnold, J. \& Coombs, C. (2014). Reassessing the protean career concept: Empirical findings, conceptual components, and measurement. Journal of Organizational Behavior, 35, S23-S40.

Hall, D. (2004). The Protean Career: A Quarter-Century Journey. Journal of Vocational Behavior, 65, 1-13.

Hall, D. \& Chandler, D. (2004). Psychological success: When the career is a calling. Journal of Organizational Behavior, 25, 1-22.

Hite, L. \& McDonald, K. (2003). Career aspirations of non-managerial women: Adjustment and adaptation. Journal of Career Development, 29, 221-235.

Kraimer, M., Seibert, S, Wayne, S., Liden, R., \& Bravo, J. (2011). Antecedents and outcomes of organizational support for development: The critical role of career opportunities. Journal of Applied Psychology, 96, 485-500.

Leccardi, C. (2005). Por um novo significado do futuro: mudança social, jovens e tempo. Tempo Social, 17, 35-57. 
Lima, G., Neto, A., \& Tanure, B. (2012). Executivos jovens e seniores no topo da carreira: conflitos e complementaridades. REAd. Revista Eletrônica de Administração, 18, 63-96. Lopes, A. \& Silva, J. R. (2009). Expectativas Profissionais no Discurso de Terceirizados em TI. Revista de Administração de Empresas - Eletrônica, 8, artigo 7.

Metz, A., Fouad, N., \& Ihle-Helledy, K. (2009). Career aspirations and expectations of college students: Demographics and labor market influences. Journal of Career Assessment, 17, 155-171.

Moreno Júnior, V., Cavazotte, F. \& Farias, E. (2009). Carreira e relações de trabalho na prestação de serviços de tecnologia da informação: a visão dos profissionais de TI e seus gerentes. Revista de Gestão da Tecnologia e Sistemas de Informação, 6, 437-463.

O'Neill, O., Stanley, L. \& O'Reilly, C. (2011). Disaffected Pollyannas: The influence of positive affect on salary expectations, turnover, and long-term satisfaction. Journal of Occupational and Organizational Psychology, 84, 599-617.

Oliveira, M. \& Gomes, W. (2014). Estilos reflexivos e atitudes de carreira proteana e sem fronteiras nas organizações contemporâneas brasileiras. Revista Psicologia: Organizações e Trabalho, 14, 105-118.

Oliveira, M., Zanon, C., Silva, I., Pinhatti, M., Gomes, W. \& Gauer, G. (2010). Validação da Versão Brasileira da Escala de Atitudes de Carreira Sem-Fronteiras. Arquivos Brasileiros de Psicologia, 62(3), 106-114.

Pearce, J. L., \& Randel, A. E. (2004). Expectations of organizational mobility, workplace social inclusion, and employee job performance. Journal of Organizational Behavior, 25, $81-98$.

Pisarik, C. T., \& Shoffner, M. F. (2009). The Relationship among Work Possible Selves, Socioeconomic Position, and the Psychological Well-Being of Individuals in Early Adulthood. Journal of Career Development, 35, 306-325. 
Prince, J. B. (2003). Career opportunity and organizational attachment in a blue-collar unionized environment. Journal of Vocational Behavior, 63, 136-150.

Schmitt, A., Zacher, H., \& Lange A. (2013). Focus on opportunities as a boundary condition of the relationship between job control and work engagement: A multi-sample, multimethod study. European Journal of Work and Organizational Psychology, 22, 505-519.

Stahl, G., Miller, E. \& Tung, R. (2002). Toward the boundaryless career: a closer look at the expatriate career concept and the perceived implications of an international assignment. Journal of World Business, 37, 216-227.

Strauss, K., Griffin, M. \& Parker, S. K. (2012). Future work selves: how salient hoped-for identities motivate proactive career behaviors. Journal of Applied Psychology, 97, 58098.

Stroh, L., \& Reilly, A. (1997). Rekindling Organizational Loyalty: The Role of Career Mobility. Journal of Career Development, 24, 39-54.

Tolfo, S. (2002). Carreira Profissional e seus movimentos: Revendo conceitos e formas de gestão. Revista Psicologia: Organizações e Trabalho, 2, 39-63.

Treadway, D., Breland, J., Adams, G., Duke, A. \& Willians, L. (2010). The interactive effects of political skill and future time perspective on career and community networking behavior. Social Networks, 32, 138-147.

van Dam, K., van der Vorst, J.D. \& van der Heijden, B.I. (2009). Employees' intentions to retire early: A case of planned behavior and anticipated work conditions. Journal of Career Development, 35, 265-289.

Vasconcellos, V. C., Borges-Andrade, J. E., Porto, J. \& Fonseca, A. M. (no prelo). Carreira nas organizações: revisão da produção brasileira no âmbito do microcomportamento organizacional. Revista Psicologia: Organizações e Trabalho. 
Veloso, E., Dutra, J., Fischer, A., Pimentel, J., Silva, R. \& Amorim, W. (2011). Gestão de carreiras e crescimento profissional. Revista Brasileira de Orientação Profissional, 12, $61-72$.

Veloso, E., Silva, R. D., \& Dutra, J. (2012). Diferentes gerações e percepções sobre carreiras inteligentes e crescimento profissional nas organizações. Revista Brasileira de Orientação Profissional, 13(2), 197-208.

Walsh, J. (2012). Not Worth the Sacrifice? Women's Aspirations and Career Progression in Law Firms. Gender, Work and Organization, 19, 508-531.

Wilkoszynski, C. \& Oliveira, F. (2013). Carreiras Contemporâneas: Desafios e Contradições Frente às Mudanças do Mundo do Trabalho. Desenvolve: Revista de Gestão da Unisalle, $39-58$.

Zacher, H. \& Frese, M. (2011). Maintaining a focus on opportunities at work: The interplay between age, job complexity, and the use of selection, optimization, and compensation strategies. Journal of Organizational Behavior, 32, 291-318.

Zacher, H., Heusner, S., Schmitz, M., Zwierzanska, M. \& Frese, M. (2010). Focus on opportunities as a mediator of the relationships between age, job complexity, and work performance. Journal of Vocational Behavior, 76, 374-386. 


\section{MANUSCRITO 2}

Assim como o manuscrito anterior, o Manuscrito 2 relata uma revisão de literatura. $\mathrm{O}$ objetivo deste manuscrito é prover um panorama com as possibilidades de investigação acadêmica sobre o futuro das organizações na perspectiva de seus profissionais (isto é, no nível micro-organizacional). O manuscrito fornece balizas para compreender esse assistemático campo de pesquisa, sumariando seus principais estudos empíricos e diferenciando-o de áreas de investigação voltadas para o nível macro-organizacional (planejamento estratégico e visão da organização, por exemplo). Trata-se de um campo pouco desenvolvido do ponto de vista conceitual, carente de medidas adequadas e com pequena produção empírica, lacunas que estimularam a realização dos estudos descritos em outros manuscritos da tese. 


\section{MANUSCRITO 2}

Futuro Organizacional na Perspectiva Individual:

Possibilidades e Tendências na Literatura

Organizational Future in the Individual Perspective:

Possibilities and Trends in the Literature

Vinicius Carvalho de Vasconcellos

Universidade de Brasília 


\title{
Resumo
}

O dinamismo e a imprevisibilidade do cenário organizacional tornam o exercício de projetar e prospectar o futuro cada vez mais relevante no cotidiano das organizações. Tal relevância se expressa, por exemplo, em estudos de nível macro-organizacional sobre planejamento, estratégia e desenvolvimento/mudança organizacional. Todavia, pouca atenção é concedida às projeções de futuro das organizações em nível micro-organizacional, isto é, na perspectiva de seus profissionais. Considerando o crescimento fragmentado de pesquisas com esse teor, este artigo revisa estudos sobre futuro organizacional do ponto de vista dos profissionais, sistematizando suas possibilidades de investigação e discutindo suas potencialidades.

Especificamente, são analisados os construtos/variáveis mais utilizados para tratar do tema, o contexto institucional de realização dos estudos, os instrumentos empregados e a variáveis relacionadas testadas pela literatura. Foram identificados três grandes grupos de construtos/variáveis: (a) imagens/visão de futuro desejado; (b) expectativas, otimismo e percepções quanto ao futuro provável; e (c) incertezas sobre o futuro. Detectou-se igualmente que grande parte dos estudos ocorre em contexto de mudanças organizacionais episódicas e que os instrumentos tendem a ser unidimensionais e com poucos itens. Na parte final do artigo, realiza-se uma síntese da literatura sobre o tópico (com ênfase nas suas tendências e limitações) e uma agenda de investigação é proposta.

Palavras-chave: futuro organizacional, expectativas, prospecção, estudos do futuro, revisão de literatura

\begin{abstract}
The dynamism and unpredictability of organizational scenario make the exercise of project and exploring the future more and more relevant in the organizations' daily life. This relevance is expressed, for example, in macro-organizational level studies on planning, strategy and organizational development and change. However, little attention is given to organizational future projections in micro-organizational level, that is, in their members' perspective. Considering the fragmented growth of research with that content, this paper reviews studies about organizational future projections based on the professional's point of view, systematizing the research possibilities and discussing its potential. Specifically, we analyze the constructs and variables employed to address this topic, the institutional context of such studies, the instruments used and the related variables tested in the literature. Three groups of constructs/variables were identified: (a) images/desired future vision; (b) expectations, perceptions and optimism about the probable future; and (c) uncertainties about the future. This review also identified that many of the studies take place in the context of episodic organizational changes and that the instruments tend to be one-dimensional and with few items. The final part of the article offers a literature overview of the topic (focusing on trends and limitations) and proposes a research agenda.
\end{abstract}

Keywords: organizational future, expectations, prospecting, future studies, literature review 
O tempo constituiu dimensão básica para a realização do trabalho, sendo fundamental para compreender a dinâmica organizacional. Todavia, surpreendentemente, a temporalidade costuma ser negligenciada ou tratada de forma periférica em pesquisas sobre organizações e trabalho (Ancona, Goodman, Lawrence \& Tushman, 2001; Caetano, 2012; Lee \& Liebenau, 1999; Sonnentag, 2012). Isto é, malgrado a quase ubiquidade dos efeitos do tempo nos processos de trabalho e sua condição de variável crítica para as organizações, manifesta-se certa carência na investigação do assunto.

Nas organizações, a temporalidade pode ser estudada a partir de diversas lentes, incluindo a própria trajetória de empresas/instituições, as mudanças nas políticas/práticas ao longo de sua história, a forma como as organizações lidam com prazos/cronogramas, os ciclos/ritmos de realização do trabalho e a orientação temporal dos profissionais (Ancona et al., 2001). Uma das formas de se refletir sobre temporalidade no contexto organizacional concerne ao exercício de prospectar, imaginar e projetar o futuro das organizações, iniciativa cada vez mais relevante em função da instabilidade/dinamismo da economia no cenário contemporâneo. Com efeito, termos como cenários, mudança, risco e planejamento são recorrentes no vernáculo da gestão, refletindo assim a intensidade com a qual as organizações relacionam-se com o futuro.

A despeito da literatura de planejamento e estratégia abordar tradicionalmente o futuro, pouca atenção é concedida às projeções e visões de futuro organizacional em nível microorganizacional. Assim, este artigo objetivou discutir as possibilidades de investigação acadêmica sobre futuro organizacional adotando o ponto de vista dos profissionais. Uma revisão sobre o tema justifica-se, em primeiro lugar, porque estudos nessa perspectiva já revelaram sua importância na relação indivíduo-trabalho-organização (Chiu, 2002; Harris \& Mossholder, 1996; Hui \& Lee, 2000); em segundo lugar, porque esse campo apresenta pouca sistematização, o que torna uma compilação de estudos especialmente útil. 
Para fornecer as bases para a revisão, a próxima seção apresenta brevemente áreas de pesquisa, conceitos e modelos tradicionais na área de administração e comportamento organizacional que lidam com o futuro no nível macro-organizacional. A seção subsequente, cerne do artigo, discute estudos no nível micro-organizacional que buscam compreender como os trabalhadores percebem, projetam e se relacionam com o futuro de suas organizações. São destacados os conceitos e instrumentos utilizados nas pesquisas e a variáveis relacionadas testadas. Realiza-se a seguir uma síntese da literatura que revela as tendências e lacunas sobre o tópico e as interseções entre a literatura macro-organizacional e micro-organizacional. Nas considerações finais, uma agenda de investigação é proposta.

\section{Futuro no Nível Macro-Organizacional: Planejamento, Cenários, Desenvolvimento e Mudanças}

Iniciativas acadêmicas interessadas em deslindar padrões temporais das organizações não são recentes. Greiner (1972), em representação esquemática do crescimento das organizações, propõe modelo com fases de evolução (períodos sem grandes reformulações nas práticas) e de revolução (períodos de reviravolta na vida organizacional). Tais fases alternam-se em uma tendência praticamente linear de crescimento conforme a organização envelhece. Em outro exemplo, o modelo de equilíbrio pontuado (Tushman \& Romanelli, 1985) advoga que as organizações evoluem por meio de períodos de convergência (fases relativamente longas, com predomínio da consistência interna entre as atividades), que são interrompidos por períodos de reorientação/recriação (mais curtos e dotados de mudanças descontínuas, abruptas e profundas).

Esses modelos, assim como muitos posteriores, dispõem as trajetórias organizacionais em um continuum temporal, no qual fases ou ciclos se sucedem. A rigor, essa sucessão de eventos é apreendida pelos membros da organização a partir dos três quadros temporais básicos: passado, presente e futuro. Isto é, partindo de um dado momento da trajetória 
organizacional, é possível apontar fases/ciclos/eventos que já ocorreram, que estão em curso ou que provavelmente constituirão o futuro da organização.

Na gestão contemporânea, o esforço de apreender os eventos que moldarão o futuro ganha notável relevância. Essa orientação para o futuro, a rigor, vincula-se à tentativa dos gestores de antever e controlar os caminhos que as organizações trilharão em contextos geralmente instáveis. Em tese, quanto maior o conhecimento do futuro, maior a possibilidade de se obter bons níveis de desempenho e de assegurar a sobrevivência da organização.

Em consonância ao proeminente papel do futuro na gestão, a literatura debruça-se sobre a temática a partir de diversas frentes de investigação. Uma dessas frentes vincula-se aos chamados estudos do futuro. Trata-se de um campo multidisciplinar voltado para a tentativa de antecipar e/ou construir o futuro e que adquire cada vez mais espaço no contexto organizacional (Schenatto, Polacinski, Abreu \& Abreu, 2011). Esse campo abrange grande variedade de termos e métodos - incluindo previsões, cenários, prospecções, futuros possíveis, entre outros - cada qual atrelado ao momento histórico e ao contexto social/cultural de sua criação (Masini, 2010; Schenatto et al., 2011). Nesse campo, há uma distinção entre estudos de previsão e de prospecção: os primeiros tendem a utilizar modelos determinísticos e quantitativos, nos quais o passado pavimenta, de modo relativamente fixo, a concepção de futuro; os últimos baseiam-se em modelos qualitativos e subjetivos que assumem o futuro como incerto e múltiplo (Schenatto et al., 2011).

Nas organizações, estudos do futuro ganham materialidade no âmbito do planejamento, da estratégia e da formulação de cenários. Conforme definição clássica, planejamento referese à concepção de um futuro desejado, bem como dos meios para atingi-lo (Ackoff, 1970). O planejamento estratégico, especificamente, alude ao procedimento sistemático de gestão que, considerando as alternativas, fundamenta a estratégia futura de uma organização, sem supor que o futuro seja mera extrapolação do passado (Ansoff \& McDonnell, 1993). Tal 
procedimento busca aproximar a organização do futuro desejado ao fornecer uma direção de trabalho aos seus profissionais.

Na prática, o planejamento estratégico baseia-se em prospecções do ambiente interno e externo que favorecem a formulação de metas e a identificação de tendências, ameaças, oportunidades e descontinuidades que possam alterar o curso da organização (Ansoff \& McDonnell, 1993). Nesse contexto, emergem as noções de visão da organização (tradicionalmente utilizada para expressar o que a organização deseja ser no futuro) e de aspirações organizacionais (níveis de desempenho e resultados desejados) que são traduzidas, em geral, em objetivos futuros a serem alcançados (Harrison, 2005; Shinkle, 2012). Apesar das limitações do planejamento estratégico diante das vicissitudes da dinâmica econômica e organizacional, constata-se que este se encontra amplamente difundido, fomentando a elaboração de futuros almejados e de estratégias para alcançá-los.

Por seu turno, a utilização de cenários como ferramenta de planejamento fortaleceu-se em função da imprevisibilidade da economia após a crise do petróleo de 1973 (Porter, 1989). Mesmo carecendo de definição consensual na literatura, cenários versam essencialmente sobre histórias que descrevem estados futuros de determinado ambiente de negócios (van der Heijden, 2004) ou, ainda, sobre uma visão internamente consistente de um futuro possível (Porter, 1989). Cenários não exprimem previsões e, sim, a elaboração de situações futuras dotadas de incerteza. Partindo da construção de múltiplos cenários (com diferentes níveis de probabilidade), uma organização pode explorar possibilidades e se preparar diante de eventuais mudanças em variáveis importantes para seu funcionamento.

Godet (2000) sublinha que cenários e planejamento estratégico estão intimamente articulados nos atuais modelos de gestão, embora sejam entidades distintas. Os cenários respondem à pergunta “O que pode ocorrer?”, enquanto o planejamento estratégico se endereça às questões: “O que podemos fazer?” e "O que vamos fazer e como?”. Nesse 
sentido, o planejamento por cenários apresenta-se como o esforço de antecipação da evolução de variáveis-chave do ambiente externo e interno, assim como a reação da organização diante desse quadro; configura, portanto, insumo para o processo decisório e para a implantação da estratégia (Godet, 2000). Pesquisas recentes atestam a aplicabilidade dos cenários em diversos setores da economia brasileira, bem como seu relevante papel no estabelecimento de estratégias empresariais (Faller \& Almeida, 2014; Silva, Spers, Wright \& Costa, 2013).

Além do planejamento estratégico e da prospecção de cenários, o elo presente-futuro encontra expressão, outrossim, na gestão da mudança e no desenvolvimento organizacional. Mudança organizacional pode ser compreendida como qualquer alteração, planejada ou não, em componentes que caracterizam a organização como um todo e que traz alguma consequência, positiva ou negativa, para os resultados organizacionais ou para sua sobrevivência (Neiva \& Paz, 2012). Neste campo, convém discernir entre mudanças contínuas - cumulativas, constantes e intrínsecas ao desenvolvimento - e mudanças episódicas, isto é, alterações descontínuas/radicais que almejam recuperar o equilíbrio perdido (Weick \& Quinn, 1999).

Com amplitude menor do que o conceito de mudança, desenvolvimento organizacional concerne à aplicação/transferência do conhecimento das ciências do comportamento em prol do desenvolvimento planejado e do fortalecimento de estratégias, estruturas e processos que levam à efetividade organizacional (Cummings \& Worley, 2013). Desenvolvimento organizacional constitui, a um só tempo, um campo de estudos e um conjunto de práticas/intervenções na realidade das organizações, notadamente por meio de mudanças planejadas. Nas últimas décadas, em face de um mundo hiperturbulento e imprevisível, a prática do desenvolvimento organizacional assistiu à ascensão de métodos de gestão de mudança, capazes de lidar com alterações não planejadas e episódicas. 
O desenvolvimento e a mudança organizacional movem as organizações em direção a um estado futuro (seja ele desejado ou indesejado, planejado ou imprevisto) que assume formato dissimilar diante da configuração atual. Assim, ambos os processos comportam per se uma dimensão temporal e estão, essencialmente, orientados para o futuro. No fundo, os modelos de mudança/desenvolvimento organizacional exprimem um processo sistemático de construção do futuro organizacional. Por essa razão, recorre-se a essa literatura a fim de conhecer os atributos (componentes) da organização primordiais na discussão do futuro organizacional.

Nessa linha, o modelo de Mintzberg e Westley (1992) advoga que a mudança pode ocorrer no estado básico da organização ou em sua estratégia. Mudanças no estado básico incluem alterações na cultura, na estrutura organizacional, nos sistemas/procedimentos de gestão e na força de trabalho (admissão/desligamento de profissionais, por exemplo). De sua parte, mudanças de estratégia abarcam transformações na visão, direção dos negócios, produtos/mercado da organização, iniciativas estratégicas e instalações/equipamentos.

Há ainda modelos que descrevem não apenas os atributos relacionados à mudança/desenvolvimento em direção ao futuro, mas também seu fluxo de interações em diversos níveis, servindo assim como ferramenta de diagnóstico e de implantação de modificações (Burke \& Litwin, 1992; Cummings \& Worley, 2013; Porras \& Robertson, 1992). De modo geral, tais modelos representam o ambiente externo como variável que influencia diversos atributos macro-organizacionais, como estratégia (incluindo metas e visão da organização), liderança, cultura organizacional, estrutura formal (organograma e divisão/coordenação do trabalho), procedimentos e políticas de gestão, tecnologia/métodos de produção e ambiente físico (instalações e equipamentos).

Mudanças nesses primeiros atributos desdobram-se para variáveis de nível grupal (clima organizacional e redes informais de trabalho, por exemplo) e de nível individual 
(motivação, habilidades, valores, cognições e comportamento dos membros da organização). Em última instância, todos os elementos confluem para o desempenho/efetividade dos indivíduos, grupos e da própria organização. Os modelos não sustentam padrão sequencial e unidirecional, de modo que são previstos efeitos recíprocos entre os atributos e os diferentes níveis da organização.

Com base no exposto, a Tabela 1 condensa os atributos presentes nos quatro modelos citados e faculta a comparação entre eles. A contribuição de Mintzberg e Westley (1992) destoa das demais, posto que esta não se propõe a construir um modelo capaz de representar os diversos níveis organizacionais nem a relação da organização com o mundo exterior. De todo modo, a Tabela 1 põe em evidência ambiente externo, estratégia, cultura organizacional, estrutura, sistemas de gestão/controle e desempenho/efetividade como pontos principais de entroncamento entre os modelos no nível macro-organizacional. Estes são, possivelmente, atributos-chave para compreender a mudança, o desenvolvimento e, por conseguinte, o futuro organizacional. 
Tabela 1

Principais Atributos dos Modelos de Desenvolvimento e Mudança Organizacional

\begin{tabular}{lcccc}
\hline \multicolumn{1}{c}{ Atributos } & $\begin{array}{c}\text { Burke e } \\
\text { Litwin } \\
(\mathbf{1 9 9 2})\end{array}$ & $\begin{array}{c}\text { Cummings } \\
\text { e Worley } \\
\text { (2013) }\end{array}$ & $\begin{array}{c}\text { Mintzberg } \\
\text { e Westley } \\
\text { (1992) }\end{array}$ & $\begin{array}{c}\text { Porras e } \\
\text { Robertson } \\
\text { (1992) }\end{array}$ \\
\hline Ambiente externo & $\checkmark$ & $\checkmark$ & & $\checkmark$ \\
Estratégia (missão/visão/decisões/iniciativas) & $\checkmark$ & $\checkmark$ & $\checkmark$ & $\checkmark$ \\
Cultura organizacional & $\checkmark$ & $\checkmark$ & $\checkmark$ & $\checkmark$ \\
Estrutura formal & $\checkmark$ & $\checkmark$ & $\checkmark$ & $\checkmark$ \\
Sistemas, políticas e práticas de gestão & $\checkmark$ & $\checkmark$ & $\checkmark$ & $\checkmark$ \\
Mecanismos de coleta de informação/controle & $\checkmark$ & $\checkmark$ & $\checkmark$ & $\checkmark$ \\
Instalações/configuração espacial & & & $\checkmark$ & $\checkmark$ \\
Tecnologia & & & & $\checkmark$ \\
Liderança $_{\text {Efetividade/desempenho organizacional }}$ & $\checkmark$ & $\checkmark$ & & $\checkmark$ \\
Variáveis no nível grupal & & $\checkmark$ & & $\checkmark$ \\
Variáveis no nível individual & & $\checkmark$ & & $\checkmark$ \\
\hline
\end{tabular}

\footnotetext{
${ }^{\mathrm{a}}$ Equipamentos e procedimentos de produção.

${ }^{\mathrm{b}}$ Exemplos: clima e efetividade/desempenho do grupo de trabalho.

${ }^{\mathrm{c}}$ Exemplos: motivação, significado trabalho, autonomia e efetividade/desempenho dos indivíduos.
}

Ao analisar os modelos, cabe destacar ainda a presença de efetividade/desempenho como variável dependente final em três deles (Burke \& Litwin, 1992; Cummings \& Worley, 2013; Porras \& Robertson, 1992). De fato, a presença de indicadores de desempenho e efetividade é plenamente justificada visto que estes são capazes de sinalizar até que ponto os esforços de mudança/desenvolvimento foram exitosos em aprimorar as organizações. A rigor, a distinção entre efetividade e desempenho não é clara na literatura. Sobre o tópico, Richard, Devinney, Yip e Johnson (2009) definem efetividade como pletora de resultados valorizados pelos públicos de interesse da organização (membros, clientes, gerentes, acionistas, entre outros), incluindo desde aspectos operacionais até medidas subjetivas, como reputação. Desempenho, com escopo menor, surge como um dos indicadores de efetividade, sendo 
composto por três tipos de básicos de resultados: financeiro (lucro e retorno sobre investimentos, por exemplo), participação no mercado e retorno para os acionistas (variação dos preços das ações e dividendos).

No término dessa seção, sublinham-se alguns pontos relevantes para a sequência do artigo. Os parágrafos anteriores evidenciaram diferentes formas de conceber, representar e projetar o futuro no nível macro-organizacional, incluindo futuros desejados e futuros possíveis/prováveis. Desvelaram também, por meio dos modelos de desenvolvimento e mudança, que existem distintos atributos da organização a ser considerados nas projeções de futuro. A próxima seção permitirá avaliar até que ponto essas diferentes formas de representar o futuro e os distintos atributos organizacionais considerados são também explorados em estudos sobre o futuro organizacional na perspectiva individual.

\section{Futuro Organizacional: Possibilidades de Investigação na Perspectiva Individual}

Ao contrário dos modelos macro-organizacionais, nesta seção o acento repousa no que os indivíduos desejam, projetam, pensam, percebem ou sentem sobre o futuro de suas organizações. No intuito de facilitar a redação, doravante a expressão projeções de futuro organizacional será utilizada genericamente para se referir a esse conjunto de manifestações. Considerando que as pesquisas encontram-se pulverizadas em diversas variáveis, cada qual com definições e instrumentos peculiares, esta seção agrupa os estudos de acordo com a proximidade entre os tipos de projeção pesquisados.

Três tipos de projeções de futuro organizacional foram identificados na literatura: (a) imagens/visão de futuro desejado ou ideal; (b) expectativas, otimismo e percepções quanto ao futuro provável; e (c) incertezas sobre o futuro. Dedica-se, a seguir, uma subseção para cada um desses grupos. Ao abordar as pesquisas, questões metodológicas são privilegiadas na medida em que a menção aos instrumentos facilita a compreensão do tipo de fenômeno que 
foi, de fato, objeto de análise. Reporta-se, igualmente, o contexto institucional da organização e as variáveis relacionadas às projeções de futuro organizacional testadas nas investigações.

\section{Imagens e Visão de Futuro Desejado}

Uma das formas de projetar o futuro organizacional trata de interrogar sobre como a organização deveria ser no futuro. Dentro dessa proposta, Reger, Gustafson, Demarie e Mullane (1994), em artigo teórico, chamam a atenção para a distinção entre a identidade organizacional atual e a identidade organizacional ideal. Esta última é composta pelos desejos dos membros acerca do futuro da organização, sendo sintetizada na ideia: "aquilo que queremos ser”. A discrepância entre as duas identidades, segundo os autores, pode ser um elemento motivacional importante para alterar o status quo da organização.

Apoiados no trabalho de Reger et al. (1994), Gioia e Thomas (1996), em pesquisa com executivos de universidades, indagaram sobre quais características seriam desejáveis para suas organizações no futuro. Denominada de imagem futura desejada da organização, a variável foi aferida por escala likert que incluía itens sobre prestígio, clima acadêmico, inovação e estrutura administrativa, entre outros. Os autores constataram que a imagem futura desejada pode operar como potente mecanismo para alterar a atual identidade organizacional, principalmente se for capaz de despertar, em momentos de mudança, novos significados para o trabalho e para a organização nos profissionais.

Baseadas nessas pesquisas, Margolis e Hansen (2003) examinaram imagens de futuro organizacional construídas por membros de uma companhia aérea em processo de fusão. As imagens foram coletadas por entrevistas nas quais os trabalhadores discorriam sobre o futuro de sua organização dois anos à frente. O corpus analisado apontou a existência de diferentes formas de se relacionar com o futuro organizacional, entre as quais: a construção de imagens de futuro ideal, de futuro temido e de futuro esperado. A primeira dessas formas expressava o que os profissionais desejavam como futuro ideal da organização (as entrevistas citaram 
crescimento no mercado e alcance de excelência operacional), no mesmo escopo de investigação de Gioia e Thomas (1996). Já as imagens de futuro temido indicavam afetos negativos sobre o provir da organização. Nas entrevistas, assomaram especialmente medo e preocupações sobre a sobrevivência da empresa e a substituição de valores organizacionais. As imagens de futuro esperado, por sua vez, versam sobre expectativas e serão discutidas na próxima subseção, cuja intenção é precisamente compilar variáveis com esse teor.

Apesar de estarem no nível micro-organizacional, as concepções de futuro ideal/desejado da organização presentes nessas pesquisas se aproximam, em grandes linhas, da visão organizacional (mencionada na seção precedente ao se discutir planejamento estratégico) na medida em que ambas expressam futuros almejados. Observando essa similitude, alguns pesquisadores (Kantabutra \& Avery, 2009) se interessaram pela visão organizacional elaborada pelos membros da organização, isto é, transpuseram o conceito formal do planejamento para o nível individual de análise.

Nesse estudo de Kantabutra e Avery (2009), gerentes e seus subordinados foram perguntados se tinham uma visão organizacional pessoal e, em caso positivo, eram instados a escrevê-la (no caso, as organizações eram lojas de varejo). Juízes independentes avaliaram as visões quanto à presença/ausência de determinados atributos. Os dados apontaram que lojas cujos gerentes apresentaram visão organizacional pessoal e nas quais há maior compartilhamento/similaridade entre as visões do líder e de seus subordinados tendem a exibir níveis maiores de satisfação de clientes e de trabalhadores. Não houve relação entre a presença de atributos específicos e a satisfação de clientes e subordinados.

\section{Expectativas, Otimismo e Percepções de Futuro Organizacional}

Se a seção anterior centrou-se no futuro organizacional desejado/ideal, esta colige pesquisas direcionadas a cognições sobre o que provavelmente ocorrerá com a organização 
no futuro na visão dos profissionais. Esta abordagem permite mais facilmente a emergência de projeções negativas ou neutras sobre o estado futuro da organização.

Alguns desses estudos se alicerçaram na análise de expectativas, isto é, crenças sobre a probabilidade de ocorrência de um evento/situação no futuro (Oettingen \& Mayer, 2002). Por exemplo, Dackert, Jackson, Brenner e Johansson (2003) estudaram expectativas de empregados de dois órgãos públicos prestes a se fundir. Por meio da técnica de diferencial semântico, o instrumento solicitava aos participantes que descrevessem como seria a nova organização a partir de certas características institucionais, entre os quais clima e cultura organizacional. Os autores relataram convergência entre os profissionais das duas organizações acerca da expectativa de dominância cultural de uma delas na formação da nova organização. Tal expectativa levou o grupo não dominante a sentir sua identidade profissional ameaçada e a esperar maior carga de trabalho.

Hubbard e Purcell (2001) inquiriram a formação de expectativas de profissionais de duas empresas envolvidas em uma situação de aquisição. As entrevistas revelaram expectativas quanto à cultura da nova organização e, sob a ótica dos impactos individuais, o receio perante possíveis transferências ou desligamentos. O papel da liderança e a qualidade/credibilidade da comunicação foram identificados como fatores relevantes para a formação dessas expectativas.

A pesquisa de Margolis e Hansen (2003) sobre uma fusão no setor aéreo, citada anteriormente, detectou no discurso dos profissionais imagens de futuro organizacional esperado, definidas simplesmente como o que os profissionais esperavam do futuro de sua organização. As entrevistas indicaram expectativas tais como a continuidade da missão e do crescimento da organização, a alteração de alguns valores organizacionais e o surgimento de uma imagem mais positiva para os consumidores. Ademais, conforme estudos já mencionados (Dackert et al., 2003; Hubbard \& Purcell, 2001), o discurso dos profissionais 
articulava o futuro organizacional ao futuro na carreira; neste caso, os entrevistados esperavam oportunidades de crescimento e aumento nos salários/benefícios na nova organização.

Em paralelo às expectativas, alguns autores selecionaram o otimismo como pedra de toque no estudo das projeções de futuro organizacional. Otimismo refere-se a um estado no qual há expectativa generalizada de que o futuro será positivo (Bruininks \& Malle, 2005). Assim, otimismo e expectativas guardam semelhanças semânticas, diferindo notadamente na conotação sempre positivada e no caráter mais global do primeiro termo.

Em uma situação de reestruturação organizacional, Mossholder, Settoon, Harris e Armenakis (1995) pesquisaram o otimismo de gerentes quanto ao futuro da organização. Foram utilizados dois itens: "Estou otimista quanto ao futuro da organização no curto prazo" e "Estou otimista quanto ao futuro da organização no longo prazo". Entre outros resultados, o otimismo mostrou correlações positivas moderadas com comprometimento organizacional e autonomia de decisão e correlações negativas com ambiguidade e conflito de papel. Estudo posterior com a mesma escala (Harris \& Mossholder, 1996), aplicada dessa vez em uma empresa passando por transformação cultural, sinalizou que a discrepância percebida entre cultura atual e cultura ideal relacionou-se negativamente como otimismo sobre o futuro organizacional.

Fora de situações de mudança organizacional, Posner (2010) pesquisou expectativas de líderes sobre o futuro de sua organização e da sua vida pessoal, oferecendo três opções de resposta (otimista, pessimista e sentimentos mesclados). O otimismo quanto ao futuro organizacional de supervisores (45\%) foi inferior ao otimismo da média gerência (58\%) e dos gerentes executivos $(62 \%)$. O otimismo desses três estratos perante o futuro na vida pessoal foi, via de regra, superior ao otimismo quanto ao futuro organizacional. 
Com maior grau de refinamento, Chiu, Hui e Lai (2007) propuseram o construto otimismo organizacional, definido como avaliação positiva e favorável dos indivíduos sobre o desenvolvimento futuro de sua organização. Com sete itens em uma escala de concordância, o instrumento indagava aos respondentes se sua organização seria capaz de responder a mudanças, se seria mais lucrativa no futuro, continuaria a atrair profissionais qualificados e prosseguiria melhorando sua eficiência operacional. Com estrutura unidimensional, tal variável mostrou correlações fracas com variáveis demográficas; por outro lado, satisfação com salários/benefícios foi preditor de otimismo organizacional.

O termo confiança também é evocado para sinalizar projeções sobre o futuro organizacional. Nesta acepção, destoa do construto confiança organizacional, variável orientada para o presente e que designa percepções sobre a capacidade, benevolência e integridade da organização (Rêgo, Filho \& Lima, 2013). Ao empregar o termo direcionandoo para o futuro, Zhou, Li e Zhou (2004) mediram a confiança dos profissionais no desempenho organizacional futuro por meio de dois itens ("Dentro de um ano o desempenho da empresa será...” e “Dentro de cinco anos o desempenho da empresa será...”), ambos respondidos em escala que variava de muito bom a muito ruim. Satisfação com o trabalho e comprometimento organizacional, além da percepção de orientação para o mercado, relacionaram-se com a variável. O tipo de organização influenciou os níveis de confiança (profissionais de empresas públicas mostraram-se menos confiantes), todavia, isto não ocorreu com o cargo do respondente (gerentes e não gerentes).

McGovern (2000) aferiu confiança no futuro organizacional por intermédio de dois itens concernentes ao sucesso da organização no curto e no longo prazo. No instrumento, os respondentes indicavam sua confiança em uma escala de 10 pontos com as âncoras confiança muito baixa e confiança muito alta. Entre os resultados mais relevantes, está a correlação positiva entre confiança nos futuros líderes das empresas e no próprio futuro organizacional. 
Para além de expectativas, otimismo e confiança, outros autores preferiram simplesmente trabalhar com percepções de futuro organizacional. Nesse rumo, White (2010) analisou o contexto pós-fusão de órgãos militares e se deparou com percepções bipolares sobre o futuro. Baseada principalmente em grupos de foco e em respostas abertas de questionários, a autora relata que alguns participantes enxergavam o futuro com esperança, ressaltando que a organização cumpriria com êxito sua missão, seria admirada socialmente e apresentaria integração entre seus diversos setores. No reverso da moeda, outros participantes assinalavam que, no futuro, a organização tornar-se-ia segregada, reacionária e ineficiente.

Pesquisando diversas organizações, Chiu (2002) utilizou uma escala que questionava os participantes se eles percebiam que a organização detinha clara direção de desenvolvimento e se, no futuro, apresentaria melhorias na gestão e na produção. Essa variável, nomeada de prospectos organizacionais, registrou escores mais elevados em empresas privadas do que em empresas estatais e joint-ventures. Idade, sexo, estado civil e cargo ocupado (gerencial ou não gerencial) não influenciaram de forma significativa a percepção de prospectos organizacionais. Todavia, prospectos organizacionais foram preditores de comprometimento organizacional afetivo.

Em proposta mais elaborada, Chen, Hsu e Yip (2011) aferiram percepções de desempenho futuro com itens que estimulavam os respondentes a comparar o desempenho de sua empresa com empresas similares nos próximos cincos anos. Constavam do instrumento os seguintes atributos: lucratividade, crescimento em vendas e em fatia de mercado, satisfação dos trabalhadores, qualidade de produtos/serviços, entre outros. Percepção de efetividade e do envolvimento da área de recursos humanos na estratégia organizacional foram antecedentes significativos da variável. 


\section{Incertezas sobre o Futuro Organizacional}

O grau de certeza/incerteza e de clareza/ambiguidade dos trabalhadores sobre o futuro organizacional constitui outra possibilidade de análise. Neste caso, ganham cartaz o senso de dúvida e a dificuldade dos indivíduos em prospectar eventos que ocorrerão no futuro da organização. Tal incerteza surge amiúde na mudança organizacional, notadamente quando o processo de comunicação e planejamento da mudança não ocorreu a contento (Oreg, Valoka \& Armenakis, 2011). Com efeito, diante da mudança, os indivíduos podem vivenciar dúvidas sobre estrutura organizacional, metas da organização, continuidade das atividades/cargos existentes e até mesmo sobre possíveis demissões, tornando a incerteza uma das reações mais comuns nessa situação institucional (Bordia, Hobman, Jones, Gallois \& Callan, 2004).

Assim, Ullrich, Wieseke \& van Dick (2005), ao analisar o processo de identificação com a organização em conjuntura pós-fusão, detectaram em suas entrevistas considerável grau de incerteza sobre estrutura organizacional (os participantes eram convidados a falar sobre a situação da nova companhia gerada 12 meses à frente). Nessas entrevistas, as incertezas brotaram combinadas com dúvidas sobre o próprio futuro profissional dos indivíduos, o que gerou empecilhos para que estes últimos se identificassem e realizassem esforços em prol do desenvolvimento da organização.

Por sua vez, Greenhalgh e Jick (1989), pesquisando organização hospitalar também em contexto pós-fusão, mediram a ambiguidade percebida sobre o futuro organizacional (o artigo não relata o texto dos itens). Duas variáveis de personalidade (intolerância à ambiguidade e necessidade de segurança) foram testadas como antecedentes e, embora significativa, a relação negativa encontrada foi discreta. Como variável independente, a ambiguidade percebida sobre o futuro não foi capaz de predizer estresse no trabalho, problemas de saúde, satisfação no trabalho e intenção de rotatividade, mas manifestou relação negativa com envolvimento com o trabalho. 
Além de fusões, há exemplos de estudos baseados em outros tipos de mudança organizacional. Bordia et al. (2004) coletaram dados em um departamento governamental que acabara de ser separado de outro, o que ensejou a criação de novas gerências, realocação de profissionais e alterações nas atividades. Os autores mensuraram duas variáveis de futuro organizacional: incerteza estratégica e incerteza estrutural. A primeira tocava na capacidade da organização de, no futuro, atender às necessidades dos clientes, atingir seus objetivos/missão e sobreviver diante do cenário externo. A segunda indagava se haveria, no futuro, mudanças na estrutura organizacional, na cadeia de comando e no papel/contribuição dos setores para o resultado geral da organização. Cada instrumento continha quatro itens e os profissionais indicavam em escala de sete pontos seu grau de incerteza sobre esses tópicos.

Bordia et al. (2004) reportaram que a qualidade no processo de comunicação da mudança figurou como antecedente (relação negativa) de incerteza estratégica, mas não de incerteza estrutural. Inversamente, a participação dos trabalhadores nas decisões relativas à mudança despontou como antecedente (relação negativa) de incerteza estrutural, contudo, não de incerteza estratégica. Os dois tipos de incerteza correlacionaram-se positivamente.

Exemplificando pesquisas em contexto de mudança contínua, Hui e Lee (2000) investigaram uma empresa com recentes alterações na estrutura de cargos e salários. Os autores mediram a variável incerteza de mudança positiva com dois itens: "A organização mudará para melhor" e "A organização sobreviverá e crescerá em tempos difíceis" (os indivíduos indicavam na escala seu grau de incerteza). Esta variável mostrou-se preditora relevante de comprometimento organizacional, mas não de motivação no trabalho e absenteísmo. Já Lord e Hartley (1998) averiguaram uma organização pública passando por mudanças que visavam ao incremento na integração entre setores e na identificação dos funcionários com as metas organizacionais. Os autores analisaram a insegurança dos profissionais quanto ao futuro organizacional e às ameaças de privatização. A variável exibiu 
correlações negativas com comprometimento organizacional, satisfação no trabalho e envolvimento com a mudança, mas não houve associação com idade e tempo de organização.

Como exposto, existem algumas formas de se pesquisar o futuro organizacional na perspectiva individual. A próxima seção sintetiza a literatura e aponta suas tendências.

\section{Futuro Organizacional na Perspectiva Individual: Síntese e Tendências na Literatura}

Nesta revisão, as pesquisas sobre futuro organizacional na perspectiva individual diferiram em três aspectos importantes: contexto organizacional (ocorrência ou não de mudança organizacional), tipos de projeção (forma de apreender/representar o futuro) e atributos projetados (componentes da organização considerados). A Figura 1 sumaria as possibilidades de investigação nesses aspectos e traz exemplos de estudos. Novas pesquisas sobre o tema devem atentar para esses aspectos para obter o melhor delineamento possível.

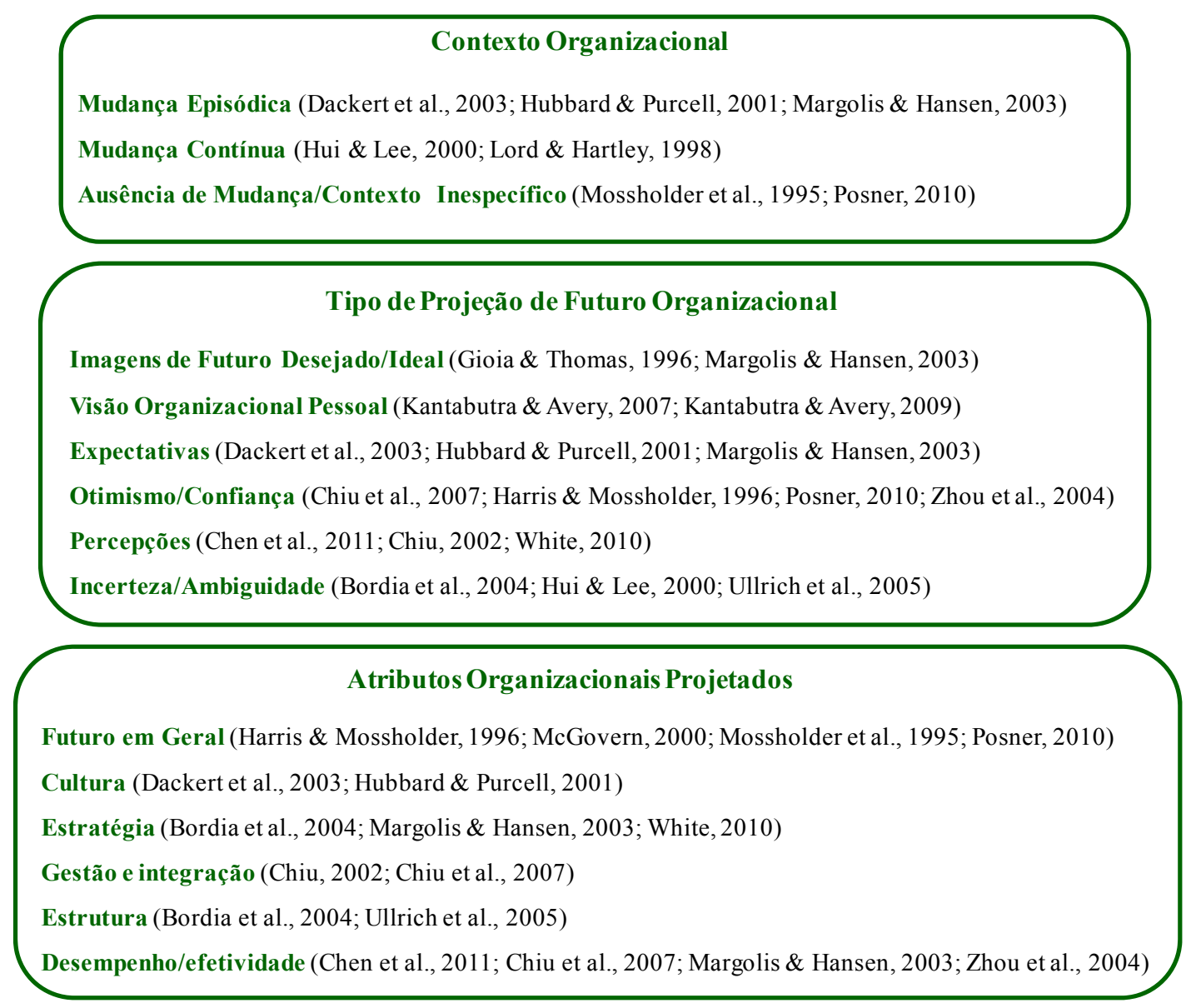

Figura 1. Possibilidades de investigação de futuro organizacional na perspectiva individual. 
Ao apreciar o contexto desses estudos, nota-se que boa parte deles vincula-se à mudança/desenvolvimento organizacional. Essa relação estreita advém, em primeiro lugar, da intrínseca orientação para o futuro que perpassa a mudança organizacional (como aludido anteriormente). Em segundo lugar, ao contrário do planejamento estratégico, geralmente a cargo de especialistas/gerentes no alto escalão, tais experiências instigam toda a força de trabalho a refletir sobre o destino da organização, tornando-as prolíficas em termos de projeções sobre o futuro. Por fim, ressalta-se que o campo de estudos sobre mudança abriu-se nas últimas décadas para a adoção do indivíduo como unidade de análise, inclusive no Brasil (Guimarães \& Marques, 2011; Neiva \& Paz, 2012). Logo, as consequências/impactos das mudanças nos profissionais, bem como suas reações diante do processo, entraram definitivamente na pauta, favorecendo análises sobre projeções de futuro organizacional.

Por outro lado, investigações sobre futuro organizacional não se restringem a mudanças episódicas e radicais, como ilustra a Figura 1. De fato, há estudos em contextos de mudança contínua ou de estabilidade, sugerindo que tais projeções não afloram somente em circunstâncias críticas. Neste ponto, cabe frisar que expectativas de manutenção do status quo também configuram um futuro organizacional possível, sendo plausíveis notadamente em organizações do setor público ou situadas em mercados estáveis. Os próprios modelos de trajetórias organizacionais, citados no início do artigo, assinalam como a história das organizações é pontuada pela alternância entre períodos de continuidade e de mudança.

Sobre o tipo de projeção, é possível firmar paralelos entre os estudos de nível micro e macro-organizacional. Nesse sentido, a elaboração de futuros desejados e/ou almejados surge tanto no nível micro-organizacional (como nos citados estudos sobre imagem futura de organização) quanto no nível macro-organizacional (por exemplo, na visão/aspirações da organização vinculadas à estratégia). Similarmente, a formulação de futuros possíveis/prováveis constitui, concomitantemente, a base dos estudos sobre expectativas dos 
indivíduos e das pesquisas sobre cenários a cargo das áreas de planejamento das organizações.

Quanto aos atributos abordados nas pesquisas de nível micro-organizacional, há variáveis/construtos que tratam do futuro em geral (Posner, 2010), outras que investem em um único atributo específico (Chen et al., 2011, por exemplo) e poucas que tocam em mais de um atributo (Bordia et al., 2004). A tendência da literatura é trabalhar com variáveis genéricas ou dotadas de apenas um atributo. Por outro lado, embora de forma isolada, ressalta-se que as pesquisas de nível micro-organizacional contemplam diversos componentes dos modelos de desenvolvimento/mudança organizacional (como cultura, estratégia, estrutura e efetividade). Esse padrão atesta que os atributos considerados críticos nos modelos/teorias macro-organizacionais estão, em grandes linhas, espelhados nas pesquisas empíricas com indivíduos. Desempenho/efetividade desponta como o atributo mais frequente nos construtos e instrumentos dos estudos na perspectiva individual.

Além desses pontos, cumpre tecer considerações sobre a relação das projeções de futuro organizacional com outras variáveis. Várias publicações (Chiu, 2002; Chiu et al., 2007; Hui \& Lee, 2000; Lord \& Hartley, 1998) expressam associação fraca ou inexistente entre variáveis demográficas (sexo, idade e tempo na organização) e projeções de futuro organizacional. Sobre o cargo do respondente, os resultados divergem: há pesquisas que sugerem que o cargo influencia as projeções (Posner, 2010) e outras que não sinalizam tal efeito (Chiu, 2002; Chiu et al., 2007; Zhou et al., 2004).

Atitudes no trabalho, como satisfação e comprometimento organizacional, são bastante estudadas, corroborando sua fértil produção no campo do comportamento organizacional em geral (Judge \& Kammeyer-Mueller, 2012). Variáveis que expressam otimismo, confiança ou percepções positivas sobre o futuro organizacional tendem a se relacionar positivamente com satisfação com o trabalho (Chiu et al., 2007; Harris \& Mossholder, 1996; Zhou et al., 2004) e 
comprometimento organizacional (Chiu, 2002; Harris \& Mossholder, 1996; Mossholder et al., 1995; Zhou et al., 2004). Otimismo ainda se associa de forma positiva com envolvimento no trabalho (Harris \& Mossholder, 1996) e negativa com intenção de rotatividade e ambiguidade/conflito de papel (Harris \& Mossholder, 1996; Mossholder et al., 1995).

Nos estudos sobre incerteza/insegurança/ambiguidade sobre o futuro organizacional, as correlações com satisfação com o trabalho e comprometimento organizacional são negativas (Hui \& Lee, 2000; Lord \& Hartley, 1998) ou não significativas (Greenhalgh \& Jick, 1989). Tais projeções relacionam-se ainda negativamente com envolvimento no trabalho (Greenhalgh \& Jick, 1989), mas não se associam à intenção de rotatividade (Greenhalgh \& Jick, 1989; Lord \& Hartley, 1998).

Pesquisas com desenho qualitativo e exploratório trazem indícios da vinculação entre projeções de futuro organizacional e de futuro na carreira (Hubbard \& Purcell, 2001; Margolis \& Hansen, 2003; Ullrich et al., 2005). Um dos raros estudos nacionais que aludem, mesmo que fugazmente, ao futuro organizacional (especificamente perspectivas de crescimento), identificou em suas entrevistas que os trabalhadores com maior nível de frustração no trabalho e na carreira são os mais pessimistas sobre o tópico (Moreno Júnior, Cavazotte \& Farias, 2009).

Convém ainda uma nota sobre aspectos metodológicos. Em desenhos quantitativos, os construtos relativos às projeções de futuro organizacional foram, em geral, concebidos de modo unidimensional e avaliados por escalas com reduzido número de itens. As escalas apresentam diferentes formas de lidar com a referência (horizonte) de tempo futuro: desde a omissão a qualquer limite (Bordia et al., 2004; Chiu, 2002) até sua delimitação precisa em anos (Chen et al., 2011; Margolis \& Hansen, 2003; Zhou et al., 2004), passando por propostas intermediárias, como a menção ao curto/longo prazo (Harris \& Mossholder, 1996; McGovern, 2000). 
Ao encerrar esta seção, cabe trazer a lume as principais limitações encontradas nessa literatura. Em primeiro lugar, salienta-se que a produção acadêmica é relativamente pequena e que os autores pouco dialogam entre si, visto que são raras as referências cruzadas entre pesquisas. Além dessa fragmentação, construtos e variáveis de projeções sobre o futuro organizacional geralmente são formuladas com arcabouço teórico insuficiente e mensuradas por instrumentos desprovidos de discussão mais profunda sobre os tipos de projeção, dimensionalidade e atributos. Conjuntamente, essas limitações obstruem o acúmulo de evidências sobre a relação das projeções de futuro organizacional com outras variáveis e o desenvolvimento de estudos mais qualificados sobre o tópico.

\section{Considerações Finais}

As limitações da literatura sobre futuro organizacional na perspectiva individual devem ser entendidas como estímulo para novos estudos. Em última instância, trata-se de um campo pouco explorado, mas com considerável potencial. Nesse sentido, autores que discutem mais detidamente a temática (Margolis \& Hansen, 2003) enfatizam como a literatura apresenta lacunas e assinalam a necessidade de mais pesquisas. No Brasil, tal recomendação precipitase com mais força, haja vista a quase inexistente produção acadêmica.

Considerando o cenário do campo, a agenda para estudos futuros deve começar por maior desenvolvimento conceitual e metodológico. Do ponto de vista conceitual, seria oportuna a realização de mais pesquisas exploratórias e discussões teóricas. Estas poderiam embasar a proposição de construtos mais abrangentes, eventualmente capazes de agrupar os diferentes atributos de futuro organizacional. O desenvolvimento metodológico surgirá a reboque dos avanços conceituais, proporcionando assim instrumentos mais completos e qualificados, o que pode diminuir a fragmentação da literatura no longo prazo. A rigor, na literatura consultada, não foram encontradas publicações cujo cerne fosse a validação de medidas sobre o futuro organizacional na perspectiva individual. 
Essa agenda adquire força ao se delinear as implicações práticas de estudos com esse cariz. As pesquisas citadas indicam a associação das projeções de futuro organizacional com comprometimento organizacional e satisfação com o trabalho. Existem ainda indícios do impacto da confiança no futuro organizacional no engajamento no trabalho (Swarnalatha \& Prasanna, 2013) e da articulação, em entrevistas, das expectativas sobre futuro profissional e futuro organizacional (Dackert et al., 2003; Hubbard \& Purcell, 2001). Neste último ponto, seria oportuno testar tal associação com métodos quantitativos. Estudos futuros podem investir em outras variáveis, como rotatividade, produtividade e desempenho no trabalho. Todos esses tópicos são relevantes para a gestão de recursos humanos e, em um plano maior, para o alcance das metas organizacionais.

Por derradeiro, cabe mencionar as contribuições e limites do presente artigo. Entre seus limites, alerta-se que este estudo provavelmente não contemplou todas as formas de se pesquisar o futuro organizacional na perspectiva individual. Tal empreitada seria especialmente intrincada dada a variedade de termos/variáveis existentes e a ausência de linhas de pesquisas e construtos amplamente disseminados. Este padrão dificultou, por sinal, a realização de uma revisão sistemática.

Em termos de contribuição, o artigo estruturou a literatura sobre projeções de futuro organizacional na perspectiva individual, organizando as pesquisas quanto ao contexto organizacional, tipos de projeção, atributos estudados e variáveis relacionadas. O artigo aponta ainda lacunas na literatura, o que ajuda a direcionar a produção acadêmica. Assim, a intenção foi estimular novos estudos e facilitar o descortino da inter-relação entre os quadros temporais (passado, presente e futuro) em estudos em organizações. Fomentar tal produção acadêmica significa valorizar a dimensão temporal no desenho das pesquisas na cena organizacional, aspecto que, conforme mencionado no início do artigo, é amiúde preterido. 


\section{Referências}

Ackoff, R. (1970). A concept of corporate planning. Long Range Planning, 3(1), 2-8.

Ancona, D., Goodman, P., Lawrence, B. \& Tushman, M. (2001). Time: A new research lens. Academy of Management Review, 26, 645-663.

Ansoff, H. \& McDonnell, E. (1993). Implantando a administração estratégica. São Paulo: Atlas.

Bordia, P., Hobman, E., Jones, E., Gallois, C., \& Callan, V. J. (2004). Uncertainty during organizational change: Types, consequences, and management strategies. Journal of Business and Psychology, 18(4), 507-532.

Bruininks, P., \& Malle, B. (2005). Distinguishing Hope from Optimism and Related Affective States. Motivation and Emotion, 29, 324-352.

Burke, W. \& Litwin, G. (1992). A Causal Model of Organizational Performance and Change. Journal of Management, 18, 523-545.

Caetano, A. (2012). Psicologia organizacional e do trabalho na era da aceleração: macro e nanodesafios atuais na pesquisa e na prática profissional. Revista Psicologia: Organizações e Trabalho, 12(1), 85-96.

Chen, Y., Hsu, Y. \& Yip, F. (2011). Friends or rivals: comparative perceptions of human resource and line managers on perceived future firm performance. International Journal of Human Resource Management, 22(8), 1703-1722.

Chiu, W. (2002). Do types of economic ownership matter in getting employees to commit? An exploratory study in the People's Republic of China. International Journal of Human Resource Management, 13, 865-882.

Chiu, W., Hui, C. \& Lai, G. (2007). Psychological ownership and organizational optimism amid China's corporate transformation: effects of an employee ownership scheme and a 
management-dominated board. International Journal of Human Resource Management, $18,303-320$.

Cummings, T. \& Worley, C. (2013). Organization Development \& Change. Australia: SouthWestern/Cengage Learning.

Dackert, I., Jackson, P., Brenner, S. \& Johansson, C. (2003). Eliciting and analysing employees' expectations of a merger. Human Relations, 56(6), 705-725.

Faller, L. \& Almeida, M. (2014). Planning scenarios: preparing small retail custom furniture companies for a competitive future. Revista de Administração (São Paulo), 49, 171-187.

Gioia, D. A. \& Thomas, J. B. (1996). Identity, image, and issue interpretation: Sensemaking during strategic change in academia. Administrative Science Quarterly, 41, 370-403.

Godet, M. (2000). The art of scenarios and strategic planning: Tools and pitfalls. Technological Forecasting and Social Change, 65(1), 3-22.

Guimarães, R. \& Marques, A. (2011). Gestão da mudança: uma alternativa para a avaliação do impacto da mudança organizacional. Revista de Administração FACES Journal, 10(1), 95-113.

Greenhalgh, L. \& Jick, T. (1989). Survivor Sense Making and Reactions to Organizational Decline Effects of Individual Differences. Management Communication Quarterly, 2(3), 305-327.

Greiner, L. E. (1972). Evolution and revolution as organizations grow. Harvard Business Review, 76(3), 55.

Harris, S. \& Mossholder, K. (1996). The affective implications of perceived congruence with culture dimensions during organizational transformation. Journal of Management, 22(4), $527-547$.

Harrison, J. (2005). Administração estratégica de recursos e relacionamentos. Porto Alegre: Bookman. 
Hubbard, N. \& Purcell, J. (2001). Managing employee expectations during acquisitions. Human Resource Management Journal, 11, 17-33.

Hui, C. \& Lee, C. (2000). Moderating effects of organization-based self-esteem on organizational uncertainty: Employee response relationships. Journal of Management, $26,215-232$.

Judge, T. \& Kammeyer-Mueller, J. (2012). Job attitudes. Annual Review of Psychology, 63, $341-367$

Kantabutra, S. \& Avery, G. (2009). Shared vision in customer and staff satisfaction: relationships and their consequences. Journal of Applied Business Research, 25(4), 9-22.

Kantabutra, S. \& Avery, G. (2007). Vision effects in customer and staff satisfaction: an empirical investigation. Leadership \& Organization Development Journal, 28(3), 209229.

Lee, H. \& Liebenau, J. (1999). Time in organizational studies: towards a new research direction. Organization Studies, 20, 1035-1058.

Lord, J. \& Hartley, A. (1998). Organizational commitment and job insecurity in a changing public service organization. European Journal of Work and Organizational Psychology, 7(3), 341-354.

Margolis, S. \& Hansen, C. (2003). Visions to guide performance: a typology of multiple future organizational images. Performance Improvement Quarterly, 16(4), 40-58.

Masini, E. (2010). The past and the possible futures of Futures Studies: Some thoughts on Ziauddin Sardar's 'the namesake'. Futures, 42(3), 185-189.

McGovern, M. T. (2000). The Impact of mentoring on stakeholder confidence in family owned businesses (Tese de Doutorado). California School of Professional Psychology, Los Angeles. 
Mintzberg, H. \& Westley, F. (1992). Cycles of organizational change. Strategic Management Journal, 13(S2), 39-59.

Moreno Júnior, V., Cavazotte, F. \& Farias, E. (2009). Carreira e relações de trabalho na prestação de serviços de tecnologia da informação: a visão dos profissionais de TI e seus gerentes. Revista de Gestão da Tecnologia e Sistemas de Informação, 6, 437-463.

Mossholder, K. W., Settoon, R. P., Harris, S. G., \& Armenakis, A. A. (1995). Measuring emotion in open-ended survey responses: An application of textual data analysis. Journal of Management, 21(2), 335-355.

Neiva, E. \& Paz, M. (2012). Percepção de mudança individual e organizacional: o papel das atitudes, dos valores, do poder e da capacidade organizacional. Revista de Administração (São Paulo), 47(1), 22-37.

Oettingen, G. \& Mayer, D. (2002). The Motivating Function of Thinking About the Future: Expectations Versus Fantasies. Journal of Personality and Social Psychology, 83, 11981212.

Oreg, S., Vakola, M., \& Armenakis, A. (2011). Change recipients' reactions to organizational change: A 60-year review of quantitative studies. Journal of Applied Behavioral Science, 47(4), 461-524.

Porras, J. \& Robertson, P. (1992). Organization development: Theory, practice, and research. In M. D. Dunnette \& L. M. Hough (Eds.). Handbook of Industrial and Organizational Psychology (pp. 719-822). Palo Alto, CA: Consulting Psychologists Press.

Porter, M. (1989). Vantagem Competitiva. Rio de Janeiro: Elsevier.

Posner, B. (2010). Values and the American manager: A three-decade perspective. Journal of Business Ethics, 91(4), 457-465. 
Reger, R., Gustafson, L., Demarie, S. \& Mullane, J. (1994). Reframing the organization: Why implementing total quality is easier said than done. Academy of Management Review, 19(3), 565-584.

Rêgo, R., Filho, J. \& Lima, D. (2013). Confiança organizacional e compartilhamento e uso do conhecimento tácito. Revista de Administração de Empresas, 53(5), 500-511.

Richard, P. J., Devinney, T. M., Yip, G. \& Johnson, G. (2009). Measuring organizational performance: Towards methodological best practice. Journal of Management, 35(3), 718-804.

Shinkle, G. A. (2012). Organizational Aspirations, Reference Points, and Goals Building on the Past and Aiming for the Future. Journal of Management, 38(1), 415-455.

Schenatto, F., Polacinski,E., Abreu, A. \& Abreu, P. (2011). Análise crítica dos estudos do futuro: uma abordagem a partir do resgate histórico e conceitual do tema. Gestão e Produção, 18(4), 739-754.

Silva, A., Spers, R., Wright, J., Costa, P. (2013). Cenários prospectivos para o comércio internacional de etanol em 2020. Revista de Administração (São Paulo), 48(4), 727-738.

Sonnentag, S. (2012). Time in organizational research: Catching up on a long neglected topic in order to improve theory. Organizational Psychology Review, 2(4), 361-368.

Swarnalatha, C. \& Prasanna, T. S. (2013). Employee Engagement: A Theoretical Study. International journal of Advanced Research in Management, 4, 16-25.

Tushman, M. L. \& Romaneli, E. (1985). Organizational evolution: A metamorphosis model of convergence and reorientation. Research in Organizational Behavior, 7, 171-222.

Ullrich, J., Wieseke, J., \& van Dick, R. V. (2005). Continuity and Change in Mergers and Acquisitions: A Social Identity Case Study of a German Industrial Merger. Journal of Management Studies, 42(8), 1549-1569.

van der Heijden, K. (2004). Planejamento de cenários. Porto Alegre: Bookman. 
Weick, K. E. \& Quinn, R.E. (1999). Organizational change and development. Annual Review of Psychology, 50, 361-387.

White, J. (2010). Understanding Identity in the Workplace: Exploring Current Organizational Perceptions Pertaining to Change Events and Future State (Tese de Doutorado). Walden University, Minneapolis.

Yuan, F., \& Woodman, R.W. (2007). Formation of expectations regarding change outcomes: Integrating information and social effects. Academy of Management Journal, 16, 81-104.

Zhou, K., Li, J. \& Zhou, N. (2004). Employee's Perception of Market Orientation in a Transitional Economy: China as an Example. Journal of Global Marketing, 17, 5-22. 


\section{MANUSCRITO 3}

O Manuscrito 3 propõe o construto expectativas de carreira na organização e relata o desenvolvimento de um instrumento para medi-lo, a Escala de Expectativas de Carreira na Organização (EECO). A construção dessa escala justifica-se na medida em não foi encontrado na literatura instrumento que abarcasse a constelação de atributos avaliados como relevantes para o fenômeno, que fosse construído especificamente para o mundo organizacional e que fosse claramente orientado para o futuro. A EECO foi empregada nos manuscritos 5, 6 e 7, sendo fundamental para o teste das hipóteses e dos modelos propostos. Além de franquear pesquisas acadêmicas, ressalta-se que a EECO pode ser livremente utilizada como ferramenta de diagnóstico pelas áreas de recursos humanos das organizações. 


\section{MANUSCRITO 3}

Escala de Expectativas de Carreira na Organização:

Desenvolvimento e Evidências de Validade

Career Expectations in the Organization Scale:

Development and Validity Evidence

Vinicius Carvalho de Vasconcellos

Universidade de Brasília 


\title{
Resumo
}

Expectativas de carreira figuram como elemento importante para compreender a relação dos profissionais com seu trabalho e organização. Nesse sentido, o objetivo deste artigo é descrever os procedimentos de desenvolvimento e fornecer evidências de validade da Escala de Expectativas de Carreira na Organização, instrumento que afere expectativas dos indivíduos sobre o futuro de suas carreiras em suas respectivas organizações. Dois estudos foram conduzidos. O Estudo 1 relata a análise fatorial exploratória do instrumento $(n=183)$ e o Estudo 2 trata da análise fatorial confirmatória conduzida em amostra independente $(n=352)$. Ambas as amostras eram de trabalhadores adultos de diversas organizações. Os resultados indicaram a presença de dois fatores: Conquistas Profissionais (nove itens; $\rho=0,95$; $\alpha=0,95$ ) e Relação Carreira-Vida Pessoal (quatro itens; $\rho=0,90 ; \alpha=0,90$ ). A discussão ressalta como o instrumento facilita análises sobre o papel das expectativas de carreira na ligação indivíduo-trabalho-organização, tanto no âmbito da academia quanto das organizações. Neste último caso, o instrumento pode ser especialmente útil como ferramenta de diagnóstico na gestão de recursos humanos.

Palavras-chave: carreira, expectativas, análise fatorial, medidas

\begin{abstract}
Career expectations are an important element to understand the relationship between professionals and their work/organization. In this direction, the objective of this paper is to describe the procedures for development and provide evidence of validity of the Career Expectations in the Organization Scale, an instrument that assesses individuals' expectations about the future of their careers in their respective organizations. Two studies were conducted. Study 1 reports the exploratory factor analysis of the instrument $(n=183)$ and Study 2 describes a confirmatory factor analysis conducted on an independent sample $(n=352)$. Both samples were formed by adult employees of different organizations. The results indicated the presence of two factors: Professional Achievements (nine items; $\rho=.95$; $\alpha=.95$ ) and Career-Personal Life Relationship (four items; $\rho=.90 ; \alpha=.90$ ). The discussion highlights how the scale facilitates analyzes of the career expectations role in the individualjob-organization connection in academy and organizations. In the latter case, the instrument could be particularly useful as a diagnostic tool in human resources management.
\end{abstract}

Keywords: career, expectations, factor analysis, measures 
O exercício de projetar o futuro faz parte da relação dos indivíduos com o trabalho. Expectativas, aspirações e desejos sobre o futuro na carreira comumente emergem no cotidiano de profissionais ou de estudantes se preparando para o mercado de trabalho. Com efeito, perspectivas de desenvolvimento/crescimento na carreira despontam entre as características mais valorizadas por trabalhadores em organizações (Tolfo, 2002) e por jovens na escolha de suas futuras organizações (Cavazotte, Lemos \& Viana, 2012; Garay, 2006).

O futuro na carreira, embora seja objeto de estudo tradicional da psicologia vocacional (Metz, Fouad \& Ihle-Helledy, 2009; Oliveira, 2011; Souza, Pereira, Funck \& Formiga, 2013), ainda carece de pesquisas mais sistemáticas no domínio organizacional (Vasconcellos \& Neiva, 2015). Apesar de incipientes, as investigações neste último domínio sugerem o elo entre expectativas de carreira e variáveis relevantes para a gestão, como atitudes no trabalho e intenções de desligamento (Chay \& Aryee, 1999; Chen, Ployhart, Cooper-Thomas, Anderson \& Bliese, 2011; Prince, 2003; Stroh \& Reilly, 1997).

O contexto contemporâneo, por sinal, parece colocar o futuro na carreira no centro das atenções dos indivíduos. Posto que as trajetórias profissionais são caracterizadas cada vez mais pela imprevisibilidade nos vínculos de trabalho, crescente mobilidade e maior responsabilidade do indivíduo na gestão de carreira (Gluber, Arnold \& Coombs, 2014), os indivíduos tendem a monitorar atentamente oportunidades profissionais e a refletir constantemente sobre o futuro. Ou seja, como o percurso é cada vez menos linear e préestabelecido, o futuro na carreira surge mais frequentemente como questão em aberto.

O cenário contemporâneo e as evidências da literatura mencionadas assinalam a relevância de se estudar, no âmbito organizacional, a visão dos profissionais sobre o futuro de sua carreira. A investigação da temática, por sua vez, é favorecida caso existam medidas válidas e confiáveis. Nessa linha, o objetivo deste artigo é descrever os procedimentos de desenvolvimento e fornecer evidências de validade da Escala de Expectativas de Carreira na 
Organização (EECO), instrumento que afere expectativas dos indivíduos sobre o futuro de suas carreiras em suas respectivas organizações.

O artigo revisa, inicialmente, as possibilidades de investigação e os instrumentos da literatura concernentes ao futuro na carreira em organizações. A partir da literatura, propõe-se um novo construto e justifica-se o desenvolvimento do novo instrumento. São descritos então dois estudos: o primeiro relata a análise fatorial exploratória do instrumento e o segundo trata da análise fatorial confirmatória conduzida em amostra independente. Na última parte do artigo, discute-se o formato final da escala e as contribuições/limitações do estudo.

\section{Futuro na Carreira nas Organizações: Possibilidades de Investigação e Instrumentos}

A carreira, entendida como sequência de experiências de trabalho no curso da vida de uma pessoa (Greenhaus, Callanan \& Godshalk, 1999), passa por um processo de transformação. Décadas atrás, era comum os profissionais permanecerem longo tempo na mesma organização, realizando as mesmas atividades e conhecendo de antemão cada etapa de sua carreira. Atualmente, seja por iniciativa própria ou em função de pressões organizacionais/mercadológicas, cresce o número de profissionais com trajetórias dotadas de grande mobilidade, flexibilidade e autogerenciamento (Arthur, 1994; Bendassolli, 2009; Hall, 2004). Assim, o futuro na carreira figura como projeto aberto, mescla de riscos e oportunidades que captura constantemente a atenção dos trabalhadores.

No âmbito organizacional, a literatura investiga o futuro na carreira principalmente por meio de afetos (ansiedade e medo, por exemplo), aspirações (preferências, objetivos e desejos) e expectativas/percepções sobre como será o futuro (Vasconcellos \& Neiva, 2015). Tais autores sublinham, igualmente, que as pesquisas diferenciam-se quanto ao ambiente de referência dado aos participantes: pode-se indagar sobre o futuro na atual organização, em outras organizações ou de modo inespecífico. Considerando a natureza da escala proposta 
neste artigo, a revisão a seguir centra-se em variáveis/instrumentos que aferem expectativas e percepções dos profissionais sobre o futuro de suas carreiras na organização atual.

Pesquisas nesse campo sinalizam a relevância teórica e prática das percepções e expectativas de futuro na carreira, variável associada a comprometimento organizacional (Chay \& Aryee, 1999; Prince, 2003; Stroh \& Reilly, 1997), satisfação com o trabalho (Burke \& MacDermind, 1999), desligamentos e intenções de desligamento (Buckley, Fedor, Veres, Wiese \& Carraher, 1998; Chay \& Aryee, 1999; Stroh \& Reilly, 1997) e desempenho no trabalho (Zacher \& Frese, 2011). No conjunto, esses resultados indicam como a temática merece um olhar cuidadoso da área de recursos humanos das organizações.

Contudo, existem distintas formas de investigar e aferir o fenômeno. Um dos caminhos trilhados na literatura pesquisa o futuro genericamente, isto é, sem explicitar atributos específicos. Nessa linha, Buckley et al. (1998), baseados em amostra de recém-admitidos em uma organização, aferiram expectativas quanto ao novo trabalho com itens como "Ficarei satisfeito com esse trabalho" (escala de cinco itens e $\alpha=0,92$ ). Similarmente, Carr, Pearson, Vest e Boyar (2006) mensuraram expectativas de recém-admitidos por meio de itens como "Espero que trabalhar nessa organização seja ótimo" (escala de três itens e $\alpha=0,74$ ). Essas pesquisas valorizam a visão geral da futura experiência de trabalho, de modo que os respondentes poderiam pensar em promoções, aumento salarial, reconhecimento ou qualquer outra vivência profissional ao participar da pesquisa.

Na mesma direção, o construto perspectiva de tempo futuro organizacional (Treadway, Breland, Adams, Duke \& Willians, 2010) não alude a atributos particulares ao abordar o futuro na carreira. Definido como as percepções dos profissionais sobre o tempo que lhes resta em seu papel organizacional, tal construto é aferido por uma escala de 10 itens $(\alpha=0,88)$. "Nesta organização, muitas oportunidades esperam por mim no futuro" constitui um exemplo de item dessa escala. 
Essa linha genérica de investigação sobre o futuro encontra outro representante no construto foco em oportunidades (Schmitt, Zacher \& Lange, 2013; Zacher \& Frese, 2011), definido como as crenças dos indivíduos acerca dos novos objetivos, opções e possibilidades existentes em seu futuro ocupacional. Todavia, ao contrário de Treadway et al. (2010), a medida de Zacher e Frese (2011) não faz referência a um ambiente organizacional específico, podendo inclusive ser aplicada em desempregados ou trabalhadores informais.

Nessas últimas pesquisas, o termo oportunidade(s) é utilizado em itens orientados para o futuro. Contudo, há instrumentos que o utilizam em itens que não aludem nitidamente ao futuro. Assim, Kraimer, Seibert, Wayne, Liden e Bravo (2011) aferiram oportunidades de carreira percebidas com itens como "Existem oportunidades nesta organização atraentes para mim". Como texto está redigido no tempo presente e não menciona a palavra futuro, os respondentes podem considerar a existência de oportunidades apenas na atualidade. De fato, a percepção sobre oportunidades no presente e as expectativas de oportunidades no futuro não coincidem necessariamente. Profissionais que percebem poucas oportunidades de carreira atualmente podem vislumbrar oportunidades futuras ao presumir a expansão dos negócios da organização no porvir ou como consequência de incremento na sua qualificação profissional.

Para além das opções mais genéricas (avaliações globais e oportunidades/possibilidades no futuro), outros autores analisaram o futuro na carreira a partir de atributos específicos. Neste ponto, destaca-se a mobilidade, isto é, as mudanças de atividade, cargo, ocupação ou organização (Feldman \& Ng, 2007). A variável prospectos de carreira (Burke \& Macdermid, 1999) ilustra tal abordagem ao versar sobre expectativas de promoções em um instrumento de três itens $(\alpha=0,66)$. Por seu turno, Prince (2003) desenvolveu um instrumento para avaliar não apenas as expectativas de mobilidade vertical (promoções), mas também de mobilidade horizontal (mudança de cargo no mesmo nível hierárquico). Tal escala conta com cinco itens $(\alpha=0,82)$, entre os quais "Nos próximos dois anos, terei a chance de assumir uma posição 
mais alta no meu cargo/ocupação" e "Nos próximos dois anos, terei a chance de mudar para um cargo similar em outra localidade ou área".

Nesse mesmo estudo, Prince (2003) introduziu uma medida sobre expectativas de melhoria de papel, isto é, projeções sobre progressos nas atividades realizadas. A escala $(\alpha=0,82)$ contém sete itens como, por exemplo, "Nos próximos dois anos, minhas tarefas exigirão que eu aja de forma mais independente". Inversamente, outros autores interessaramse pela percepção de que o conteúdo das atividades seria limitado no futuro (Eby, Allen \& Brinley, 2005). Entre os seis itens dessa escala $(\alpha=0,78)$ estão: “As tarefas do meu trabalho atual se tornarão rotina no futuro" e "Minhas responsabilidades no trabalho crescerão significativamente no futuro" (pontuação reversa).

Outro atributo trazido à cena são as expectativas salariais. Gibson e Lawrence (2010), por exemplo, operacionalizaram a variável expectativa de carreira por meio do nível salarial esperado pelos profissionais ao se aposentar/desligar da organização. De modo similar, O’Neill, Stanley e O’Reilly (2011) mediram o quanto indivíduos no início da trajetória profissional esperavam receber de salário no topo de suas carreiras. Diferentemente de Gibson e Lawrence (2010), a medida era inespecífica quanto ao ambiente organizacional de desenvolvimento da carreira. Nessas pesquisas, os autores não construíram escalas, optando por medidas diretas e de item único na coleta de dados.

De sua parte, a variável expectativas de trabalho (Chen et al., 2011), definida como expectativas dos profissionais sobre as experiências e condições futuras do trabalho atual, conjuga diversos atributos. A escala de 12 itens $(\alpha=0,90)$ abrange projeções de salário, de mobilidade/desenvolvimento de carreira e de desafios no trabalho (atributos presentes em pesquisas já citadas), além de expectativas sobre relações com pares/chefia e condições de trabalho. Os respondentes estimavam como esses aspectos do trabalho mudariam nos meses seguintes (variando entre piorarão muito até melhorarão muito). 
$\mathrm{Na}$ esfera nacional, o futuro na carreira geralmente é examinado por meio de entrevistas realizadas em grupos ocupacionais específicos, como trabalhadores de tecnologia da informação (Lopes \& Silva, 2009), mulheres que trabalham em abatedouros (Graf \& Coutinho, 2010), profissionais da área de limpeza e conservação (Diogo, 2007) ou vendedores de shoppings centers (Lima, Antloga \& Araújo, 2008). Excluindo a pesquisa de Lopes e Silva (2009), as demais se ocuparam de aspirações (e não de expectativas ou percepções) e apenas tangenciaram o futuro na carreira no delineamento do estudo, posto que foram centradas em outras agendas de investigação.

Em abordagens quantitativas, nota-se o predomínio de estudos sobre percepções de oportunidades de crescimento na carreira no tempo presente (Borges-Andrade, Cameschi \& Xavier, 1990; Brandão \& Bastos, 1993). Pesquisas recentes (Veloso et al., 2011; Veloso, Silva \& Dutra, 2012) aferiram percepções de crescimento na carreira na organização com três itens, todos oriundos de uma pesquisa voltada para clima organizacional e práticas de gestão. São eles: “Acredito que trabalhando nesta empresa terei oportunidade de fazer carreira e crescer", "Sei o que devo fazer para crescer profissionalmente nesta empresa" e "Considero justos os critérios de promoção e carreira adotados nesta empresa”. Na verdade, os dois últimos itens não abordam o futuro na carreira e um deles exprime uma avaliação das práticas de carreira da organização.

Entre as escalas claramente orientadas para o futuro, cita-se a Escala de Expectativa de Futuro (Souza et al., 2013). Todavia, sua intenção é captar expectativas em geral, incluindo projeções não apenas sobre a vida profissional, mas também sobre o desenvolvimento da sociedade e da vida pessoal. Além disso, essa escala não é dirigida para profissionais atuando em organizações, e sim, para estudantes. 


\section{Proposição da Escala de Expectativas de Carreira na Organização}

Após revisar a literatura, o presente estudo optou por formular uma proposta integradora, mas que fosse, concomitantemente, capaz de delimitar fronteiras nítidas para o objeto de pesquisa. Expectativas de carreira na organização são definidas, neste artigo, como as crenças dos indivíduos sobre sua futura trajetória profissional na atual organização.

Em um cenário de carreira sem fronteiras (Arthur, 1994), a referência à atual organização pode gerar estranhamento. Contudo, há indícios que essa opção predomina nos estudos sobre futuro na carreira (Vasconcellos \& Neiva, 2015). Provavelmente, tal padrão relaciona-se com a suposição que esse enfoque fornece um horizonte mais concreto para se projetar o futuro (sendo assim valorizado pelos pesquisadores), além de propiciar insumos mais diretos para as organizações (sendo mais atraente para os gestores e possibilitando mais estudos). Em adição, estudar expectativas de carreira na organização não se contrapõe ao modelo de carreira sem fronteiras. Ao contrário, pode ajudar a compreendê-lo, dado que expectativas desfavoráveis na atual organização podem incitar carreiras neste modelo.

A utilização do termo expectativas no construto reforça sua orientação para o futuro; ademais, o termo está entre os mais empregados nos estudos sobre futuro na carreira (Chen et al., 2011; Gibson \& Lawrence, 2010; O’Neill et al., 2011; Prince, 2003). Expectativas refletem crenças sobre a probabilidade de ocorrência de um evento/situação no futuro (Oettingen \& Mayer, 2002). Assim, expectativas de carreira referem-se às crenças sobre a probabilidade de determinados estados/situações ocorrerem no futuro profissional. Esses acontecimentos/situações, na prática, constituem os atributos da EECO. A aferição de expectativas traz ainda vantagens sobre a mensuração de oportunidades e possibilidades. Primeiramente, evita a imprecisão quanto à orientação temporal (presente versus futuro). Em adição, a aferição de expectativas captura o caso de profissionais com carreiras consolidadas 
que detêm visão positiva do futuro pela simples manutenção de sua posição, sem necessidade de novas oportunidades e possibilidades.

Sobre os instrumentos, a revisão de literatura possibilitou sumariar as principais formas de se abordar o futuro na carreira, assim como os atributos pesquisados. Para além das avaliações generalistas (Buckley et al., 1998; Carr et al., 2006) e das projeções sobre o grau de abertura (existência de possibilidades/oportunidades) com o qual o futuro se apresenta (Treadway et al., 2010; Zacher \& Frese, 2011), os autores pautaram-se em mobilidade de cargos/funções (Burke \& Macdermid, 1999; Prince, 2003; Veloso et al., 2011), remuneração/salários (Chen et al., 2011; Gibson \& Lawrence, 2010; O’Neill et al., 2011), características das atividades (Chen et al., 2011; Eby et al., 2005; Prince, 2003) e relações/condições de trabalho (Chen et al., 2011).

Ao se analisar tais estudos, nenhum instrumento parece delimitar, de forma completa e precisa, as expectativas de carreira na organização. Pesquisas alicerçadas em avaliações generalistas e no grau de abertura do futuro na carreira figuram como opções demasiadamente inespecíficas. Impedem também o discernimento de eventuais diferenças nos atributos que caracterizam a carreira futura, fornecendo poucos insumos para a gestão organizacional. Por outro lado, estudos que valorizam apenas um ou poucos atributos (mobilidade, remuneração ou características das atividades) expressam visões parciais do fenômeno. A proposta mais completa (Chen et al., 2011), por sua vez, inclui expectativas sobre relações/condições de trabalho, aspectos que concernem mais ao futuro da organização (ou da equipe de trabalho) do que à carreira do indivíduo.

Na literatura brasileira, a carreira tende a ser analisada em questionários sobre clima organizacional ou outros construtos relacionados. Nesses instrumentos, os itens sobre carreira, em pequeno número, estão geralmente orientados para o presente e para práticas/políticas de recursos humanos, com forte acento nas promoções. Recentemente, 
ocorreu a publicação de uma escala sobre percepção de sucesso na carreira (Costa, 2014), contudo, esta não trata do futuro e não compartilha dos mesmos atributos aqui endossados. De sua parte, a Escala de Expectativa de Futuro (Souza et al., 2013), embora voltada para o futuro, afere expectativas em geral (não apenas sobre trabalho/carreira) e está dirigida prioritariamente para estudantes (e não para profissionais atuando em organizações).

Por sua vez, a EECO parte de uma constelação de atributos que permite visão mais completa do fenômeno, ao contrário das escalas internacionais que tendem a mensurar atributos isolados. Ademais, a EECO, ao aferir expectativas de carreira na organização, surge como instrumento delineado especificamente para o mundo organizacional e claramente orientado para o futuro, em contraposição à inclinação geral das escalas nacionais, centradas no momento atual da carreira. Considerando as limitações da literatura, a EECO coloca-se como alternativa diante das escalas anteriores. Desta feita, as próximas seções descrevem os dois estudos que compuseram o desenvolvimento da escala.

\section{Estudo 1}

O objetivo do Estudo 1 foi construir os itens da escala e submetê-los à análise fatorial exploratória. Para redação dos itens, recorreu-se primeiramente à revisão de literatura descrita anteriormente e a uma pesquisa exploratória empreendida no país (Vasconcellos \& Neiva, 2014) sobre os principais aspectos considerados pelos indivíduos no seu futuro profissional na atual organização. Os resultados apontaram projeções de crescimento na carreira (isto é, lograr sucesso, avanços e conquistas profissionais, notadamente por meio de mobilidade), de melhoria na remuneração/recompensas e de experiências futuras positivas no trabalho (obter realização/reconhecimento profissional e tarefas com significado pessoal) como os principais atributos a ancorar uma visão favorável da carreira no futuro.

$\mathrm{Na}$ escala, as expectativas de crescimento na carreira foram traduzidas por itens que versam sobre o alcance de progressos/conquistas profissionais e o cumprimento de objetivos 
na carreira. Essa opção segue outros estudos da literatura (Prince, 2003) e respeita a ampla gama de possibilidades de desenvolvimento de carreira, haja vista que os respondentes podem optar por não priorizar promoções no percurso profissional. Outros aspectos abordados na pesquisa exploratória e na literatura, como projeções de remuneração/recompensas e de experiências positivas no trabalho, também foram contemplados na escala. Neste último caso, foram incluídos atributos como reconhecimento, prestígio e a realização de tarefas dentro dos interesses profissionais dos indivíduos.

A inclusão de atributos que não se enquadram na ideia tradicional de crescimento na carreira (promoções e remuneração) relaciona-se à emergência, nos últimos decênios, de novas formas de trajetórias profissionais (cada vez menos lineares e verticais, dificultando as promoções) e de novos direcionadores na condução das carreiras (como realização profissional e relação carreira-vida pessoal). Artigos teóricos no campo da carreira associam tais atributos à ideia de sucesso subjetivo/psicológico (alcance de objetivos com sentido pessoal), aspecto que ganha crescente valorização no contexto contemporâneo (Hall \& Chandler, 2004; Heslin, 2005). Torna-se relevante, assim, sua incorporação na EECO.

A relação carreira-vida pessoal, na verdade, não foi observada nos construtos/instrumentos revisados e, embora presente na pesquisa exploratória citada (Vasconcellos \& Neiva, 2014), não constou entre os principais atributos. Todavia, sua inclusão justifica-se do ponto de vista teórico. Por exemplo, o modelo arco-íris da vida e carreira (Super, 1980) advoga que o desenvolvimento da carreira ocorre por meio da relação entre os diversos papéis sociais desempenhados pelos indivíduos ao longo da vida (trabalhador, cônjuge, cidadão, entre outros). Isto é, a trajetória profissional está entremeada pela vida pessoal. Em reforço, recente revisão no campo da carreira argumenta que atentar para interdependência do trabalho e da vida familiar/doméstica é fundamental para compreender as trajetórias profissionais atuais (Greenhaus \& Kossek, 2014). 


\section{Método}

\section{Participantes.}

A amostra submetida à análise fatorial exploratória foi de 183 profissionais advindos de diversas organizações. Superou-se assim o mínimo de 100 casos e a relação de 10 casos por item (foram 16 itens no total, conforme explicitado a seguir) requerido para esse tipo de análise (Hair, Black, Babin, Anderson \& Tatham, 2010; Pasquali, 2010). Todos os participantes apresentavam escolaridade igual ou maior do que nível médio, a idade média foi de 38,39 anos $(\mathrm{DP}=11,21), 63 \%$ eram mulheres e $72 \%$ não exerciam cargo gerencial.

\section{Procedimentos.}

A pesquisa foi divulgada por meio de listas de e-mails e redes sociais. Na divulgação da pesquisa constava um link de acesso que direcionava os participantes para a página eletrônica com as explicações sobre estudo e o questionário. Este era respondido individual e voluntariamente. $\mathrm{O}$ anonimato das respostas foi afiançado aos participantes.

\section{Instrumentos.}

A partir da definição do construto e da revisão da literatura, foram escritos 22 itens que convidavam o participante a pensar sobre seu futuro profissional na atual organização. Os itens aludiam a um estado futuro positivado (exemplo: "Serei um profissional bem-sucedido na minha carreira") e o participante assinalava na escala o quão provável seria tal estado/situação, supondo sua permanência naquela organização pelos próximos cinco anos. A escala continha sete pontos e era rotulada nas extremidades (1=nada provável até 7=extremamente provável). Esse formato contempla na escala o caráter probabilístico das expectativas e provê referência temporal aos participantes. A indicação de um ponto específico no futuro facilita a emissão das respostas, pois oferece horizonte concreto para as expectativas dos profissionais. O período de cinco anos justifica-se porque não força o 
respondente a pensar em prazos muito longos (evitando inconsistências), além de já ter sido utilizado na literatura de futuro na carreira (De Souza, 2002).

$\mathrm{O}$ conjunto inicial de itens foi submetido à análise de juízes e à análise semântica. $\mathrm{Na}$ primeira, seis especialistas do campo (professores, mestres e doutorandos em psicologia organizacional ou administração) avaliaram os itens quanto a sua adequação diante do construto e seu grau de clareza. Foram retidos os itens que apresentaram $80 \%$ ou mais de avaliações positivas dos juízes. A análise semântica consistiu em pré-testes dos itens com vistas a verificar sua inteligibilidade diante de uma pequena amostra da população-alvo. Nessa etapa, participaram 26 profissionais de diferentes organizações e com pelo menos nível médio completo. De fato, como a escala demanda certo grau de abstração, recomenda-se sua aplicação em profissionais com pelo menos esse nível de escolaridade. Após a análise de juízes e semântica, seis itens foram suprimidos, pois foram considerados vagos, repetitivos ou dispensáveis. Assim, além das variáveis demográficas, o questionário contou com 16 itens sobre expectativas de carreira para a análise fatorial exploratória.

\section{Análise de dados.}

Após tratamento de casos extremos/atípicos e dados faltantes, procedeu-se à inspeção das matrizes de correlações e anti-imagem e à aplicação dos testes de Barlett e de KaiserMeyer-Olkin (KMO). A definição do número de fatores foi realizada pela análise de componentes principais e considerou múltiplos critérios, prática recomendada no contexto organizacional (Conway \& Huffcut, 2003). Os critérios foram: a análise de scree plot, o critério de Kaiser-Guttman (retenção de fatores com autovalor > 1), o percentual de variância explicada e a análise paralela (comparação de autovalores empíricos e randômicos). Os autovalores randômicos foram calculados pelo programa Monte Carlo PCA. A análise paralela tende a exibir vantagem diante de critérios tradicionais por fornecer indicação mais precisa sobre o número de fatores a reter (Damásio, 2012; Laros, 2012). Após o 
estabelecimento da quantidade de fatores, optou-se pelo método de extração Principal Axis Factoring (rotação Promax). A análise fatorial exploratória foi realizada no SPSS 19.

\section{Resultados e Discussão}

Considerando o conjunto de 16 itens, constatou-se que o determinante da matriz registrou um valor próximo, contudo, diferente de zero. Todas as correlações item-item foram significativas $(p<0,05)$ e $88 \%$ superaram 0,30 . As correlações anti-imagem foram baixas (93\% abaixo de 0,30, em módulo), configuração favorável para realização de análise fatorial (Tabachnick \& Fidell, 2007). O KMO foi de 0,90, avaliado como meritório (Hair et al., 2010) e o teste de Bartlett foi significativo $\left(\chi^{2}=2249,93 ; p<0,01\right)$.

As avaliações do scree plot, do critério de Kaiser-Guttman e do percentual de variância explicada indicaram solução com até três fatores. Os autovalores e o percentual de variância explicada dos três fatores foram respectivamente: $8,43(52,65 \%), 2,29(14,29 \%)$ e 1,25 (7,79\%). A análise paralela apontou a existência de dois fatores, pois o autovalor empírico do terceiro fator $(1,25)$ foi inferior ao autovalor aleatório correspondente $(1,34)$. Considerando o resultado da análise paralela, o alto percentual de variância explicada com apenas dois fatores (66,93\%) e a busca por parcimônia, foi escolhida a solução bidimensional.

Ao se realizar a análise fatorial exploratória (Principal Axis Factoring), dois itens obtiveram comunalidades inferiores a 0,50 , prejudicando a obtenção de estrutura fatorial bem definida (Hair et al., 2010). Foram então excluídos. A nova matriz (14 itens) permaneceu fatorável e o caráter bidimensional tornou-se mais claro (além da análise paralela, o scree plot e o critério de Kaiser-Guttman passaram também a indicar dois fatores). A Tabela 1 expõe as cargas fatoriais da solução de dois fatores. Todas superaram 0,50 e apenas duas registram valores inferiores a 0,70 . As comunalidades de todos os itens excederam 0,50 . A solução com dois fatores explicou, no total, $65 \%$ de variância dos dados. 
Tabela 1

Cargas Fatoriais na Análise Fatorial Exploratória da EECO

\begin{tabular}{lcc}
\hline \multicolumn{1}{c}{ Item } & F1 & F2 \\
\hline 5. Terei conseguido conquistas profissionais relevantes na minha carreira. & 0,91 \\
15. Atingirei meus objetivos de carreira estabelecidos para esse período. & 0,82 \\
3. Serei bem remunerado em relação às minhas responsabilidades profissionais. & 0,79 \\
9. Estarei satisfeito com o progresso da minha carreira. & 0,79 \\
16. Serei um profissional bem-sucedido na minha carreira. & 0,77 \\
1. Serei reconhecido pela organização por minhas contribuições no trabalho. & 0,77 \\
6. Minha remuneração será compatível com minhas expectativas de salário para esse período. & 0,74 \\
2. Terei prestígio entre meus colegas em função do trabalho realizado. & 0,70 \\
7. Minhas atividades profissionais serão mais interessantes do que hoje. & 0,69 \\
10. Realizarei um trabalho compatível com minhas preferências profissionais. & 0,57 \\
17. Minha vida pessoal estará preservada de interferências do trabalho. & \\
19. Minha carga horária de trabalho será compatível com minhas necessidades pessoais. & 0,94 \\
18. Terei boa qualidade de vida mesmo considerando as exigências do trabalho. & 0,91 \\
12. Conseguirei equilíbrio entre vida pessoal e trabalho. & 0,84 \\
\hline Percentual de variância explicada (\%) & 0,83 \\
Confiabilidade (alfa de Cronbach) & 50,94 & 13,85 \\
Média das correlações interitem & 0,94 & 0,93 \\
Média das correlações item-total corrigidas & 0,59 & 0,77 \\
\hline Nota. EECO-Escala Exp & 0,74 & 0,84 \\
\hline
\end{tabular}

Nota. EECO=Escala de Expectativas de Carreira na Organização. São exibidas apenas as cargas fatoriais acima de 0,30 .

O primeiro fator (F1 na Tabela 1) foi denominado de Conquistas Profissionais. Os itens com maior carga nesse fator tratam da consecução de conquistas/objetivos de carreira e parecem funcionar como eixo para o qual convergem elementos tipicamente considerados pelos indivíduos em seu futuro profissional: recompensa/remuneração, prestígio/reconhecimento e tarefas interessantes e alinhadas às preferências pessoais. Tais elementos estão entre os mais citados na pesquisa exploratória mencionada e expressam atributos contemplados na literatura (Chen et al., 2011; Gibson \& Lawrence, 2010; O’Neill et al., 2011; Prince, 2003; Vasconcellos \& Neiva, 2014). O segundo fator (F2 na Tabela 1) foi 
nomeado de Relação Carreira-Vida Pessoal. Abarca itens relativos às expectativas de obtenção de uma relação favorável entre a vida privada e o trabalho/carreira no futuro. Sob essa ótica, faz emergir o conjunto de efeitos recíprocos entre essas duas esferas, distinguindose, portanto, do primeiro fator. Assim, contempla-se no instrumento a relação entre os papéis associados ao trabalho e à vida pessoal, tema salientado por contribuições teóricas da literatura sobre carreira (Greenhaus \& Kossek, 2014; Super, 1980).

A fidedignidade dos fatores (alfa de Cronbach) suplantou o mínimo de 0,70 citado pela literatura (Damásio, 2012; Field, 2009; Hair et al., 2010). Como esta medida é influenciada pelo número de itens, outras formas de fidedignidade foram trazidas à cena, entre as quais a média das correlações interitem e a média das correlações item-total corrigidas (Field, 2009; Hair et al., 2010). Hair et al. (2010) recomendam 0,30 e 0,50 como patamares mínimos para as médias das correlações interitem e item-total corrigidas, respectivamente. Nota-se na Tabela 1 que os dois fatores extraídos ultrapassam essas referências.

\section{Estudo 2}

O objetivo do Estudo 2 foi submeter a EECO à análise fatorial confirmatória, a fim de se testar a estrutura revelada no Estudo 1.

\section{Método}

\section{Participantes.}

Na nova amostra coletada ( $n=352)$, a idade média foi de 42,26 anos (DP=12,57), 51\% eram homens e 58\% não exerciam cargo gerencial. Os respondentes apresentavam escolaridade igual ou superior ao nível médio e trabalhavam em diversas organizações (cerca de metade da amostra atuava em empresas privadas). O recrutamento dos participantes foi realizado por consultoria especializada contratada para esse fim. 


\section{Procedimentos.}

A consultoria enviou correio eletrônico para os potenciais respondentes com um link para a página eletrônica da pesquisa (taxa de resposta de $25 \%$ ), na qual constavam as instruções e o questionário. Este foi respondido individualmente, de forma voluntária e anônima. Um incentivo de cerca de R \$ 15 reais foi oferecido aos participantes da pesquisa.

\section{Instrumentos.}

Os participantes responderam aos 14 itens da EECO dispostos na solução fatorial final do Estudo 1. Ademais, o questionário contava com itens demográficos.

\section{Análise de dados.}

Após tratamento de casos extremos/atípicos e dados faltantes, executou-se a análise fatorial confirmatória (estimação por máxima verossimilhança). Como os dados não exibiram normalidade multivariada (com base no índice de Mardia), recorreu-se à técnica de bootstrapping (500 subamostras foram geradas) para se avaliar a estabilidade dos parâmetros estimados (Byrne, 2010).

Para determinar a estrutura fatorial que melhor se ajustava à EECO, os seguintes indicadores foram observados: GFI (Goodness-of-Fit Index), CFI (Comparative Fit Index), RMSEA (Root Mean Square Error of Approximation), SRMR (Standardized Root Mean Residual) e a diferença entre os valores de $\chi^{2}$ (qui-quadrado) entre modelos. A confiabilidade do construto foi calculada pelo rho( $\rho)$ de Jöreskog, uma alternativa ao alfa de Cronbach, atualmente criticado por ser impreciso nas estimativas de confiabilidade (Hair et al., 2010; Peterson \& Kim, 2013). O programa AMOS 18 foi utilizado na análise fatorial confirmatória.

\section{Resultados e Discussão}

Ao executar a análise fatorial confirmatória, os resultados iniciais indicaram que o item 1 (“Serei reconhecido pela organização por minhas contribuições no trabalho") exibiu resíduos padronizados elevados com alguns itens, sendo então suprimido. Além desse critério 
estatístico, a supressão do item 1 apoiou-se nos seguintes pontos: (a) seu conteúdo está coberto em boa medida pelo item 2, (b) seu conteúdo não apareceu entre os principais atributos revelados pela revisão de literatura e pela pesquisa exploratória mencionada e (c) o fator Conquistas Profissionais já figurava com boa quantidade de itens.

Após a exclusão do item, três modelos foram gerados. Inicialmente, testou-se um modelo de fator único, prática recomendada quando não há indicação teórica sobre o número de fatores (Kline, 2011). Examinou-se então o modelo de dois fatores do Estudo 1. Por fim, o terceiro modelo reflete versão reduzida desse último modelo. Esta versão foi proposta para diminuir o tamanho dos questionários quando a EECO for aplicada junto a outras escalas. Para compor a versão reduzida foram observados os seguintes critérios: (a) os principais atributos expostos pela revisão de literatura e pesquisa exploratória deveriam continuar representados; (b) os itens suprimidos deveriam contar, de preferência, com conteúdo coberto parcialmente por itens remanescentes e pertencer ao fator Conquistas Profissionais (que abriga nove itens) e (c) os itens suprimidos deveriam estar entre aqueles com maiores resíduos padronizados. O modelo reduzido (detalhado posteriormente) contou com 10 itens distribuídos nos mesmos fatores do modelo completo de dois fatores do Estudo 1.

A Tabela 2 evidencia os indicadores de ajuste dos três modelos. O modelo de fator único manifestou ajuste ruim e foi superado pelo modelo completo de dois fatores em todos os indicadores. A diferença de qui-quadrado entre esses modelos, $\Delta \chi_{(1)}^{2}=386,28, p<0,01$, foi elevada e significativa, reforçando a existência de dois fatores. Com efeito, ambos os modelos de dois fatores (completo e reduzido) exibiram ajustes adequados observando os parâmetros da literatura (Hair et al., 2010; Tabachnick \& Fidell, 2007), exceto pelo valor significativo do qui-quadrado. Todavia, tal significância estatística (indesejada em modelos de equações estruturais) deve ser relativizada em função de sua alta sensibilidade diante do tamanho da amostra (Tabachnick \& Fidell, 2007). 
Tabela 2

Indicadores de Ajuste dos Modelos Testados no Desenvolvimento da EECO

\begin{tabular}{lccccccc}
\hline \multicolumn{1}{c}{ Modelos $^{\mathrm{a}}$} & $\chi^{2}$ & $\boldsymbol{g l}$ & GFI & CFI & RMSEA & IC $_{\text {RMSEA }}$ & SRMR \\
\hline Fator único & $596,07^{* *}$ & 63 & 0,75 & 0,87 & 0,16 & {$[0,14-0,17]$} & 0,08 \\
Dois fatores completo & $209,79^{* *}$ & 62 & 0,92 & 0,96 & 0,08 & {$[0,07-0,09]$} & 0,04 \\
Dois fatores reduzido & $129,49^{* *}$ & 34 & 0,93 & 0,96 & 0,09 & {$[0,07-0,11]$} & 0,04 \\
\hline
\end{tabular}

Nota. EECO=Escala de Expectativas de Carreira na Organização. gl=graus de liberdade; GFI=Goodness-of-Fit Index; $\mathrm{CFI}=$ Comparative Fit Index; RMSEA=Root Mean Square Error of Approximation; $\mathrm{IC}_{\mathrm{RMSEA}}=$ Intervalo de confiança de 90\% do RMSEA; SRMR=Standardized Root Mean Residual.

${ }^{a}$ Duas ligações de erro foram permitidas nos modelos de fator único e de dois fatores completo.

$* * p<0,01$.

Com base nesses elementos, a estrutura de dois fatores foi confirmada como a mais adequada. Assim, a Tabela 3 explicita a composição final dos modelos de dois fatores (completo e reduzido) e as cargas fatoriais padronizadas de seus itens. Todas as cargas fatoriais foram estatisticamente significativas nos modelos $(p<0,01)$.

Tabela 3

Cargas Fatoriais na Análise Fatorial Confirmatória da EECO

\begin{tabular}{lccc}
\hline Fator & Item & $\begin{array}{c}\text { Modelo de } \\
\text { Dois Fatores } \\
\text { (completo) }\end{array}$ & $\begin{array}{c}\text { Modelo de } \\
\text { Dois Fatores } \\
\text { (reduzido) }\end{array}$ \\
\hline & Item 2 & 0,70 & 0,70 \\
& Item 3 & 0,75 & - \\
& Item 5 & 0,85 & 0,87 \\
Conquistas Profissionais & Item 6 & 0,75 & 0,76 \\
& Item 7 & 0,84 & 0,83 \\
& Item 9 & 0,93 & - \\
& Item 10 & 0,84 & 0,82 \\
& Item 15 & 0,87 & 0,86 \\
Relação Carreira-Vida Pessoal & Item 16 & 0,84 & - \\
& Item 12 & 0,82 & 0,82 \\
& Item 17 & 0,82 & 0,82 \\
& Item 18 & 0,89 & 0,89 \\
& Item 19 & 0,82 & 0,82 \\
\hline
\end{tabular}

Nota. EECO=Escala de Expectativas de Carreira na Organização. Todas as cargas são estatisticamente significativas $(p<0,01)$. 
As médias das cargas fatoriais das subamostras do bootstrapping foram praticamente idênticas às cargas fatoriais da Tabela 3 (a diferença máxima não alcançou nem 0,01), com baixo erro padrão (entre 0,01 e 0,03 ). Esses resultados, presentes tanto no modelo completo como no reduzido, demonstram a estabilidade das cargas e fornecem evidência sobre a adequação do processo de estimação dos modelos.

Para testar a validade de construto dos modelos de dois fatores (completo e reduzido), foram examinadas as validades convergente e discriminante, seguindo as indicações de Hair et al. (2010) e Kline (2011). No caso da validade convergente, três pontos foram abordados. O primeiro foi a magnitude das cargas fatoriais dos itens em cada fator. Como exposto na Tabela 3, todas as cargas fatoriais igualam ou ultrapassam o patamar sugerido 0,70 para soluções fatoriais ótimas. O segundo ponto foi a variância média extraída por fator (ou seja, a média das comunalidades de seus itens). O fator Conquistas Profissionais obteve valores de 0,67 e 0,66 no modelo completo e reduzido, respectivamente. O fator Relação Carreira-Vida Pessoal registrou 0,70 nos dois modelos. Em todos os casos, os valores extrapolam 0,50, referência que indica convergência adequada do construto. $\mathrm{O}$ terceiro ponto foi a confiabilidade do construto, calculada pelas medidas rho de Jöreskog e alfa de Cronbach. A confiabilidade de Conquistas Profissionais no modelo completo $(\rho=0,95 ; \alpha=0,95)$ e no reduzido $(\rho=0,92 ; \alpha=0,92)$, assim como do fator Relação Carreira-Vida Pessoal $(\rho=0,90$; $\alpha=0,90$ em ambos os modelos), suplantam 0,70 , limiar que indica bons níveis de confiabilidade. Esses três pontos indicam a validade convergente da medida.

Na validade discriminante, a questão é mensurar até que ponto os dois fatores em pauta diferenciam-se. Nos dois modelos, a validade discriminante torna-se particularmente relevante dada a correlação entre os fatores, que atingiu 0,73 no modelo completo e 0,74 no modelo reduzido ( $p<0,01$ em ambos os casos). Em modelos bem definidos, a correlação entre fatores deve ser inferior a 0,90 (Kline, 2011). Portanto, a correlação entre fatores nos dois 
modelos fornece evidência de validade discriminante. Outro indício de validade discriminante emerge quando as variâncias médias extraídas dos fatores excedem o quadrado da correlação entre eles, posto que o construto deve explicar melhor seus itens do que outro construto. As variâncias médias extraídas dos fatores no modelo completo $(0,67$ e 0,70$)$ superam o quadrado de sua correlação $\left(0,73^{2}=0,53\right)$. No modelo reduzido, as variâncias médias extraídas dos fatores $(0,66$ e 0,70$)$ também excedem o quadrado de sua correlação $\left(0,74^{2}=0,55\right)$. Corrobora-se assim, nos dois modelos, a validade discriminante.

\section{Discussão Geral}

Partindo de lacunas na literatura, este artigo propôs o construto expectativas de carreira na organização, descreveu a construção de uma escala para mensurá-lo (EECO) e apresentou evidências de validade e confiabilidade. Entre suas características distintivas, a EECO adota clara orientação para o futuro, afere expectativas de profissionais sobre sua carreira na atual organização e assume uma proposta integradora capaz de cobrir adequadamente o fenômeno.

A estrutura fatorial encontrada sugere a existência de dois conjuntos de expectativas. $\mathrm{O}$ primeiro fator agrupou conquistas estritamente dentro do ambiente de trabalho, incluindo atributos como remuneração, prestígio entre pares, avanços/crescimento/sucesso na carreira e realização de atividades interessantes e alinhadas às preferências individuais. A confluência desses atributos em um mesmo fator sugere o caráter imbricado dessas expectativas. Por seu turno, o segundo fator versa sobre a relação da carreira/trabalho com a vida pessoal/privada. Em seu conjunto de itens, a escala alinha-se a estudos teóricos e empíricos que, ao discutir a carreira contemporânea, frisam a importância de sua interface com a vida fora do trabalho, a obtenção do sucesso psicológico e a realização de tarefas com sentido pessoal (Greenhaus \& Kossek, 2014; Hall \& Chandler, 2004; Heslin, 2005; Prince, 2003), muito embora seja difícil generalizar a importância desses elementos para além das sociedades capitalistas ocidentais. 
Em funções das características da EECO, o presente estudo contribui para a academia e a gestão das organizações. Na esfera acadêmica, oferece escala que porta visão abrangente e integrada das expectativas de carreira, com bons índices de validade e confiabilidade, adaptada ao contexto brasileiro e rapidamente aplicada. Em consequência, a utilização da EECO pode auxiliar na identificação de antecedentes e consequentes das expectativas de carreira e colaborar na compreensão da intrincada ligação indivíduo-trabalho-organização. Neste particular, a versão reduzida da escala pode ser útil notadamente em pesquisas compostas por longos questionários.

Em acréscimo, a EECO pode ser empregada pelas organizações para diagnosticar as expectativas dos profissionais sobre seu futuro. Como exposto na introdução, a imprevisibilidade nos vínculos de trabalho, a crescente mobilidade e a maior responsabilidade do indivíduo na gestão da carreira contemporânea impulsionam os trabalhadores a constantemente monitorar oportunidades profissionais e refletir sobre o futuro. Por essa razão, conhecer as expectativas de carreira dos profissionais pode aprimorar a gestão de recursos humanos nas organizações. Com efeito, tais expectativas relacionam-se com atitudes no trabalho e intenções de desligamento (Chay \& Aryee, 1999; Chen et al., 2011; Prince, 2003; Stroh \& Reilly, 1997), dados que reforçam sua relevância. Recomenda-se a versão completa da escala quando o objetivo é efetuar um diagnóstico organizacional, dado que essa versão propicia mais dados para a gestão.

Cumpre esclarecer que os resultados da EECO devem ser apurados respeitando sua estrutura fatorial. Isto é, os resultados devem ser calculados individualmente por fator a partir da média aritmética simples de seus itens. Na interpretação dos dados, deve-se considerar que quanto maior for o escore obtido, maior a probabilidade de ocorrência das situações/estados descritos pelos itens na visão dos respondentes. Como a redação dos itens adquire sempre conotação positiva, escores maiores sinalizam expectativas mais favoráveis. 
Entre as limitações deste estudo, informa-se que a EECO, na atual configuração, deve ser aplicada apenas em profissionais com pelo menos nível médio de escolaridade. Outra limitação concerne à necessidade de novas amostras para validar a solução fatorial descortinada, posto que os resultados aqui expostos são mais indicativos do que conclusivos. Salienta-se igualmente o caráter não aleatório das amostras como outra limitação.

De todo modo, a expectativa é que a EECO fomente novas investigações sobre as expectativas de carreira na literatura. Analisar a inter-relação da trajetória pregressa dos indivíduos, suas atitudes/afetos/cognições sobre sua atual situação de trabalho e suas expectativas de carreira configura possibilidade promissora de pesquisa. A área de comportamento organizacional ainda devota pouca atenção às variáveis e aos construtos relacionados ao tempo. Espera-se que a publicação da EECO contribua, dentre de suas possibilidades, para reverter esse quadro. 


\section{Referências}

Arthur, M. B. (1994). The boundaryless career: A new perspective for organizational inquiry. Journal of Organizational Behavior, 15(4), 295-306.

Bendassolli, P. (2009). Recomposição da relação sujeito-trabalho nos modelos emergentes de carreira. Revista de Administração de Empresas, 49(4), 387-400.

Borges-Andrade, J. A., Cameschi, C. E. \& Xavier, O. S. (1990). Comprometimento organizacional em instituição de pesquisa: diferenças entre meio e fim. Revista de Administração, 25(4), 29-43.

Brandão, M. G. \& Bastos, A. V. (1993). Comprometimento organizacional em uma instituição universitária. Revista de Administração, 28, 50-61.

Buckley, M., Fedor, D, Veres, J., Wiese, D. \& Carraher, S. (1998). Investigating newcomer expectations and job-related outcomes. Journal of Applied Psychology, 83, 452-461.

Burke, R. \& Macdermid, G. (1999). Are workaholics job satisfied and successful in their careers? Career Development International, 4, 277-282.

Byrne, B. (2010). Structural equation modeling with AMOS. New York: Taylor \& Francis.

Carr, J., Pearson, A., Vest, M., \& Boyar, S. (2006). Prior Occupational Experience, Anticipatory Socialization, and Employee Retention. Journal of Management, 32, 1-17.

Cavazotte, F., Lemos, A. \& Viana, M. (2012). Novas gerações no mercado de trabalho: expectativas renovadas ou antigos ideais. Cadernos EBAPE, 10(1), 162-180.

Chay, Y. \& Aryee, S. (1999). Potential moderating influence of career growth opportunities on careerist orientation and work attitudes: Evidence of the protean career era in Singapore. Journal of Organizational Behavior, 20(5), 613-623.

Chen, G., Ployhart, R. E., Cooper-Thomas, H. D., Anderson, N., \& Bliese, P. D. (2011). The power of momentum: A new model of dynamic relationships between job satisfaction change and turnover intentions. Academy of Management Journal, 54, 159-181. 
Conway, J. \& Huffcutt, A. I. (2003). A review and evaluation of exploratory factor analysis practices in organizational research. Organizational Research Methods, 6(2), 147-168.

Costa, L.V. (2014). Sucesso na carreira. In M.M. Siqueira (Org.). Novas medidas do comportamento organizacional (pp. 280-297). Porto Alegre: Artmed.

Damásio, B.F. (2012). Uso da análise fatorial exploratória em psicologia. Avaliação Psicológica, 11(2), 213-228.

De Souza, G. (2002). A Study of the Influence of Promotions on Promotion Satisfaction and Expectations of Future Promotions among Managers. Human Resource Development Quaterly, 13(3), 325-340.

Diogo, M.F. (2007). Os sentidos do trabalho de limpeza e conservação. Psicologia em Estudo (Maringá), 12, 483-492.

Eby, L. T., Allen, T. D., \& Brinley, A. (2005). A cross-level investigation of the relationship between career management practices and career-related attitudes. Group and Organization Management, 30, 565-596.

Feldman, D. C., \& Ng, T. W. (2007). Careers: Mobility, embeddedness, and success. Journal of Management, 33, 350-377.

Field, A. P. (2009). Discovering statistics using SPSS. Thousand Oaks, CA: Sage.

Garay, A. (2006). A responsabilidade social corporativa como elemento de atração de talentos: percepção dos alunos destaques do curso de Administração. Revista Eletrônica de Administração, 12(3). Obtido em: http://www.lume.ufrgs.br/handle/10183/20195.

Gibson, D. \& Lawrence, B. (2010). Women's and men's career referents: how gender composition and comparison level shape career expectations. Organization Science, 21, 1159-1175. 
Gubler, M., Arnold, J., \& Coombs, C. (2014). Reassessing the protean career concept: Empirical findings, conceptual components, and measurement. Journal of Organizational Behavior, 35(S1), S23-S40.

Graf, L. P. \& Coutinho, M. C. (2010). Trajetórias de mulheres atuantes em pequenos abatedouros de animais. Cadernos de Psicologia Social do Trabalho, 13(1), 119-132.

Greenhaus, J., Callanan, G., \& Godshalk, V. (1999). Career management. Orlando: Harcourt. Greenhaus, J. \& Kossek, E. (2014). The Contemporary Career: A Work-Home Perspective. Annual Review of Organizational Psychology and Organizational Behavior, 1, 361-388.

Hair, J.F., Black, W., Babin, B., Anderson, R. \& Tatham, R. (2010). Multivariate Data Analysis (sétima edição). Upper Saddle River, NJ: Prentice Hall.

Hall, D. (2004). The Protean Career: A Quarter-Century Journey. Journal of Vocational Behavior, 65, 1-13.

Hall, D. \& Chandler, D. (2004). Psychological success: When the career is a calling. Journal of Organizational Behavior, 25, 1-22.

Heslin, P.A. (2005). Conceptualizing and evaluating career success. Journal of Organizational Behavior, 26, 113-136.

Kline, R. (2011). Principles and practice of structural equation modeling. New York: Guilford Press.

Kraimer, M. L., Seibert, S. E., Wayne, S. J., Liden, R., \& Bravo, J. (2011). Antecedents and outcomes of organizational support for development: The critical role of career opportunities. Journal of Applied Psychology, 96, 485-500.

Laros, J. A. (2012). O uso da Análise Fatorial: Algumas diretrizes para pesquisadores. In L. Pasquali. (Org.). Análise Fatorial para pesquisadores (pp.163-193). Brasília: LabPAM. 
Lima, H. K., Antloga, C. S. \& Araújo, A. J. (2008). "Seguir carreira como vendedor, de jeito nenhum!": um estudo comparativo da atividade de vendedores em shoppings centers. Revista Psicologia: Organizações e Trabalho, 8(2), 139-158.

Lopes, A. L. \& Silva, J. R. (2009). Expectativas profissionais no discurso de terceirizados em TI. Revista de Administração de Empresas Eletrônica, 8. Obtido em: http://www.scielo.br/scielo.php?pid=S1676-56482009000200002\&script=sci_arttext.

Metz, A., Fouad, N., \& Ihle-Helledy, K. (2009). Career aspirations and expectations of college students: Demographics and labor market influences. Journal of Career Assessment, 17, 155-171.

O'Neill, O. A., Stanley, L. J., \& O'Reilly, C. A. (2011). Disaffected Pollyannas: The influence of positive affect on salary expectations, turnover, and long-term satisfaction. Journal of Occupational and Organizational Psychology, 84, 599-617.

Oettingen, G. \& Mayer, D. (2002). The Motivating Function of Thinking About the Future: Expectations vs Fantasies. Journal of Personality and Social Psychology, 83, 1198-1212.

Oliveira, L. B. D. (2011). Percepções e estratégias de inserção no trabalho de universitários de administração. Revista Brasileira de Orientação Profissional, 12(1), 83-95.

Pasquali, L. (2010). Instrumentação Psicológica. Porto Alegre: Artmed.

Peterson, R. \& Kim, Y. (2013). On the relationship between coefficient alpha and composite reliability. Journal of Applied Psychology, 98, 194-198.

Prince, J. B. (2003). Career opportunity and organizational attachment in a blue-collar unionized environment. Journal of Vocational Behavior, 63, 136-150.

Schmitt, A., Zacher, H., \& Lange A. (2013). Focus on opportunities as a boundary condition of the relationship between job control and work engagement: A multi-sample, multimethod study. European Journal of Work and Organizational Psychology, 22, 505-519. 
Souza, M., Pereira, P., Funck, A., Formiga, N. (2013). Consistência interna e estrutura fatorial da escala de expectativa de futuro em brasileiros. Boletim da Academia Paulista de Psicologia, 33(85), 330-353.

Stroh, L., \& Reilly, A. (1997). Rekindling Organizational Loyalty: The Role of Career Mobility. Journal of Career Development, 24, 39-54.

Super, D. E. (1980). The life span, life space approach to career development. Journal of Vocational Behavior, 16, 282-298.

Tabachnick, B. G. \& Fidell, L. S. (2007). Using multivariate statistics. Boston: Pearson. Tolfo, S. (2002). Carreira Profissional e seus movimentos: Revendo conceitos e formas de gestão. Revista Psicologia: Organizações e Trabalho, 2(2), 39-63.

Treadway, D. C., Breland, J. W., Adams, G. L., Duke, A. B, \& Willians, L. (2010). The interactive effects of political skill and future time perspective on career and community networking behavior. Social Networks, 32, 138-147.

Vasconcellos, V.\& Neiva, E. (2014). Avaliação de futuro profissional e sua relação com bem-estar no trabalho e intenção de desligamento. Gestão e Planejamento, 15, 410-427.

Vasconcellos, V. \& Neiva, E. (2015). Futuro na Carreira no Contexto Organizacional: Possibilidades e Tendências na Literatura. Manuscrito em preparação para submissão.

Veloso, E., Dutra, J., Fischer, A., Pimentel, J., Silva, R. \& Amorim, W. (2011). Gestão de carreiras e crescimento profissional. Revista Brasileira de Orientação Profissional, 12, 61-72.

Veloso, E., Silva, R. D., \& Dutra, J. (2012). Diferentes gerações e percepções sobre carreiras inteligentes e crescimento profissional nas organizações. Revista Brasileira de Orientação Profissional, 13(2), 197-208.

Zacher, H. \& Frese, M. (2011). Maintaining a focus on opportunities at work: The interplay between age, job complexity, and the use of selection, optimization, and compensation strategies. Journal of Organizational Behavior, 32, 291-318. 


\section{MANUSCRITO 4}

O Manuscrito 4 apresenta o construto expectativas de futuro organizacional e descreve o desenvolvimento de um instrumento para medi-lo, a Escala de Expectativas de Futuro Organizacional (EEFO). A formulação desse instrumento justifica-se visto que os instrumentos internacionais consultados mostram-se limitados e pouco fundamentados. Em adição, não foram localizadas na literatura nacional medidas similares. Ao aferir expectativas de futuro organizacional, a rigor, a EEFO faculta investigações quantitativas em novo flanco da relação do indivíduo com organização, sendo profícua tanto na seara acadêmica quanto em pesquisas institucionais efetuadas nas organizações. Nesta tese, a EEFO foi aplicada nas pesquisas relatadas nos Manuscritos 6 e 7 . 


\section{MANUSCRITO 4}

Escala de Expectativas de Futuro Organizacional:

Desenvolvimento e Evidências de Validade

Organizational Future Expectations Scale:

Development and Validity Evidence

Vinicius Carvalho de Vasconcellos

Universidade de Brasília 


\title{
Resumo
}

Em meio a um cenário de instabilidade na economia e no mundo organizacional, a relação das organizações com o futuro ganhou especial atenção a partir das últimas décadas do século XX. Tal atenção se reflete tanto no desenvolvimento de ferramentas/práticas de planejamento, estratégia e cenários, quanto nas projeções de futuro organizacional formuladas pelos profissionais (isto é, no nível micro-organizacional). Partindo da literatura que aponta a importância dessas projeções na relação indivíduo-trabalho-organização, este estudo descreve o processo de desenvolvimento e fornece evidências de validade da Escala de Expectativas de Futuro Organizacional (EEFO), instrumento que afere expectativas dos indivíduos sobre o futuro de suas respectivas organizações. Nesse sentido, três estudos são relatados. O Estudo 1 expõe uma pesquisa exploratória $(n=75)$ respondida por profissionais de várias organizações, cujos objetivos foram desvelar os atributos das expectativas de futuro organizacional e fundamentar a redação dos itens. Utilizando tais itens, o Estudo 2 descreve a análise fatorial exploratória aplicada em nova amostra de profissionais de diversas organizações $(n=164)$. O Estudo 3 relata análise fatorial confirmatória conduzida a partir de amostra independente em uma autarquia federal $(n=324)$. A versão final da EEFO contou com nove itens distribuídos em dois fatores: Efetividade Organizacional (cinco itens; $\rho=0,92$; $\alpha=0,92$ ) e Gestão e Ambiente Organizacional (quatro itens; $\rho=0,93 ; \alpha=0,93$ ), explicando mais de $70 \%$ da variância do construto. Na discussão, a estrutura fatorial da EEFO é analisada e ressalta-se seu papel como ferramenta de diagnóstico para a gestão.

Palavras-chave: futuro organizacional, expectativas, estudos do futuro, análise fatorial, medidas

\begin{abstract}
Considering the instability in the economy and organizational scene, the relationship between organizations and the future has gained special attention in the last decades of the twentieth century. Such attention is reflected both in the development of planning and strategy tools, and in the organizational future projections made by professionals (at the microorganizational level). Based on the literature which indicates the importance of these projections in individual-work-organization relationship, this study describes the development process and provide validity evidence of the Organizational Future Expectations Scale (OFES), instrument that measures expectations of individuals about the future of their respective organizations. In this way, three studies are reported. Study 1 describes an exploratory study $(n=75)$, answered by professionals from different organizations, that aimed to reveal the attributes of the organizational future expectations and support the elaboration of the items of the scale. Using these items, Study 2 reports the exploratory factor analysis applied in new sample of professionals from different organizations $(n=164)$. Study 3 exposes the confirmatory factor analysis conducted from independent sample in a government agency $(n=324)$. The final version of OFES has nine items distributed on two factors: Organizational Effectiveness (five items; $\rho=.92 ; \alpha=.92$ ) and Management and Organizational Environment (four items; $\rho=.93 ; \alpha=.93$ ), explaining more than $70 \%$ of the variance of the construct. The discussion analyses the OFES factor structure and emphasizes its role as a diagnostic tool for management.
\end{abstract}

Keywords: organizational future, expectations, future studies, factor analysis, measures 
O tempo constitui uma dimensão fundamental da vida organizacional e condiciona a realização do trabalho em diversos níveis. Desde o estabelecimento de prazos para as mais simples tarefas até a formulação dos mais complexos cenários para o futuro, a influência do tempo é indelével na dinâmica das organizações. Contudo, apesar de sua relevância, a temporalidade costuma desempenhar papel pouco expressivo na literatura sobre organizações e trabalho (George \& Jones, 2000; Lee \& Liebenau, 1999; Sonnentag, 2012).

A forma mais intuitiva de apreender o tempo remete à utilização de três quadros básicos: passado, presente e futuro. Esses quadros temporais facilitam a sistematização e a atribuição de significados às experiências vividas. Com efeito, a trajetória de uma organização pode sempre ser representada por meio de suas origens e a história pregressa (passado), de sua atual configuração (presente) e de suas perspectivas e projetos (futuro).

Destacadamente, a relação das organizações com o futuro ganhou especial atenção a partir das últimas décadas do século XX. Desde então, desequilíbrios macroeconômicos, avanços tecnológicos e a volatilidade no mercado financeiro trouxeram instabilidade para a economia e o mundo organizacional (Grant, 2003). Nessa conjuntura marcada por rápidos fluxos de mudança, o futuro assume alto grau de incerteza, exigindo que as organizações empenhem cada vez recursos no exercício de planejar e prospectar o porvir.

Nesse contexto, a literatura investe sobre o futuro organizacional em diversas frentes. Estudos sobre planejamento, estratégia, cenários e desenvolvimento/mudança organizacional tocam no futuro das organizações. Na mesma linha, a perspectiva dos estudos do futuro adquire crescente espaço no ambiente organizacional (Schenatto, Polacinski, Abreu \& Abreu, 2011). A rigor, esses campos de investigação focalizam, em suas formulações teóricas e pesquisas empíricas, o futuro do ponto de vista macro-organizacional.

Todavia, há formas de representar e projetar o futuro da organização que emergem no nível micro-organizacional, isto é, são formuladas pelos profissionais. Apesar de minoritária 
na literatura, essa perspectiva aponta que expectativas, percepções e otimismo dos profissionais sobre o futuro de suas organizações surgem como variáveis importantes na relação indivíduo-trabalho-organização (Chiu, 2002; Harris \& Mossholder, 1996; Hubbard \& Purcell, 2001). Considerando a pertinência de se analisar tal fenômeno, um passo importante para avançar nesse campo trata do desenvolvimento de instrumentos válidos e fidedignos. Nessa direção, este artigo descreve os procedimentos de construção e fornece evidências de validade da Escala de Expectativas de Futuro Organizacional (EEFO), instrumento que afere expectativas dos indivíduos sobre o futuro de suas respectivas organizações.

Para cumprir esse objetivo apresenta-se inicialmente uma revisão de pesquisas e instrumentos que abordaram o futuro organizacional do ponto de vista dos indivíduos. A seguir, o desenvolvimento da EEFO é descrito por meio de três estudos que incluem uma pesquisa exploratória sobre a temática e análises fatoriais exploratória e confirmatória da escala. Optou-se por organizar o artigo em três estudos para tornar mais clara a construção da medida, especialmente porque foram utilizadas três amostras diferentes. Por fim, a configuração final e as qualidades psicométricas da escala são discutidas.

\section{Futuro Organizacional: Estudos e Instrumentos na Perspectiva Individual}

A faculdade dos indivíduos de projetar e representar o futuro opera papel central na vida psíquica, influenciando decisões e comportamentos realizados no presente (Carvalho, Pocinho \& Silva, 2010). Tal faculdade, contudo, não se manifesta de uma única forma, desabrochando em diversos fenômenos subjetivos, incluindo aspirações/desejos, afetos (preocupação, por exemplo) e expectativas (Aspinwall, 2005).

Essa diversidade de formas de apreender o futuro está presente na literatura sobre futuro organizacional na perspectiva individual. Vasconcellos e Neiva (2015) identificaram nessa literatura três formas principais dos indivíduos projetarem/representarem o futuro de suas organizações: a) imagens/visão de futuro desejado (variáveis na esfera do querer/desejar 
que expressam como a organização deveria ser no futuro), b) expectativas/otimismo e percepções sobre o que provavelmente ocorrerá com a organização no futuro e c) incertezas sobre o futuro (grau de ambiguidade/dúvida sobre o destino da organização).

Não obstante a importância dos demais tipos de variáveis, nesta revisão, percepções, otimismo e expectativas sobre o futuro serão privilegiadas, dado que é o campo com maior qualidade e quantidade de pesquisas e porque a escala desenvolvida adota tal abordagem. Consonante com o objetivo do presente artigo, a revisão a seguir focaliza as definições, os instrumentos e os atributos de futuro organizacional presentes nessa literatura. Ressalta-se que este panorama da literatura serviu de lastro para a construção da EEFO.

Procede do campo da mudança organizacional boa parte das investigações sobre a temática. Neste enquadre, Hubbard e Purcell (2001) investigaram qualitativamente expectativas de futuro organizacional em duas empresas envolvidas em processo de aquisição. Expectativas foram definidas como crenças individuais sobre o desenvolvimento de determinado ambiente (neste caso, o organizacional). As entrevistas retrataram expectativas quanto à cultura da nova organização e ao ambiente laboral, tocando em pontos como a autonomia para realização do trabalho, sobrecarga de trabalho e relação de equipe.

Em um cenário de fusão de companhias aéreas, Margolis e Hansen (2003) examinaram imagens de futuro organizacional esperado, definidas como o que o profissional espera do futuro de sua organização. As entrevistas semiestruturadas buscavam conhecer as expectativas sobre o futuro organizacional dos respondentes dois anos à frente. Os dados indicaram que os profissionais vislumbravam a continuidade da missão e do crescimento da organização (fatia de mercado), assim como o surgimento de uma imagem mais positiva para os consumidores. As autoras atestam que, de modo geral, as imagens de futuro organizacional podem adquirir matizes positivos ou negativos e assumir diversos conteúdos. 
Dackert, Jackson, Brenner e Johansson (2003) descreveram expectativas de profissionais de dois órgãos públicos também em situação de fusão. Apesar de não delimitar conceitualmente tais expectativas, o instrumento, baseado em diferencial semântico, convidava os participantes a descrever como seria a nova organização em termos gestão, clima e cultura organizacional, entre outros pontos. Nos funcionários do órgão de menor porte surgiram expectativas de que a nova organização apresentaria administração mais centralizada e menos voltada paras as pessoas, em linha com o padrão cultural do outro órgão envolvido no processo.

Conjuntamente à análise das expectativas, é possível localizar na literatura exemplos de investigações sobre otimismo quanto ao futuro organizacional. Otimismo refere-se a um estado no qual há expectativa generalizada de que o futuro será positivo (Bruininks \& Malle, 2005). Otimismo e expectativas são semelhantes, exibindo diferenças especialmente na conotação sempre positivada e no caráter mais global do primeiro termo.

Assim, Mossholder, Settoon, Harris e Armenakis (1995) pesquisaram, em organização passando por reestruturação, o otimismo quanto ao seu sucesso e sobrevivência no futuro. Dois itens foram utilizados: "Estou otimista quanto ao futuro da organização no curto prazo" e "Estou otimista quanto ao futuro da organização no longo prazo" $(\alpha=0,66)$. A investigação assinalou a relação do otimismo com comprometimento organizacional e conflito de papel. A mesma escala foi aplicada posteriormente (Harris \& Mossholder, 1996), dessa vez em uma empresa atravessando uma transformação cultural. Neste caso, a discrepância percebida entre cultura atual e ideal influenciou o otimismo sobre o futuro organizacional.

Fora de situações de mudança organizacional, Posner (2010) constitui outro exemplo de investigação sobre otimismo. O autor debruçou-se sobre expectativas de líderes acerca do futuro de suas respectivas organizações. O instrumento, com item único, indagava: “Quando penso nos prospectos da minha organização nos próximos 10 a 15 anos, estou...” e oferecia 
três opções de resposta (otimista, pessimista e sentimentos mesclados). O otimismo parece ser afetado pelo nível do cargo gerencial: o percentual de supervisores otimistas (45\%) foi inferior ao da média gerência (56\%) e ao dos gerentes executivos (62\%).

Por outro lado, Chiu, Hui e Lai (2007) definiram otimismo organizacional como avaliação positiva/favorável dos empregados sobre o desenvolvimento futuro de sua organização. O construto foi mensurado por sete itens (escala de concordância), entre os quais, “A organização continuará a melhorar sua eficiência operacional”, “A organização continuará a atrair empregados qualificados" e "Creio que a organização conseguirá lucros no futuro". Todavia, esses itens, redigidos no tempo futuro, mesclavam-se com outros orientados para o presente: "A organização é capaz de responder às mudanças”, “A organização apresenta direção para se desenvolver no longo prazo" e "A organização é agressiva nos negócios". A análise de componentes principais indicou estrutura unidimensional (51\% de variância explicada e $\alpha=0,84)$. Otimismo organizacional correlacionou-se fracamente com variáveis demográficas; todavia, satisfação extrínseca com o trabalho (particularmente com salários e benefícios) foi preditor de otimismo organizacional.

O termo confiança também é empregado para estudar o futuro organizacional na perspectiva dos profissionais. Dessa forma, mesmo carecendo de conceituação formal, Zhou, Li e Zhou (2004) pesquisaram a variável confiança no desempenho organizacional futuro. Esta foi aferida por dois itens (“Dentro de um ano o desempenho da empresa será...” e “Dentro de cinco anos o desempenho da empresa será...”). A escala apresentava cinco opções de resposta ( $1=$ muito bom a $5=$ muito ruim $)$ e adequado índice de confiabilidade $(\alpha=0,83)$.

Os dados de Zhou et al. (2004) indicaram que quanto mais os profissionais percebiam suas organizações orientadas para o mercado, maior sua confiança no futuro organizacional. Cultura de grupo (estímulo ao trabalho em equipe, cooperação e envolvimento dos indivíduos nas decisões organizacionais) e tipo de organização (profissionais de empresas públicas 
mostraram-se menos confiantes) surgiram como antecedentes da variável. Análises adicionais registraram que o cargo ocupado (gerencial versus não gerencial) não afetou a confiança no futuro organizacional e que esta variável correlacionou-se com satisfação com o trabalho e comprometimento organizacional.

Ao invés de expectativas, otimismo ou confiança, há autores que optaram simplesmente por trabalhar com percepções de futuro organizacional. Valendo-se de grupos de foco e respostas abertas de questionários, White (2010) investiu sobre as percepções de futuro organizacional em um cenário pós-fusão de órgãos militares. A autora relata que alguns participantes enxergavam o futuro com esperança, ressaltando que a organização cumpriria com êxito sua missão, seria admirada socialmente e apresentaria integração entre seus setores. Ao revés, outros participantes assinalavam que, no futuro, a organização tornar-se-ia desestabilizada, segregada, reacionária e ineficiente.

Por sua vez, Chen, Hsu e Yip (2011) abordaram percepções de desempenho futuro da organização com itens que instavam os respondentes a comparar o desenvolvimento de sua empresa com empresas similares nos próximos cincos anos. Valendo-se de uma escala de cinco pontos (1=entre as 20\% melhores empresas até 5=entre 20\% piores empresas), os respondentes indicavam a situação da organização no futuro. O único fator $(\alpha=0,91)$ incluía os seguintes atributos: lucratividade, fluxo de caixa, crescimento (número de vendas e fatia de mercado), qualidade (satisfação dos profissionais e qualidade de produtos e serviços) e responsabilidade social. $\mathrm{Na}$ análise efetuada, percepção de efetividade das práticas de recursos humanos associou-se positivamente à percepção de desempenho futuro.

Ainda no campo das percepções, Chiu (2002) introduziu a variável prospectos organizacionais. Dotado de cinco itens dispostos em escala de concordância, o instrumento aferia as percepções dos respondentes sobre o desenvolvimento da organização e se, no futuro, esta apresentaria melhorias na gestão e na produção (o autor indica $\alpha>0,80$ ). Entre os 
resultados, empresas privadas manifestaram prospectos superiores às estatais e joint-ventures. Idade, sexo e cargo ocupado (gerencial ou não gerencial) não se associaram significativamente aos prospectos organizacionais. Em adição, esta variável figurou como antecedente de comprometimento afetivo, mas não de comprometimento instrumental.

\section{Proposição da Escala de Expectativas de Futuro Organizacional}

A revisão de literatura evidencia que a pesquisa sobre futuro organizacional na perspectiva individual está em estágio inicial, desprovida de um eixo conceitual aglutinador e/ou linhas de pesquisas sistemáticas. Com efeito, há diversos termos para expressar o futuro organizacional na perspectiva individual (percepções, imagens, expectativas e otimismo) e nenhuma das pesquisas examinadas buscou diferenciá-los. No fundo, o objeto de estudo carece de refinamento conceitual e tende a se inserir secundariamente nas investigações.

Entre as pesquisas consultadas, apenas duas (Chiu et al., 2007; Margolis \& Hansen, 2003) indicaram formalmente sua conceituação do fenômeno. Margolis e Hansen (2003) definiram imagens de futuro organizacional esperado como expectativas dos profissionais sobre o futuro de sua organização, ao passo que Chiu et al. (2007) estabeleceram otimismo organizacional como avaliação positiva e favorável dos empregados sobre o desenvolvimento futuro de sua organização. As duas definições comportam orientação para o futuro, todavia, não delineiam claramente o que se deve considerar nesse futuro.

Por sinal, os estudos variaram sobre os atributos de futuro organizacional contemplados. Alguns autores (Mossholder et al., 1995; Posner, 2010), por exemplo, simplesmente indagaram os profissionais se estes estavam otimistas quanto ao futuro da organização. Trata-se, portanto, de uma visão genérica do fenômeno, pois não determina nenhum atributo do futuro organizacional. Entre aqueles que determinaram atributos, desempenho/efetividade e procedimentos de gestão são os mais contemplados (nessa ordem) nas pesquisas com escalas (Chen et al., 2011; Chiu, 2002; Chiu et al., 2007; Zhou et al., 
2004). Nas pesquisas qualitativas, além desses atributos, cultura organizacional e clima/ambiente de trabalho também são mencionados (Hubbard \& Purcell, 2001).

Um breve esclarecimento se impõe acerca da distinção de desempenho e efetividade organizacional. Recente revisão nessa área (Richard, Devinney, Yip \& Johnson, 2009) identifica desempenho organizacional a resultados financeiros (como lucro e retorno sobre investimento), vendas (fatia de mercado, por exemplo) e retorno para os acionistas (como desempenho de ações). Já efetividade organizacional refere-se a um construto maior, que engloba desempenho, mas também outros resultados, como medidas de eficiência operacional, alcance de metas/objetivos e relação com públicos de interesse (como satisfação de clientes ou funcionários).

Com base nos conceitos e atributos explorados na literatura, propõe-se aqui a formulação do construto expectativas de futuro organizacional, definido como as crenças dos profissionais sobre a gestão e a efetividade de sua organização no futuro. A definição assume gestão e efetividade como atributos centrais para o construto em função de sua forte presença na literatura. Quando emergiram nas pesquisas, ambiente/clima de trabalho e cultura organizacional vincularam-se ao estilo de gestão, de modo que não foi privilegiado como atributo separado. Seguindo tal encaminhamento, o construto inclui expectativas dos profissionais sobre o aperfeiçoamento dos procedimentos administrativos e a constituição de um ambiente organizacional favorável (gestão) e sobre a obtenção de resultados organizacionais positivos (efetividade) no futuro. Ao explicitar na definição do construto esses elementos, a proposta é torná-lo menos vago do que as definições de estudos anteriores (Chiu et al., 2007; Margolis \& Hansen, 2003).

Utiliza-se na definição o termo expectativas pois este porta inerentemente a ideia de futuro, ao contrário de termos como percepção ou confiança. Expectativas refletem crenças sobre a probabilidade de ocorrência de um evento/situação no futuro (Oettingen \& Mayer, 
2002). Assim, expectativas de futuro organizacional referem-se às crenças dos indivíduos sobre a probabilidade de determinados acontecimentos ou situações ocorrerem no futuro das organizações.

Estabelecido o construto, o próximo passo na construção da EEFO foi avaliar os instrumentos pré-existentes na literatura. Como não foram encontradas escalas brasileiras, a discussão recai somente sobre as escalas internacionais citadas anteriormente. Nestas, nota-se predomínio de instrumentos unidimensionais e dotados de reduzido número de itens (Chen et al., 2011; Chiu, 2002; Chiu et al., 2007; Mossholder et al., 1995; Zhou et al., 2004). A rigor, não há indicação teórica sobre a dimensionalidade, de forma que a estrutura unidimensional detectada pode se vincular ao pequeno número de itens dos instrumentos. No presente estudo, a dimensionalidade do construto será testada a partir de uma amostra maior de itens.

Malgrado suas semelhanças na estrutura, as escalas divergem quanto à referência (horizonte) de tempo futuro utilizada. Há escalas que não explicitam nenhuma delimitação de futuro (Chiu, 2002, por exemplo), ao passo que outras concedem referência precisa em anos (Chen et al., 2011; Posner, 2010; Zhou et al., 2004) ou adotam soluções intermediárias ao empregar os termos curto e longo prazo (Harris \& Mossholder, 1996). A referência esposada pela EEFO será abordada adiante, quando o processo de construção da escala for detalhado.

A partir da revisão das escalas da literatura, constata-se que nenhuma está adequada para mensurar ao construto aqui proposto. Em primeiro lugar, porque essas escalas não trabalham com a ideia de probabilidade subjetiva de ocorrência de situações futuras, cerne da definição proposta. Ademais, apesar da confiabilidade aceitável, alguns instrumentos (Chiu, 2002; Chiu et al., 2007) mesclam itens orientados para o presente e para o futuro, opção problemática quando se deseja delimitar o futuro como quadro temporal de referência para o construto. Outras escalas não cobrem adequadamente o fenômeno tal como conceituado aqui, 
seja por apresentar poucos itens ou por se centrar em apenas um atributo (Chen et al., 2011; Mossholder et al., 1995; Zhou et al., 2004).

Esse quadro incita a formulação de um novo instrumento, efetivamente voltado para expectativas de futuro organizacional, com um conjunto mais abrangente de itens e elaborado no contexto nacional. Três estudos foram conduzidos para o desenvolvimento da EEFO. O Estudo 1 refere-se a uma pesquisa exploratória que visou a conhecer as expectativas de futuro organizacional em profissionais brasileiros, fundamentando assim a redação dos itens do instrumento. Utilizando nova amostra, o Estudo 2 descreve os procedimentos iniciais de construção da escala e análise fatorial exploratória. Por fim, o Estudo 3 expõe a análise fatorial confirmatória conduzida em amostra independente dos estudos anteriores.

\section{Estudo 1}

O Estudo 1 reporta pesquisa exploratória que visou a conhecer, dentro da realidade dos profissionais brasileiros, os principais atributos das expectativas de futuro organizacional.

\section{Método}

\section{Participantes.}

A pesquisa exploratória contou com amostra de 75 participantes de diferentes organizações (45\% do setor público, 25\% de empresas de economia mista, 23\% de empresas privadas e $7 \%$ do terceiro setor). Houve equilíbrio entre homens (49\%) e mulheres (51\%), a idade média foi de 36,30 anos ( $\mathrm{DP}=9,58)$ e o tempo médio de vínculo com a organização foi de $5,55 \operatorname{anos}(\mathrm{DP}=6,58)$.

\section{Procedimentos.}

A amostra foi obtida por meio da divulgação da pesquisa em listas de $e$-mails e redes sociais. O link de acesso direcionava os participantes para uma página eletrônica, na qual o instrumento era respondido de forma individual, voluntária e anônima. 


\section{Instrumentos.}

As expectativas de futuro organizacional foram abordadas, primeiramente, por meio de um item fechado no qual o respondente indicava o quão favorável parecia ser o futuro daquela organização (1=muito desfavorável até 5=muito favorável). Este item era seguido por uma questão aberta na qual os respondentes relatavam os aspectos considerados no item fechado. Buscou-se assim estimulá-los a descrever os componentes de suas expectativas a partir de uma perspectiva mais global (dada pelo item fechado). Se a questão aberta fosse apresentada diretamente, provavelmente as respostas seriam lacônicas e meramente avaliativas (por exemplo: “o futuro da organização será ótimo”).

\section{Análise de dados.}

Realizou-se análise de conteúdo temática da questão aberta (Bardin, 2011) para identificar os atributos das expectativas de futuro organizacional. A média e o desvio-padrão do item fechado também foram calculados.

\section{Resultados e Discussão}

A média do item fechado foi de $3,52(\mathrm{DP}=0,97)$, portanto, acima do ponto médio da escala, o que denota certo grau de otimismo quanto ao futuro organizacional. A análise de conteúdo indicou as seguintes categorias: posição no mercado e possibilidades futuras de negócios (29\%), tipo de gestão/estratégia da organização no futuro (16\%), perspectivas de crescimento (lucro, número de trabalhadores e estrutura organizacional) e de investimento (13\%) e o papel da organização na sociedade (12\%). Esta última categoria versa sobre expectativas de que a organização ofertará produtos e serviços essenciais para a sociedade, o que garantiria seu sucesso (ou pelo menos sua sobrevivência) no futuro.

Os resultados da análise de conteúdo alinha-se à tendência da literatura de privilegiar a efetividade, como ilustram as categorias sobre posição de mercado e crescimento/lucro da organização. Elemento presente na literatura, a gestão da organização também surgiu nos 
relatos, especialmente no sentido de apontar seu papel na construção de um bom ambiente institucional e no provimento de adequadas condições para execução do trabalho. Aliado à revisão da literatura, o resultado da pesquisa exploratória fomentou a redação de 16 itens escritos com o intuito de representar expectativas de futuro organizacional.

\section{Estudo 2}

O Estudo 2 relata os resultados dos procedimentos iniciais de construção da escala (análise de juízes e semântica) e da análise fatorial exploratória realizada.

\section{Método}

\section{Participantes.}

A amostra foi composta por 164 profissionais de diversas organizações. Superou-se assim o mínimo absoluto de 100 casos e a relação casos/itens requeridos para análise fatorial exploratória (Hair, Black, Babin, Anderson \& Tatham, 2010; Pasquali, 2010). Todos os respondentes apresentavam escolaridade igual ou superior ao nível médio e a idade média foi de 37,99 anos ( $\mathrm{DP}=11,64)$. De fato, como a escala demanda certo grau de abstração, recomenda-se sua aplicação em profissionais com pelo menos esse nível de escolaridade. Na amostra, $65 \%$ dos respondentes eram mulheres, $71 \%$ não exerciam cargo gerencial e houve distribuição equilibrada em função do tipo de organização: empresas privadas (34\%), empresa pública/economia mista (33\%) e funcionalismo público (31\%).

\section{Procedimentos.}

A amostra foi obtida por meio da divulgação da pesquisa em listas de $e$-mails e redes sociais. O link de acesso direcionava os participantes para uma página eletrônica, na qual o instrumento era respondido de forma individual, voluntária e anônima.

\section{Instrumentos.}

A redação dos itens apoiou-se na definição do construto expectativas de futuro organizacional, nos resultados da pesquisa exploratória e na revisão dos instrumentos citados 
anteriormente. Em adição, foi consultada a Medida de Percepção de Efetividade Organizacional (Fernandes, Barale, Santos, Costa \& Gomide Jr., 2008), instrumento que, ao contrário da EEFO, está orientado para o tempo presente. Tal consulta se justifica dada a importância da efetividade organizacional no construto aqui proposto.

Os 16 itens escritos concerniam a expectativas de efetividade, gestão e ambiente de trabalho das organizações no futuro. No caso da efetividade, vários aspectos foram abordados, incluindo satisfação de clientes, posição no mercado de atuação, cumprimento de metas/objetivos e crescimento nos lucros. O texto sempre aludia a um estado futuro positivado (exemplo: “Os clientes da organização estarão satisfeitos com seus produtos/serviços.”). Os participantes assinalavam em escala de sete pontos o quão provável seria tal estado cinco anos à frente (1=nada provável até 7=extremamente provável). Dessa forma, o caráter probabilístico das expectativas foi contemplado nas próprias opções de resposta. A indicação de um ponto específico do futuro facilita a emissão das respostas, uma vez que oferece horizonte concreto para as expectativas dos profissionais. A opção pela referência temporal de cinco anos, além de ser encontrada na literatura (Chen et al., 2011; Zhou et al., 2004), justifica-se na medida em que não força o respondente a pensar em prazos muito longos, situação que poderia tornar as respostas inconsistentes.

Esses 16 itens foram submetidos à análise de juízes e à análise semântica. Na primeira, seis especialistas (professores, mestres e doutorandos em psicologia organizacional ou administração) avaliaram os itens quanto a sua clareza e adequação diante do construto. Foram retidos para etapas posteriores os itens que apresentaram $80 \%$ ou mais de avaliações favoráveis (Pasquali, 2010). Na análise semântica, 26 profissionais de diversas organizações (todos com escolaridade igual ou maior do que o nível médio) verificaram a inteligibilidade dos itens. Quatro itens foram suprimidos nessas duas etapas pois foram considerados vagos, repetitivos ou dispensáveis. Portanto, iniciou-se a análise fatorial exploratória com 12 itens. 


\section{Análise de dados.}

Para testar se o conjunto de itens permitia a análise fatorial exploratória, foram adotados os seguintes procedimentos (Hair et al., 2010; Tabachnick \& Fidell, 2007): inspeção das matrizes de correlações e anti-imagem e aplicação dos testes de Barlett e de KaiserMeyer-Olkin (KMO). Como os resultados foram favoráveis, utilizou-se a análise de componentes principais para extração dos fatores. A definição do número de fatores considerou múltiplos critérios, prática recomendada em pesquisas nas organizações (Conway \& Huffcutt, 2003). Os critérios foram: a análise de scree plot, o critério de Kaiser-Guttman (retenção de fatores com autovalor $>1$ ), o percentual de variância explicada e a análise paralela. Este último critério inclui a comparação de autovalores empíricos e randômicos e tende a exibir vantagem diante dos critérios tradicionais, especialmente por deter maior precisão no estabelecimento do número de fatores a reter (Damásio, 2012; Laros, 2012). Os autovalores randômicos foram calculados pelo programa Monte Carlo PCA.

Após o estabelecimento da quantidade de fatores, optou-se pelo método de extração Principal Axis Factoring devido a sua reconhecida capacidade de gerar soluções fatoriais de qualidade (Damásio, 2012). Nas soluções com mais de um fator testadas, utilizou-se a rotação oblíqua Promax. Neste estudo, o alfa de Cronbach foi priorizado como medida de confiabilidade. Toda a análise fatorial exploratória foi realizada no SPSS 19.

\section{Resultados e Discussão}

Na inspeção inicial dos dados, constatou-se que o item "O lucro da organização terá crescido (deixe em branco caso sua organização não tenha fins lucrativos)" apresentou alto percentual de dados faltantes. Esse padrão ocorreu posto que a amostra continha considerável proporção de respondentes do funcionalismo público. O item foi então excluído da análise.

Considerando os demais itens, constatou-se que a matriz de correlação era fatorável. O determinante da matriz registrou um valor próximo, contudo, diferente de zero. Todas as 
correlações foram significativas $(p<0,01)$ e superiores a 0,30 . As correlações anti-imagem foram baixas ( $89 \%$ abaixo de 0,30), favorecendo a análise fatorial (Tabachnick \& Fidell, 2007). O KMO foi meritório $(0,92)$ e o teste de Bartlett significativo $\left(\chi^{2}=1339,11 ; p<0,01\right)$.

Para determinação do número de fatores, realizou-se inicialmente uma análise de componentes principais para se investigar a dimensionalidade. A avaliação do scree plot indicou solução com dois fatores. O autovalor do primeiro fator foi $6,93(63,03 \%$ da variância explicada) e o do segundo foi 1,27 (adicionando 11,56\% de explicação). Desta forma, o critério de Kaiser-Guttman e a apreciação de percentual de variância explicada também sugerem dois fatores. $\mathrm{Na}$ análise paralela, autovalor empírico do segundo fator $(1,27)$ foi ligeiramente inferior ao autovalor aleatório correspondente $(1,28)$.

Assim, a solução unidimensional surgiu como candidata, uma vez que está embasada pela análise paralela, responde por grande parcela da variância e afigura-se como opção mais parcimoniosa. Por outro lado, cumpre frisar que os demais critérios sugerem solução bidimensional e que os autovalores aleatórios e empíricos do segundo fator são muito próximos. Nesse cenário, assumiu-se a princípio a solução unidimensional. Entretanto, tendo em vista o caráter exploratório dessa análise inicial, o estágio embrionário da delimitação do construto e a posterior realização de uma análise confirmatória, a configuração bidimensional foi igualmente investigada.

Realizou-se então a análise fatorial exploratória pelo método Principal Axis Factoring. Hair et al. (2010) sustentam que cargas fatoriais acima de 0,70 apontam estrutura fatorial bem definida e que os itens devem apresentar, preferencialmente, comunalidades superiores a 0,50. Ao se explorar as soluções com um e dois fatores, buscou-se alcançar esses parâmetros. A solução final foi composta por nove itens e, nessa nova matriz, os dados sobre fatorabilidade e avaliação de dimensionalidade quedaram-se com o mesmo padrão da matriz inicial de itens. Os dois itens excluídos foram: “A gestão da organização superará as 
adversidades mesmo se passar por momentos difíceis" e "A organização, por meio de seus produtos/serviços, cumprirá papel relevante na sociedade”.

A Tabela 1 expõe as cargas fatoriais das soluções de um e dois fatores. Em ambas, as cargas sinalizam estrutura fatorial bem definida. A única carga fatorial abaixo de 0,70 registrou valor muito próximo desse patamar $(0,69)$. A solução com dois fatores assinalou, no total, $73 \%$ de variância explicada, ao passo que a estrutura com fator único explicou $63 \%$.

Tabela 1

Cargas Fatoriais na Análise Fatorial Exploratória da EEFO

\begin{tabular}{lccc}
\hline \multicolumn{1}{c}{ Item } & Fator & Dois fatores \\
\cline { 3 - 4 } & Único & F1 & F2 \\
\hline 9. A organização estará em posição de destaque no seu setor/mercado de atuação. & 0,78 & 0,98 \\
7. Os clientes da organização estarão satisfeitos com seus produtos/serviços. & 0,81 & 0,88 \\
10. As metas da organização para esse período (5 anos) serão cumpridas. & 0,80 & 0,76 \\
11. A organização oferecerá produtos/serviços de alta qualidade. & 0,84 & 0,72 \\
6. Os clientes da organização a perceberão como um caso de sucesso. & 0,81 & 0,70 \\
3. A execução do trabalho será facilitada pelos métodos de gestão da organização. & 0,76 & \\
2. O ambiente de trabalho na organização será estimulante para seus profissionais. & 0,80 & & 0,97 \\
5. O ambiente de trabalho será aperfeiçoado pela gestão da organização. & 0,75 & 0,80 \\
1. A gestão da organização estará aperfeiçoada. & 0,78 & 0,69 \\
\hline Percentual de variância explicada & $63 \%$ & $64 \%$ & $9 \%$ \\
Confiabilidade (alfa de Cronbach) & 0,94 & 0,93 & 0,92 \\
Média das correlações interitem & 0,63 & 0,73 & 0,73 \\
Média das correlações item-total corrigidas & 0,77 & 0,82 & 0,81 \\
\hline
\end{tabular}

Nota. EEFO=Escala de Expectativas de Futuro Organizacional. São exibidas apenas as cargas fatoriais acima de 0,30 e os itens foram ordenados de acordo com as cargas fatoriais da solução com dois fatores para facilitar sua visualização.

A distribuição dos itens na solução com dois fatores está coerente com a revisão da literatura e a pesquisa exploratória. O primeiro fator (F1 na Tabela 1) aglutinou itens dedicados aos resultados da organização, sendo denominado de Efetividade Organizacional. 
O segundo fator (F2 na Tabela 1) abarca itens sobre gestão e ambiente de trabalho, temas bastante imbricados. Por essa razão, foi intitulado de Gestão e Ambiente Organizacional.

Como exposto na Tabela 1, a fidedignidade dos fatores atingiu, em ambas as soluções, valores superiores ao mínimo de 0,70 citado amiúde pela literatura (Damásio, 2012; Field, 2009; Hair et al., 2010). Como esta medida é influenciada pelo número de itens, foram consideradas outras formas de aferir fidedignidade. $\mathrm{Na}$ análise fatorial exploratória, a literatura destaca a média das correlações interitem e a média das correlações item-total corrigidas (Field, 2009; Hair et al., 2010; Laros \& Puente-Palacios, 2004). Hair et al. (2010) recomendam 0,30 e 0,50 como patamares mínimos para as médias das correlações interitem e item-total corrigidas, respectivamente. Nota-se na Tabela 1 que todos os fatores extraídos ultrapassam essas referências.

\section{Estudo 3}

O Estudo 3 testou a estrutura fatorial da EEFO via análise fatorial confirmatória, além de avaliar a confiabilidade e as validades convergente e discriminante da escala.

\section{Método}

\section{Participantes.}

A amostra independente do Estudo 3 contou 324 indivíduos, todos funcionários de uma autarquia federal. Os respondentes apresentavam escolaridade igual ou superior ao nível médio, idade média de 44,28 anos ( $\mathrm{DP}=9,75)$, tempo médio de organização de 13,77 anos $(\mathrm{DP}=10,23), 76 \%$ eram homens e $67 \%$ não exerciam cargo gerencial.

\section{Procedimentos.}

Com apoio da área de recursos humanos da autarquia, o link para o questionário foi enviado para os e-mails de funcionários selecionados a partir de lista gerada aleatoriamente do efetivo total da organização. O questionário foi respondido de forma individual, voluntária e confidencial. 


\section{Instrumentos.}

Os participantes responderam aos nove itens da EEFO presentes na Tabela 1. O questionário contava igualmente com itens demográficos.

\section{Análise de dados.}

Com duas soluções referendadas por bons indicadores, o Estudo 3 testou os modelos concorrentes via análise fatorial confirmatória. Esta foi executada pelo método de estimação máxima verossimilhança. Como os dados não exibiram normalidade multivariada (avaliada pelo índice de Mardia), recorreu-se à técnica de bootstrapping (500 subamostras foram geradas) para se avaliar a estabilidade dos parâmetros estimados (Byrne, 2010). A comparação do ajuste dos modelos observou os seguintes indicadores: GFI (Goodness-of-Fit Index), CFI (Comparative Fit Index), RMSEA (Root Mean Square Error of Approximation), SRMR (Standardized Root Mean Residual) e a diferença entre os valores de $\chi^{2}$ (quiquadrado) entre os modelos. A confiabilidade do construto foi calculada pelo rho( $\rho)$ de Jöreskog. Trata-se de uma alternativa ao alfa de Cronbach, estatística sensível ao número de itens e criticada atualmente por ser imprecisa nas estimativas de confiabilidade das medidas (Hair et al., 2010; Peterson \& Kim, 2013). O programa AMOS 18 foi utilizado na análise fatorial confirmatória.

\section{Resultados e Discussão}

$\mathrm{Na}$ análise fatorial exploratória da amostra do Estudo 3, o KMO foi de 0,92, o teste de Bartlett foi significativo $\left(\chi^{2}=2537,30 ; p<0,01\right)$ e todas as comunalidades superaram 0,50 . Quanto à dimensionalidade, os dados espelharam a amostra do Estudo 2: a análise paralela indicava fator único e os demais critérios, dois fatores. A solução com um fator explicou 64\% da variância, com todas as cargas fatoriais superiores a 0,70 . De sua parte, a solução de dois fatores (rotação oblíqua Promax) explicou $74 \%$ da variância (65\% no primeiro fator e $9 \%$ no segundo) e todas as cargas excederam igualmente 0,70 . Os coeficientes de confiabilidade 
(alfa de Cronbach) foram: 0,94 (fator único), 0,92 (fator Efetividade Organizacional) e 0,93 (fator Gestão e Ambiente Organizacional).

Assim, a análise fatorial exploratória do Estudo 3 replicou de forma praticamente idêntica os resultados do Estudo 2. A amostra foi então submetida à análise fatorial confirmatória e os dois modelos foram testados (unidimensional e bidimensional). A Tabela 2 expressa os indicadores de ajuste de ambos os modelos. O modelo de fator único manifestou ajuste ruim em todos os indicadores considerados. De outra parte, o modelo de dois fatores exibiu excelente ajuste observando os parâmetros fornecidos pela literatura (Hair et al., 2010; Tabachnick \& Fidell, 2007), exceto pelo valor significativo do qui-quadrado. Porém, tal significância estatística (indesejada em modelos de equações estruturais) deve ser relativizada em função do tamanho da amostra (Tabachnick \& Fidell, 2007).

Tabela 2

Indicadores de Ajuste dos Modelos Testados no Desenvolvimento da EEFO

\begin{tabular}{lccccccc}
\hline \multicolumn{1}{c}{ Modelos } & $\chi^{\mathbf{2}}$ & $\boldsymbol{g l}$ & GFI & CFI & RMSEA & IC $_{\text {RMSEA }}$ & SRMR \\
\hline Fator único & $426,46^{* *}$ & 26 & 0,74 & 0,84 & 0,22 & {$[0,20-0,24]$} & 0,09 \\
Dois fatores & $63,36^{* *}$ & 25 & 0,96 & 0,98 & 0,07 & {$[0,05-0,09]$} & 0,03 \\
\hline
\end{tabular}

Nota. EEFO=Escala de Expectativas de Futuro Organizacional. Foi permitida uma ligação entre erros de itens em ambos os modelos. GFI=Goodness-of-Fit Index; CFI=Comparative Fit Index; RMSEA=Root Mean Square Error of Approximation; $\mathrm{IC}_{\mathrm{RMSEA}}=$ Intervalo de confiança de $90 \%$ do RMSEA; SRMR=Standardized Root Mean Residual. $* * p<0,01$.

O modelo de dois fatores sobrepuja o modelo de fator único em todos os indicadores de ajuste. A diferença de qui-quadrado entre os modelos, $\Delta \chi_{(1)}^{2}=363,10, p<0,01$, foi bastante elevada e significativa, reforçando a existência de dois fatores. Com base nesses elementos, a estrutura de dois fatores foi selecionada como mais adequada para a EEFO. Assim, a Figura 1 explicita o modelo de dois fatores com as cargas fatoriais padronizadas dos itens. A correlação entre fatores e todos os coeficientes da Figura 1 foram estatisticamente significativos $(p<0,01)$. 


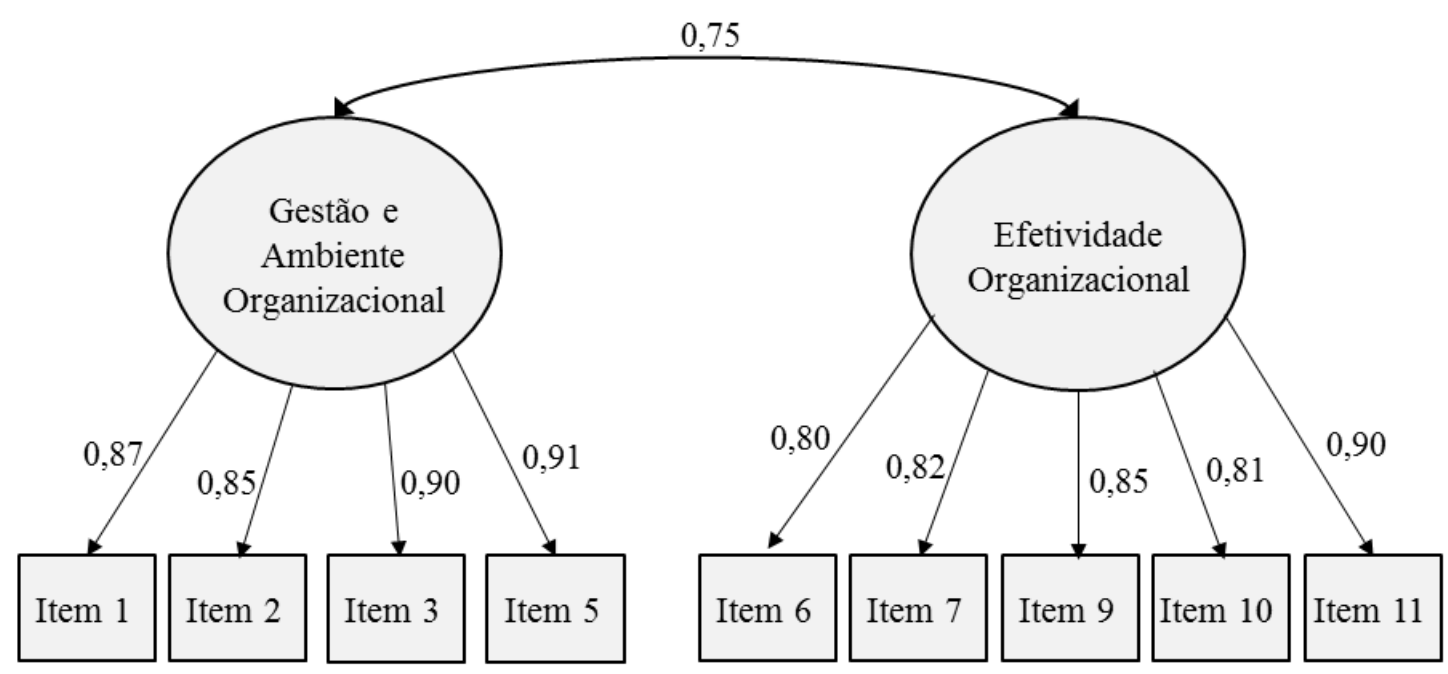

Figura 1. Modelo de dois Fatores da Escala de Expectativas de Futuro Organizacional (EEFO).

As médias das cargas fatoriais das subamostras advindas do bootstrapping foram praticamente idênticas às cargas fatoriais da Figura 1 (a diferença máxima não atingiu 0,01), com baixo erro padrão (entre 0,01 e 0,03). Esses resultados demonstram a estabilidade das cargas e fornecem evidência sobre a adequação do processo de estimação dos modelos.

Para testar a validade de construto do modelo de dois fatores, foram examinadas as validades convergente e discriminante dos fatores, conforme referências da literatura (Hair et al., 2010; Kline, 2011). No caso da validade convergente, três pontos foram abordados. O primeiro foi a magnitude das cargas fatoriais dos itens em cada fator. Na Figura 1, todas as cargas fatoriais ultrapassam o patamar sugerido de 0,70 para soluções fatoriais ótimas. $\mathrm{O}$ segundo ponto foi a variância média extraída por fator, ou seja, a média das comunalidades dos itens de determinado fator. Os escores obtidos nos fatores Efetividade Organizacional $(0,70)$ e Gestão e Ambiente Organizacional $(0,78)$ extrapolam 0,50 , referência que indica convergência adequada do construto. O terceiro ponto foi a confiabilidade do construto (rho de Jöreskog). A confiabilidade de Efetividade Organizacional $(0,92)$ e Gestão e Ambiente Organizacional $(0,93)$ suplantam 0,70 , patamar sugerido como indicador de bom nível de confiabilidade. Por sinal, a confiabilidade medida pelo rho de Jöreskog e pelo alfa de 
Cronbach foram iguais em números arredondados, proximidade já detectada em meta-análise sobre tal relação (Peterson \& Kim, 2013). Em conjunto, esses três pontos apontam para a validade convergente da medida.

No caso da validade discriminante, a questão central é mensurar até que ponto os construtos (no caso, os dois fatores em pauta) se diferenciam. Kline (2011) preconiza que, em modelos bem definidos, a correlação entre fatores deve ser inferior a 0,90. Portanto, a correlação dos fatores no modelo (Figura 1) fornece evidência de validade discriminante. Por sua vez, Hair et al. (2010) advogam que a validade discriminante estabelece-se na medida em que as variâncias médias extraídas dos fatores excedem o quadrado da correlação entre eles, posto que o construto deve explicar melhor seus itens do que outro construto. As variâncias médias extraídas de ambos os fatores $(0,70$ e 0,78$)$ superam o quadrado de sua correlação $(0,56)$, corroborando a validade discriminante.

\section{Discussão Geral}

O estágio inicial dos estudos sobre futuro organizacional na perspectiva individual serviu de estímulo para a presente pesquisa. Após discutir a literatura e propor um novo construto, este artigo descreveu o desenvolvimento e assinalou evidências de validade de um instrumento que afere expectativas de futuro organizacional. A EEFO constituiu-se a partir de nove itens distribuídos em dois fatores (Efetividade Organizacional e Gestão e Ambiente Organizacional), estrutura fatorial que explica mais de $70 \%$ da variância do construto e demonstra indícios de validade.

A EEFO diferencia-se de escalas anteriores por sua clara orientação para o futuro. Outros instrumentos mesclam itens orientados para o presente e para o futuro (Chiu, 2002; Chiu et al., 2007), opção que dificulta a delimitação da referência temporal do construto. Ao adotar uma visão mais completa do fenômeno, a EEFO também se distingue de outras escalas no número de itens e dimensionalidade. Com efeito, a maioria das escalas na literatura não 
supera cinco itens (Chen et al., 2011; Chiu, 2002; Mossholder et al., 1995; Posner, 2010; Zhou et al., 2004) e tendem a exibir estrutura unidimensional, como no caso dos instrumentos voltados para desempenho futuro da organização (Chen et al., 2011; Zhou et al., 2004).

A rigor, não foi localizada na literatura clara indicação teórica sobre a dimensionalidade do construto, o que reflete o estágio embrionário de sua discussão conceitual. Nesse sentido, a estrutura fatorial tende a espelhar o grau de abrangência do construto utilizado em cada pesquisa. No caso da EEFO, a solução com dois fatores alinha-se à definição do construto e encontra fundamentação em estudos anteriores. De fato, desempenho/efetividade (Chen et al., 2011; Margolis \& Hansen, 2003; White, 2010; Zhou et al., 2004) e tipo de gestão/ambiente de trabalho (Chiu, 2002; Chiu et al., 2007; Dackert et al., 2003; White, 2010) são atributos reconhecidos e contemplados pela literatura ao se tratar de expectativas e percepções sobre o futuro organizacional. Ademais, os dois fatores cobrem as categorias da análise de conteúdo trazidas a lume pela pesquisa exploratória.

O presente estudo contribui para a academia e a gestão das organizações. No âmbito acadêmico, propõe um construto que avança na conceituação do fenômeno, uma vez que delimita com maior clareza seus principais atributos. Colabora igualmente ao oferecer uma escala dotada de uma visão abrangente e integrada das expectativas de futuro organizacional, completamente orientada para o futuro, com bons índices de validade/confiabilidade, adaptada ao contexto brasileiro e rapidamente aplicada. Por suas características, a EEFO pode favorecer a identificação dos principais antecedentes e consequentes das expectativas de futuro organizacional incrementando, assim, a produção acadêmica.

Do ponto de vista prático, a EEFO pode ser utilizada pelas organizações para diagnosticar as expectativas dos profissionais sobre o futuro organizacional. Cobrindo importante aspecto da relação indivíduo-trabalho-organização, tais expectativas relacionamse com variáveis-chave para a gestão de recursos humanos, tais como atitudes no trabalho 
(Chiu, 2002; Chiu et al., 2007; Mossholder et al., 1995; Zhou et al., 2004), expectativas de carreira (Hubbard \& Purcell, 2001; Margolis \& Hansen, 2003) e intenção de rotatividade (Harris \& Mossholder, 1996). A partir dessa teia de relações, torna-se útil monitorar essas expectativas a fim de mitigar possíveis efeitos negativos de expectativas desfavoráveis e potencializar eventuais efeitos positivos de expectativas favoráveis.

Para efeito de diagnóstico, os resultados da EEFO devem ser apurados respeitando sua estrutura fatorial. Assim, os resultados devem ser calculados individualmente por fator a partir da média simples de seus itens. Na interpretação dos dados, deve-se considerar que quanto maior for o escore obtido, maior a probabilidade atribuída pelos respondentes à ocorrência das situações/estados descritos pelos itens. Como a redação desses últimos adquire sempre conotação positiva, escores maiores sinalizam expectativas mais favoráveis.

Sobre as limitações deste estudo, frisa-se que a EEFO, na atual configuração, está restrita a profissionais de nível médio ou escolaridade maior. Contudo, é possível desenvolver no futuro uma versão adaptada para profissionais de nível fundamental. Outra limitação refere-se à forma de recrutamento de respondentes nos Estudos 1 e 2 (divulgação na internet) e ao fato da amostra do Estudo 3 ter sido composta por profissionais de apenas uma organização pública, sendo necessárias novas amostras a fim de se corroborar a solução fatorial encontrada. No fundo, recomenda-se o contínuo refinamento da EEFO por meio de pesquisas futuras, o que pode incluir alteração no conjunto de itens e, quiçá, na própria dimensionalidade da escala. Nessa direção, uma possibilidade é aplicar a escala em organizações com fins lucrativos reincluindo o item 12 (sobre expectativas de lucro). Dada sua centralidade no contexto empresarial, seria oportuno realizar nova análise fatorial contando com esse item. Tal iniciativa não foi possível neste artigo em função das características das amostras utilizadas. 
De todo modo, os resultados relatados figuram como ponto de partida útil para novas investigações sobre o futuro organizacional na perspectiva individual. Investir em estudos com esse teor justifica-se porquanto a relação dos indivíduos com o futuro influi na atribuição de significado, tomada de decisão, emergência de estados afetivos e aspectos comportamentais (Carvalho et al., 2010). Ao se debruçar sobre o tópico, pesquisadores da área organizacional abrirão nova vereda para analisar e compreender a intrincada relação indivíduo-trabalho-organização. 


\section{Referências}

Aspinwall, L. G. (2005). The Psychology of Future-Oriented Thinking: From Achievement to Proactive Coping, Adaptation, and Aging. Motivation and Emotion, 29(4), 203-235.

Bardin, L. (2011). Análise de conteúdo. São Paulo: Edições 70.

Bruininks, P., \& Malle, B. (2005). Distinguishing Hope from Optimism and Related Affective States. Motivation and Emotion, 29(4), 324-352.

Byrne, B. (2010). Structural equation modeling with AMOS. New York: Taylor \& Francis.

Carvalho, R., Pocinho, M. \& Silva, C. (2010). Comportamento adaptativo e perspectivação do futuro: Algumas evidências nos contextos da educação e da saúde. Psicologia: Reflexão e Crítica, 23(3), 554-561.

Chen, Y. P., Hsu, Y. S., \& Yip, F. W. (2011). Friends or rivals: comparative perceptions of human resource and line managers on perceived future firm performance. International Journal of Human Resource Management, 22(8), 1703-1722.

Chiu, W. (2002). Do types of economic ownership matter in getting employees to commit? An exploratory study in the People's Republic of China. International Journal of Human Resource Management, 13(6), 865-882.

Chiu, W., Hui, C. \& Lai, G. (2007). Psychological ownership and organizational optimism amid China's corporate transformation: effects of an employee ownership scheme and a management-dominated board. International Journal of Human Resource Management, $18,303-320$.

Conway, J. M. \& Huffcutt, A. I. (2003). A review and evaluation of exploratory factor analysis practices in organizational research. Organizational Research Methods, 6(2), 147-168.

Dackert, I., Jackson, P., Brenner, S. \& Johansson, C. (2003). Eliciting and analysing employees' expectations of a merger. Human Relations, 56(6), 705-725. 
Damásio, B.F. (2012). Uso da análise fatorial exploratória em psicologia. Avaliação Psicológica, 11(2), 213-228.

Fernandes, M. N., Barale, R. F., Santos, T. R. C., Costa, T. \& Gomide Jr., S. (2008). Percepção de Efetividade Organizacional: construção e validação de uma medida do constructo. Revista Psicologia: Organizações e Trabalho, 7(2), 90-102.

Field, A. P. (2009). Discovering statistics using SPSS. Thousand Oaks, CA: Sage.

George J. M. \& Jones, G. R. (2000). The role of time in theory and theory building. Journal of Management, 26(4), 657-684.

Grant, R. M. (2003). Strategic planning in a turbulent environment: evidence from the oil majors. Strategic Management Journal, 24(6), 491-517.

Hair, J., Black, W., Babin, B., Anderson, R. \& Tatham, R. (2010). Multivariate Data Analysis (sétima edição). Upper Saddle River, NJ: Prentice Hall.

Harris, S. G., \& Mossholder, K. W. (1996). The affective implications of perceived congruence with culture dimensions during organizational transformation. Journal of Management, 22(4), 527-547.

Hubbard, N. \& Purcell, J. (2001). Managing employee expectations during acquisitions. Human Resource Management Journal, 11(2), 17-33.

Hui, C. \& Lee, C. (2000). Moderating effects of organization-based self-esteem on organizational uncertainty: employee response relationships. Journal of Management, $26(2), 215-232$.

Kline, R. B. (2011). Principles and practice of structural equation modeling. New York: Guilford Press.

Laros, J. A. \& Puente-Palacios, K. E. (2004). Validação cruzada de uma escala de clima organizacional. Estudos de Psicologia (Natal), 9(1), 113-119. 
Laros, J. A. (2012). O uso da Análise Fatorial: Algumas diretrizes para pesquisadores. In L. Pasquali. (Org.). Análise Fatorial para pesquisadores (pp.163-193). Brasília: LabPAM Editora.

Lee, H. \& Liebenau, J. (1999). Time in organizational studies: towards a new research direction. Organization Studies, 20(6), 1035-1058.

Margolis, S. \& Hansen, C. (2003). Visions to guide performance: a typology of multiple future organizational images. Performance Improvement Quarterly, 16(4), 40-58.

Mossholder, K. W., Settoon, R. P., Harris, S. G., \& Armenakis, A. A. (1995). Measuring emotion in open-ended survey responses: An application of textual data analysis. Journal of Management, 21(2), 335-355.

Oettingen, G. \& Mayer, D. (2002). The Motivating Function of Thinking about the Future: Expectations Versus Fantasies. Journal of Personality and Social Psychology, 83(5), 1198-1212.

Pasquali, L. (2010). Instrumentação Psicológica: fundamentos e práticas. Porto Alegre: Artmed.

Peterson, R. A. \& Kim, Y. (2013). On the relationship between coefficient alpha and composite reliability. Journal of Applied Psychology, 98(1), 194-198.

Posner, B. Z. (2010). Values and the American manager: A three-decade perspective. Journal of Business Ethics, 91(4), 457-465.

Richard, P. J., Devinney, T. M., Yip, G. S., \& Johnson, G. (2009). Measuring organizational performance: Towards methodological best practice. Journal of Management, 35(3), 718-804.

Schenatto, F., Polacinski,E., Abreu, A. \& Abreu, P. (2011). Análise crítica dos estudos do futuro: uma abordagem a partir do resgate histórico e conceitual do tema. Gestão e Produção, 18(4), 739-754. 
Sonnentag, S. (2012). Time in organizational research: Catching up on a long neglected topic in order to improve theory. Organizational Psychology Review, 2(4), 361-368.

Tabachnick, B. G. \& Fidell, L. S. (2007). Using multivariate statistics. Boston: Pearson. Vasconcellos, V. \& Neiva, E. (2015). Futuro Organizacional na Perspectiva Individual: Possibilidades e Tendências de Investigação na Literatura. Manuscrito em preparação para submissão.

White, J. (2010). Understanding Identity in the Workplace: Exploring Current Organizational Perceptions Pertaining to Change Events and Future State (Tese de Doutorado). Walden University, Minneapolis.

Zhou, K., Li, J., \& Zhou, N. (2004). Employee's Perception of Market Orientation in a Transitional Economy: China as an Example. Journal of Global Marketing, 17, 5-22. 


\section{MANUSCRITO 5}

O Manuscrito 5 comporta a primeira série de testes de hipótese da tese. Seu objetivo foi testar em que medida a situação de carreira dos profissionais influencia suas expectativas de carreira em sua organização. Como a situação de carreira pode ser vislumbrada por diversos prismas, optou-se por operacionalizá-la por meio de um conjunto de variáveis, entre as quais, estágio de carreira (na vida laboral em geral), tempo de carreira na organização, cargo ocupado, obtenção de conquistas profissionais recentes e participação em programas de desenvolvimento de carreira. O sexo do participante também foi incluído na pesquisa visto que parte da literatura assume que tal variável influencia a evolução na carreira. Os dados obtidos nas três amostras constantes desse manuscrito franquearam uma meta-análise de pequeno porte que sumariou o tamanho do efeito das variáveis independentes nas expectativas de carreira na organização. Trata-se de estratégia consoante com as atuais tendências de análise estatística, sendo bastante proveitosa para submeter as hipóteses da pesquisa a avaliações mais robustas. 


\section{MANUSCRITO 5}

Situação de Carreira e Expectativas de Futuro na Organização

Career Situation and Future Expectations in the Organization

Vinicius Carvalho de Vasconcellos

Universidade de Brasília 


\title{
Resumo
}

Este artigo analisou em que medida a atual situação de carreira dos profissionais influencia suas expectativas de carreira em sua organização. O Estudo 1 investigou possíveis diferenças no primeiro tipo de expectativas de carreira analisado (expectativas de conquistas profissionais) em função do estágio de carreira, do tempo de carreira na organização, do cargo ocupado (gerencial ou não gerencial) e do sexo do respondente. O Estudo 2 testou os resultados do Estudo 1 em nova amostra e verificou o impacto de mais duas variáveis (obtenção de conquistas profissionais recentes e participação em programas de desenvolvimento de carreira) nas expectativas de conquistas profissionais. Ademais, o Estudo 2 analisou os efeitos de todas as variáveis independentes em outro tipo de expectativas de carreira (expectativas sobre a relação carreira-vida pessoal). O Estudo 1 contém duas amostras, sendo uma extraída de uma autarquia federal $(n=305)$ e outra de uma empresa de economia mista $(n=265)$. O Estudo 2 baseia-se em terceira amostra independente, composta por profissionais de múltiplas organizações $(n=352)$. As expectativas de carreira foram aferidas pela Escala de Expectativas de Carreira na Organização e os resultados combinados em uma meta-análise de pequeno porte. Os dados indicaram que indivíduos em cargos gerenciais e com conquistas profissionais recentes detêm escores mais elevados do que os demais respondentes nos dois tipos de expectativas. Os efeitos de estágio de carreira, tempo de carreira na organização e sexo foram pequenos ou inexistentes. A discussão analisa os resultados a luz do cenário organizacional contemporâneo.

Palavras-chave: carreira, expectativas, meta-análise

\begin{abstract}
This article examined if the current career situation of the professionals influences their career expectations in the organization. Study 1 investigated possible differences in the first type of career expectations in analysis (professional achievements expectations) according to the respondent's career stage, organizational tenure, career position (manager or non manager) and gender. Study 2 tests the Study 1 findings in a new sample and verifies the impact of two more variables (obtainment of recent professional achievements and participation in career development programs) on the professional achievements expectations. In addition, Study 2 examined the effects of all independent variables in other type of career expectations (career-personal life relationship expectations). Study 1 has two samples, one taken from a government agency $(n=305)$ and another taken from a mixed-capital corporation $(n=265)$. Study 2 presents a third independent sample of professionals from multiple organizations $(n=352)$. The career expectations were measured by the Career Expectations in the Organization Scale and the results were combined with a small scale meta-analysis. The data indicated that individuals in managerial positions and with recent professional achievements hold scores higher than others in both types of career expectations. The effects of career stage, organizational tenure and gender were small or nonexistent. The discussion analyzes the results in the context of contemporary organizations.
\end{abstract}

Keywords: career, expectations, meta-analysis 
A relação dos indivíduos com o futuro faz parte da subjetividade humana, estando presente nos mais diversos domínios sociais (trabalho, vida familiar, comunidade, entre outros). No domínio do trabalho, foco desta pesquisa, projeções sobre o futuro profissional inserem-se na discussão sobre carreira, entendida como sequência de experiências de trabalho no curso da vida de uma pessoa (Greenhaus, Callanan \& Godshalk, 1999).

Este artigo trata especificamente das expectativas dos profissionais sobre o futuro de suas carreiras na sua organização atual. Trata-se de um elemento importante na relação indivíduo-trabalho-organização, visto que perspectiva de crescimento na carreira surge entre as características mais valorizadas por trabalhadores em organizações (Tolfo, 2002) e que expectativas/percepções sobre o futuro na carreira relacionam-se com variáveis relevantes para a gestão, como atitudes no trabalho e intenções de desligamento (Chay \& Aryee, 1999; Chen, Ployhart, Cooper-Thomas, Anderson \& Bliese, 2011; Stroh \& Reilly, 1997).

Partindo da relevância da matéria, esta pesquisa analisou em que medida a situação de carreira dos profissionais influencia suas expectativas de carreira na organização. Situação de carreira foi operacionalizada por meio de uma série de variáveis descritas na próxima seção, ao passo que expectativas de carreira na organização são definidas como as crenças dos indivíduos sobre sua futura trajetória profissional na atual organização (Vasconcellos \& Neiva, 2015). Esse último construto abarca dois fatores. O primeiro, Conquistas Profissionais, trata de expectativas sobre a consecução de objetivos profissionais e de sucesso na carreira, tocando em projeções sobre recompensas/remuneração, prestígio, reconhecimento e realização de tarefas interessantes e alinhadas às preferências pessoais. $\mathrm{O}$ segundo, Relação Carreira-Vida Pessoal, aborda expectativas sobre a obtenção de uma relação favorável entre a vida privada e o trabalho/carreira no futuro profissional.

O artigo relata dois estudos. O Estudo 1 contém duas amostras diferentes e se concentra no fator Conquistas Profissionais. O Estudo 2, com amostra independente, inclui os dois 
fatores de expectativas de carreira. Como os resultados referentes às conquistas profissionais foram aferidos em três amostras, estes foram compilados em uma meta-análise de pequeno porte que contribuiu para avaliação final das hipóteses da pesquisa. Como adendo, recorreuse à meta-análise para estabelecer escores de referência para esse fator, informação útil para profissionais de recursos humanos $(\mathrm{RH})$ que desejam aplicar a escala em suas organizações.

\section{Situação de Carreira e sua Relação com Expectativas de Carreira}

A situação de carreira de um profissional pode ser analisada por diversas lentes, de sorte que as próximas seções tratam de variáveis que podem ser empregadas para esse fim. Primeiramente, será discutido o estágio de carreira considerando toda vida laboral e, subsequentemente, a situação de carreira na atual organização (tempo de carreira na organização e cargo ocupado). A seção seguinte versa sobre uma variável que não configura situação de carreira, mas que é amiúde evocada como fator que influi no desenvolvimento de carreira: o sexo do profissional. Cada seção discute o efeito dessas variáveis nas expectativas de conquistas profissionais, derivando hipóteses que serão testadas nos dois estudos do artigo.

\section{Estágio de Carreira, Idade e Expectativas de Carreira na Organização}

Modelos de estágios de carreira partem da premissa que as tarefas, as preocupações, os valores e as necessidades relativas à carreira variam em função dos diferentes períodos da vida laboral (Hall, 2002). Como o envelhecimento altera prioridades e preferências no trabalho e na vida social, a idade é o marcador usual a delimitar esses períodos (Darcy, McCarthy, Hill \& Grady, 2012). A imprevisibilidade das atuais trajetórias de carreira, todavia, instiga questionamentos acerca da pertinência destes modelos na atualidade. Sobre este tópico, Hall (2002) advoga que os modelos continuam como referências importantes, embora as análises tenham que se sofisticar para lidar com a mobilidade de carreira que marca o mundo contemporâneo. 
O modelo de arco-íris e carreira (Super, 1980) está entre os mais tradicionais e citados da literatura. Este propõe estágios de desenvolvimento de carreira que surgem integrados aos papéis da vida social. Os cinco estágios propostos organizam-se a partir das idades aproximadas de sua ocorrência: a) crescimento (4-13 anos), b) exploração (14-24 anos), c) estabelecimento (25-44 anos), d) manutenção (45-65 anos) e e) declínio (após 65 anos).

Os estágios de estabelecimento e manutenção dominam a vida laboral. No primeiro, os indivíduos enfrentam a tarefa de estabilizar, consolidar e progredir na área ocupacional escolhida (Magalhães, 2005). Embora possam ocorrer ensaios e mudanças de direção, no fim desse estágio, a área ocupacional estará definida para a maioria dos profissionais. O papel de trabalhador torna-se muito saliente na vida social e o autoconceito profissional sedimenta-se. Já o estágio de manutenção consiste prioritariamente na conservação da posição de carreira alcançada, sendo menos frequentes os comportamentos exploratórios (Magalhães, 2005). O foco está em manter os ganhos e desfrutá-los, crescendo o espaço do lazer na vida social. A chance dos indivíduos fixarem-se em platôs de carreira aumenta.

Como as expectativas de carreira se configuram nesses estágios? É provável que, em função da demanda por progressão, indivíduos no estágio de estabelecimento estejam mais engajados em se qualificar e buscar oportunidades profissionais, o que pode favorecer a emergência de expectativas elevadas. Inversamente, profissionais no estágio de manutenção buscam conservar a posição adquirida, acarretando, em tese, menor motivação para adquirir novas competências e assumir riscos em outras atividades. Os avanços na carreira tornar-seiam mais limitados, podendo ocasionar rebaixamento ou acomodação de expectativas.

Nessa discussão, Zacher e Frese (2011) analisaram as crenças dos profissionais acerca dos novos objetivos, opções e possibilidades existentes em seu futuro de carreira e relataram correlação forte e negativa entre estas crenças e idade. Os resultados sugerem que profissionais jovens vislumbram o futuro profissional como projeto aberto, diminuindo o 
impacto de insucessos pontuais nos objetivos futuros. O padrão encontrado coaduna-se com a teoria da seletividade socioemocional (Lang \& Carstensen, 2002), que advoga que quando o tempo é percebido como expansivo (tipicamente nos mais jovens), os objetivos pessoais tendem a ser direcionados para o longo prazo/futuro; quando o tempo é percebido como limitado (tipicamente em indivíduos mais velhos), objetivos emocionalmente expressivos e de curto prazo ascendem em importância. Os autores também explicaram os resultados recorrendo a estudos pregressos que apontam que indivíduos mais velhos são mais avessos ao risco e à mudança organizacional e se engajam menos em desenvolvimento de carreira.

Entretanto, expectativas/percepções sobre futuro na carreira não se restringem ao surgimento de novas opções e objetivos profissionais, posto que o futuro pode ser vislumbrado como favorável pela simples manutenção de cargos/atividades já alcançadas. Nesses casos, a tendência é que indivíduos com mais idade apresentem expectativas mais favoráveis, pois boa parte deles já logrou posições destacadas em suas organizações.

De fato, pesquisas alicerçadas em variáveis diferentes da adotada por Zacher e Frese (2011) proporcionam resultados distintos. Por exemplo, expectativas salariais também se relacionam negativamente com idade, todavia, com magnitude fraca ou moderada (Gibson \& Lawrence, 2010; O’Neill, Stanley \& O’Reilly, 2011). Já percepções sobre o alcance de objetivos profissionais no futuro exibem correlações próximas a zero com idade (Chay \& Aryee, 1999). Para esses atributos de futuro na carreira, a influência da idade parece ser menos nítida. Apesar dessas divergências, a maioria das contribuições teóricas e empíricas sugere a relação negativa entre estágios de carreira e idade com expectativas/percepções de futuro na carreira. Logo, é possível estipular que:

Hipótese $1 a$ - Profissionais no estágio de estabelecimento detêm expectativas de carreira (fator Conquistas Profissionais) maiores que aqueles no estágio de manutenção. 
Como a categorização por estágios implica perda de informação estatística, a idade, aferida como variável métrica, também foi analisada. Diante do exposto, propõe-se que:

Hipótese $1 b$ - Idade relaciona-se negativamente com expectativas de carreira (fator Conquistas Profissionais).

\section{Tempo de Carreira na Organização e Expectativas de Carreira}

A análise isolada da influência dos estágios de carreira/idade nas expectativas de carreira detém uma fragilidade: a inobservância do possível impacto das mudanças de organização ao longo da vida laboral. A rigor, é difícil comparar a situação de carreira de dois profissionais com a mesma idade se um está há 20 anos na organização e o outro acabou de ser contratado. Logo, o tempo de organização deve ser considerado nessa discussão.

$\mathrm{Na}$ literatura de carreira e de comportamento organizacional, tempo de carreira na organização costuma ser aferido como variável métrica em anos (Gibson \& Lawrence, 2010) ou como variável não métrica que indica o estágio de carreira na atual organização (Cohen, 1991; Jans, 1989; Ng \& Feldman, 2011; Wright \& Bonett, 2002). No último caso, as fronteiras que balizam os estágios variam entre as pesquisas, porém, o uso de intervalos de cinco anos está entre as opções mais frequentes (Ng \& Feldman, 2011; Wright \& Bonett, 2002).

Como o tempo de carreira na organização pode influir nas expectativas de carreira? É plausível supor que a passagem do tempo permite aos profissionais ganhar experiência, compreender melhor a dinâmica organizacional e desenvolver as habilidades requeridas pelo trabalho (Ng \& Feldman, 2011). Nessa mesma linha, meta-análise recente (Ng \& Feldman, 2010) apontou relação positiva entre tempo de organização e desempenho. Partindo da premissa que desempenho mais elevado e experiência no ambiente de trabalho propiciam vantagens na evolução de carreira, é possível conceber a relação positiva entre tempo de organização e expectativas de carreira na organização. É provável ainda que profissionais 
com baixas expectativas de carreira não permaneçam muito tempo na organização, o que também favoreceria a correlação positiva entre as variáveis.

Contudo, essa relação parece ser mais intrincada. Em discussão teórica, Taormina (1997) propõe que os primeiros anos de organização geralmente despertam níveis elevados de expectativas em função da novidade e excitação trazidas pela nova fase na carreira. Depois de adquirir mais clareza sobre a cultura e as práticas organizacionais, os profissionais enfrentam um choque de realidade e dividem-se então em três grupos. O primeiro é composto por uma minoria com grande talento, o que permite a continuidade das expectativas favoráveis de carreira. O segundo, formado por grande contingente de profissionais de desempenho mediano, reduz suas expectativas de carreira após o choque de realidade e o mantém em um platô por longo período. O terceiro, com indivíduos de desempenho limitado, diminui sucessivamente as expectativas de carreira, sendo grande a possibilidade de desligamento.

Neste enquadre, os primeiros anos de organização se caracterizariam pela associação negativa das variáveis (pouco tempo de organização e expectativas elevadas). Nos períodos seguintes, a maioria dos profissionais apresentaria um platô de expectativas, o que sinaliza ausência de relação entre as variáveis (a passagem do tempo não aumentaria nem diminuiria expectativas). Esse padrão é consistente com o efeito "lua de mel" (período inicial de avaliação positiva do trabalho) e "ressaca" (decréscimo nessa avaliação ao longo do tempo), sugerido pela literatura de atitudes no trabalho (Judge \& Kammeyer-Mueller, 2012).

Investigações empíricas desvelaram relação negativa, porém fraca, entre tempo de carreira na organização e medidas genéricas sobre projeções de futuro na carreira na organização (Chay \& Aryee, 1999; Chen et al., 2011; Vasconcellos \& Neiva, 2014). Outros estudos identificaram correlações na mesma direção ao medirem expectativas de níveis salariais (Gibson \& Lawrence, 2010) e a confiança dos indivíduos em conseguir um futuro favorável na organização (Jans, 1989), contudo, com magnitude maior (cerca de -0,30). Além 
da correlação, Jans (1989) testou a diferença de médias de grupos em distintos estágios de tempo de carreira na organização e os dados alinharam-se ao efeito "lua de mel" e "ressaca".

Seguindo essa indicação, o presente estudo, além da análise correlacional, investiga se as médias de expectativas de carreira diferem entre grupos com distintos tempos de organização no cenário nacional. Em conjunto, os dados sugerem relação negativa, malgrado a divergência sobre o tamanho do efeito. Assim, conjectura-se que:

Hipótese $2 a$ - Profissionais no estágio inicial de carreira na organização detêm expectativas de carreira (fator Conquistas Profissionais) maiores do que os demais. Hipótese $2 b$ - Tempo de carreira na organização (como variável métrica) correlacionase negativamente com expectativas de carreira (fator Conquistas Profissionais).

\section{Cargo Ocupado e Expectativas de Carreira na Organização}

O cargo ocupado pelo profissional figura como outra variável que descreve a situação de carreira. Esta pesquisa comparou cargos gerenciais e não gerenciais, haja vista que tal distinção existe em praticamente todas as organizações. Assume-se aqui cargo gerencial como posição formal de liderança nas organizações, destinada em geral a profissionais que coordenam atividades em equipes de trabalho. Não obstante a variedade de rótulos para tal atividade, gerente será o termo genérico utilizado para designá-la nessa pesquisa.

O trabalho gerencial costuma exigir habilidades de negociação, facilidade para estabelecer bons relacionamentos interpessoais, capacidade de monitorar/processar grande volume de informações (inclusive confidenciais) e perícia para tomar boas decisões (Mintzberg, 1990). Em complemento, cargos gerenciais habitualmente demandam elevadas cargas de trabalho e jornada laboral extensa, sendo comuns os conflitos com a vida pessoal (Lima, Neto \& Tanure, 2012).

Como a atuação gerencial pode influenciar expectativas de carreira? Em artigo teórico, Kahneman e Lovallo (1993) sustentam que boa parte dos gestores constrói uma autoimagem 
que supõe alto controle sobre indivíduos e eventos. Tal suposição de controle pode se desdobrar para o próprio futuro profissional e engendrar expectativas positivas sobre este último. Evidências nesse sentido procedem do campo experimental. Ao manipular entre os participantes os papéis de gerente e subordinado, Fast, Gruenfeld, Sivanathan e Galinsky (2009) destacam que a experiência de poder nos gerentes levou à ilusão de controle pessoal e, sequencialmente, aumentou seu grau de otimismo sobre os resultados do trabalho.

Outras razões para presumir níveis mais altos de expectativas de carreira em gerentes podem ser aventadas. Gerentes, em geral, detêm acesso privilegiado a informações e grande rede de contatos, elementos que permitem antecipar mudanças organizacionais e tomar decisões de carreira mais fundamentadas, melhorando suas expectativas profissionais. Adicionalmente, como a designação para cargo gerencial costuma ser interpretada como atestado de qualificação, competência e/ou importância dos promovidos (De Souza, 2002), gerentes tendem a apresentar autoavaliação profissional positiva, facilitando a emergência de crenças sobre a obtenção/manutenção de boas posições e recompensas no futuro na carreira.

Pesquisas empíricas convergem em sinalizar tal relação. Veloso et al. (2011) relataram que executivos percebem mais oportunidades de crescimento na organização do que não executivos. De Souza (2002) desvelou que o número de promoções recebidas no passado opera como preditor de expectativas de promoção no futuro e que profissionais que desejavam, mas que não lograram cargos gerenciais e promoções, reduzem suas expectativas de promoções futuras. Similarmente, há relação forte e positiva do atual nível hierárquico na organização com expectativas de salário no futuro (Gibson \& Lawrence, 2010) e com percepção de novas opções e possibilidades de carreira no futuro da organização (Treadway, Breland, Adams, Duke \& Willians, 2010). Assim, formula-se a hipótese de que:

Hipótese 3 - Gerentes apresentam expectativas de carreira (fator Conquistas Profissionais) maiores do que não gerentes. 


\section{Sexo do Profissional e Expectativas de Carreira na Organização}

Ao longo do século XX, a participação das mulheres no mercado de trabalho aumentou substancialmente. Entretanto, há evidências de que as mulheres ainda estão sub-representadas em posições de liderança, o que sugere a existência de barreiras invisíveis, fenômeno conhecido na literatura como teto de vidro (Cook \& Glass, 2014; Olidi, Parejo \& Padilla, 2013). Entre as possíveis causas para o teto de vidro estão: a) persistência de estereótipos de gênero e discriminação; b) escolha, por parte das mulheres, de profissões menos valorizadas socialmente e/ou de cargos menos elevados, por exemplo, para ter mais tempo com família; c) exclusão de atividades sociais (fora do trabalho) que favorecem a formação da rede profissional de contatos (Barnett, 2004; Cook \& Glass, 2014; Odili et al., 2013).

Nas últimas décadas, em contraste à influência do fenômeno teto de vidro, o aumento de escolaridade das mulheres e a redução do tempo despendido por elas em tarefas domésticas (Barnett, 2004) sugerem maior equilíbrio na evolução de carreira de homens e mulheres. Neste cenário de possível transformação social, esta pesquisa investiga, na realidade nacional, em que medida as expectativas de carreira diferem em função do sexo.

Pesquisas pautadas em variáveis genéricas de percepções de oportunidades futuras e otimismo na carreira são inconsistentes sobre o tópico. Há estudos que relataram médias mais elevadas para os homens (Coetzee, 2012), que não acusaram diferença entre os sexos (Stroh \& Reilly, 1997) e que assinalaram percepções mais positivas em mulheres (Treadway et al., 2010). Todavia, ao focalizar apenas expectativas sobre recompensas, salários e promoções, outro quadro emerge. Gibson e Lawrence (2010), ao revisar a temática, sinalizaram que investigações empíricas convergem ao apontar que mulheres exibem expectativas mais baixas sobre recompensas formais. E os dados obtidos por esses mesmos autores corroboraram esses estudos prévios. Em consonância, O’Neill et al. (2011) evidenciaram que as expectativas de salário de topo da carreira entre mulheres eram inferiores às expectativas dos homens. 
Apesar do dissenso da literatura em abordagens mais genéricas, assumiu-se a hipótese de que os homens suplantam as mulheres nas expectativas de conquistas profissionais, haja vista que estas incluem expectativas de remuneração e recompensas, matéria na qual a literatura aponta mais nitidamente médias maiores entre os homens. Assim, estipula-se que:

Hipótese 4 - Homens apresentam expectativas de carreira (fator Conquistas Profissionais) maiores do que as mulheres.

\section{Estudo 1}

O objetivo do Estudo 1 foi testar, em amostras extraídas de duas organizações, as quatro hipóteses propostas anteriormente.

\section{Método}

\section{Participantes.}

A amostra A $(n=305)$ foi coletada em uma autarquia federal. Entre os respondentes, $74 \%$ eram homens e 70\% não atuavam em cargo gerencial. A idade média foi 44,04 anos $(\mathrm{DP}=9,50)$, com $51 \%$ dos profissionais no estágio de estabelecimento e $49 \%$ no estágio de manutenção. O tempo médio de carreira médio foi de 13,36 anos ( $\mathrm{DP}=9,91)$, com a seguinte distribuição: até cinco anos (28\%), entre seis e dez anos (20\%) e 11 anos ou mais (52\%).

A amostra B $(n=265)$ provém de uma empresa de economia mista. Entre os respondentes, $75 \%$ eram homens e $88 \%$ não atuavam em cargo gerencial. O questionário respeitou o padrão das pesquisas da organização de aferir idade e tempo na organização por meio de categorias. As categorias da variável idade não coincidiram com a divisão por estágio de carreira, mas informase que o grupo mais numeroso foi o de 35 a 49 anos (40\%). Por tempo de organização, a distribuição foi: até cinco anos (35\%), entre seis e 10 anos (37\%) e 11 anos ou mais (28\%).

Nas duas amostras, todos os indivíduos detinham escolaridade igual ou maior que o nível médio e verificou-se que as proporções dos grupos nas amostras foram similares àquelas encontradas na organização inteira. $\mathrm{O}$ tamanho de cada amostra superou o mínimo requerido para 
obter poder de $80 \%$ nos testes paramétricos e correlações, considerando $\alpha=0,05$ e expectativa de efeito pequeno para moderado ( $c$ mo $d=0,35, r=0,20$ e $\eta^{2}=0,04$ ).

\section{Procedimentos.}

Nas duas amostras, os respondentes, selecionados aleatoriamente de uma lista de profissionais de cada organização, receberam um correio eletrônico com informações sobre o estudo, instruções, contato do pesquisador e link de acesso ao questionário. O questionário foi respondido individualmente, de forma voluntária e confidencial.

\section{Instrumentos.}

O questionário continha itens sobre sexo, idade, tempo na organização, cargo ocupado (gerencial ou não gerencial) e a versão completa do fator Conquistas Profissionais da Escala de Expectativas de Carreira na Organização (EECO). Nesse instrumento, validado por Vasconcellos e Neiva (2015), os participantes assinalam na escala a probabilidade da situação positiva descrita no item ocorrer cinco anos à frente (1=nada provável até $7=$ extremamente provável). Seus nove itens aludem à futura situação de carreira do indivíduo naquela organização (exemplo: “Atingirei meus objetivos de carreira estabelecidos para esse período"). O alfa de Cronbach foi de 0,94 nas duas amostras. Os dados relativos à idade foram usados para dividir os respondentes em diferentes grupos por estágio de carreira (Super, 1980).

\section{Análises de Dados.}

Não houve outliers e os casos omissos estavam distribuídos assistematicamente. O escore consolidado do fator Conquistas Profissionais expressa a média dos itens. Os programas SPSS 19 e Statistica 8 foram utilizados para calcular correlações e realizar os testes estatísticos.

\section{Resultados e Discussão}

Inicialmente, todas as variáveis seriam submetidas a testes paramétricos. Contudo, nos casos de sexo e cargo ocupado, houve diferenças consideráveis no tamanho dos grupos, o que pode prejudicar a precisão desses testes (Field, 2009). Optou-se então, em ambos os casos, 
pelo teste não paramétrico de Mann-Whitney. Nas demais variáveis, os grupos, além exibir igualdade de variância, registraram tamanhos razoavelmente equilibrados (Field, 2009), situação que favorece testes via análise de variância (ANOVA).

A Tabela 1 explicita os diferentes patamares de expectativas de carreira na organização (fator Conquistas Profissionais) em função das variáveis independentes, além de reportar os testes de hipóteses. Na amostra B, não foi possível adaptar a categorização de idade adotada pela organização para os estágios de carreira, impossibilitando a análise por essa variável.

Tabela 1

Expectativas de Conquistas Profissionais na Organização por Situação de Carreira e Sexo

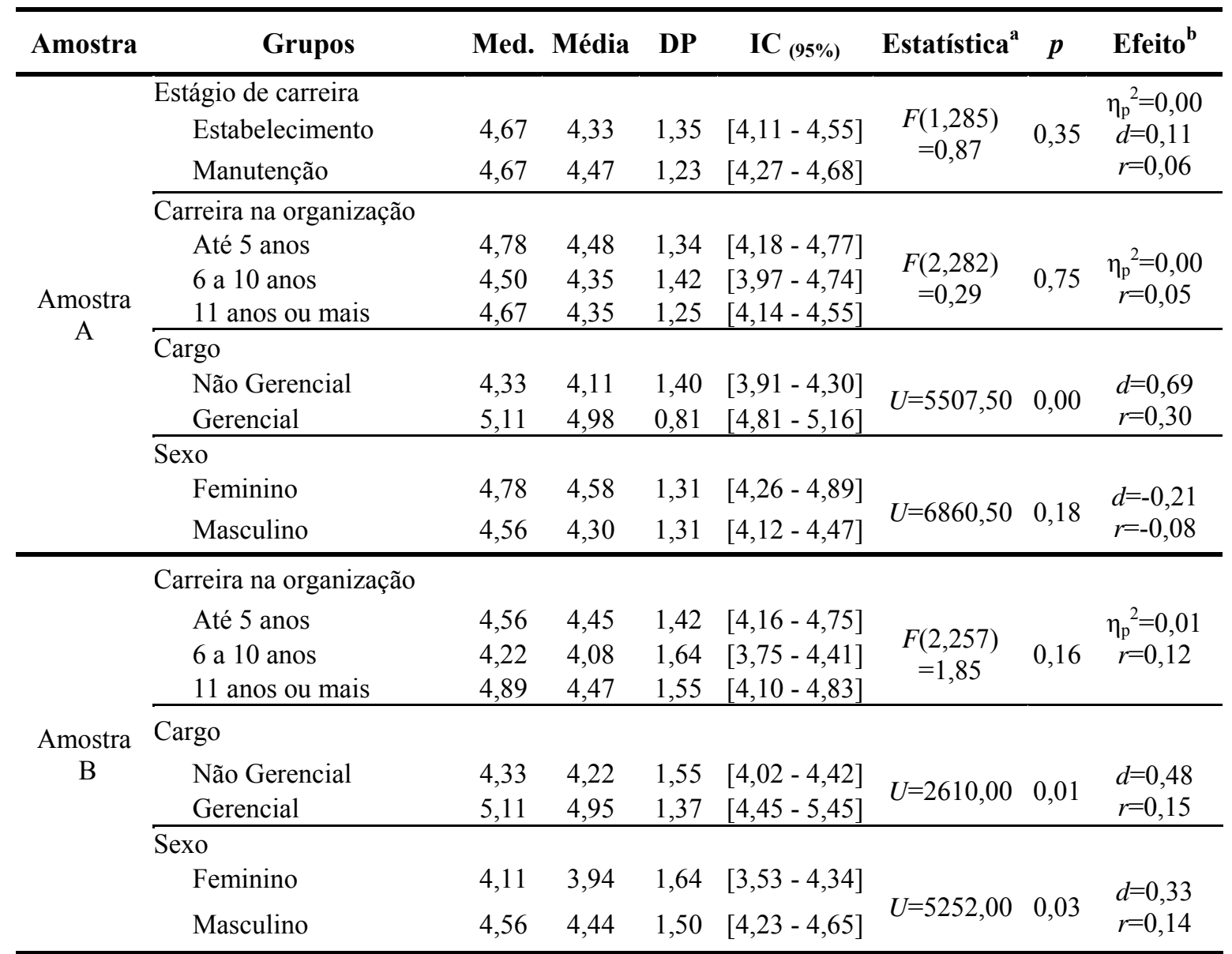

Nota. Med.=Mediana. $\mathrm{IC}_{(95 \%)}=$ Intervalo de Confiança de $95 \%$ da média. Amostra $\mathrm{A}=$ coletada em autarquia federal. Amostra $\mathrm{B}=$ coletada em empresa de economia mista.

${ }^{a}$ Estatísticas dos testes Mann-Whitney $(U)$ e análise de variância $(F)$. Os graus de liberdade estão entre parênteses.

${ }^{\mathrm{b}}$ Tamanho do efeito da diferença entre grupos. Foi utilizada a forma não enviesada de cálculo de $d$ (Cumming, 2012). Para one-way ANOVAs: $\eta_{\mathrm{p}}{ }^{2}=\eta^{2}$. 
A hipótese 1a não foi suportada: profissionais nos dois estágios de carreira manifestaram expectativas de carreira similares. Os dados também não apoiaram a hipótese 1 b. A relação entre expectativas de carreira e idade (como variável métrica), calculada apenas na amostra A, foi fraca e não significativa $(r=0,06 ; p=0,32)$, ao contrário da correlação negativa prevista.

A segmentação por tempo de carreira na organização, expressa na Tabela 1, respeitou a proposta de Ng e Feldman (2011). As diferenças entre as médias dos grupos não foram significativas em nenhuma das amostras, em oposição à hipótese 2a. Testada apenas na amostra A, a hipótese $2 b$, que indicava relação negativa entre tempo de organização (como variável métrica) e expectativas de carreira, também não se sustentou: $r=-0,02, p=0,68$.

Por outro lado, as duas amostras suportaram a hipótese 3: gerentes explicitaram expectativas de carreira na organização maiores do que não gerentes, sendo o tamanho do efeito maior na amostra da autarquia (magnitude moderada). A hipótese 4 obteve apoio parcial. Na amostra $\mathrm{A}$, homens e mulheres não diferiram estatisticamente nas expectativas de carreira. Contudo, na amostra B, os escores dos homens foram estatisticamente superiores aos das mulheres (considerando $\alpha=0,05$ ), embora o efeito tenha sido pequeno.

Em suma, apenas cargo exerceu claro efeito nas expectativas de carreira, resultado que converge com estudos pregressos. No caso de estágio de carreira e tempo de carreira na organização (assim como nas variáveis métricas correspondentes), havia dissenso na literatura. Os dados aqui relatados alinharam-se, ao contrário do previsto, às pesquisas que evidenciaram ausência de efeito. Finalmente, a análise por sexo reportou resultados contraditórios entre as duas amostras, espelhando a própria inconsistência da literatura no quadro geral das expectativas. Como estudos anteriores indicaram escores maiores dos homens especificamente nas expectativas de recompensas/remuneração, os itens sobre essa temática foram testados isoladamente quanto à diferença entre os grupos. Contudo, os dados não evidenciaram padrão dissonante nesses itens diante do escore consolidado do fator. 
Entre suas limitações, frisa-se que o Estudo 1 abarcou somente duas organizações, não analisou outras variáveis de situação de carreira e não examinou o impacto das variáveis independentes no segundo fator das expectativas de carreira. Tais limitações estimularam a realização do Estudo 2.

\section{Estudo 2}

Os Estudo 2 objetivou: a) testar se os resultados do Estudo 1 se replicavam em amostra independente e com maior número de organizações, b) verificar o impacto de duas novas variáveis de situação de carreira nas expectativas de carreira e c) analisar o efeito da situação de carreira no segundo fator das expectativas de carreira (Relação Carreira-Vida Pessoal). Não foram localizados na literatura construtos/instrumentos sobre expectativas atinentes à relação carreira-vida pessoal, o que dificultou a formalização de hipóteses específicas para esse fator. Neste particular, o Estudo 2 assumiu natureza exploratória.

Conforme exposto, o Estudo 2 analisa duas novas variáveis de situação de carreira. A primeira foi a obtenção ou não de conquistas de carreira recentes e significativas na organização, dado que denota percepção de evolução ou estagnação profissional. Tal variável oferece perspectiva diferente da simples informação sobre o cargo ocupado pelo profissional. Com efeito, a atividade gerencial não constitui a única forma de conquista na carreira; ademais, gerentes designados há bastante tempo e sem avanços recentes podem se sentir estagnados. Chen et al. (2011), fundamentados em desdobramentos da teoria dos prospectos (Kahneham, 1999), identificaram que mudanças recentes na satisfação com o trabalho predizem expectativas sobre a carreira e o ambiente de trabalho. Isto é, para além do atual patamar de satisfação, a mudança (melhoria ou piora) produz efeito nas expectativas. Propõese aqui testar essa dinâmica com mudanças na carreira ao invés de mudanças na satisfação no trabalho. Seguindo tais indicações, estabelece-se que: 
Hipótese 5 - Profissionais com conquistas de carreira significativas e recentes exibem expectativas de carreira (fator Conquistas Profissionais) maiores que os outros profissionais.

A segunda variável incluída no Estudo 2 foi a participação recente em programas de desenvolvimento de carreira. Nessa linha, profissionais de empresas que adotam tais programas (por exemplo, mentoria, coaching, rodízio técnico, sucessão gerencial, suporte para planejamento de carreira, entre outros) percebem mais oportunidades de conseguir atividades desafiadoras (Eby, Allen \& Brinley, 2005) e de crescer na carreira no futuro (Veloso et al., 2011). Essas duas pesquisas, contudo, aferiram se a organização do profissional ofertava tais práticas e não se o profissional, de fato, participava delas. A presente investigação avalia a relação da participação recente dos profissionais nessas práticas com suas expectativas de carreira. Baseado na literatura pregressa, conjectura-se que:

Hipótese 6 - Profissionais que participam ou participaram recentemente de programas de desenvolvimento de carreira exibem expectativas de carreira na organização (fator Conquistas Profissionais) maiores que os outros profissionais.

\section{Método}

\section{Participantes.}

Na amostra C $(n=352)$, a idade média foi de 42,26 anos $(\mathrm{DP}=12,57), 51 \%$ eram homens e 58\% não exerciam cargo gerencial. Os respondentes trabalhavam em diversas organizações, a maioria (55\%) na iniciativa privada. A distribuição nos estágios de carreira foi: estabelecimento (59\%) e manutenção (41\%). O tempo de organização médio foi de 8,44 anos $(\mathrm{DP}=8,42)$, com a seguinte divisão: até cinco anos (52\%), entre seis e 10 anos $(21 \%)$ e 11 anos ou mais (27\%). Todos os respondentes detinham escolaridade igual ou superior ao nível médio. Os participantes foram recrutados por consultoria especializada. O tamanho amostral superou o 
mínimo requerido para obter poder de $80 \%$ nos testes paramétricos e correlações, considerando $\alpha=0,05$ e expectativa de efeito pequeno para moderado (como $d=0,35, r=0,20$ e $\eta^{2}=0,04$ ).

\section{Procedimentos.}

A consultoria enviou correio eletrônico para os potenciais respondentes com um link para a página eletrônica da pesquisa (taxa de resposta de $25 \%$ ), na qual constavam as instruções e o questionário. Este foi respondido individualmente, de forma voluntária e anônima. Um incentivo de cerca de R \$ 15 reais foi concedido aos participantes.

\section{Instrumentos.}

O questionário incluiu, além dos itens sobre sexo, idade, tempo na organização e cargo ocupado, os dois fatores da EECO (Vasconcellos \& Neiva, 2015): Conquistas Profissionais (nove itens e $\alpha=0,95$ ) e Relação Carreira-Vida Pessoal (quatro itens e $\alpha=0,90$ ). Havia ainda duas questões dicotômicas (sim/não) referentes às novas variáveis de situação de carreira. Uma indagava se o respondente fazia atualmente parte ou se tinha participado, nos últimos dois anos, de programas de desenvolvimento de carreira. Em caso positivo, o respondente deveria citar o programa (exemplos indicados: rodízio técnico, coaching, mentoria, aconselhamento de carreira, cursos de alto impacto na carreira, entre outros). A análise dos programas citados confirmou a validade do item. A outra questão perguntava se o profissional tinha obtido alguma conquista de carreira significativa na organização nos últimos dois anos.

\section{Análises de Dados.}

Foram realizadas análises multivariadas de variância (MANOVA) para detectar eventuais diferenças na combinação linear dos escores dos fatores de expectativas de carreira (calculados como a média dos itens) em função das variáveis independentes. Como sugerem Hair, Black, Babin, Anderson e Tatham (2010), após as MANOVAs, o estudo foi complementado por ANOVAs separadas por variável dependente. Contudo, adotou-se nível de significância mais rigoroso $(\alpha=0,025)$ para conter a inflação do erro tipo I. Como apenas $20 \%$ dos respondentes 
participaram de programas de desenvolvimento de carreira, a MANOVA não foi aplicada nessa variável. Optou-se nesse caso por testes de Mann-Whitney, executados separadamente por variável dependente. Foram utilizados os mesmos programas estatísticos do Estudo 1.

\section{Resultados e Discussão}

Considerando as indicações de Hair et al. (2010) e Tabachnick e Fidell (2007), os dados atenderam os pressupostos requeridos para MANOVAs. Na primeira variável analisada, estágio de carreira, a MANOVA não indicou diferença significativa entre os grupos: $F(2,319)=2,20$, $p=0,11, \eta_{\mathrm{p}}{ }^{2}=0,01$. As ANOVAs realizadas para cada fator de expectativas de carreira (Tabela 2) apontaram efeitos de pequena magnitude e resultados acima do nível de significância adotado $(\alpha=0,025)$. Assume-se que os dados não apoiaram a hipótese 1a (diferença de expectativas no fator Conquistas Profissionais) e que esse padrão estendeu-se ao fator Relação Carreira-Vida Pessoal. A hipótese 1b também não foi suportada: a relação negativa de idade com expectativas de conquistas profissionais não se confirmou $(r=0,09, p=0,08)$. A correlação de idade com o fator Relação Carreira-Vida Pessoal foi de 0,13 ( $p=0,01)$. 
Tabela 2

Expectativas de Carreira na Organização por Situação de Carreira e Sexo

\begin{tabular}{|c|c|c|c|c|c|c|c|c|}
\hline $\begin{array}{l}\text { Fatores de } \\
\text { expectativas } \\
\text { de carreira }\end{array}$ & Grupos & Med. & Média & DP & IC $(95 \%)$ & $\begin{array}{c}\text { Estatística }^{\mathrm{a}} \\
(\mathrm{gl})\end{array}$ & $p$ & Efeito $^{b}$ \\
\hline \multirow{19}{*}{$\begin{array}{l}\text { Conquistas } \\
\text { Profissionais }\end{array}$} & Estágio de Carreira & & & & & \multirow{3}{*}{$\begin{array}{c}F(1,320) \\
=3,75\end{array}$} & \multirow{3}{*}{0,05} & \multirow{3}{*}{$\begin{aligned} \eta_{\mathrm{p}}{ }^{2} & =0,01 \\
d & =0,22 \\
r & =0,11\end{aligned}$} \\
\hline & Estabelecimento & 4,78 & 4,46 & 1,46 & {$[4,25-4,67]$} & & & \\
\hline & Manutenção & 5,00 & 4,77 & 1,29 & {$[4,55-4,99]$} & & & \\
\hline & Carreira na organização & & & & & \multirow{4}{*}{$\begin{array}{c}F(2,348) \\
=0,71\end{array}$} & \multirow{4}{*}{0,49} & \multirow{4}{*}{$\begin{aligned} \eta_{\mathrm{p}}{ }^{2} & =0,00 \\
r & =0,06\end{aligned}$} \\
\hline & Até 5 anos & 5,00 & 4,57 & 1,42 & {$[4,36-4,78]$} & & & \\
\hline & 6 a 10 anos & 5,06 & 4,74 & 1,36 & {$[4,42-5,05]$} & & & \\
\hline & 11 anos ou mais & 4,67 & 4,48 & 1,52 & {$[4,17-4,79]$} & & & \\
\hline & Cargo & & & & & \multirow{3}{*}{$\begin{array}{c}F(1,350) \\
=31,51\end{array}$} & \multirow{3}{*}{0,00} & \multirow{3}{*}{$\begin{aligned} \eta_{\mathrm{p}}{ }^{2} & =0,08 \\
d & =0,61 \\
r & =0,29\end{aligned}$} \\
\hline & Não Gerencial & 4,56 & 4,23 & 1,47 & {$[4,02-4,43]$} & & & \\
\hline & Gerencial & 5,44 & 5,06 & 1,23 & {$[4,86-5,26]$} & & & \\
\hline & Sexo & & & & & \multirow{3}{*}{$\begin{array}{c}F(1,350) \\
=7,21\end{array}$} & \multirow{3}{*}{0,01} & \multirow{3}{*}{$\begin{aligned} \eta_{\mathrm{p}}{ }^{2} & =0,02 \\
d & =0,29 \\
r & =0,14\end{aligned}$} \\
\hline & Feminino & 4,67 & 4,37 & 1,51 & {$[4,14-4,60]$} & & & \\
\hline & Masculino & 5,11 & 4,78 & 1,32 & {$[4,58-4,97]$} & & & \\
\hline & Conquistas recentes na carreira & & & & & \multirow{3}{*}{$\begin{array}{c}F(1,330) \\
=47,88\end{array}$} & \multirow{3}{*}{0,00} & \multirow{3}{*}{$\begin{aligned} \eta_{\mathrm{p}}{ }^{2} & =0,13 \\
d & =0,76 \\
r & =0,36\end{aligned}$} \\
\hline & Não & 4,06 & 4,01 & 1,51 & {$[3,77-4,25]$} & & & \\
\hline & Sim & 5,22 & 5,03 & 1,18 & {$[4,86-5,21]$} & & & \\
\hline & Desenvolvimento de carreira $^{c}$ & & & & & \multirow{3}{*}{$U=6702,50$} & \multirow{3}{*}{0,00} & \multirow{3}{*}{$\begin{array}{l}d=0,54 \\
r=0,22\end{array}$} \\
\hline & Não & 4,78 & 4,43 & 1,45 & {$[4,26-4,60]$} & & & \\
\hline & Sim & 5,44 & 5,19 & 1,17 & {$[4,91-5,47]$} & & & \\
\hline \multirow{19}{*}{$\begin{array}{l}\text { Relação } \\
\text { Carreira e } \\
\text { Vida Pessoal }\end{array}$} & Estágio de carreira & & & & & \multirow{3}{*}{$\begin{array}{c}F(1,320) \\
=3,71\end{array}$} & \multirow{3}{*}{0,06} & \multirow{3}{*}{$\begin{aligned} \eta_{\mathrm{p}}{ }^{2} & =0,01 \\
d & =0,22 \\
r & =0,11\end{aligned}$} \\
\hline & Estabelecimento & 5,00 & 4,76 & 1,48 & {$[4,55-4,97]$} & & & \\
\hline & Manutenção & 5,25 & 5,06 & 1,19 & {$[4,86-5,26]$} & & & \\
\hline & Carreira na organização & & & & & & & \\
\hline & Até 5 anos & 5,00 & 4,87 & 1,40 & {$[4,67-5,08]$} & \multirow{3}{*}{$\begin{array}{c}F(2,348) \\
=0,14\end{array}$} & \multirow{3}{*}{0,87} & \\
\hline & 6 a 10 anos & 5,13 & 4,96 & 1,33 & {$[4,66-5,27]$} & & & $\begin{aligned} \eta_{\mathrm{p}} & =0,00 \\
r & =0,03\end{aligned}$ \\
\hline & 11 anos ou mais & 5,00 & 4,86 & 1,36 & {$[4,59-5,14]$} & & & \\
\hline & Cargo & & & & & & & $\eta_{\mathrm{p}}{ }^{2}=0,02$ \\
\hline & Não Gerencial & 5,00 & 4,74 & 1,35 & {$[4,55-4,93]$} & $F(1,550)$ & 0,02 & $d=0,26$ \\
\hline & Gerencial & 5,25 & 5,09 & 1,37 & {$[4,87-5,32]$} & & & $r=0,13$ \\
\hline & Sexo & & & & & & & $\eta_{\mathrm{p}}{ }^{2}=0,01$ \\
\hline & Feminino & 5,00 & 4,76 & 1,42 & {$[4,55-4,98]$} & $\begin{array}{c}F(1,550) \\
=300\end{array}$ & 0,08 & $d=0,19$ \\
\hline & Masculino & 5,25 & 5,01 & 1,31 & {$[4,82-5,20]$} & & & $r=0,09$ \\
\hline & Conquistas recentes na carreira & & & & & & & $\eta_{\mathrm{p}}^{2}=0,03$ \\
\hline & Não & 4,75 & 4,64 & 1,34 & {$[4,43-4,85]$} & $F(1,350)$ & 0,00 & $d=0,36$ \\
\hline & Sim & 5,25 & 5,12 & 1,37 & {$[4,92-5,32]$} & & & $r=0,17$ \\
\hline & Desenvolvimento de carreira $^{c}$ & & & & & & & \\
\hline & Não & 5,00 & 4,85 & 1,38 & {$[4,69-5,01]$} & $U=8737,00$ & 0,17 & $\begin{array}{l}d=0,15 \\
r=0,07\end{array}$ \\
\hline & Sim & 5,25 & 5,06 & 1,31 & {$[4,75-5,38]$} & & & \\
\hline
\end{tabular}

Nota. Med.=Mediana. IC ${ }_{(95 \%)}=$ Intervalo de confiança de $95 \%$.

${ }^{a}$ Estatísticas dos testes Mann-Whitney $(U)$ e análise de variância $(F)$.

${ }^{\mathrm{b}}$ Tamanho do efeito da diferença entre os grupos calculado com base nas estatísticas $F$ e $U$. Foi utilizada a forma não enviesada de cálculo de $d$ (Cumming, 2012). Para one-way ANOVAs: $\eta_{\mathrm{p}}{ }^{2}=\eta^{2}$.

${ }^{\mathrm{c}}$ Participação recente em práticas de desenvolvimento de carreira. 
A MANOVA não indicou diferença significativa nos grupos divididos por tempo de carreira na organização: $F(4,696)=0,41, p=0,80, \eta_{\mathrm{p}}{ }^{2}=0,00$. As ANOVAs individuais (Tabela 2) desvelaram ausência de efeito nos dois fatores de expectativas de carreira. Portanto, não houve suporte para a hipótese 2a (trabalhadores no estágio inicial de carreira na organização detêm expectativas de conquistas profissionais maiores do que os demais). A hipótese $2 b$ seguiu o mesmo caminho: a correlação de tempo de carreira na organização com expectativas de conquistas profissionais foi baixa $(r=-0,04, p=0,43)$ e com expectativas sobre a relação carreira-vida pessoal foi nula $(r=0,00, p=0,94)$.

Contudo, a MANOVA executada por cargo acusou a influência dessa variável nas expectativas de carreira: $F(2,349)=17,45, p<0,00, \eta_{\mathrm{p}}{ }^{2}=0,09$. As ANOVAs separadas (Tabela 2) corroboraram a hipótese 3 (gerentes apresentaram expectativas de conquistas profissionais maiores do que não gerentes) e evidenciaram diferenças significativas, na mesma direção, no fator Relação Carreira-Vida Pessoal. Neste último caso, trata-se de resultado instigante, haja vista que a literatura pontua que gerentes detêm jornada e carga de trabalho elevadas, o que poderia ocasionar conflito na relação entre carreira e vida pessoal.

Homens apresentaram escores mais elevados do que mulheres na combinação das variáveis de expectativas de carreira: $F(2,349)=3,60, p=0,03, \eta_{\mathrm{p}}{ }^{2}=0,02$. Conforme Tabela 2 , a diferença é mais saliente nas expectativas de conquistas profissionais (a Hipótese 4 foi suportada) do que nas expectativas sobre a relação carreira-vida pessoal.

Profissionais que vivenciaram conquistas recentes na carreira (51\% do total) exibiram expectativas maiores do que os demais profissionais na combinação dos fatores: $F(2,349)=25,75, p<0,00, \eta_{\mathrm{p}}{ }^{2}=0,14$. Esse padrão replica-se nas ANOVAs individuais (Tabela 2), mas o efeito é maior no fator Conquistas Profissionais, em suporte à hipótese 5. Profissionais que participam ou participaram recentemente de programas de desenvolvimento de carreira revelaram expectativas de conquistas profissionais maiores do que os outros 
profissionais (sustentando a hipótese 6). Contudo, o efeito da variável nas expectativas sobre a relação carreira-vida pessoal foi fraco e não significativo. As novas variáveis de situação de carreira introduzidas no Estudo 2 mostraram efeito considerável nas expectativas de conquistas profissionais, resultado na mesma direção de estudos anteriores que averiguaram questões assemelhadas (Chen et al., 2011; Eby et al., 2005; Veloso et al., 2011).

Além da apreciação dessas novas variáveis, o Estudo 2 possibilitou outra forma de análise: a comparação das médias dos fatores dentro de cada grupo. A Figura 1 demonstra que, embora os dois fatores apresentem escores similares nos gerentes, o mesmo padrão não ocorre nos não gerentes (as expectativas de conquistas profissionais são mais baixas). Por sua vez, participantes de programas de desenvolvimento de carreira exibiram expectativas de conquistas profissionais tão elevadas que superam (em valores absolutos) as expectativas sobre a relação carreira-vida pessoal (Figura 1). Esse padrão se inverte entre aqueles que não participaram desses programas.
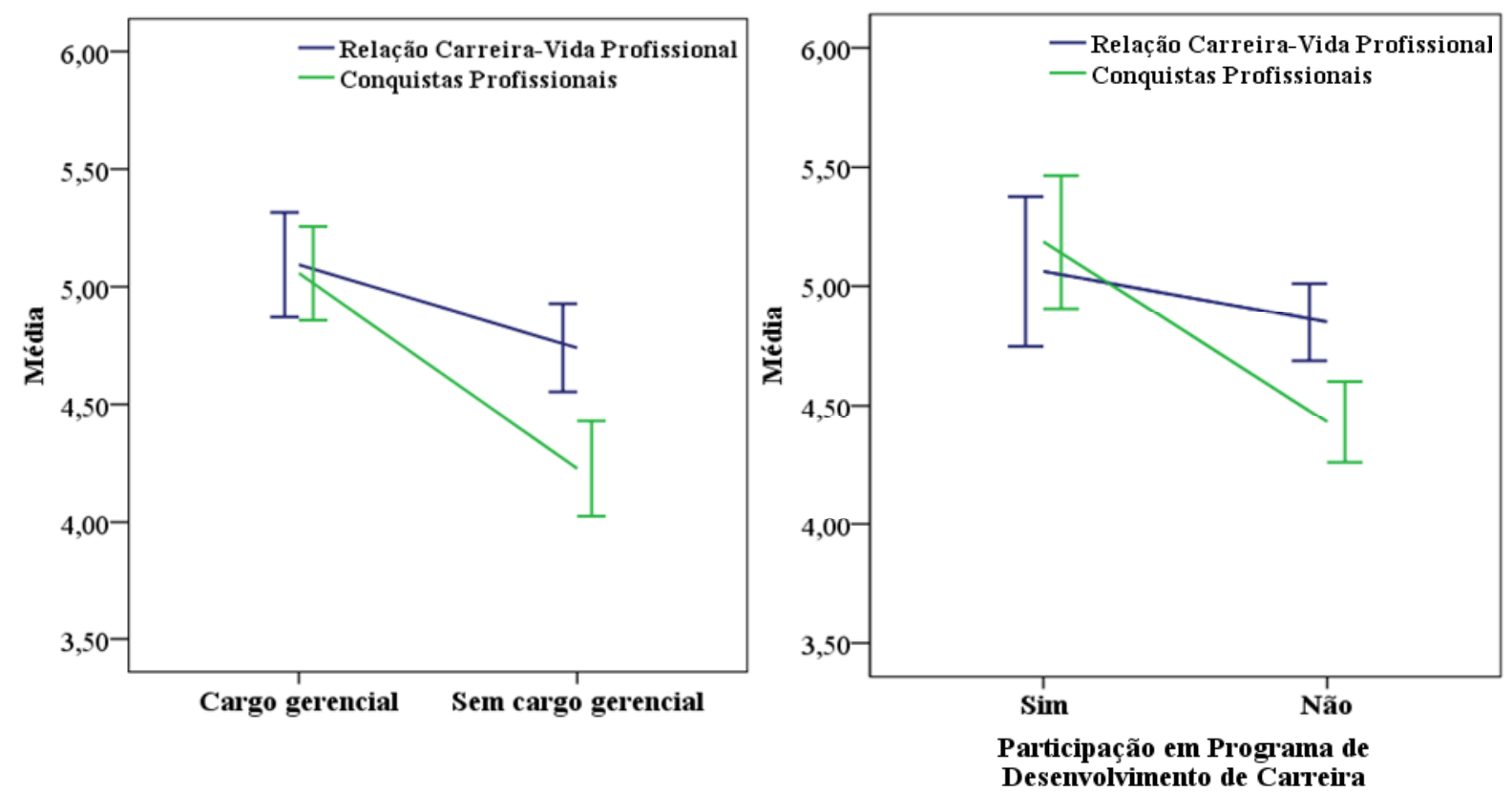

Figura 1. Médias e intervalos de confiança (95\%) dos fatores de expectativas de carreira em função do cargo ocupado e da participação recente em programas de desenvolvimento de carreira. 


\section{Síntese dos Estudos e Meta-Análise}

O Estudo 2 replicou os resultados do Estudo 1 sobre as diferenças de expectativas de conquistas profissionais por estágio de carreira/idade, tempo de carreira na organização e cargo. No caso de sexo, os dados do Estudo 2 alinharam-se àqueles obtidos na amostra $\mathrm{B}$ do Estudo 1 (homens com média mais elevada). Todavia, na amostra A do Estudo 1, as mulheres exibiram média maior, embora a diferença não tenha sido estatisticamente significativa.

Como os resultados referentes ao fator Conquistas Profissionais foram apurados em três amostras, optou-se por executar uma meta-análise de pequeno porte no intuito de se obter maior precisão nas estimativas dos efeitos. Os cálculos seguiram as orientações de Cumming (2012) e foram executados por modelos de efeitos randômicos nos programas Exploratory Software for Confidence Intervals e Comprehensive Meta Analysis. A meta-análise combinou os valores não enviesados do $d$ de Cohen (Tabelas 1 e 2) referentes às diferenças entre grupos.

Para a hipótese 1a (relação entre estágio de carreira e expectativas), os estudos registraram efeito inexistente (amostra A) e efeito fraco (Amostra C). A meta-análise contou só com essas duas amostras (a variável não foi aferida na amostra B), perfazendo o total de 609 respondentes. O resultado encontrado, $d=0,17,[0,01-0,33]$, insere-se na faixa de ausência de efeito (Cohen, 1992). A hipótese 2a, que previa diferenças nas expectativas por tempo de carreira na organização, apresentou efeito inexistente nas três amostras $\left(\eta_{\mathrm{p}}{ }^{2}\right.$ máximo foi de 0,01$)$. A metaanálise não foi realizada nessa variável, pois a análise par a par dos três grupos seria laboriosa e injustificada considerando a inexistência de efeito geral.

Na variável cargo ocupado, as amostras B, C e A indicaram, respectivamente, efeitos fraco para moderado, moderado e moderado para forte. A combinação meta-analítica (Figura 2) consolidou o efeito como moderado (corroborando a hipótese 3 ) e reduziu o intervalo de confiança, provendo mais clareza na interpretação dos dados. O intervalo de confiança coincide quase perfeitamente com os limites propostos por Cohen (1992) para essa faixa de efeito. 


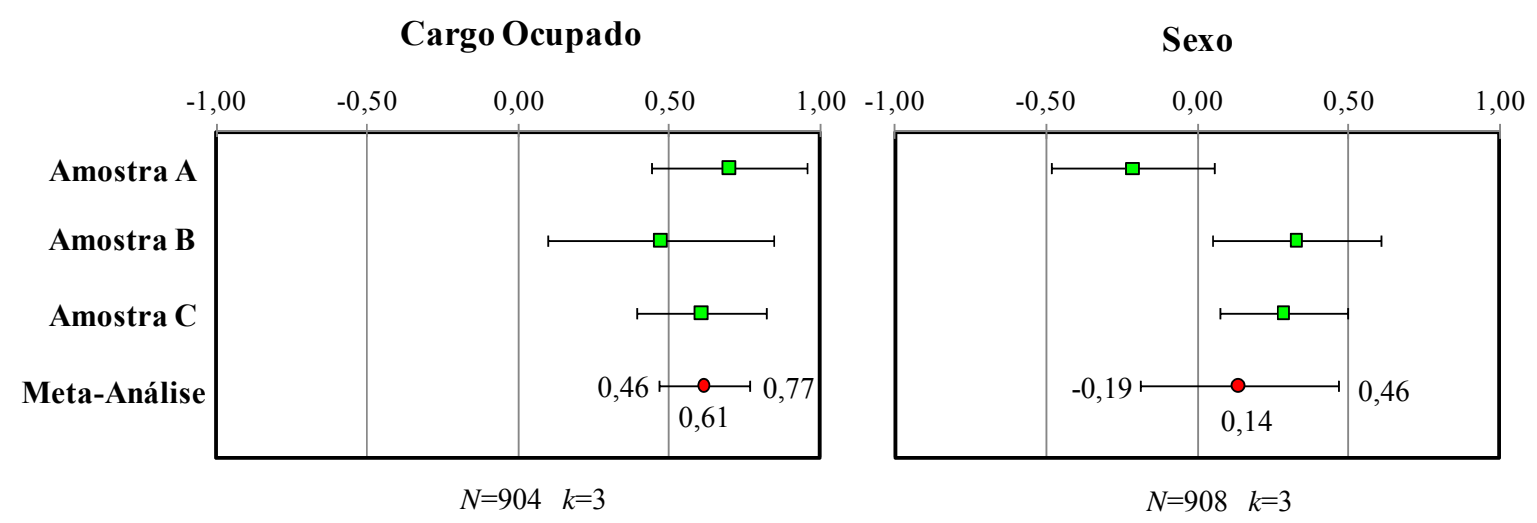

Figura 2. Meta-análise de efeitos randômicos da diferença de médias do fator Conquistas Profissionais ( $d$ de Cohen não enviesado e intervalo de confiança de $95 \%$ ) entre os grupos das variáveis cargo ocupado e sexo. Valores positivos indicam médias maiores para gerentes e homens. Amostra $\mathrm{A}=$ autarquia federal; Amostra $\mathrm{B}=$ empresa de economia mista; Amostra $\mathrm{C}=$ múltiplas organizações. $N=$ tamanho da amostra acumulada e $k=$ número de amostras.

Na variável sexo, a amostra $\mathrm{A}$ apontou expectativas mais elevadas nas mulheres, mas com efeito fraco e não significativo. As amostras B e C também assinalaram efeitos fracos, porém, significativos e na direção oposta. A combinação meta-analítica (Figura 2) redundou em efeito praticamente nulo (Cohen, 1992), com intervalo de confiança englobando o zero. Com base na estimativa de efeito da meta-análise, firma-se que a hipótese 4 não encontrou apoio empírico.

Como informação adicional, as médias do fator Conquistas Profissionais e de seus itens foram combinadas por meta-análise (Figura 3). Ao aplicar a EECO em suas organizações, profissionais de RH podem utilizar tal referência na interpretação de seus resultados.

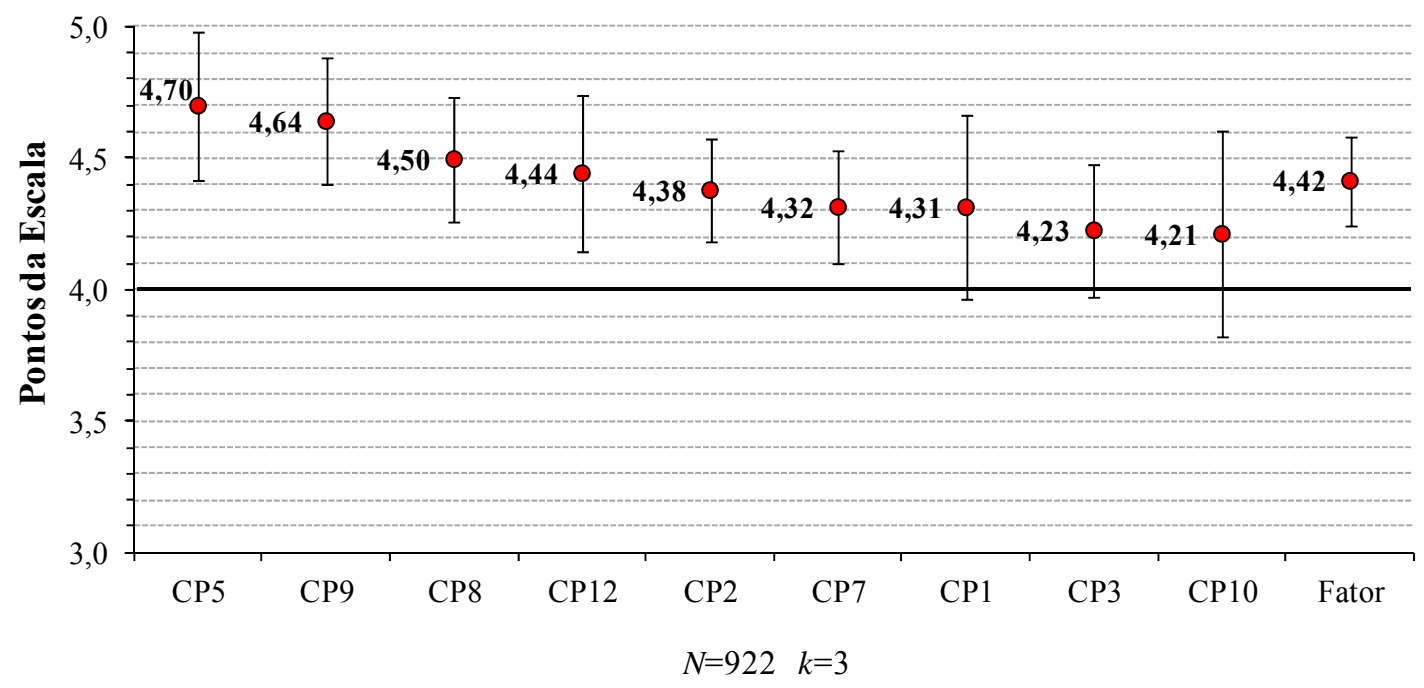

Figura 3. Meta-análise das médias e intervalos de confiança (95\%) dos itens e do fator Conquistas Profissionais. A escala contém sete pontos. $N=$ tamanho da amostra acumulada; $k=$ número de amostras. $\mathrm{CP} 1=$ Terei conseguido conquistas profissionais relevantes na minha carreira. 
$\mathrm{CP} 2=$ Serei bem remunerado em relação às minhas responsabilidades profissionais.

CP3=Minha remuneração será compatível com minhas expectativas de salário para esse período.

CP5=Terei prestígio entre meus colegas em função do trabalho realizado.

$\mathrm{CP} 7=$ Estarei satisfeito com o progresso da minha carreira.

CP8=Atingirei meus objetivos de carreira estabelecidos para esse período.

CP9=Serei um profissional bem-sucedido na minha carreira.

$\mathrm{CP} 10=$ Minhas atividades profissionais serão mais interessantes do que hoje.

CP12=Realizarei um trabalho compatível com minhas preferências profissionais.

As estimativas pontual e intervalar da média do fator superam o ponto médio da escala (4), denotando expectativas relativamente positivas. As estimativas pontuais ultrapassam o ponto médio da escala em todos os itens. Entretanto, as estimativas intervalares dos três itens com as médias mais baixas romperam esse patamar. Cumpre observar que há sobreposição nos intervalos de confiança de todos os itens indicando, de forma geral, proximidade em seus patamares.

\section{Discussão Geral}

Os resultados evidenciaram efeitos dessemelhantes das variáveis independentes nas expectativas de conquistas profissionais na organização. No caso de estágio de carreira/idade e tempo de carreira na organização, os dados filiam-se aos estudos que descrevem ou propõem relação fraca/inexistente entre essas variáveis e expectativas de carreira na organização (Chay \& Aryee, 1999; Chen et al., 2011; Gibson \& Lawrence, 2010; O’Neill et al., 2011; Vasconcellos \& Neiva, 2014). Nessa linha, se há fatores que tendem a elevar expectativas nos jovens e recém-contratados (como a percepção de futuro ilimitado e a "lua de mel" com a organização), existem igualmente elementos que favorecem as expectativas dos mais velhos e antigos na organização (maior experiência, alto desempenho e rede de contatos ampliada). No cenário contemporâneo, as aposentadorias são mais tardias, o que desafia as áreas de RH na temática da gestão de carreira. A presente pesquisa indica que expectativas favoráveis de carreira não se limitam aos mais jovens e recém-admitidos.

A relação do sexo do respondente com as expectativas de carreira é controversa na literatura. O resultado meta-analítico, particularmente útil para sintetizar os resultados relativamente discrepantes encontrados, sugere que, malgrado o fenômeno do teto de vidro citado 
na literatura (Cook \& Glass, 2014; Olidi et al., 2013), as expectativas de carreira não diferem substancialmente entre homens e mulheres. É possível que a atual discussão na sociedade e nas organizações sobre equidade de gênero esteja finalmente rendendo frutos.

Por outro lado, o cargo ocupado exerceu considerável efeito nas expectativas de conquistas profissionais. Nas análises, gerentes obtiveram médias mais elevadas que não gerentes, conforme estudos prévios (De Souza, 2002; Gibson \& Lawrence, 2010; Veloso et al., 2011). Gerentes tendem a apresentar autoavaliação profissional positiva, acesso privilegiado a informações e grande rede de contatos. Surpreendentemente, a jornada elevada e a intensa carga de trabalho dos gerentes, sugeridas na literatura, não se desdobraram em expectativas desfavoráveis sobre a relação carreira-vida pessoal, resultado que talvez reflita a maior autonomia e liberdade dos gerentes para programar e conduzir suas atividades profissionais.

A obtenção de avanços recentes na carreira também influenciou as expectativas de conquistas profissionais. Esse resultado complementa a pesquisa de Chen et al. (2011) que identificou que melhorias recentes na satisfação com o trabalho aumenta expectativas de carreira. A presente pesquisa sinalizou que avanços (melhorias) recentes especificamente na carreira parecem atuar na mesma direção. Por sua vez, participantes em programas de desenvolvimento de carreira detêm expectativas de conquistas profissionais mais positivas. Esse resultado era esperado, posto que tais programas tendem a qualificar seus participantes e a abrir novos horizontes para o futuro profissional.

Esta pesquisa contribui para a literatura, primeiramente, ao analisar em que medida os resultados citados na literatura internacional sobre a temática em pauta vigoram no contexto nacional. Contribui também ao empregar um instrumento que abarca, além de vários atributos de expectativas de conquistas profissionais, expectativas específicas sobre a relação carreiravida pessoal. Em geral, as pesquisas trabalham com apenas um atributo (expectativas salariais, por exemplo), fornecendo um quadro limitado do fenômeno. 
Entre suas contribuições práticas, o estudo aborda e analisa tópico relevante na gestão de $\mathrm{RH}$, qual seja, as semelhanças/dessemelhanças entre grupos de profissionais acerca de suas expectativas de carreira. Os dados foram repassados para as organizações pesquisadas como insumo para suas políticas e práticas de gestão. Ademais, a meta-análise das médias dos itens e do escore do fator Conquista Profissionais fornece, aos profissionais de RH de outras organizações, referências preliminares para interpretar os resultados da EECO. Embora essa meta-análise contenha apenas três estudos, novos resultados podem ser incorporados a essa base a fim de se obter estimativas mais precisas do cenário nacional.

Entre as limitações da pesquisa, sublinha-se a impossibilidade de derivar relações causais, a aferição das variáveis via autorrelato e o corte transversal da pesquisa. Sobre os participantes, embora as amostras A e B tenham sido geradas de listas aleatórias das organizações, a amostra $\mathrm{C}$ não passou por esse tipo de controle. Outra limitação refere-se à ausência, na pesquisa, de variáveis que podem exercer papel significativo nas expectativas de carreira, tais como traços de personalidade, desempenho no trabalho, políticas/práticas de RH e expectativas sobre o futuro da organização. Investigações futuras devem considerar o efeito dessas variáveis nas expectativas de carreira, assim como avaliar se estágio de carreira e tempo de carreira na organização (variáveis com efeito pequeno/nulo) atuam como moderadores dessas relações.

Por fim, se o futuro na carreira está entre as características mais valorizadas por trabalhadores em organizações (Tolfo, 2002), tal assunto não pode ser preterido. Mesmo que contrariem suposições iniciais, análises sobre o tema podem subsidiar as organizações com informações úteis para a formulação de políticas/práticas organizacionais. A presente pesquisa deu um passo nessa direção. Espera-se que tanto a academia quanto as organizações invistam cada vez mais em estudos sobre desenvolvimento e expectativas de carreira. 


\section{Referências}

Barnett, R. (2004). Women and work: where are we, where did we come from, and where are we going. Journal of Social Issues, 60(4), 667-674.

Chay, Y. \& Aryee, S. (1999). Potential moderating influence of career growth opportunities on careerist orientation and work attitudes: Evidence of the protean career era in Singapore. Journal of Organizational Behavior, 20(5), 613-623.

Chen, G., Ployhart, R., Cooper-Thomas, H., Anderson, N., \& Bliese, P. (2011). The power of momentum: A new model of dynamic relationships between job satisfaction change and turnover intentions. Academy of Management Journal, 54, 159-181.

Coetzee, M. (2012). Distance learning students' graduateness as predictors of their job satisfaction and optimism about future career prospects. Journal of Social Sciences, 33(3), 305-313.

Cohen, A. (1991). Career stage as a moderator of the relationships between organizational commitment and its outcomes: A meta-analysis. Journal of Occupational Psychology, 64(3), 253-268.

Cohen, J. (1992). A power primer. Psychological Bulletin, 112(1), 155-159.

Cook, A. \& Glass, C. (2014). Women and top leadership positions: towards an institutional analysis. Gender, Work \& Organization, 21(1), 91-103.

Cumming, G. (2012). Understanding the new statistics: Effect sizes, confidence intervals, and meta-analysis. New York: Routledge.

Darcy, C., McCarthy, A., Hill, J. \& Grady, G. (2012). Work-life balance: One size fits all? An exploratory analysis of the differential effects of career stage. European Management Journal, 30(2), 111-120. 
De Souza, G. (2002). A Study of the Influence of Promotions on Promotion Satisfaction and Expectations of Future Promotions among Managers. Human Resource Development Quaterly, 13(3), 325-340.

Eby, L. T., Allen, T. D., \& Brinley, A. (2005). A cross-level investigation of the relationship between career management practices and career-related attitudes. Group and Organization Management, 30, 565-596.

Fast, N., Gruenfeld, D., Sivanathan, N. \& Galinsky, A. (2009). Illusory control a generative force behind power's far-reaching effects. Psychological Science, 20(4), 502-508.

Field, A. (2009). Discovering statistics using SPSS. Thousand Oaks, CA: Sage.

Gibson, D. \& Lawrence, B. (2010). Women's and men's career referents: how gender composition and comparison level shape career expectations. Organization Science, 21, 1159-1175.

Greenhaus, J., Callanan, G. \& Godshalk, V. (1999). Career management. Orlando: Harcourt. Hair, J.F., Black, W., Babin, B., Anderson, R. \& Tatham, R. (2010). Multivariate Data Analysis (sétima edição). Upper Saddle River, NJ: Prentice Hall.

Hall, D. (2002). Careers in and out of organizations. London: Sage Publications Series. Jans, N. (1989). Organizational commitment, career factors and career/life stage. Journal of Organizational Behavior, 10(3), 247-266.

Judge, T. \& Kammeyer-Mueller, J. (2012). Job attitudes. Annual Review of Psychology, 63, 341-367.

Kahneman, D. (1999). Objective happiness. In D. Kahneman, E. Diener, \& N. Schwartz (Eds.). Well-being: The foundations of hedonic psychology (pp. 3-25). New York: Sage.

Kahneman, D. \& Lovallo, D. (1993). Timid choices and bold forecasts: A cognitive perspective on risk taking. Management Science, 39(1), 17-31.

Lang, F. \& Carstensen, L. (2002). Time counts: Future time perspective, goals, and social relationships. Psychology \& Aging, 17(1), 125-139. 
Lima, G., Neto, A. \& Tanure, B. (2012). Executivos jovens e seniores no topo da carreira: conflitos e complementaridades. Revista Eletrônica de Administração, 18, 63-96.

Magalhães, M. (2005). Personalidades vocacionais e desenvolvimento na vida adulta: generatividade e carreira profissional (Tese de Doutorado). Universidade Federal do Rio Grande do Sul, Rio Grande do Sul.

Mintzberg, H. (1990). The manager's job: folklore and fact. Harvard Business Review, 68, 163-176.

Ng, T. \& Feldman, D. (2010). Organizational tenure and job performance. Journal of Management, 36(5), 1220-1250.

Ng, T. \& Feldman, D. (2011). Affective organizational commitment and citizenship behavior: Linear and non-linear moderating effects of organizational tenure. Journal of Vocational Behavior, 79(2), 528-537.

O'Neill, O., Stanley, L. \& O'Reilly, C. (2011). Disaffected Pollyannas: The influence of positive affect on salary expectations, turnover, and long-term satisfaction. Journal of Occupational and Organizational Psychology, 84, 599-617.

Olidi, C., Parejo, S. \& Padilla, S. (2013). ¿Entre Obstáculos Anda el Camino? Trayectoria y Mujer Directiva. Revista Psicologia: Organizações e Trabalho, 13, 75-88.

Stroh, L. \& Reilly, A. (1997). Rekindling Organizational Loyalty: The Role of Career Mobility. Journal of Career Development, 24, 39-54.

Super, D. (1980). The life span, life space approach to career development. Journal of Vocational Behavior, 16, 282-298.

Tabachnick, B. \& Fidell, L. (2007). Using multivariate statistics. Boston: Pearson.

Taormina, R. (1997). Organizational socialization: A multidomain, continuous process model. International Journal of Selection and Assessment, 5(1), 29-47.

Tolfo, S. (2002). Carreira Profissional e seus movimentos: Revendo conceitos e formas de gestão. Revista: Psicologia, Organizações e Trabalho, 2(2), 39-63. 
Treadway, D., Breland, J., Adams, G., Duke, A. \& Willians, L. (2010). The interactive effects of political skill and future time perspective on career and community networking behavior. Social Networks, 32, 138-147.

Vasconcellos, V.\& Neiva, E. (2014). Avaliação de futuro profissional e sua relação com bem-estar no trabalho e intenção de desligamento. Gestão e Planejamento, 15, 410-427.

Vasconcellos, V. \& Neiva, E. (2015). Escala de Expectativas de Carreira na Organização: Desenvolvimento e Evidências de Validade. Manuscrito em preparação para submissão.

Veloso, E., Dutra, J., Fischer, A., Pimentel, J., Silva, R. \& Amorim, W. (2011). Gestão de carreiras e crescimento profissional. Revista Brasileira de Orientação Profissional, 12, 6172.

Wright, T. \& Bonett, D. (2002). The moderating effects of employee tenure on the relation between organizational commitment and job performance: a meta-analysis. Journal of Applied Psychology, 87(6), 1183-1190.

Zacher, H. \& Frese, M. (2011). Maintaining a focus on opportunities at work: The interplay between age, job complexity, and the use of selection, optimization, and compensation strategies. Journal of Organizational Behavior, 32, 291-318. 


\section{MANUSCRITO 6}

O Manuscrito 6 comporta o primeiro modelo de equações estruturais testado na tese. Trata-se de um estudo que se alinha à proposta do Manuscrito 5 de analisar variáveis que influenciam a emergência de expectativas positivas de carreira na organização. Todavia, o Manuscrito 6 submete à prova outras variáveis antecedentes, tais como percepções de políticas e práticas de recursos humanos $(\mathrm{RH})$, bem-estar no trabalho e as próprias expectativas de futuro organizacional, variável já abordada em outros manuscritos da tese. Neste modelo, bem-estar no trabalho e percepções de políticas e práticas de RH também são avaliadas como antecedentes de expectativas de futuro organizacional. Considerando as possibilidades oferecidas pelos modelos de equações estruturais, as relações entre as variáveis foram submetidas a testes de mediação e moderação, enriquecendo sobremaneira as análises. 


\section{MANUSCRITO 6}

Como Será o Amanhã? Examinando Antecedentes

de Expectativas de Carreira na Organização

What Tomorrow Brings? Examining Antecedents of Career Expectations in the Organization

Vinicius Carvalho de Vasconcellos

Universidade de Brasília 
Resumo

A questão “Como será meu futuro nesta organização?” é parte relevante da vida laboral da maioria dos profissionais empregados. Assumindo tal relevância, esta pesquisa testou um modelo no qual percepções de políticas e práticas de recursos humanos $(\mathrm{RH})$, bem-estar no trabalho e expectativas de futuro organizacional atuavam como antecedentes de expectativas de carreira na organização. A amostra de 305 profissionais, obtida em uma autarquia federal, respondeu a um questionário com diversas escalas validadas no país. Os resultados, obtidos por modelos de equações estruturais, apontaram que os efeitos diretos de bem-estar no trabalho e de expectativas de futuro organizacional nas expectativas de carreira foram positivos e de magnitude moderada, no primeiro caso, e forte, no segundo. $\mathrm{O}$ efeito de percepções de políticas e práticas de RH nas expectativas de carreira foi totalmente mediado por bem-estar no trabalho e expectativas de futuro organizacional. Em complemento, o teste de moderação via análise multigrupo sugere que o efeito de bem-estar no trabalho nas expectativas de carreira é maior entre os veteranos na organização e que o efeito de expectativas de futuro organizacional nas expectativas de carreira é maior entre os não veteranos. A discussão traz interpretações sobre os resultados encontrados e sinaliza possibilidades de pesquisas futuras.

Palavras-chave: carreira, expectativas, futuro organizacional, recursos humanos, bem-estar no trabalho

\begin{abstract}
The question "What will my future be in this organization?" is an important part of working life of most employees. Considering such importance, this study tested a model in which perceptions about policies and practices of human resources management (HRM), well-being at work and organizational future expectations act as antecedents of career expectations in the organization. The sample of 305 professionals (from a government agency) answered a questionnaire with several scales validated in Brazil. The results, obtained by structural equation models, indicate that the direct effects of well-being at work and organizational future expectations on career expectations were positive with moderate size (in the first case) and strong size (in the second case). The effect of perceptions about policies and practices of HRM on career expectations was fully mediated by well-being at work and organizational future expectations. In addition, the moderation test via multi-group analysis suggests that the effect of well-being at work on career expectations is higher in veterans (high organizational tenure) and that the effect of organizational future expectations on career expectations is higher in non veterans (low/medium organizational tenure). The discussion brings interpretations of the results and indicates future research possibilities.
\end{abstract}

Keywords: career, expectations, organizational future, human resources, well-being at work 
O desenvolvimento de carreira passou por substanciais mudanças nas últimas décadas. Transformações socioeconômicas e nos modelos de gestão das organizações desembocaram em um cenário no qual as trajetórias de carreira tornaram-se imprevisíveis, não lineares e marcadas por constantes mudanças (Guest \& Sturges, 2007; Magalhães \& Bendassolli, 2013; Prince, 2003). Assim, se durante grande parte do século XX a tendência era os profissionais permanecerem longo tempo na mesma organização, realizando as mesmas atividades e conhecendo de antemão cada etapa da evolução na carreira, agora, torna-se cada vez mais difícil encontrar roteiros pré-estabelecidos.

Dada a imprevisibilidade do percurso profissional, o futuro na carreira transmuda-se em um projeto aberto, fonte de preocupação e alvo de constante monitoramento. Com efeito, a interrogação “Como será meu futuro nesta organização?” torna-se uma questão-chave, de sorte que perspectivas de desenvolvimento/crescimento na carreira despontam entre as características mais valorizadas por trabalhadores em organizações (Tolfo, 2002).

Focalizando indivíduos empregados, pesquisas empíricas já revelaram a importância do futuro na carreira na relação indivíduo-trabalho-organização. Nessa linha, expectativas e percepções de futuro na carreira figuram como antecedentes de comprometimento organizacional, envolvimento e desempenho no trabalho, intenções de desligamento e desligamento (Chay \& Aryee, 1999; G. Chen, Ployhart, Cooper-Thomas, Anderson \& Bliese, 2011; Kraimer, Seibert, Wayne, Liden \& Bravo, 2011; Prince, 2003; Stroh \& Reilly, 1997; Zacher, Heusner, Schmitz, Zwierzanska \& Frese, 2010).

Se a forma como os indivíduos projetam o futuro na carreira opera papel relevante na ligação dos profissionais com seu trabalho e organização, cumpre interrogar sobre os elementos que a influenciam. Surpreendentemente, investigações que adotam expectativas e percepções de futuro na carreira como variável dependente são relativamente escassas, de modo que seus antecedentes ainda permanecem elusivos. 
Partindo desses pontos, este artigo testou um modelo de antecedentes de expectativas de carreira na organização, definidas como crenças dos indivíduos sobre sua futura trajetória profissional na atual organização (Vasconcellos \& Neiva, 2015a). Ao tratar de expectativas isto é, crenças sobre o futuro provável (Oettingen \& Mayer, 2002) - esta investigação diferencia-se de estudos sobre carreira voltados para variáveis orientadas para o presente (como satisfação com a carreira) ou para o futuro desejado e ideal (aspirações e objetivos de carreira), mais frequentes em pesquisas qualitativas brasileiras (Graf \& Coutinho, 2010; Soares \& Sestren, 2007).

O modelo proposto, detalhado a seguir, inclui três variáveis antecedentes de expectativas de carreira na organização: percepções de políticas e práticas de recursos humanos $(\mathrm{RH})$, bem-estar no trabalho e expectativas de futuro organizacional. Até onde a revisão avançou, não foi encontrado na literatura modelo similar. Mesmo examinando pontualmente a relação de cada dupla de variáveis, na maioria dos casos, existem poucos estudos empíricos. Ao testar esse modelo, busca-se aprofundar as investigações sobre expectativas de carreira e, em uma perspectiva mais ampla, contemplar a dimensão temporal nos estudos sobre trabalho/organizações, aspecto em geral negligenciado ou tratado inadequadamente nessa área (Caetano, 2012; Sonnentag, 2012).

\section{Modelo de Investigação Proposto e Desenvolvimento de Hipóteses}

Há longa tradição na psicologia em estudar experiências passadas, características disposicionais e observação do desempenho alheio como antecedentes de expectativas positivas (Bandura, 1977; Monga \& Rao, 2006; Scheier \& Craver, 1985). Ao discutir especificamente expectativas de carreira, o modelo aqui proposto (Figura 1) contribui para a literatura ao avançar em outra direção. Em primeiro lugar, ao incluir percepções de políticas/práticas de RH e bem-estar no trabalho como antecedentes, o modelo testa o papel de componentes perceptuais e afetivos da atual situação do profissional na formação das 
expectativas de carreira. Ademais, ao abarcar expectativas de futuro organizacional, o modelo verifica o efeito de uma variável orientada para o futuro, opção pouco usual na literatura. As subseções a seguir pontuam o desenvolvimento de cada hipótese da pesquisa.

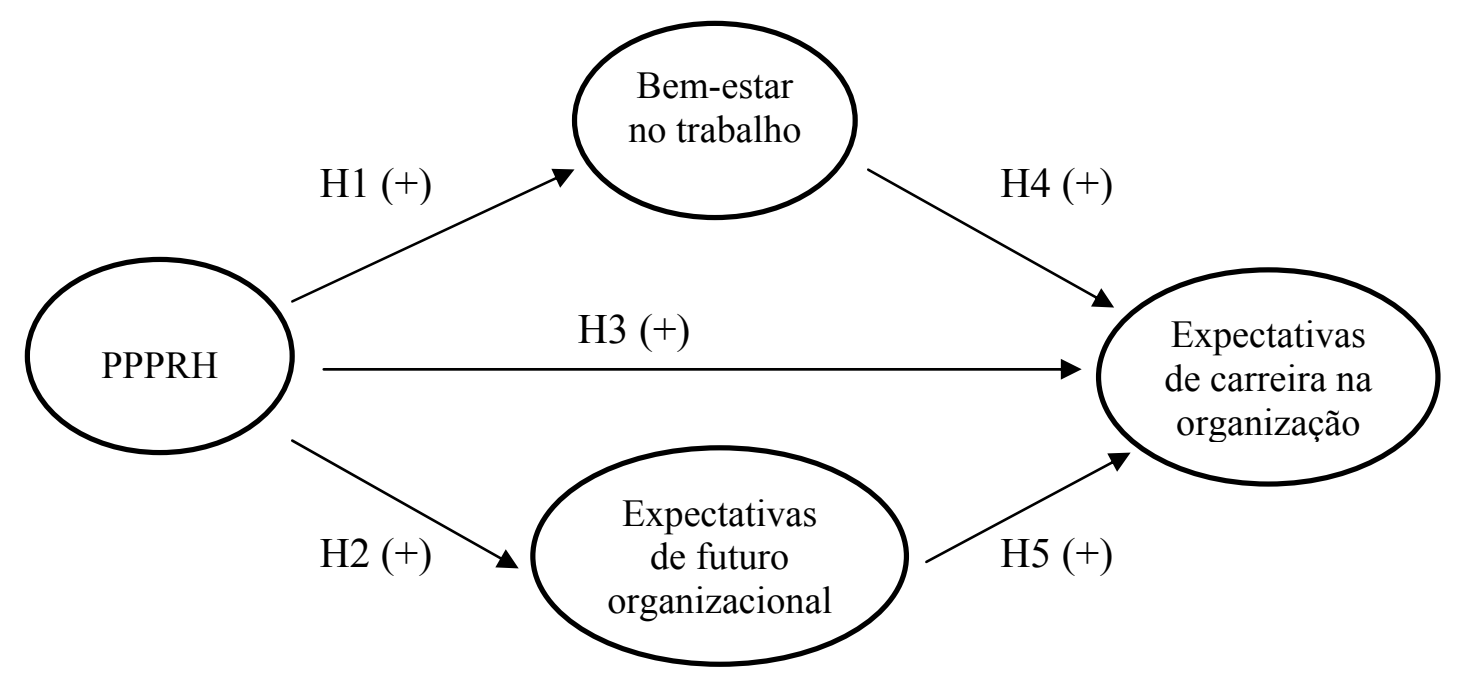

Figura 1. Modelo estrutural proposto. PPPRH=Percepções de políticas/práticas de recursos humanos. Cargo ocupado (gerencial/não gerencial) atua como variável de controle, sendo omitida acima para simplificar a representação do modelo.

\section{Percepções de Políticas/Práticas de RH e Bem-estar no Trabalho}

A gestão de RH adquire função cada vez mais estratégica e relevante para o alcance dos objetivos organizacionais e aquisição de vantagem competitiva (Bohlander \& Snell, 2010; Jackson, Schuler \& Werner, 2012). Com efeito, meta-análises recentes (Combs, Liu, Hall \& Ketchen, 2006; Subramony, 2009) identificaram associação positiva e significativa entre medidas de desempenho organizacional e práticas de $\mathrm{RH}$.

A gestão de RH, em seu escopo de gerenciar e orientar o comportamento humano no trabalho, lança mão de políticas e práticas (Fischer, 2002). As políticas expressam diretrizes ou propostas articuladas que servem de referência para a consecução dos resultados desejados pela organização, ao passo que as práticas (ou processos) sobressaem como os componentes mais visíveis da gestão, visto que são cursos de ação operacionalizados (Demo, Neiva, Nunes \& Rozzett, 2012; Fischer, 2002). Entre outras possibilidades, políticas e práticas de RH englobam recrutamento e seleção, treinamento/desenvolvimento, condições de trabalho, 
avaliação de desempenho e competências, remuneração/recompensa e o envolvimento dos profissionais com a organização (Demo, Neiva, Nunes \& Rozzett, 2014). Revisão de literatura recente (Meneses, Coelho Júnior, Ferreira, Paschoal \& Isidro-Filho, 2014) indica que práticas e políticas de treinamento/desenvolvimento e de remuneração são as mais pesquisadas no Brasil.

Além de seu papel na consecução de objetivos organizacionais, a gestão de RH influencia a relação dos profissionais com seu trabalho e organização. O modelo proposto investe nesta perspectiva e investiga os efeitos das percepções de políticas/práticas de RH no bem-estar no trabalho, assumido aqui como a prevalência de emoções positivas sobre as negativas, além da percepção do indivíduo de que, no trabalho, expressa e desenvolve seu potencial e habilidades, avançando no alcance de suas metas (Paschoal \& Tamayo, 2008).

Esse conceito conjuga dois componentes tipicamente evocados nos estudos sobre bemestar: hedonismo e eudaimonia. O primeiro ressalta a obtenção de prazer como essência do bem-estar (Ryan \& Deci, 2001), enquanto o segundo realça a capacidade do indivíduo de expressar seu potencial e conseguir realizações pessoais em uma trajetória dotada de sentido (Waterman, 1993). Embora distintas, essas perspectivas afiguram-se complementares e positivamente relacionadas entre si, de modo que conjugá-las enriquece o estudo do bemestar em geral (Ryan \& Deci, 2001) e no trabalho (Paschoal \& Tamayo, 2008).

É plausível supor que bem-estar no trabalho seja predito pelas percepções dos profissionais sobre as políticas/práticas de $\mathrm{RH}$, uma vez que estas condicionam largamente o ambiente organizacional e a relação dos indivíduos com suas atividades. Essa proposição está respaldada no modelo teórico de Warr (2013), que propõe como antecedentes ambientais de bem-estar elementos condicionados pela gestão de RH, entre os quais, remuneração, desenvolvimento de competências, condições de trabalho e características das atividades.

Pesquisas anteriores registraram relação positiva entre gestão de RH e bem-estar no trabalho, todavia, definindo esta última variável como comprometimento organizacional e 
satisfação com o trabalho (Baptiste, 2008; Horta, Demo \& Roure, 2012). Demo e Paschoal (2013) recentemente validaram a versão em inglês da Escala de Bem-Estar no Trabalho (Paschoal \& Tamayo, 2008) e sustentaram sua validade nomológica ao reportar forte associação positiva de bem-estar com as percepções de práticas/políticas de RH. A amostra foi composta por profissionais do setor industrial estadunidense. Na presente pesquisa, tal relação será posta à prova dentro de um modelo estrutural distinto, utilizando uma amostra brasileira oriunda de outro setor da economia. De toda forma, em função do suporte teórico e empírico explicitado, a primeira hipótese estipula que:

Hipótese 1 - Percepções de políticas/práticas de RH relacionam-se positivamente ao bem-estar no trabalho.

\section{Percepções de Políticas/Práticas de RH e Expectativas de Carreira na Organização e de Futuro Organizacional}

Se as políticas/práticas de RH adquirem crescente relevância estratégica e competitiva, é bastante provável que estas influenciem o futuro das organizações. Todavia, será que esta relação, tão decantada na literatura de gestão, é percebida pelos profissionais? Esta pesquisa testa exatamente a relação entre percepções de políticas/práticas de RH dos profissionais e suas expectativas de futuro organizacional, definidas como as crenças dos indivíduos sobre a gestão e a efetividade de sua organização no futuro (Vasconcellos \& Neiva, 2015b).

Poucos estudos debruçaram-se sobre o futuro organizacional sob as lentes dos trabalhadores. Porém, aqueles que o fizeram apontam essa variável como aspecto relevante da relação indivíduo-trabalho-organização (Chiu, 2002; Harris \& Mossholder, 1996; Hui \& Lee, 2000). A única pesquisa empírica localizada sobre gestão de RH e futuro organizacional na perspectiva dos indivíduos (Y. Chen, Hsu \& Yip, 2011) revelou correlação moderada e positiva entre as percepções de efetividade de RH e de desempenho futuro da organização em amostra de gerentes. O presente estudo amplia e complementa essa pesquisa anterior ao 
utilizar amostra com gerentes e não gerentes, ao empregar construtos e instrumentos mais abrangentes e ao testar tal relação em um modelo estrutural distinto. De todo modo, os elementos realçados facultam supor o impacto positivo do bom funcionamento das políticas e práticas de RH no futuro organizacional, sendo tal relação refletida não só em indicadores objetivos, mas também na subjetividade dos profissionais. Logo, a hipótese 2 atesta que:

Hipótese 2 - Percepções de políticas/práticas de RH relacionam-se positivamente às expectativas de futuro organizacional.

Em adição, é possível conjecturar sobre a ligação das percepções de políticas/práticas de RH com o próprio futuro na carreira. Neste tópico, é provável que indivíduos que se percebam beneficiados/contemplados pelas políticas/práticas de RH (isto é, consideram positivos os treinamentos, as condições de trabalho, as recompensas e o reconhecimento recebido) visualizem o futuro como alvissareiro na sua organização. Nessa linha, ao perceber a gestão de RH como adequada, justa e efetiva, os profissionais tenderiam a construir crenças de que a organização fornece as condições para seu desenvolvimento e evolução profissional, ocasionando assim expectativas positivas para a carreira.

Tal conjectura ampara-se igualmente na teoria da motivação na carreira (London, 1983). Esta reconhece a importância de características situacionais da organização (entre as quais ambiente/condições de trabalho, práticas de recompensa e apoio ao treinamento e desenvolvimento) na formação de expectativas de carreira. No flanco empírico, há indícios de que a existência de determinadas práticas de $\mathrm{RH}$ (notadamente de treinamento e desenvolvimento) relacionam-se positivamente a uma visão mais favorável das oportunidades de carreira e das possibilidades de crescimento profissional (Kraimer et al., 2011; Veloso et al., 2011). Nesta pesquisa, executa-se teste mais abrangente, já que vários aspectos da gestão de RH estão abarcados. Ademais, ao contrário das pesquisas citadas (mais centradas em 
percepções sobre oportunidades de carreira no momento presente), o foco aqui recai sobre expectativas de carreira. De todo modo, a hipótese 3 assume que:

Hipótese 3 - Percepções de políticas/práticas de RH relacionam-se positivamente às expectativas de carreira na organização.

\section{Bem-estar no Trabalho e Expectativas de Carreira na Organização}

Estudos fora do campo organizacional já sinalizaram que afetos positivos influenciam diversos pensamentos e comportamentos orientados para o futuro (Aspinwall, 2005) e que estes, em geral, induzem expectativas de resultados favoráveis (Monga \& Rao, 2006). Tais autores ponderam que afetos positivos tendem a ativar recordações de resultados passados sintônicos (ou seja, também positivos), que moldam então projeções positivas de futuro.

Na literatura de psicologia organizacional e do trabalho, o papel dos afetos na modulação de comportamentos e cognições foi alvo de teorias e modelos nas últimas décadas. O modelo de infusão de afetos (Forgas \& George, 2001) sugere que os afetos infundem-se e "colorem" a formulação de atitudes, avaliações, deliberações e comportamentos, especialmente em situações mais abertas (ou seja, sem respostas padronizadas). Como a formação de expectativas de carreira traduz-se em um processamento cognitivo aberto, é plausível supor que afetos positivos (negativos) no trabalho influenciem expectativas favoráveis (desfavoráveis) sobre o futuro profissional. No mesmo sentido, a teoria dos eventos afetivos (Weiss \& Cropanzano, 1996) atesta que as reações afetivas dos indivíduos a eventos (acontecimentos) relevantes no ambiente laboral influem nos seus comportamentos e atitudes perante o trabalho. Esta teoria descortina como os afetos podem modular dinamicamente aspectos cognitivos da relação indivíduo-trabalho-organização. Como as expectativas de carreira representam cognições sobre essa relação, é provável que também sejam influenciadas pelos estados afetivos dos profissionais. 
De sua parte, a teoria do ampliar-e-construir (Fredrickson, 2003) prediz que a presença de emoções positivas amplia o repertório cognitivo dos indivíduos e desenvolve, no longo prazo, recursos pessoais duráveis que favorecem a adaptação ao trabalho e às organizações. Indivíduos com altas cargas de afetos positivos tendem a ser mais integrados socialmente, criativos e motivados nas tarefas, características que sugerem maior resiliência, capacidade e confiança para lidar com eventuais condições adversas no porvir (Aspinwall, 2005; Fredrickson, 2003). Emoções negativas operariam no sentido contrário, qual seja, estreitando o repertório e o poder de adaptação. Dessa forma, a prevalência de emoções positivas sobre negativas (bem-estar) no trabalho pode levar indivíduos a se perceberem mais aptos e adaptados ao trabalho/organização, ensejando expectativas mais favoráveis sobre a carreira.

No campo empírico, há ainda indícios que afetos positivos correlacionam-se positivamente com expectativas de salário em indivíduos no início da trajetória profissional (O’Neill, Stanley \& O'Reilly, 2011). A proposta aqui é expandir a pesquisa de O’Neill et al. (2011), visto que a presente investigação vai além de expectativas salariais, inclui profissionais em diversas etapas de carreira e afere estados afetivos (esses autores, a rigor, basearam seu questionário em traços de afetividade).

Toda a argumentação anterior sobre a associação de bem-estar no trabalho e expectativas de carreira centra-se em afetos, embora o conceito de bem-estar adotado inclua realização profissional. Sobre este tópico, pesquisa exploratória recente desvelou que realização profissional correlaciona-se forte e positivamente com a visão de futuro de carreira dos indivíduos (Vasconcellos \& Neiva, 2014). Nesse estudo, esta última variável foi aferida por um único item no qual o respondente indicava o quão favorável parecia ser seu futuro na sua atual organização. Com delineamento mais robusto, a presente investigação parte de um instrumento com múltiplos itens e de uma amostra maior para testar tal relação em um modelo estrutural. Respaldada pelos pontos arrolados, a quarta hipótese postula que: 
Hipótese 4 - Bem-estar no trabalho relaciona-se positivamente com expectativas de carreira na organização.

\section{Expectativas de Futuro Organizacional e de Carreira na Organização}

Estudar a conexão entre futuro da organização e futuro na carreira torna-se essencial no contexto atual, no qual a globalização, os avanços tecnológicos e a necessidade de inovação impelem as organizações a mudar constantemente (Bohlander \& Snell, 2010). Nesse sentido, mudanças organizacionais podem ser percebidas tanto como uma ameaça para progressão futura na carreira, quanto como uma oportunidade de nova trilha profissional, dependendo da natureza da mudança e de como a organização a conduz (Lips-Wiersma \& Hall, 2007).

Por meio de entrevistas, algumas pesquisas evidenciaram, no discurso dos participantes, o entrelaçamento do futuro organizacional e profissional, de maneira que as preocupações, os riscos e as oportunidades para os indivíduos brotavam casados com a suposta configuração futura da organização (Lips-Wiersma \& Hall, 2007; Margolis \& Hansen, 2003; Ullrich, Wieseke \& van Dick, 2005). Por exemplo, Margolis e Hansen (2003), investigando companhia aérea em processo de fusão, relatam que os profissionais, ao mesmo tempo em que esperavam o crescimento dos negócios, a alteração da cultura organizacional e melhorias na reputação da organização, cultivaram expectativas de avanços na carreira e de aumento nos salários e benefícios. Nessa linha, é plausível supor que profissionais que enxergam perspectivas favoráveis para a organização - como mudanças positivas na gestão e expansão nas operações - provavelmente vislumbrarão um futuro mais positivo para si, posto que tais perspectivas podem se desdobrar em benesses para eles mesmos.

Se, por um lado, tais estudos exploratórios sugerem ligação entre expectativas de futuro organizacional e de carreira, por outro, o reduzido número de investigações dessa natureza estimula a realização de análises mais estruturadas e complexas. Por sinal, Margolis e Hansen (2003) enfatizam como a literatura apresenta lacunas no que concerne à compreensão das 
projeções de futuro na carreira e recomendam novas pesquisas sobre o tema. Atendendo à recomendação, analisa-se aqui a relação de expectativas de futuro organizacional e de carreira na organização, desta feita, por intermédio de análises quantitativas. A hipótese 5, alicerçada nas pesquisas qualitativas e exploratórias citadas, determina que:

Hipótese 5 - Expectativas de futuro organizacional relacionam-se positivamente às expectativas de carreira na organização.

Observando a literatura que embasou as hipóteses precedentes, constata-se que há indícios de que percepções de políticas/práticas de RH relacionam-se ao bem-estar no trabalho e às expectativas de futuro organizacional e que estas duas últimas variáveis, por sua vez, atuam como antecedentes de expectativas de carreira (Y. Chen et al., 2011; Demo \& Paschoal, 2013; Margolis \& Hansen, 2003; O’Neill et al., 2011). Em conjunto, esses indícios suportam a proposição de um modelo de mediação, conforme exposto na Figura 1. Como a análise da literatura prévia também sugere efeito direto das percepções de políticas/práticas de RH nas expectativas de carreira (London, 1983: Veloso et al., 2011), propõe-se aqui que as variáveis mediadoras explicam apenas parcialmente tal efeito. Como não foi encontrado na literatura um modelo que analisasse conjuntamente essas variáveis, seria injustificado supor de antemão a mediação total. De toda forma, a possibilidade de mediação total foi avaliada nas análises descritas a seguir.

Sexo, idade, tempo de organização e cargo ocupado (gerencial ou não) foram cogitados como variáveis de controle, todavia, pesquisas anteriores indicaram que apenas a última variável relaciona-se consistentemente com expectativas de carreira e de futuro organizacional (Chay \& Aryee, 1999; G. Chen et al., 2011; Hui \& Lee, 2000; Stroh \& Reilly, 1997; Veloso et al., 2011). Logo, apenas cargo ocupado foi incluído como controle, o que evita a elaboração de um modelo desnecessariamente complexo. Embora não tenha sido empregada como controle, a variável tempo de organização foi aproveitada para uma análise complementar. Estudos prévios revelaram que tempo de organização modera a relação de variáveis relevantes em comportamento 
organizacional (Ng \& Feldman, 2011; Wright \& Bonett, 2002), inclusive entre atitudes no trabalho e expectativas de carreira (G. Chen et al., 2011). Verificou-se então se o modelo conservava as mesmas características entre profissionais com diferentes tempos de organização.

\section{Método}

\section{Participantes}

Na amostra coletada $(n=305)$, a idade média foi 44,04 anos $(\mathrm{DP}=9,50)$, o tempo de organização foi 13,36 anos (DP=9,91), 74\% eram homens e 30\% atuavam em cargo gerencial. Todos apresentavam escolaridade igual ou superior ao nível médio e trabalhavam em uma autarquia federal. Verificou-se que as proporções dos grupos na amostra (inclusive nos estratos por idade e tempo de organização) foram similares àquelas encontradas na organização inteira. Para $\alpha=0,05$, essa amostra fornece poder estatístico superior a $80 \%$ em todos os modelos relatados a seguir, considerando $\varepsilon_{0} \leq 0,05$ e $\varepsilon_{\mathrm{a}}=0,08$, respectivamente, como hipótese nula e valor testado do Root Mean Square Error of Approximation (RMSEA).

\section{Procedimentos}

Os respondentes, selecionados aleatoriamente de uma lista com todos os profissionais da organização, receberam um correio eletrônico (enviado pela área de RH da organização) com informações sobre o estudo, instruções, contato do pesquisador e link de acesso ao questionário. Este foi respondido individualmente, de forma voluntária e confidencial.

\section{Instrumentos}

\section{Expectativas de Carreira na Organização e de Futuro Organizacional.}

Foram empregadas a versão reduzida da Escala de Expectativas de Carreira na Organização (EECO) e a Escala de Expectativas de Futuro Organizacional (EEFO), validadas respectivamente por Vasconcellos e Neiva (2015a) e por Vasconcellos e Neiva (2015b). Em ambas, os participantes assinalam em escala de sete pontos a probabilidade da situação positiva descrita no item ocorrer cinco anos à frente (1=nada provável até 7=extremamente 
provável). As assertivas da EECO aludem à futura situação de carreira do indivíduo naquela organização (exemplo: “Atingirei meus objetivos de carreira estabelecidos para esse período”) e as da EEFO remetem à situação da organização no futuro (exemplo: “O ambiente de trabalho será aperfeiçoado pela gestão da organização"). A EECO é composta pelos fatores Conquistas Profissionais e Relação Carreira-Vida Pessoal, contudo, em função da negociação com a organização e da necessidade de encurtar o questionário, só o fator Conquistas Profissionais foi utilizado (seis itens e $\alpha=0,90$ ). Os dois fatores da EEFO foram aproveitados: Gestão e Ambiente Organizacional (quatro itens e $\alpha=0,92$ ) e Efetividade Organizacional (cinco itens e $\alpha=0,92$ ).

\section{Percepção de Políticas e Práticas de Recursos Humanos.}

Foram utilizados três fatores da versão reduzida da Escala de Políticas e Práticas de Recursos Humanos (Demo et al., 2014): Treinamento, Desenvolvimento e Educação (três itens e $\alpha=0,81$ ), Remuneração e Recompensas (quatro itens e $\alpha=0,74$ ) e Condições de Trabalho (cinco itens e $\alpha=0,77$ ). A escala contém seis fatores, porém, sua aplicação integral aumentaria muito o tamanho do questionário. Optou-se por esses fatores por refletirem aspectos centrais e tradicionais da gestão de RH e porque todos os seus itens se adequaram ao contexto institucional da autarquia. Como ilustração, segue exemplo de um item do fator Treinamento, Desenvolvimento e Educação: “A organização onde trabalho estimula a aprendizagem e a produção de conhecimento.” Os itens foram respondidos por meio de escala de concordância (1=discordo totalmente até $5=$ concordo totalmente $)$.

\section{Bem-estar no trabalho.}

Foram aplicados os três fatores da Escala de Bem-Estar no Trabalho (Paschoal \& Tamayo, 2008): Afetos Positivos (nove itens e $\alpha=0,95$ ), Afetos Negativos (12 itens e $\alpha=0,93$ ) e Realização (nove itens e $\alpha=0,94$ ). "Nos últimos seis meses, meu trabalho tem me deixado contente" constitui exemplo de item do fator Afetos Positivos. Os itens sobre afetos foram respondidos em escala de intensidade (1=nem um pouco até 5=extremamente) e os itens do fator Realização (exemplo: 
"Neste trabalho faço o que realmente gosto de fazer") por meio de escala de concordância (1=discordo totalmente até 5=concordo totalmente).

\section{Variáveis demográficas.}

O questionário incluía ainda itens sobre sexo, idade, tempo na organização e o cargo ocupado ( $0=$ não gerencial e $1=$ gerencial $)$ pelo respondente.

\section{Análise de Dados}

A investigação contou com duas etapas: análise fatorial confirmatória (para testar o modelo de mensuração) e a avaliação do modelo estrutural (para testar as hipóteses). Nos modelos, o construto expectativas de carreira na organização contou com os seus seis itens como variáveis empíricas. Os demais construtos utilizaram as médias de seus fatores. Essa estratégia de agregação é comum na literatura, pois favorece o surgimento de variáveis com distribuição mais intervalar, normal e confiável (Hall, Snell \& Foust, 1999). Os modelos foram estimados no programa AMOS 18 por máxima verossimilhança. Como a normalidade multivariada não foi rigorosamente alcançada (a razão crítica do teste de Mardia foi igual a 11,57), foram geradas 500 subamostras por bootstrapping para se avaliar a estabilidade dos parâmetros (Byrne, 2010). Nos testes de hipóteses, foram observados sinal, magnitude e significância dos coeficientes, além do ajuste dos modelos a partir dos indicadores: GFI (Goodness-of-Fit Index), CFI (Comparative Fit Index), SRMR (Standardized Root Mean Residual) e RMSEA. O modelo proposto foi comparado a modelos alternativos, pois tal prática constitui teste mais rigoroso do que a análise isolada de seu ajuste (Hair, Black, Babin, Anderson \& Tatham, 2010).

\section{Resultados}

\section{Estatísticas Descritivas e Análise Fatorial Confirmatória}

As estatísticas descritivas e as correlações estão na Tabela 1. Expectativas de carreira e de futuro organizacional correlacionaram-se positivamente com os demais construtos (afora o fator Afetos Negativos de bem-estar no trabalho), de forma congruente com as hipóteses do modelo. 
Tabela 1

Médias, Desvios-padrão e Correlações das Variáveis da Pesquisa

\begin{tabular}{|c|c|c|c|c|c|c|c|c|c|c|c|c|}
\hline Variáveis & Média (DP) & 1 & 2 & 3 & 4 & 5 & 6 & 7 & 8 & 9 & 10 & 11 \\
\hline 1. Tempo de organização & $13,36(9,91)$ & - & & & & & & & & & & \\
\hline 3. ECO Conquistas Profissionais & $4,29(1,31)$ & $-0,02$ & 0,31 & - & & & & & & & & \\
\hline 4. EFO Gestão e Ambiente Organizacional & $3,97(1,34)$ & 0,04 & 0,24 & 0,66 & - & & & & & & & \\
\hline 5. EFO Efetividade Organizacional & $4,62(1,23)$ & 0,03 & 0,30 & 0,60 & 0,67 & - & & & & & & \\
\hline 6. PPPRH TDE & $3,35(0,93)$ & 0,01 & 0,25 & 0,58 & 0,52 & 0,43 & - & & & & & \\
\hline 7. PPPRH Condições de Trabalho & $3,70(0,76)$ & 0,11 & 0,23 & 0,43 & 0,50 & 0,43 & 0,52 & - & & & & \\
\hline 8. PPPRH Remuneração e Recompensas & $2,65(0,82)$ & 0,14 & 0,35 & 0,56 & 0,47 & 0,40 & 0,54 & 0,51 & - & & & \\
\hline 10. BET Afetos Positivos & $2,68(0,87)$ & 0,14 & 0,23 & 0,51 & 0,43 & 0,32 & 0,47 & 0,43 & 0,47 & 0,72 & - & \\
\hline 11. BET Afetos Negativos & $2,21(0,87)$ & $-0,11$ & $-0,09$ & $-0,33$ & $-0,29$ & $-0,17$ & $-0,39$ & $-0,29$ & $-0,31$ & $-0,42$ & $-0,54$ & - \\
\hline
\end{tabular}

Nota. ECO=Expectativas de Carreira na Organização; EFO=Expectativas de Futuro Organizacional; PPPRH=Percepções de Políticas e Práticas de Recursos Humanos;

$\mathrm{TDE}=$ Treinamento, Desenvolvimento e Educação; BET $=$ Bem-estar no Trabalho. Todas as correlações (em módulo) iguais ou acima de 0,15 são significativas para $\alpha=0,01$;

entre 0,11 e 0,14 passam a ser significativas considerando $\alpha=0,05$.

${ }^{\text {a }}$ Cargo ocupado: $0=$ não gerencial e $1=$ gerencial. 
Os resultados da análise fatorial confirmatória estão na Tabela 2. O modelo proposto (dotado de quatro fatores) exibiu bom ajuste em todos os indicadores. Todas as suas cargas fatoriais foram significativas $(p<0,01)$ e superiores a 0,55 . Similarmente, todas as correlações entre construtos foram significativas $(p<0,01)$. Além do modelo com um único fator (tradicionalmente testado neste tipo de análise), outro modelo alternativo detinha sentido lógico: unir as variáveis orientadas para o futuro (os dois tipos de expectativas) em um fator e as variáveis orientadas para o presente (bem-estar no trabalho e percepções de políticas e práticas de RH) em outro fator. Como ilustra a Tabela 2, os modelos alternativos foram estatisticamente inferiores (pela diferença de $\chi^{2}$ ) e manifestaram indicadores de ajuste piores do que o modelo proposto. Portanto, a análise seguiu com o modelo de mensuração proposto.

Tabela 2

Indicadores de Ajuste dos Modelos na Análise Fatorial Confirmatória

\begin{tabular}{lcccccccc}
\hline \multicolumn{1}{c}{ Modelo } & $\chi^{2}$ & gl & GFI & CFI & RMSEA & IC RMSEA & SRMR & $\Delta \chi^{2}$ \\
\hline Quatro fatores (proposto) $^{2}$ & $224,34^{* *}$ & 79 & 0,92 & 0,94 & 0,08 & {$[0,07-0,09]$} & 0,04 & - \\
Dois fatores $^{\text {a }}$ & $375,03 * *$ & 86 & 0,86 & 0,89 & 0,11 & {$[0,09-0,12]$} & 0,06 & $150,69 * *$ \\
Um fator & $494,95^{* *}$ & 88 & 0,82 & 0,81 & 0,12 & {$[0,11-0,13]$} & 0,07 & $270,60^{* *}$ \\
\hline
\end{tabular}

Nota. GFI=Goodness-of-Fit Index; CFI=Comparative Fit Index; RMSEA=Root Mean Square Error of Approximation; $\mathrm{IC}_{\mathrm{RMSEA}}=$ Intervalo de confiança $90 \%$ do RMSEA; SRMR=Standardized Root Mean Residual. Em todos os modelos, há duas ligações entre erros de variáveis empíricas.

${ }^{a}$ Expectativas de carreira e de futuro organizacional como um único fator e bem-estar no trabalho e percepções de políticas e práticas de recursos humanos como um único fator.

$* * p<0,01$.

As médias das cargas fatoriais das subamostras do bootstrapping foram praticamente idênticas às cargas fatoriais do modelo proposto (a diferença não alcançou 0,01 em nenhum caso), com baixo erro padrão (entre 0,02 e 0,05). Esses resultados fornecem evidência da estabilidade das cargas e da adequação do processo de estimação do modelo.

Como todas as variáveis foram obtidas no mesmo questionário, havia o risco de viés de método comum. Embora o questionário tenha sido desenhado para atenuá-lo, garantindo o 
anonimato das respostas e adotando introduções e escalas diferentes para cada variável

(Podsakoff, MacKenzie, Lee \& Podsakoff, 2003), verificou-se até que ponto o risco persistia. As técnicas para detectar tal viés ainda são limitadas/imprecisas, de sorte que não há consenso na literatura sobre qual delas é a melhor (Podsakoff et al., 2003; Richardson, Simmering \& Sturman, 2009). Nesta pesquisa, optou-se pelo teste de Harman, difundida técnica na qual se executa uma análise fatorial exploratória sem rotação com todos os itens do modelo. Se o primeiro fator explicar mais de 50\% da variância, há indícios de viés (Podsakoff et al., 2003), fato que não se consumou no modelo proposto. Uma variante dessa técnica ganhou espaço na literatura recentemente: gera-se um modelo de fator único na análise fatorial confirmatória e seu ajuste é avaliado (Podsakoff et al., 2003). Tal modelo manifestou ajuste ruim (Tabela 2). Logo, não parece existir risco elevado de viés de método comum.

\section{Modelo Estrutural e Teste de Hipóteses}

O modelo estrutural proposto registrou bom ajuste: $\chi^{2}(g l)=224,38(80), p<0,01$, $\mathrm{GFI}=0,92, \mathrm{CFI}=0,94, \mathrm{RMSEA}[\mathrm{IC} 90 \%]=0,08[0,07-0,09]$ e $\mathrm{SRMR}=0,04$. As estimativas dos coeficientes padronizados deste modelo estão na Figura 2.

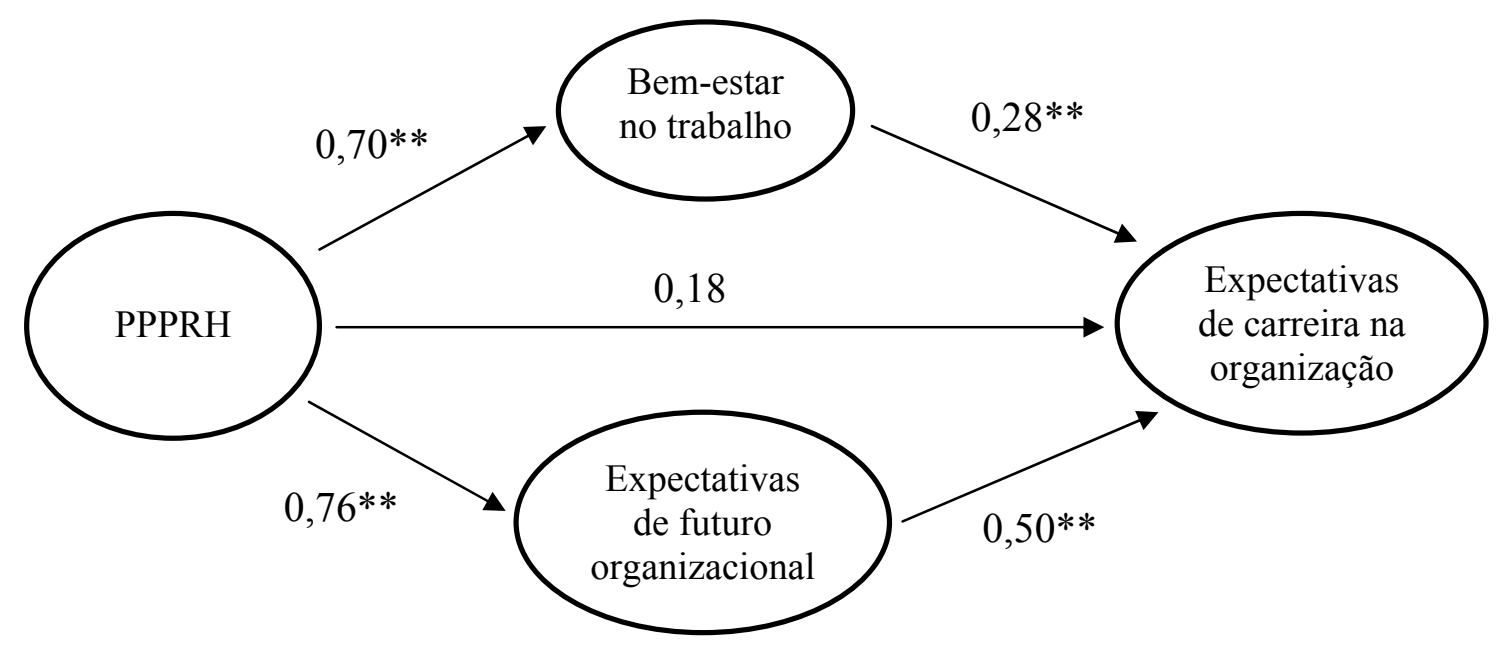

Figura 2. Coeficientes padronizados do modelo estrutural proposto. PPPRH=Percepções de políticas e práticas de recursos humanos. As ligações entre a variável de controle cargo ocupado e as demais variáveis foram omitidas para favorecer a visualização do modelo. Contudo, são comentadas posteriormente no texto. $* * p<0,01$. 
As hipóteses 1 e 2 previam que percepções de políticas/práticas de RH relacionavam-se positivamente ao bem-estar no trabalho e às expectativas de futuro organizacional. Ambas foram suportadas, registrando efeito de grande magnitude. Por outro lado, a hipótese 3 (percepções de políticas/práticas de $\mathrm{RH}$ relacionam-se positivamente às expectativas de carreira na organização) não foi respaldada. $O$ efeito foi fraco e não significativo $(p=0,12)$. Nesse sentido, os dados sugerem que a relação entre percepções de políticas/práticas de RH e expectativas de carreira na organização detectada no modelo de mensuração $(r=0,78 ; p<0,01)$ foi totalmente mediada por bem-estar no trabalho e expectativas de futuro organizacional.

As hipóteses 4 e 5 indicavam, respectivamente, que bem-estar no trabalho e expectativas de futuro organizacional relacionavam-se positivamente com expectativas de carreira na organização. As hipóteses foram suportadas, com efeito de magnitude moderada, no primeiro caso, e forte, no segundo. A variável de controle cargo ocupado sustentou efeito fraco $(0,10)$ e marginalmente significativo $(p=0,047)$ em bem-estar no trabalho; seus efeitos nas variáveis de expectativas foram positivos, porém, fracos e não significativos $(p>0,10)$.

O modelo proposto foi cotejado a modelos alternativos como forma de executar teste mais rigoroso de seu ajuste. Partindo da não aceitação da hipótese 3, no modelo alternativo 1(A1), a relação direta de percepções de políticas/práticas de RH em expectativas de carreira na organização foi suprimida. A diferença de qui-quadrado dos modelos, $\Delta \chi^{2}(1)=2,20$, não foi significativa $(p>0,10)$. Os indicadores de ajuste do modelo A1 (GFI=0,92, CFI=0,94, RMSEA=0,08 e SRMR=0,05) foram praticamente idênticos aos do modelo proposto. Logo, a exclusão dessa relação não piorou o ajuste do modelo, o que sinaliza sua superfluidade e configura nova evidência de mediação total entre essas variáveis. A variável de controle cargo ocupado replicou, no modelo A1, o mesmo padrão de relações presente no modelo proposto.

No modelo alternativo 2(A2), foi adicionado ao modelo proposto o efeito direto de bemestar no trabalho em expectativas de futuro organizacional. Apesar de não ter sido possível 
aventar essa hipótese com base na literatura, existia a chance de que bem-estar no trabalho influenciasse não só as expectativas sobre a carreira, mas também as expectativas de futuro organizacional. A diferença no qui-quadrado entre os modelos, $\Delta \chi^{2}(1)=0,03, p=0,86$, não foi significativa. Os demais indicadores de ajuste do modelo A2 foram virtualmente idênticos aos do modelo proposto. Destarte, a adição dessa nova ligação não melhorou o ajuste do modelo e o tornou, desnecessariamente, mais complexo.

Comparando os três modelos, adotou-se o A1 como modelo final do estudo. Este apresenta os mesmos níveis de ajuste do modelo proposto, todavia, com duas vantagens: maior parcimônia e significância estatística em todos os coeficientes estruturais entre construtos. Os coeficientes padronizados do modelo A1 estão na Figura 3 e corroboram o suporte obtido pelas hipóteses 1, 2, 4 e 5 do modelo proposto. O efeito padronizado indireto de percepções de políticas e práticas de $\mathrm{RH}$ em expectativas de carreira na organização atingiu $0,72(0,48$ via expectativas de futuro organizacional e 0,24 via bem-estar no trabalho). No cômputo geral, o modelo explicou larga parte da variância de expectativas de carreira na organização $\left(R^{2}=0,75\right)$.

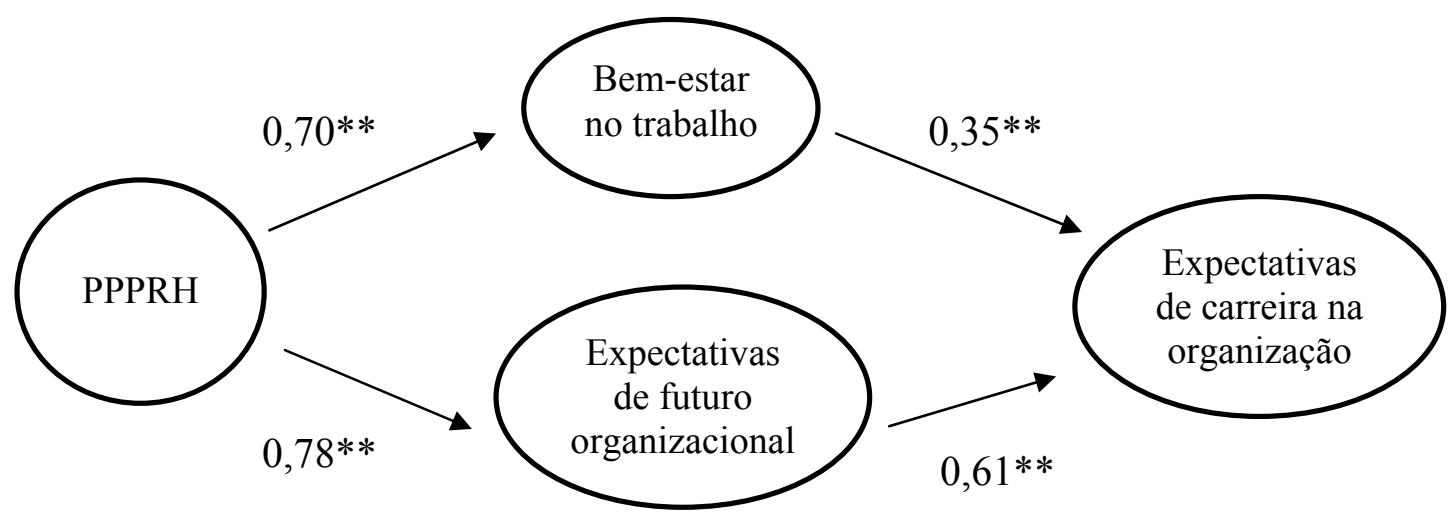

Figura 3. Coeficientes padronizados do modelo alternativo 1 (A1). PPPRH=Percepções de políticas e práticas de recursos humanos. A variável de controle cargo ocupado foi omitida para favorecer a visualização do modelo. ** $p<0,01$.

\section{Análise Complementar: Tempo de Organização Altera o Modelo?}

Como análise complementar, buscou-se avaliar se o modelo A1 conservava as mesmas características a despeito do tempo de organização dos profissionais. Inspirando-se na 
segmentação adotada por Ng e Feldman (2011), dois grupos foram criados: a) profissionais com pequeno/médio tempo de organização (até 10 anos) denominados aqui de não veteranos ( $45 \%$ da amostra) e b) profissionais com elevado tempo de organização (acima de 10 anos) rotulados, neste artigo, de veteranos (55\% da amostra).

Realizou-se então um teste de moderação via análise multigrupo, técnica que requer duas formas de invariância entre grupos no modelo de mensuração (Hair et al., 2010). A primeira (invariância de configuração) é assumida se os grupos conservam a mesma estrutura fatorial em um modelo sem restrições, no qual as cargas fatoriais são livremente estimadas para cada grupo (Hair et al., 2010; Kline, 2011). O ajuste desse modelo é avaliado, bem como a equivalência dos grupos quanto ao número de fatores e alocação dos itens em cada fator. A segunda (invariância métrica) é avaliada por meio de um modelo aninhado (nested model) ao modelo sem restrições, no qual a igualdade das cargas fatoriais entre os dois grupos é imposta (Hair et al., 2010; Kline, 2011). Assume-se invariância métrica quando não existe diferença estatisticamente significativa entre os valores de $\chi^{2}$ do modelo sem restrições e do modelo no qual se impõe a igualdade das cargas entre os grupos.

Nos dois grupos, as estruturas fatoriais foram iguais (com todas as cargas fatoriais obtendo $p<0,01)$ e os indicadores de ajuste do modelo sem restrições foram aceitáveis: $\chi^{2}(160)=316,83$, $p<0,01, \mathrm{GFI}=0,89, \mathrm{CFI}=0,94, \mathrm{RMSEA}=0,06$ e SRMR=0,05. Logo, há indicação de invariância de configuração. A invariância métrica também foi obtida: a diferença de ajuste entre os modelos com e sem restrições nas cargas fatoriais não foi significativa: $\Delta \chi^{2}(10)=10,79, p=0,37$.

Partindo do modelo de invariância métrica, o modelo estrutural sem restrições (no qual os coeficientes estruturais dos dois grupos foram livremente estimados) foi comparado par a par (via $\Delta \chi^{2}$ ) com quatro modelos estruturais restritos, sendo que cada um desses últimos continha a imposição de igualdade para um dos coeficientes estruturais do modelo A1. Dois coeficientes evidenciaram indícios de moderação. No primeiro caso, o modelo que impunha igualdade na 
ligação de expectativas de futuro organizacional e expectativas de carreira exibiu diferença significativa diante do modelo sem essa restrição: $\Delta \chi^{2}(1)=7,20, p<0,01$. Quando livremente estimados entre os grupos, o efeito (coeficiente padronizado) de expectativas de futuro organizacional em expectativas de carreira foi bastante forte nos não veteranos $(0,70 ; p<0,01) \mathrm{e}$ moderado para forte nos veteranos $(0,50 ; p<0,01)$. No segundo caso, a diferença do modelo que impunha igualdade na ligação de bem-estar no trabalho com expectativas de carreira com o modelo sem tal restrição atingiu o limiar da significância estatística: $\Delta \chi^{2}(1)=3,85, p=0,05$. No modelo sem essa restrição, o efeito padronizado de bem-estar no trabalho nas expectativas de carreira foi de fraco para moderado nos não veteranos $(0,25 ; p<0,01)$ e de moderado para forte nos veteranos $(0,45 ; p<0,01)$.

\section{Discussão}

Os resultados manifestaram os efeitos positivos de percepções de políticas/práticas de $\mathrm{RH}$, bem-estar no trabalho e expectativas de futuro organizacional nas expectativas de carreira na organização, além de explicitar a grande capacidade do modelo em explicar esta última variável. Contudo, ao contrário do previsto, os testes com modelos aninhados detectaram que percepções de políticas/práticas de RH exercem efeito prioritariamente indireto nas expectativas de carreira.

O bem-estar no trabalho externou efeito moderado e positivo nas expectativas de carreira, provavelmente porque os afetos positivos instilam otimismo no processamento cognitivo que gera as expectativas (Forgas \& George, 2001) e/ou porque os indivíduos com bons níveis de bem-estar (incluindo a realização profissional) se percebem mais aptos/confiantes a lidar com os desafios futuros (Fredrickson, 2003). Neste último caso, a favorável situação laboral no presente pode ser projetada (estendida) para o futuro.

Por seu turno, expectativas de futuro organizacional expressam efeito forte e positivo nas expectativas de carreira (quanto melhores as expectativas sobre a organização, melhores 
as expectativas de carreira), superando, em magnitude, o efeito de bem-estar no trabalho. Assim, ao tratar da carreira no porvir, os profissionais concederam grande peso ao contexto organizacional futuro. Esse é um componente fora do controle dos indivíduos, sugerindo o forte papel atribuído a fatores externos nas expectativas do próprio futuro profissional.

A comparação dos modelos de profissionais em diferentes estágios de carreira na organização descortinou que o efeito de bem-estar no trabalho nas expectativas de carreira é maior entre os veteranos. Estes, em função do maior tempo de organização, possivelmente representam seu futuro como uma trajetória menos aberta, com menor possibilidade de mudança do que os profissionais não veteranos. Destarte, estão mais propensos a crer no futuro na carreira como prolongamento da atual situação de bem-estar (ou de mal-estar), o que poderia explicar o efeito maior desta última variável nas expectativas de carreira. Já os profissionais não veteranos provavelmente supõem maior chance de mudança, fragilizando um pouco essa relação.

A comparação dos modelos também revelou que o efeito de expectativas de futuro organizacional nas expectativas de carreira é maior nos não veteranos. Possivelmente porque boa parte destes ainda não consolidou seu nicho de atuação na organização, de modo que seu futuro na carreira dependeria mais fortemente de crescimento ou mudança organizacional. Os veteranos seriam um pouco menos dependentes desses elementos por já terem conquistado seu espaço.

Esta pesquisa contribui para a literatura, primeiramente, ao testar relações propostas ou identificadas por estudos anteriores. Nessa linha, os dados sustentaram a relação de percepções de políticas e práticas de RH com bem-estar no trabalho (Demo \& Paschoal, 2013) e com expectativas de futuro organizacional (Y. Chen et al., 2011). Suportaram também a relação concebida teoricamente entre expectativas de carreira na organização e bem-estar no trabalho (Forgas \& George, 2001; Fredrickson, 2003) e entre expectativas de carreira na organização e de futuro organizacional, realçada em pesquisas qualitativas 
anteriores (Margolis \& Hansen, 2003; Ullrich et al., 2005). Neste último caso, o modelo quantitativo trouxe contribuição adicional ao permitir a aferição da magnitude dessa relação.

Em segundo lugar, mais do que corroborar pesquisas anteriores, o presente estudo contribui ao explicitar a dinâmica de articulação entre as variáveis independentes na predição das expectativas de carreira, o que só é possível quando estas são testadas conjuntamente no modelo. Tal iniciativa adquire maior relevância dada a escassez de investigações que adotam expectativas de carreira na organização como variável dependente.

No que concerne à aplicação prática, os dados lançam luz sobre o poder da gestão de RH em influenciar, direta e indiretamente, variáveis relevantes para a vida organizacional. As organizações devem aprimorar continuamente suas políticas e práticas de RH a fim de incrementar o bem-estar no trabalho e as expectativas de futuro organizacional, efeito que se desdobrará em expectativas de carreira mais favoráveis. Em especial, é interessante notar a inserção das expectativas de futuro organizacional no modelo. Por um lado, as percepções sobre o RH explicam forte e positivamente as expectativas de futuro organizacional, de modo que talvez os profissionais assumam a situação atual da gestão de RH como um indício de que a organização prosperará (ou fenecerá) no futuro. Por outro, expectativas de futuro organizacional predizem fortemente expectativas de carreira na organização, o que sinaliza a necessidade de cuidados especiais, por parte dos gestores, na comunicação do planejamento estratégico e das perspectivas organizacionais.

Entre as limitações da pesquisa, sublinha-se seu corte transversal e delineamento não experimental (o que impossibilita o teste de relações causais entre as variáveis), além do fato do modelo ter sido testado em apenas uma autarquia federal. É necessário considerar as especificidades de ambientes institucionais desse tipo, nos quais geralmente predominam a centralização, a normatividade e a influência de diversos públicos de interesse na gestão de RH (Fonseca, Meneses, Isidro-Filho \& Campos, 2013). Outra limitação concerne ao uso 
exclusivo de medidas de autorrelato, potencialmente influenciadas por vieses como a desejabilidade social. Destaca-se ainda que variáveis não contempladas no modelo podem exercer papel significativo na explicação das expectativas de carreira, entre as quais traços de personalidade, desempenho e envolvimento no trabalho e comprometimento com a carreira. Investigações futuras, além de analisar o efeito dessas variáveis, devem examinar o modelo em outras organizações (inclusive na iniciativa privada) para verificar se os resultados aqui relatados se replicam. É possível ainda realizar análises multinível, nas quais variáveis nos níveis individual e organizacional interagem na predição de expectativas de carreira.

A interrogação “Como será meu futuro nesta organização?” faz parte do cotidiano dos profissionais. Esta pesquisa foi norteada pelo propósito de identificar/compreender os fatores que desencadeiam respostas favoráveis ou desfavoráveis a tal questão. Nesse ponto, os resultados apontaram a relevância tanto de variáveis situacionais orientadas para o presente quanto de variáveis orientadas para o futuro. Contudo, no cenário organizacional, ainda há vasto campo a ser explorado sobre como variáveis de diferentes quadros temporais (passado, presente e futuro) interagem e influenciam a subjetividade dos trabalhadores. Que novas investigações possam ajudar a elucidar a dinâmica intertemporal da vida organizacional. 


\section{Referências}

Aspinwall, L. G. (2005). The Psychology of Future-Oriented Thinking: From Achievement to Proactive Coping, Adaptation, and Aging. Motivation and Emotion, 29, 203-235.

Bandura, A. (1977). Self-efficacy: Toward a unifying theory of behavioral change. Psychological Review, 84, 191-215.

Baptiste, N. R. (2008). Tightening the link between employee well-being at work and performance: A new dimension for HRM. Management Decision, 46(2), 284-309.

Bohlander, G. \& Snell, S. (2010). Managing Human Resources. Mason, OH: South Western. Byrne, B. (2010). Structural equation modeling with AMOS. New York: Taylor \& Francis. Caetano, A. (2012). Psicologia organizacional e do trabalho na era da aceleração: macro e nanodesafios atuais na pesquisa e prática profissional. Revista Psicologia: Organizações e Trabalho, 12(1), 85-96.

Chay, Y. \& Aryee, S. (1999). Potential moderating influence of career growth opportunities on careerist orientation and work attitudes: Evidence of the protean career era in Singapore. Journal of Organizational Behavior, 20(5), 613-623.

Chen, G., Ployhart, R. E., Cooper-Thomas, H. D., Anderson, N., \& Bliese, P. D. (2011). The power of momentum: A new model of dynamic relationships between job satisfaction change and turnover intentions. Academy of Management Journal, 54, 159-181.

Chen, Y., Hsu, Y. \& Yip, F. (2011). Friends or rivals: comparative perceptions of human resource and line managers on perceived future firm performance. International Journal of Human Resource Management, 22(8), 1703-1722.

Chiu, W. (2002). Do types of economic ownership matter in getting employees to commit? An exploratory study in the People's Republic of China. International Journal of Human Resource Management, 13(6), 865-882. 
Combs, J., Liu, Y., Hall, A., \& Ketchen, D. (2006). How much do high-performance work practices matter? A meta-analysis of their effects on organizational performance. Personnel Psychology, 59, 501-528.

Demo, G., Neiva, E., Nunes, I., \& Rozzett, K. (2012). Human resources management policies and practices scale (HRMPPS): exploratory and confirmatory factor analysis. Brazilian Administration Review, 9(4), 395-420.

Demo, G., Neiva, E., Nunes, I., \& Rozzett, K. (2014). Políticas e práticas de recursos humanos. In M.M. Siqueira (Org.). Novas medidas do comportamento organizacional (pp. 240-255). Porto Alegre: Artmed.

Demo, G. \& Paschoal, T. (2013). Well-Being at Work Scale: Exploratory and Confirmatory Validation in the United States Comprising Affective and Cognitive Components. Anais do XXXVII Encontro da ANPAD, Rio de Janeiro.

Fischer, A. L. (2002). Um resgate conceitual e histórico dos modelos de gestão das pessoas. In M.T.L. Fleury (Org.). As Pessoas na Organização (pp. 11-34). São Paulo: Gente.

Fonseca, D., Meneses, P.P., Isidro-Filho, A. \& Campos, N. (2013). Autonomia para gestão estratégica de pessoas no setor público federal: perspectivas de análise e agenda de pesquisa. Revista de Administração Pública, 47(6), 1451-1475.

Forgas, J. P. \& George, J. M. (2001). Affective influences on judgments and behavior in organizations: An information processing perspective. Organizational Behavior and Human Decision Processes, 86, 3-34.

Fredrickson, B. L. (2003). Positive emotions and upward spirals in organizations. In K. Cameron, J. Dutton \& R. Quinn (Eds.). Positive organizational scholarship (pp. 241261). San Francisco: Berrett-Koehle.

Graf, L. P. \& Coutinho, M. C. (2010). Trajetórias de mulheres atuantes em pequenos abatedouros de animais. Cadernos de Psicologia Social do Trabalho, 13(1), 119-132. 
Guest, D., \& Sturges, J. (2007). Living to work-working to live: Conceptualizations of careers among contemporary workers. In H. Gunz, \& M.A. Peiperl (Eds.). Handbook of Career Studies (pp. 310-326). Thousand Oaks, CA: Sage.

Hair, J.F., Black, W., Babin, B., Anderson, R. \& Tatham, R. (2010). Multivariate Data Analysis (sétima edição). Upper Saddle River, NJ: Prentice Hall.

Hall, R., Snell, A., \& Foust, M. (1999). Item parceling strategies in SEM: Investigating the subtle effects of unmodeled secondary constructs. Organizational Research Methods, 2(3), 233-256.

Harris, S. \& Mossholder, K. (1996). The affective implications of perceived congruence with culture dimensions during organizational transformation. Journal of Management, 22, $527-547$.

Horta, P., Demo, G., \& Roure, P. (2012). Human resource management policies, confidence and well-being: a study in a multinational company. Revista de Administração Contemporânea, 16(4), 566-585.

Hui, C., \& Lee, C. (2000). Moderating effects of organization-based self-esteem on organizational uncertainty: employee response relationships. Journal of Management, $26,215-232$.

Jackson, S., Schuler, R. \& Werner, S. (2012). Managing Human Resources. Mason, OH: South Western, Cengage Learning.

Kline, R. (2011). Principles and practice of structural equation modeling. New York: Guilford Press.

Kraimer, M.L., Seibert, S.E., Wayne, S.J., Liden, R.C., \& Bravo, J. (2011). Antecedents and outcomes of organizational support for development: The critical role of career opportunities. Journal of Applied Psychology, 96, 485-500. 
Lips-Wiersma, M. \& Hall, D. (2007). Organizational career development is not dead: a case study on managing the new career during organizational change. Journal of Organizational Behavior, 28(6), 771-792.

London, M. (1983). Toward a theory of career motivation. Academy of Management Review, $8,620-630$.

Magalhães, M. \& Bendassolli, P. (2013). Desenvolvimento de carreira nas organizações. In L. Borges \& M. Mourão (Orgs). O trabalho e as organizações (pp. 433-464). Porto Alegre: Artmed.

Margolis, S. L., \& Hansen, C. D. (2003). Visions to guide performance: a typology of multiple future organizational images. Performance Improvement Quarterly, 16, 40-58.

Meneses, P.P., Coelho Júnior, F., Ferreira, R., Paschoal, T. \& Isidro-Filho, A. (2014). A Produção Científica Brasileira sobre a Gestão de Recursos Humanos entre 2001 e 2010. Revista de Administração Mackenzie, 15, 110-134.

Monga, A. \& Rao, A. (2006). Domain-Based Asymmetry in Expectations of the Future. Organizational Behavior and Human Decision Processes, 100, 35-46.

Ng, T. W. \& Feldman, D. C. (2011). Affective organizational commitment and citizenship behavior: Linear and non-linear moderating effects of organizational tenure. Journal of Vocational Behavior, 79(2), 528-537.

O'Neill, O. A., Stanley, L. J., \& O'Reilly, C. A. (2011). Disaffected Pollyannas: The influence of positive affect on salary expectations, turnover, and long-term satisfaction. Journal of Occupational and Organizational Psychology, 84, 599-617.

Oettingen, G. \& Mayer, D. (2002). The motivating function of thinking about the future: Expectations versus fantasies. Journal of Personality and Social Psychology, 83, 1198-1212. Paschoal, T. \& Tamayo, A. (2008). Construção e validação da Escala de bem-estar no trabalho. Avaliação Psicológica, 7(1), 11-22. 
Podsakoff, P., MacKenzie, S., Lee, J. \& Podsakoff, N. (2003). Common method biases in behavioral research: a critical review of the literature and recommended remedies. Journal of Applied Psychology, 88(5), 879-903.

Prince, J. B. (2003). Career opportunity and organizational attachment in a blue-collar unionized environment. Journal of Vocational Behavior, 63(1), 136-150.

Richardson, H., Simmering, M., \& Sturman, M. (2009). A tale of three perspectives: Examining post hoc statistical techniques for detection and correction of common method variance. Organizational Research Methods, 12(4), 762-800.

Ryan, R., \& Deci, E. (2001). On happiness and human potentials: A review of research on hedonic and eudaimonic well-being. Annual Review of Psychology, 52, 141-166.

Scheier, M. \& Carver, C. (1985). Optimism, coping, and health: assessment and implications of generalized outcome expectancies. Health Psychology, 4(3), 219-247.

Soares, D. \& Sestren, G. (2007). Projeto profissional: o redimensionamento da carreira em tempos de privatização. Psicologia \& Sociedade, 19, 66-74.

Sonnentag, S. (2012). Time in organizational research: Catching up on a long neglected topic in order to improve theory. Organizational Psychology Review, 2(4), 361-368.

Stroh, L., \& Reilly, A. (1997). Rekindling Organizational Loyalty: The Role of Career Mobility. Journal of Career Development, 24, 39-54.

Subramony, M. (2009). A meta-analytic investigation of the relationship between HRM bundles and firm performance. Human Resource Management, 48(5), 745-768.

Tolfo, S. (2002). Carreira Profissional e seus movimentos: Revendo conceitos e formas de gestão. Revista: Psicologia, Organizações e Trabalho, 2(2), 39-63.

Ullrich, J., Wieseke, J., \& van Dick, R. (2005). Continuity and Change in Mergers and Acquisitions: A Social Identity Case Study of a German Industrial Merger. Journal of Management Studies, 42(8), 1549-1569. 
Vasconcellos, V. \& Neiva, E. (2014). Avaliação de futuro profissional e sua relação com bem-estar no trabalho e intenção de desligamento. Gestão e Planejamento, 15, 410-427. Vasconcellos, V. \& Neiva, E. (2015a). Escala de Expectativas de Carreira na Organização: Desenvolvimento e Evidências de Validade. Manuscrito em preparação para submissão. Vasconcellos, V. \& Neiva, E. (2015b). Escala de Expectativas de Futuro Organizacional: Desenvolvimento e Evidências de Validade. Manuscrito em preparação para submissão.

Veloso, E., Dutra, J., Fischer, A., Pimentel, J., Silva, R. \& Amorim, W. (2011). Gestão de carreiras e crescimento profissional. Revista Brasileira de Orientação Profissional, 12, $61-72$.

Warr, P. (2013). Fuentes de felicidad e infelicidad en el trabajo: una perspectiva combinada. Revista de Psicología del Trabajo y de las Organizaciones, 29(3), 99-106.

Waterman, A. S. (1993). Two conceptions of happiness: Contrasts of personal expressiveness (eudaimonia) and hedonic enjoyment. Journal of Personality and Social Psychology, 64(4), 678-691.

Weiss, H. \& Cropanzano, R. (1996). Affective Events Theory: A theoretical discussion of the structure, causes and consequences of affective experiences at work. In B.M. Staw \& L.L. Cummings (Eds.). Research in Organization Behavior (pp. 1-74). Greenwich, CT: JAI.

Wright, T. \& Bonett, D. (2002). The moderating effects of employee tenure on the relationship between organizational commitment and job performance: A meta-analysis. Journal of Applied Psychology, 87, 1183-1190.

Zacher, H., Heusner, S., Schmitz, M., Zwierzanska, M. \& Frese, M. (2010). Focus on opportunities as a mediator of the relationships between age, job complexity, and work performance. Journal of Vocational Behavior, 76, 374-386. 


\section{MANUSCRITO 7}

Os dois últimos manuscritos desenvolveram-se tendo como mote a identificação de variáveis que influenciam as expectativas de carreira e de futuro organizacional. O último manuscrito da tese, por sua vez, parte da questão inversa: como tais expectativas influenciam outras variáveis? Essa questão afigura-se como complemento e extensão natural das questões anteriormente tratadas na tese sendo, portanto, apropriada para seu encerramento. Nesse rumo, o Manuscrito 7 examina um modelo no qual expectativas de futuro organizacional e de carreira na organização atuam como antecedentes de comprometimento organizacional afetivo e intenção de rotatividade, duas das mais relevantes variáveis de comportamento organizacional. Tal modelo busca avaliar a dinâmica intertemporal dessa relação, notadamente, a capacidade das expectativas de futuro de moldar o presente, iniciativa que fornece interessante perspectiva de análise para essas variáveis dependentes. Assim como no Manuscrito 6, testes de mediação e moderação enriqueceram a análise das relações propostas pelo modelo. 


\section{MANUSCRITO 7}

Efeitos de Expectativas de Futuro em Comprometimento Organizacional e Intenção de Rotatividade

Effects of Future Expectations on Organizational Commitment and Turnover Intention

Vinicius Carvalho de Vasconcellos

Universidade de Brasília 


\title{
Resumo
}

As expectativas sobre o futuro no contexto de trabalho figuram como um tema pouco explorado na área de comportamento organizacional. Partindo dessa lacuna, esta pesquisa testou um modelo no qual expectativas de futuro organizacional e de carreira na organização atuam como antecedentes de comprometimento organizacional afetivo e intenção de rotatividade. Investigou-se igualmente se o tipo de organização do profissional e o seu grau de orientação para o futuro operavam como moderadores dessas relações. Os respondentes $(n=370)$, oriundos de diversas organizações, responderam a um questionário com escalas validadas no Brasil. Os resultados, obtidos por modelos de equações estruturais, apontaram a relação positiva de expectativas de futuro organizacional com comprometimento organizacional afetivo e com expectativas de carreira na organização. Esta última variável, por sua vez, atuou como antecedente de comprometimento organizacional afetivo (relação positiva) e de intenção de rotatividade (relação negativa). Os dados sugerem ainda que o tipo de organização modera a relação de expectativas de carreira e intenção de rotatividade e que orientação para o futuro modera a relação de expectativas de carreira com comprometimento organizacional afetivo. A discussão analisa a importância das expectativas de futuro na compreensão do vínculo indivíduo-organização.

Palavras-chave: carreira, expectativas, comprometimento organizacional, intenção de rotatividade

\begin{abstract}
Expectations about the future in the work context are a subject still little explored in the organizational behavior field. Noting this gap, this study tested a model in which organizational future expectations and career expectations in the organization act as antecedents of affective organizational commitment and turnover intention. It also investigated whether the organization's sector (public versus private) and the levels of future time perspective operated as moderators of these relationships. The sample of 370 professionals (from several organizations) answered a questionnaire with several validated scales in Brazil. The results, obtained by structural equation models, indicated that organizational future expectations were positively related to affective organizational commitment and career expectations in the organization. The latter variable, in turn, acted as an antecedent of affective organizational commitment (positive relationship) and turnover intention (negative relationship). The data also suggest that the organization's sector moderates the effects of career expectations on turnover intention and that the level of future time perspective moderates the effects of career expectations on affective commitment. The discussion analyzes the importance of future expectations in understanding the individualorganization relationship.
\end{abstract}

Keywords: career, expectations, organizational commitment, turnover intentions 
A capacidade de se relacionar com o futuro figura como aspecto relevante da subjetividade humana. Não por acaso, modelos e teorias de grande vulto na psicologia concederam às expectativas e percepções de futuro papel notável na motivação e na produção/mudança de comportamento (Bandura, 1977; Lewin, 1939; Vroom, 1964). A partir dessas contribuições, apreende-se que o presente também é condicionado pela forma com que os indivíduos enxergam o futuro, contrariando a noção de que os quadros temporais (passado, presente e futuro) estão concatenados unidirecionalmente.

A presente pesquisa aborda especificamente o modo como o presente e o futuro se entrelaçam nas organizações contemporâneas. Nos modelos atuais de gestão, o futuro assume alto grau de incerteza em função dos rápidos fluxos de mudança derivados dos desequilíbrios macroeconômicos, dos avanços tecnológicos substanciais e da volatilidade nos mercados nas últimas décadas. Tal conjuntura de incerteza repercute não apenas nas projeções de futuro das organizações, mas também nas trajetórias de carreira dos indivíduos, cada vez mais concebidas como projetos abertos e imprevisíveis. Atualmente, independente do estágio profissional, as decisões sobre o futuro na carreira estão entre as principais fontes de preocupação e interesse dos indivíduos (Magalhães \& Bendassolli, 2013).

Para abordar o enlace presente-futuro na cena organizacional, este artigo centra-se nas expectativas dos indivíduos sobre sua carreira e sobre o futuro de sua organização. Seu objetivo é testar um modelo que propõe esses dois tipos de expectativas (variáveis orientadas para o futuro) como antecedentes de comprometimento organizacional afetivo e intenção de rotatividade (variáveis orientadas para o presente), avaliando também possíveis moderadores.

Investigações anteriores, malgrado a variabilidade de medidas e construtos adotados, relataram que projeções de futuro organizacional e de carreira correlacionam-se a diferentes atitudes e comportamentos no ambiente organizacional (Chay \& Aryee, 1999; Chiu, 2002; Prince, 2003; Stroh \& Reilly, 1997). Assim, variáveis orientadas para o futuro parecem 
conformar área promissora de estudo, embora essa literatura ainda seja incipiente e fragmentada. No fundo, a dimensão temporal (não apenas o futuro) tende a ser ignorada ou posta em segundo plano na literatura de organizações e trabalho (George \& Jones, 2000; Lee \& Liebenau, 1999; Sonnentag, 2012).

Ciente dessa lacuna, esta pesquisa aprecia o papel da temporalidade (em especial das expectativas de futuro) no seio da relação indivíduo-organização. Como a literatura sobre o tema é, ao mesmo tempo, escassa e auspiciosa, torna-se oportuno empreender tal investigação. Assim, a próxima seção detalha o modelo proposto e suas hipóteses.

\section{Modelo de Investigação Proposto e Desenvolvimento de Hipóteses}

A Figura 1 expõe o modelo de investigação proposto. Este testa o impacto das expectativas de futuro organizacional e de carreira no comprometimento organizacional afetivo e na intenção de rotatividade.

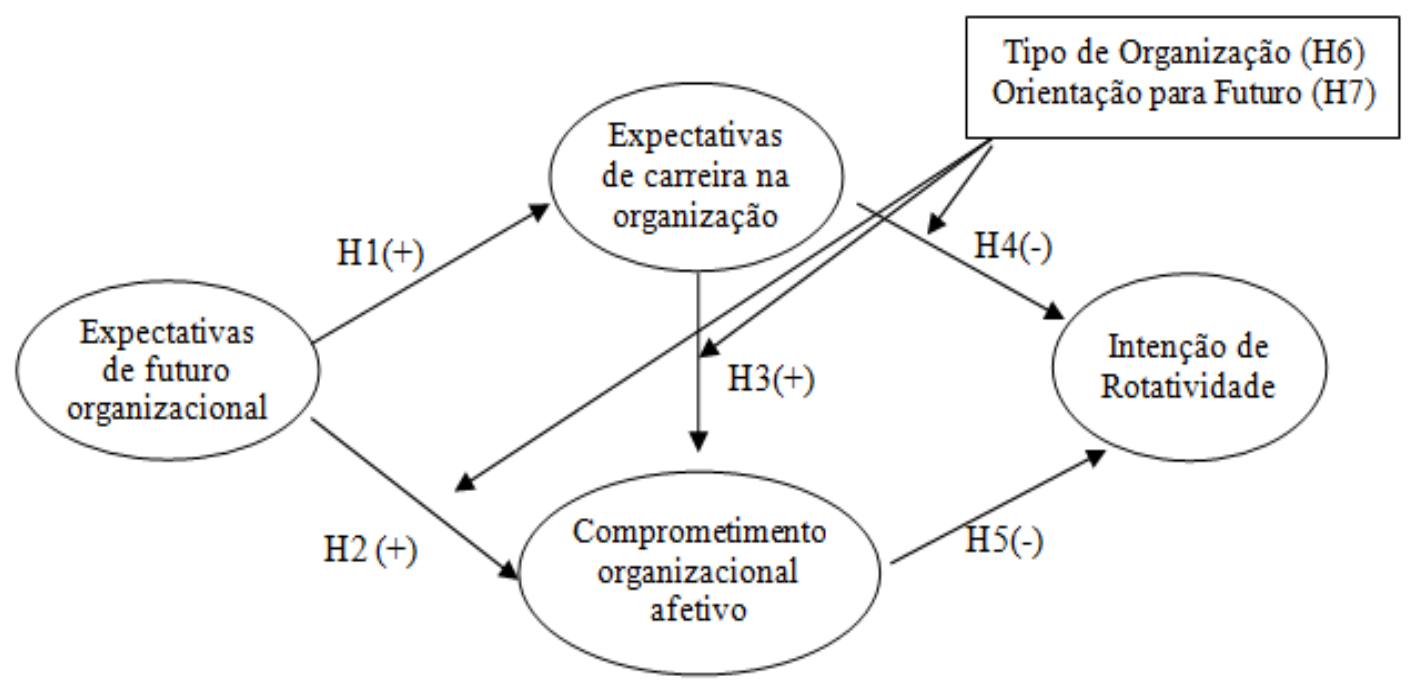

Figura 1. Modelo de investigação proposto.

Com exceção da associação entre comprometimento organizacional e intenção de rotatividade, poucos estudos exploraram empiricamente as relações propostas no modelo e, quando o fizeram, relataram efeitos isolados para cada par de variáveis. Em seu desenho, o modelo permite analisar, de forma integrada, as diversas relações entre variáveis. Ademais, 
tipo de organização do profissional e orientação para o futuro são examinados como potenciais moderadores da relação dos dois tipos de expectativas com as duas principais variáveis dependentes do estudo (comprometimento organizacional afetivo e intenção de rotatividade), iniciativa que não foi localizada na literatura.

A rigor, a proposição/teste do modelo atende aos apelos de artigos teóricos sobre carreira e intenção de rotatividade que convocam mais pesquisas com variáveis orientadas para o futuro (Lawrence \& Tolbert, 2007; Mitchell, Burch \& Lee, 2014). As hipóteses, forjadas com base em estudos pregressos de comportamento organizacional, psicologia social e psicologia do tempo, são caracterizadas nas próximas subseções.

\section{Expectativas de Futuro Organizacional e de Carreira na Organização}

No modelo, a relação dos indivíduos com futuro traduz-se em duas variáveis que aferem expectativas, isto é, crenças sobre o futuro provável (Oettingen \& Mayer, 2002). A primeira, expectativas de futuro organizacional, trata das crenças dos profissionais sobre a gestão e a efetividade de sua organização no futuro (Vasconcellos \& Neiva, 2015a). Como está no nível individual, tal construto distingue-se de construtos vinculados ao planejamento, como visão da organização e cenários prospectivos. A segunda variável, expectativas de carreira na organização, expressa as crenças dos indivíduos sobre sua futura trajetória profissional na atual organização (Vasconcellos \& Neiva, 2015b). Ao abordar expectativas, esta variável diferencia-se das variáveis de carreira orientadas para o presente (satisfação com a carreira, por exemplo) ou para o futuro desejado, preferido ou ideal (aspirações/objetivos de carreira).

Ao pensar sobre sua futura carreira na organização, parece plausível supor que os indivíduos considerem o futuro desta última. Profissionais que vislumbram perspectivas favoráveis para a organização - aprimoramento na gestão, expansão nas operações, aumento no lucro e na fatia de mercado, entre outros pontos - podem presumir que tais perspectivas se 
desdobrarão em oportunidades ou benesses para eles mesmos. Inversamente, quando o futuro organizacional afigura-se adverso, provavelmente os indivíduos nutrirão expectativas mais negativas sobre seu próprio futuro naquela organização, posto que as possibilidades de desenvolvimento e crescimento tendem a ser mais restritas.

Pesquisas qualitativas durante mudanças organizacionais já identificaram a vinculação entre expectativas de carreira e de futuro organizacional (Duarte \& Silva, 2013; Margolis \& Hansen, 2003; Ullrich, Wieseke \& van Dick, 2005). Nessas investigações, expectativas sobre crescimento dos negócios e melhorias na imagem da organização vincularam-se a expectativas de avanços na carreira e de aumento nos salários/benefícios. Por outro lado, incertezas sobre a estrutura organizacional e o ambiente de trabalho no futuro atrelaram-se à insegurança sobre o próprio futuro profissional. Esses resultados sugerem relação positiva entre os dois conjuntos de expectativas. Neste estudo, a relação entre essas variáveis será testada por meio de medidas quantitativas, proporcionando um olhar distinto, conquanto complementar, às pesquisas citadas. Assim, a primeira hipótese determina que:

Hipótese 1 - Expectativas de futuro organizacional relacionam-se positivamente às expectativas de carreira na organização.

\section{Expectativas de Futuro Organizacional e Comprometimento Organizacional Afetivo}

O modelo também propõe que expectativas de futuro organizacional associam-se ao comprometimento organizacional. Este é assumido aqui como o vínculo do indivíduo com a organização que se traduz em ligação afetiva, identificação com os valores/normas/objetivos organizacionais e realização de comportamentos em prol da organização (Bastos, Rodrigues, Moscon, Silva \& Pinho, 2013).

De que forma expectativas de futuro organizacional relacionam-se com comprometimento organizacional? É provável que indivíduos que creem em um futuro favorável para sua organização sintam-se mais inclinados a construir esse tipo de vínculo do 
que indivíduos que esperam um futuro organizacional pouco alvissareiro, cenário que faria da organização um lugar arriscado para se trabalhar a médio e longo prazo. Estudos anteriores apontam nessa mesma direção. Mossholder, Settoon, Harris e Armenakis (1995) detectaram, em amostra de gerentes, correlação positiva entre comprometimento organizacional e otimismo quanto ao futuro da organização, variável aferida a partir de uma escala que continha apenas dois itens. Por sua vez, Chiu (2002) relata que percepções sobre o desenvolvimento futuro da organização operam como antecedentes de comprometimento afetivo (relação positiva).

Como Chiu (2002), esta pesquisa enfatiza o componente afetivo do comprometimento. Todavia, adota-se aqui forma distinta de conceituar/aferir o futuro organizacional na perspectiva dos indivíduos, oferecendo à literatura teste alternativo da relação entre as variáveis. De todo modo, há na literatura base suficiente para a segunda hipótese:

Hipótese 2 - Expectativas de futuro organizacional relacionam-se positivamente ao comprometimento organizacional afetivo.

\section{Expectativas de Carreira na Organização, Comprometimento Organizacional Afetivo e}

\section{Intenção de Rotatividade}

O modelo prevê ainda expectativas de carreira na organização como preditor de comprometimento organizacional afetivo (relação positiva) e de intenção de rotatividade (relação negativa). Esta última é definida como o grau em que o indivíduo elabora planos sobre sua saída da organização na qual trabalha (Siqueira, Gomide Jr., Oliveira \& Filho, 2014). Essas hipóteses apoiam-se em dois alicerces básicos: a teoria da troca social e a norma da reciprocidade, ambas com raízes nas ciências sociais e na psicologia social. A primeira pontua que trocas sociais representam um processo de interação fundado na confiança, gratidão e interdependência dos envolvidos, no qual favores, contribuições e benefícios ofertados por uma das partes (por exemplo, a organização) desperta na outra parte (por 
exemplo, o profissional) a obrigação de retribuir (Blau, 1964). No mesmo campo semântico, a norma da reciprocidade é concebida como componente moral que define como obrigação o ato de retribuir um benefício recebido (Gouldner, 1960). O ato de reciprocidade não emerge de exigência legal, e sim, do anseio de reequilibrar a relação social.

Nessa linha, boas expectativas de carreira podem ser assumidas pelos indivíduos como um benefício ofertado pela organização, o que ensejaria a necessidade de retribuição por meio de alto comprometimento e baixa intenção de rotatividade. Constitui-se, assim, uma relação interdependente e selada na confiança recíproca. Em contraste, se há expectativas de carreira negativas, a troca social e a reciprocidade cessam, levando à diminuição no comprometimento e ao crescimento na intenção de rotatividade.

No caso da relação entre expectativas de carreira e comprometimento organizacional, outras fontes podem ser evocadas para embasar a hipótese. Por exemplo, o modelo teórico de Lawrence e Tolbert (2007) sobre decisões e comportamentos de carreira propõe que percepções favoráveis sobre oportunidades de carreira resultam em aumento de comprometimento organizacional, uma vez que os profissionais tenderiam a investir seu tempo, esforço e competências na organização, favorecendo a formação de vínculos afetivos.

Em acréscimo, pesquisas empíricas pregressas reportaram correlações positivas e moderadas entre percepção de oportunidades de carreira e comprometimento afetivo (Crawshaw, van Dick \& Brodbeck, 2012; Kraimer, Seibert, Wayne, Liden \& Bravo, 2011) e comprometimento em geral (Chay \& Aryee, 1999). Prince (2003) relata que expectativas de enriquecimento do cargo (isto é, obtenção de atividades mais complexas e autônomas) predizem comprometimento organizacional geral (efeito positivo e moderado). Esses estudos evidenciaram o elo entre comprometimento organizacional e variáveis correlatas ao construto aqui adotado (expectativas de carreira na organização). Combinando tais dados com a fundamentação teórica anterior, é possível derivar a hipótese 3: 
Hipótese 3 - Expectativas de carreira na organização relacionam-se positivamente ao comprometimento organizacional afetivo.

No caso da relação de expectativas de carreira e intenção de rotatividade, além dos mecanismos inerentes à troca social e à norma da reciprocidade, salienta-se que modelos teóricos sobre rotatividade (por exemplo, Mobley, Griffeth, Hand \& Meglino, 1979) postulam o papel de projeções sobre a carreira/trabalho na formação da intenção de sair da organização. Com efeito, expectativas de carreira elevadas podem incrementar o senso de mutualismo de interesses e dissuadir os indivíduos de planos de desligamento, até porque só continuando na organização as expectativas poderão se materializar em avanços reais na carreira. Como aponta a literatura especializada em psicologia do tempo, expectativas de sucesso motivam os indivíduos a se engajar em atividades que permitam a realização do futuro desejado (Oettingen, 2012), o que pressupõe a permanência na organização (e menor intenção de rotatividade). Assim, espera-se relação negativa entre as variáveis: elevadas (baixas) expectativas para a carreira vinculam-se à baixa (alta) intenção de rotatividade.

Do ponto de vista empírico, estudos prévios acusaram correlações negativas e moderadas entre expectativas/percepções de futuro na carreira e intenção de rotatividade (Chay \& Aryee, 1999; Chen, Ployhart, Cooper-Thomas, Anderson \& Bliese, 2011). A presente pesquisa testa esse padrão de resultados, contudo, utilizando uma forma diferente de conceber/aferir o futuro na carreira. Assim, a hipótese 4 aponta que:

Hipótese 4 - Expectativas de carreira na organização relacionam-se negativamente à intenção de rotatividade.

\section{Comprometimento Organizacional Afetivo e Intenção de Rotatividade}

Ao contrário das hipóteses anteriores, a relação entre comprometimento organizacional e intenção de rotatividade já foi bastante estudada na literatura. A quantidade de estudos 
decorre, em grande parte, da ideia intuitiva de que quanto maior a identificação e o elo afetivo com a organização (comprometimento), menor a intenção de deixá-la. Do ponto de vista empírico, a associação entre essas variáveis é realmente consistente, de sorte que a meta-análise de Meyer, Stanley, Herscovitch e Topolnytsky (2002) indica intenção de rotatividade como o mais forte consequente proximal de comprometimento afetivo (associação negativa). Esse padrão continua a assomar em investigações recentes (Boros \& Curseu, 2013; Poon, 2012). Com base no exposto, a hipótese 5 estipula que:

Hipótese 5 - Comprometimento organizacional afetivo relaciona-se negativamente à intenção de rotatividade.

Ao integrar essa hipótese às anteriores, nota-se que o modelo contém mecanismos de mediação. Propõe-se que o efeito das expectativas de futuro organizacional em intenção de rotatividade seja totalmente mediado por comprometimento organizacional afetivo e expectativas de carreira, pois não foi localizada na literatura justificativa para o efeito direto. Esperam-se ainda duas mediações parciais: o efeito das expectativas de futuro organizacional em comprometimento organizacional afetivo seria mediado por expectativas de carreira e o efeito de expectativas de carreira em intenção de rotatividade seria mediado por comprometimento organizacional afetivo. Em ambos os casos, não foram encontrados estudos anteriores que indicassem a capacidade das variáveis mediadoras em suprimir integralmente os efeitos diretos das variáveis independentes nas variáveis dependentes.

\section{Variáveis Moderadoras}

Como a literatura sobre futuro na carreira ainda carece de pesquisas sobre moderação (Crawshaw et al., 2012), esta pesquisa testa moderadores para as três relações do modelo nas quais as expectativas (de futuro organizacional e de carreira) atuam como variáveis independentes de comprometimento organizacional e intenção de rotatividade (hipóteses H2, 
H3 e H4). Tipo de organização (pública ou privada) foi o primeiro moderador testado. Estudos brasileiros (Salles \& Nogueira, 2006; Sant'anna, Paschoal \& Gosendo, 2012) sustentam que há diferenças entre os dois ambientes de trabalho no país. Em geral, o funcionalismo público (administração direta, fundações e autarquias) caracteriza-se por maior estabilidade de trabalho, vínculos de longo prazo e relacionais, previsibilidade no ambiente organizacional e por trajetórias de carreira mais limitadas, rígidas e influenciadas por tempo de serviço. Na iniciativa privada, há menor previsibilidade/estabilidade no ambiente de trabalho, os vínculos tendem a ser de curto prazo/transacionais, porém existe maior agilidade na trajetória de carreira.

No funcionalismo público, como existe maior previsibilidade quanto ao futuro da organização e da carreira, é provável que a influência das expectativas nas demais variáveis do modelo seja menor do que no setor privado. Por exemplo, a valorização da estabilidade, pelos funcionários públicos, deve minimizar o efeito das expectativas na intenção de rotatividade, em oposição à dinâmica do setor privado. De outra parte, o comprometimento organizacional vincula-se mais claramente a variáveis ligadas à carreira (como comprometimento com a carreira e adequação das políticas de promoção) nas empresas privadas do que no funcionalismo público (Bastos, 1994; Bastos \& Borges-Andrade, 2002). No setor privado, como o vínculo indivíduo-organização geralmente é mais fugaz e pragmático, o comprometimento e a permanência na organização dependeriam mais fortemente das crenças dos profissionais sobre o futuro da organização e sobre o futuro na carreira. Nessa linha, a hipótese 6 sustenta que:

Hipótese 6 - Tipo de organização modera a relação de expectativas de futuro organizacional e de carreira na organização com comprometimento organizacional afetivo e intenção de rotatividade, de forma que a relação entre as variáveis será mais forte no setor privado do que no funcionalismo público. 
A segunda variável de moderação advém do referencial teórico de orientação (perspectiva) temporal de Zimbardo e Boyd (1999). Orientação temporal refere-se ao processo não consciente pelo qual os indivíduos organizam e interpretam o fluxo de experiências pessoais/sociais. Há cinco dimensões de orientação temporal (passado-negativo, passado-positivo, presente-hedonista, presente-fatalista e futuro) e a ênfase em determinada dimensão pode atuar como tendência cognitiva capaz de condicionar sistematicamente julgamentos, intenções, decisões e comportamentos dos indivíduos.

No presente artigo, o foco recai na orientação para o futuro. Zimbardo e Boyd (1999) ponderam que indivíduos com altos escores nesta dimensão tendem a planejar e organizar cuidadosamente suas vidas e a enfatizar recompensas/objetivos futuros (inclusive de carreira), mesmo que estes demandem sacrifícios no presente (adiamento de gratificação). Com base no referencial teórico de Zimbardo e Boyd (1999), é possível supor que, em indivíduos altamente orientados para o futuro, o efeito das expectativas em comprometimento organizacional afetivo e intenção de rotatividade seja maior (em módulo) do que nos indivíduos que atribuem menor relevância a tal quadro temporal. Isto é, dada a grande importância do futuro, as expectativas (negativas ou positivas) influenciariam mais fortemente as variáveis orientadas para o presente. Assim, a hipótese 7 propõe que:

Hipótese 7 - Orientação para o futuro modera a relação de expectativas de futuro organizacional e de carreira na organização com comprometimento organizacional afetivo e intenção de rotatividade, de forma que a relação entre as variáveis será mais forte em indivíduos com elevada orientação para o futuro do que nos demais.

\section{Método}

\section{Participantes}

$\mathrm{Na}$ amostra $(n=370)$, a idade média foi de 42,04 anos $(\mathrm{DP}=12,42), 50 \%$ eram homens e todos apresentavam escolaridade igual/superior ao nível médio. Os profissionais trabalhavam 
em várias organizações, com preponderância do setor privado (49\%) e do funcionalismo público (36\%). Para $\alpha=0,05$, essa amostra fornece poder estatístico superior a $80 \%$ nos modelos relatados na seção de resultados, considerando $\varepsilon_{0} \leq 0,05$ e $\varepsilon_{\mathrm{a}}=0,08$, respectivamente, como hipótese nula e valor testado do Root Mean Square Error of Approximation (RMSEA).

\section{Procedimentos}

O recrutamento dos participantes foi realizado por consultoria especializada. A consultoria enviou para os potenciais respondentes um link para a página eletrônica da pesquisa (taxa de resposta de 25\%), na qual constavam as instruções e o questionário. Este foi respondido individualmente, de forma voluntária e anônima. Um incentivo de cerca de R\$ 15 reais foi concedido aos participantes da pesquisa.

\section{Instrumentos}

\section{Expectativas de Carreira na Organização e de Futuro Organizacional.}

Foram empregadas a Escala de Expectativas de Futuro Organizacional (EEFO) e a versão reduzida da Escala de Expectativas de Carreira na Organização (EECO) validadas, respectivamente, por Vasconcellos e Neiva (2015a) e por Vasconcellos e Neiva (2015b). As assertivas da EEFO remetem à situação da organização no futuro (exemplo: “O ambiente de trabalho será aperfeiçoado pela gestão da organização”) e as da EECO aludem à situação da carreira do indivíduo naquela organização no futuro (exemplo: "Serei um profissional bemsucedido na minha carreira"), em ambos os casos de forma positivada. Nas duas escalas, os participantes assinalam em escala de sete pontos a probabilidade dessa situação ocorrer cinco anos à frente (1=nada provável até 7=extremamente provável). A EEFO apresenta nove itens distribuídos em dois fatores: Gestão e Ambiente Organizacional (quatro itens; $\alpha=0,91$ ) e Efetividade Organizacional (cinco itens; $\alpha=0,91$ ). A EECO conta com 10 itens divididos em dois fatores: Conquistas Profissionais (seis itens; $\alpha=0,91$ ) e Relação Carreira-Vida Pessoal (quatro itens; $\alpha=0,91$ ). 


\section{Comprometimento Organizacional Afetivo.}

Foram utilizados cinco itens $(\alpha=0,87)$ da escala de Menezes e Bastos (2011), selecionados com base em suas cargas fatoriais e ligação semântica com o construto. "Sinto que existe uma forte ligação afetiva entre mim e esta organização" constitui um exemplo de item. As respostas foram dadas a partir de escala de concordância (cinco pontos).

\section{Intenção de Rotatividade.}

A variável foi medida pela Escala de Intenção de Rotatividade (Siqueira et al., 2014). Os três itens da escala $(\alpha=0,93)$ foram respondidos por intermédio de escala de frequência (1=nunca até 5=sempre). Exemplo de item: "Penso em sair da organização onde trabalho".

\section{Orientação para o Futuro.}

A variável foi mensurada pelo fator Orientação ao Futuro da Escala de Orientação Temporal (Souza, 2013). Foram selecionados os seis itens com as maiores cargas fatoriais do fator $(\alpha=0,78)$. "Tenho projetos e planos de futuro bem definidos" é um exemplo de item. A escala foi respondida por meio de escala de concordância (cinco pontos).

Além dessas variáveis, os respondentes indicavam seu sexo, idade, tempo de organização e tipo de organização empregadora. Como as variáveis foram aferidas no mesmo questionário, o viés de método comum foi uma preocupação. Para minimizar esse risco, foram seguidas as recomendações de Podsakoff, MacKenzie, Lee e Podsakoff (2003) de garantir o anonimato das respostas e de separar as variáveis no questionário tanto psicológica (ao adotar introduções customizadas para cada variável) quanto metodologicamente (usando escalas com âncoras e número de pontos diferentes).

\section{Análise de dados}

A análise dos dados compreendeu a avaliação do modelo de mensuração (via análise fatorial confirmatória) e do modelo estrutural (para testar as hipóteses). Em ambos os casos, os construtos expectativas de futuro organizacional e expectativas de carreira na organização 
utilizaram as médias de seus fatores como variáveis empíricas. Essa estratégia de agregação é bastante comum na literatura, posto que favorece o surgimento de variáveis com distribuição mais intervalar, normal e confiável (Hall, Snell \& Foust, 1999). Os modelos foram calculados no programa AMOS 18 pelo método de estimação máxima verossimilhança. Como os dados não exibiram normalidade multivariada (aferida pelo teste de Mardia), recorreu-se à técnica de bootstrapping (500 subamostras foram geradas) para se avaliar a estabilidade dos parâmetros estimados (Byrne, 2010).

No teste de hipóteses, foram observados o sinal, magnitude e significância dos coeficientes, além do ajuste geral dos modelos. Além do RMSEA, os seguintes índices foram considerados: GFI (Goodness-of-Fit Index), CFI (Comparative Fit Index), SRMR

(Standardized Root Mean Residual) e a diferença entre os valores de $\chi^{2}$ (qui-quadrado) para avaliar modelos alternativos. Comparou-se o modelo proposto a modelos alternativos haja vista que tal prática constitui teste mais rigoroso do que a análise isolada de seu ajuste (Hair, Black, Babin, Anderson \& Tatham, 2010). Análises sobre modelos alternativos, mediação e moderadores seguiram, sobretudo, as orientações de Hair et al. (2010).

As hipóteses sobre moderação foram examinadas por análise multigrupo. Os dois grupos comparados na variável tipo de organização foram: organizações do funcionalismo público e organizações privadas. Em orientação para o futuro, também foram comparados dois grupos: um com indivíduos com escores no fator acima da mediana e outro com indivíduos com escores abaixo da mediana. Na prática, todos no primeiro grupo obtiveram valor igual ou maior que 4,00, intervalo que abrange os pontos de concordância da escala (o grupo foi denominado como alta orientação para o futuro). E todos no segundo grupo obtiveram valor inferior a 4,00, intervalo que engloba os pontos de neutralidade e discordância da escala (o grupo foi denominado como média/baixa orientação para o futuro). Outros critérios de divisão de grupos presentes na literatura foram preteridos visto que formariam pelo menos um grupo com tamanho amostral 
pequeno, reduzindo o poder estatístico e dificultando o uso de modelos estruturais. Testes $t$ apontaram que os dois grupos gerados diferem fortemente $(p<0,001, d>0,80)$ nos escores do fator, o que fornece maior segurança para o teste de moderação.

\section{Resultados}

\section{Estatísticas Descritivas e Análise Fatorial Confirmatória}

A Tabela 1 exibe as estatísticas descritivas e correlações das variáveis investigadas. As expectativas de carreira e de futuro organizacional correlacionaram-se positivamente com comprometimento organizacional afetivo (efeitos moderados e fortes) e negativamente com intenção de rotatividade (efeitos moderados). Esses dados vieram em linha com o esperado. Tabela 1

Médias, Desvios-padrão e Correlações das Variáveis do Modelo de Investigação Proposto

\begin{tabular}{lccccccc}
\hline \multicolumn{1}{c}{ Variáveis } & Média (DP) & $\mathbf{1}$ & $\mathbf{2}$ & $\mathbf{3}$ & $\mathbf{4}$ & $\mathbf{5}$ & $\mathbf{6}$ \\
\hline 1. ECO Carreira e Vida pessoal & $4,85(1,41)$ & - & & & & & \\
2. ECO Conquistas Profissionais & $4,61(1,38)$ & 0,63 & - & & & & \\
3. EFO Gestão e Ambiente Organizacional & $4,60(1,31)$ & 0,47 & 0,67 & - & & & \\
4. EFO Efetividade Organizacional & $4,99(1,29)$ & 0,43 & 0,67 & 0,76 & - & & \\
5. Intenção de Rotatividade & $2,67(1,15)$ & $-0,26$ & $-0,43$ & $-0,35$ & $-0,36$ & - & \\
6. COA & $3,70(0,84)$ & 0,35 & 0,53 & 0,49 & 0,52 & $-0,47$ & - \\
7. Orientação para Futuro & $3,79(0,70)$ & 0,21 & 0,22 & 0,14 & 0,15 & $-0,09$ & 0,24 \\
\hline
\end{tabular}

Nota. $\mathrm{ECO}=$ Expectativas de Carreira na Organização; EFO=Expectativas de Futuro Organizacional; $\mathrm{COA}=$ Comprometimento Organizacional Afetivo. Todas as correlações são significativas $(p<0,01)$, exceto no caso da correlação entre orientação para futuro e intenção de rotatividade $(r=-0,09, p=0,09)$.

A adequação do modelo proposto sob a ótica da mensuração dos construtos foi avaliada por análise fatorial confirmatória, inclusive com testes de modelos alternativos (Tabela 2). $\mathrm{O}$ modelo proposto (quatro fatores) exibiu bom ajuste em todos os índices. Todas as cargas fatoriais foram significativas $(p<0,01)$ e superiores a 0,55 e não foi necessário realizar nenhuma ligação entre os termos de erro das variáveis empíricas. Os modelos alternativos (um, dois e três fatores) foram estatisticamente inferiores (pela diferença de $\chi^{2}$ ) e contaram 
com índices de ajuste piores do que o modelo proposto. Assumiu-se, portanto, a adequação do modelo de mensuração proposto.

Tabela 2

Índices de Ajuste dos Modelos na Análise Fatorial Confirmatória

\begin{tabular}{lccccccccc}
\hline \multicolumn{1}{c}{ Modelo } & $\chi^{2}$ & $\boldsymbol{g l}$ & GFI & CFI & RMSEA & IC $_{\text {RMSEA }}$ & SRMR & $\boldsymbol{\Delta} \boldsymbol{\chi} \mathbf{2}$ \\
\hline Quatro fatores (proposto) $^{2}$ & $137,54^{* *}$ & 48 & 0,94 & 0,97 & 0,07 & {$[0,06-0,09]$} & 0,04 & - \\
Três fatores $^{\mathrm{a}}$ & $206,29^{* *}$ & 51 & 0,91 & 0,95 & 0,09 & {$[0,08-0,10]$} & 0,04 & $68,75^{* *}$ \\
Dois fatores $^{\mathrm{b}}$ & $863,13^{* *}$ & 53 & 0,70 & 0,72 & 0,20 & {$[0,19-0,22]$} & 0,10 & $725,59^{* *}$ \\
Um fator $^{\text {Um }}$ & $1203,81^{* *}$ & 54 & 0,62 & 0,61 & 0,24 & {$[0,23-0,25]$} & 0,13 & $1066,27^{* *}$ \\
\hline
\end{tabular}

Nota. GFI=Goodness-of-Fit Index; CFI=Comparative Fit Index; RMSEA=Root Mean Square Error of Approximation; $\mathrm{IC}_{\mathrm{RMSEA}}=$ Intervalo de Confiança $90 \%$ do RMSEA; SRMR=Standardized Root Mean Residual.

${ }^{a}$ Expectativas de carreira e de futuro organizacional como um único fator.

${ }^{\mathrm{b}}$ Expectativas de carreira e de futuro organizacional como um único fator e intenção de rotatividade e comprometimento organizacional afetivo como um único fator.

$* * p<0,01$.

As médias das cargas fatoriais das subamostras do bootstrapping foram praticamente idênticas às cargas fatoriais do modelo proposto (a diferença máxima não atingiu 0,01 ), com baixo erro padrão (o máximo foi 0,05 ). Esses resultados demonstram a estabilidade das cargas e fornecem evidência sobre a adequação do processo de estimação do modelo.

Verificou-se então o risco de viés de método comum. As técnicas para detectar tal viés ainda são limitadas/imprecisas, de sorte que não há consenso na literatura sobre qual delas é a melhor (Podsakoff et al., 2003; Richardson, Simmering \& Sturman, 2009). Nesse cenário, optou-se aqui pelo difundido teste de Harman. Neste teste, executa-se uma análise fatorial exploratória sem rotação com todos os itens do modelo. Se o primeiro fator explicar mais de 50\% da variância, há indícios de viés (Podsakoff et al., 2003), fato que não se consumou no modelo proposto. Recentemente, uma variante dessa técnica ganhou espaço na literatura: gera-se um modelo de fator único na análise fatorial confirmatória e seu ajuste é avaliado. Como evidencia a Tabela 2, tal modelo manifestou péssimo ajuste. Logo, não parece existir risco elevado de viés de método comum. 


\section{Modelo Estrutural e Teste de Hipóteses}

O modelo estrutural proposto registrou bons índices de ajuste: $\chi^{2}(g l)=137,56(49)$, $p<0,01, \mathrm{GFI}=0,94, \mathrm{CFI}=0,97, \mathrm{RMSEA}[\mathrm{IC} 90 \%]=0,07[0,06-0,08]$ e $\mathrm{SRMR}=0,04$. As estimativas dos coeficientes padronizados estão na Figura 2 e todas foram estatisticamente significativas $(p<0,01)$. As hipóteses 1 e 2 estabeleciam que as expectativas de futuro organizacional relacionavam-se positivamente às expectativas de carreira na organização e ao comprometimento organizacional afetivo. Os resultados suportaram ambas as hipóteses.

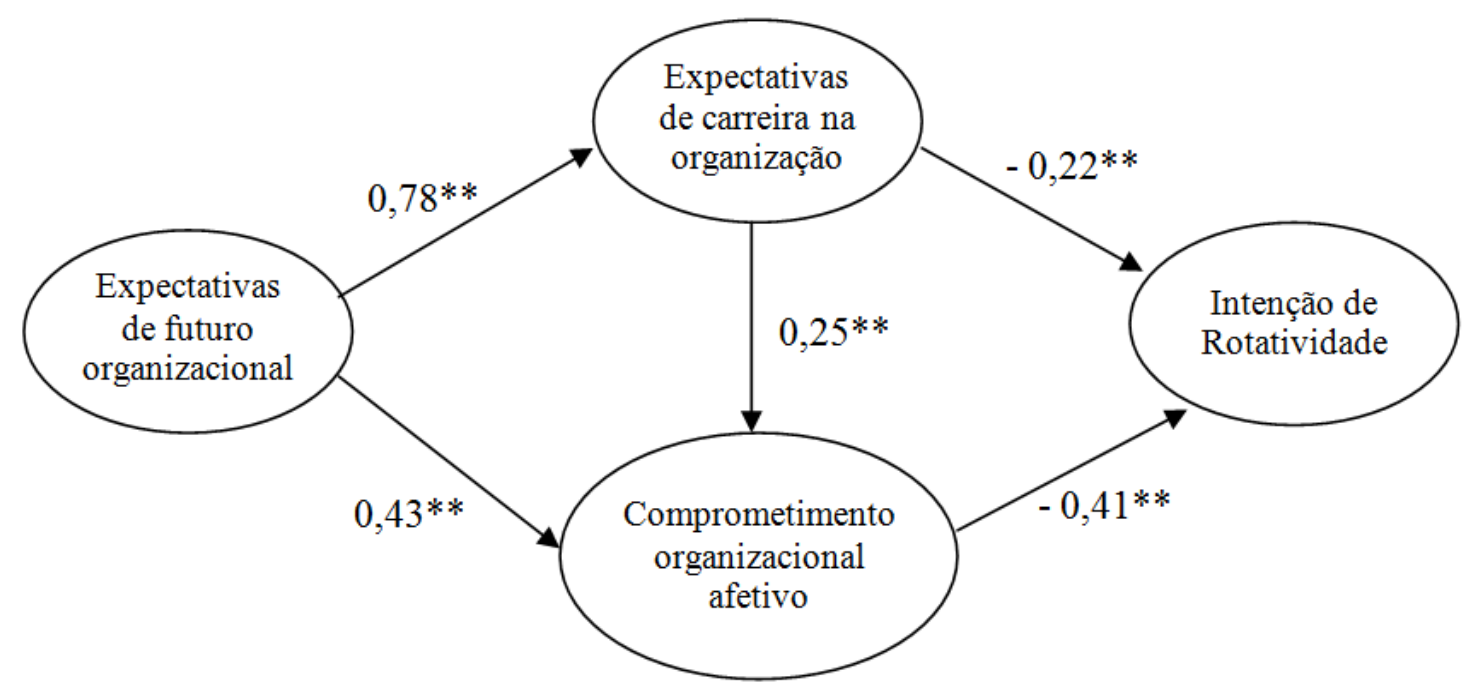

Figura 2. Coeficientes padronizados do modelo estrutural proposto $* * p<0,01$.

As hipóteses 3 e 4 previam que expectativas de carreira na organização relacionavamse positivamente ao comprometimento organizacional afetivo e negativamente à intenção de rotatividade. Os coeficientes estimados foram consistentes com ambas as hipóteses. A hipótese 5, que apontava a relação negativa de comprometimento organizacional afetivo com intenção de rotatividade, também foi suportada pelos resultados. O modelo explicou $41 \%$ da variância de comprometimento organizacional afetivo e $32 \%$ de intenção de rotatividade.

Ainda que todas as hipóteses tenham sido corroboradas, o modelo proposto foi cotejado a modelos alternativos. O primeiro modelo alternativo testado (modelo A1) adicionou ao modelo proposto a ligação direta entre expectativas de futuro organizacional e intenção de 
rotatividade. $\mathrm{O}$ coeficiente padronizado foi extremamente baixo $(0,01)$ e não significativo $(p>0,05)$. A diferença no qui-quadrado entre os modelos, $\Delta \chi^{2}(1)=0,02$, também não foi significativa $(p>0,05)$, apontando que a inclusão da ligação não melhorou o modelo proposto. Os dados sugerem, portanto, que a relação entre os dois construtos na análise fatorial confirmatória $(r=-0,42 ; p<0,01)$ foi totalmente mediada por expectativas de carreira na organização e comprometimento organizacional afetivo.

O modelo alternativo A2 visou a avaliar até que ponto a mediação parcial de expectativas de carreira na organização na relação de expectativas de futuro organizacional com comprometimento organizacional não poderia ser, na verdade, uma mediação total. Assim, procedeu-se à exclusão da ligação direta entre expectativas de futuro organizacional com comprometimento organizacional supondo que sua relação na análise fatorial confirmatória $(r=0,62$ e $p<0,01)$ pudesse ser totalmente explicada pelo mediador expectativas de carreira na organização. A exclusão da ligação resultou em piora significativa do ajuste do modelo: $\Delta \chi^{2}(1)=16,37, p<0,01$. Considerando a piora do ajuste, os dados sustentam a formulação inicial de mediação parcial.

A criação do modelo alternativo A3 objetivou aferir até que ponto a mediação parcial de comprometimento organizacional afetivo na relação de expectativas de carreira na organização com intenção de rotatividade não poderia ser, na verdade, uma mediação total. Assim, procedeu-se à exclusão da ligação direta entre expectativas de carreira na organização e intenção de rotatividade supondo que sua relação na análise fatorial confirmatória $(r=-0,46$; $p<0,01)$ pudesse ser totalmente explicada pelo mediador comprometimento organizacional afetivo. A exclusão da ligação redundou em piora significativa do ajuste do modelo: $\Delta \chi^{2}(1)=12,81, p<0,01$. Este resultado provê apoio à formulação inicial de mediação parcial. Em síntese, o modelo proposto exibe o mesmo nível de ajuste do modelo A1, contudo, é mais parcimonioso. Na comparação com os modelos A2 e A3, o modelo proposto obteve 
ajuste significativamente melhor. Assim, o modelo proposto foi assumido como o mais adequado e utilizado na análise de moderadores.

O teste de moderadores foi realizado por análise multigrupo, conforme indicado por Hair et al. (2010). Tais autores apontam, como pré-condição para esse teste, a necessidade de duas formas de invariância entre grupos no modelo de mensuração. A primeira (invariância de configuração) é assumida se os grupos conservam a mesma estrutura fatorial em um modelo sem restrições, no qual as cargas fatoriais são livremente estimadas para cada grupo (Hair et al., 2010; Kline, 2011). O ajuste desse modelo é avaliado, bem como a equivalência dos grupos quanto ao número de fatores e alocação dos itens em cada fator. A segunda (invariância métrica) é medida por meio de modelo aninhado (nested model) ao modelo sem restrições, no qual a igualdade das cargas fatoriais entre os dois grupos é imposta (Hair et al., 2010; Kline, 2011). Assume-se invariância métrica quando não há diferença estatisticamente significativa entre os valores de $\chi^{2}$ do modelo sem restrições e do modelo que impõe a igualdade das cargas entre os grupos, sinal que tais restrições não pioram o modelo.

Os dois pares de grupos (organizações do funcionalismo público versus privadas e alta versus média/baixa orientação para o futuro) foram verificados quanto à sua invariância no modelo de mensuração. Nos dois pares, as estruturas fatoriais foram iguais e os índices de ajuste dos modelos sem restrições foram aceitáveis ( $\mathrm{GFI} \geq 0,89, \mathrm{CFI} \geq 0,95$ e $\mathrm{RMSEA} \leq 0,06$ ), ou seja, há indicação de invariância de configuração. Os dados também suportaram invariância métrica nos dois pares: a diferença de ajuste $\left(\Delta \chi^{2}\right)$ entre os modelos com e sem restrição de igualdade nas cargas fatoriais registrou $p>0,05$.

O próximo passo foi testar efetivamente os moderadores. Seguindo as hipóteses estabelecidas, três relações entre construtos foram avaliadas: a) expectativas de futuro organizacional e comprometimento organizacional afetivo; b) expectativas de carreira na organização e comprometimento organizacional afetivo e c) expectativas de carreira na 
organização e intenção de rotatividade. Embora o foco esteja nessas três relações, os demais coeficientes estruturais também foram analisados de forma complementar.

Partindo dos modelos que asseguravam a invariância métrica, a moderação foi avaliada pela diferença de qui-quadrado entre o modelo estrutural sem restrições (no qual os coeficientes estruturais dos dois grupos de cada variável moderadora foram livremente estimados) e os modelos estruturais restritos (nos quais se impunha a restrição de igualdade entre grupos em cada coeficiente, um de cada vez).

O primeiro moderador analisado foi tipo de organização. Entre os cinco modelos estruturais restritos gerados (um para cada coeficiente estrutural), apenas o que igualou organizações do funcionalismo público e privadas na ligação de expectativas de carreira com intenção de rotatividade exibiu diferença estatística significativa com o modelo sem restrições: $\Delta \chi^{2}(1)=5,17 ; p=0,02$. Trata-se de um indício de moderação. Ademais, quando livremente estimado entre os grupos, o efeito (coeficiente padronizado) de expectativas de carreira em intenção de rotatividade foi moderado/significativo nas organizações privadas ($0,38 ; p<0,01)$ e fraco/não significativo nas públicas $(-0,13 ; p=0,22)$. Os demais coeficientes das organizações privadas e públicas são estatisticamente similares e muito próximos em magnitude. Considera-se a hipótese 6 parcialmente suportada.

No outro moderador examinado, orientação para o futuro, apenas o modelo que impôs igualdade entre grupos no coeficiente que liga expectativas de carreira ao comprometimento organizacional afetivo apresentou diferença estatística significativa com o modelo sem restrições: $\Delta \chi^{2}(1)=4,64 ; p=0,03$. Quando livremente estimado entre os grupos, o efeito (coeficiente padronizado) de expectativas de carreira em comprometimento organizacional foi moderado e significativo no grupo com média/baixa orientação para o futuro $(0,41$; $p<0,01)$ e ausente/não significativo no grupo com alta orientação para o futuro $(0,00$; $p=0,99)$. Os dados sugerem o papel moderador de orientação para o futuro na relação entre 
essas variáveis. Porém, o grupo com maior coeficiente foi o de média/baixa orientação para o futuro (isto é, na direção oposta da prevista); portanto, a hipótese 7 não foi sustentada. A comparação dos demais modelos com coeficientes estruturais restritos com o modelo sem restrição não acusou nenhuma diferença de qui-quadrado significativa (considerando $\alpha=0,05$ ).

\section{Discussão}

Os resultados forneceram suporte a quase todas as hipóteses estabelecidas, exceto no caso das conjecturas sobre os moderadores. O modelo estrutural obtido sugere, em primeiro lugar, que as expectativas dos indivíduos sobre suas carreiras na organização dependem fortemente das expectativas nutridas sobre o futuro da própria organização. Esse dado reforça, por meio de um modelo quantitativo, pesquisas qualitativas anteriores que identificaram tal ligação no discurso dos profissionais (Duarte \& Silva, 2013; Margolis \& Hansen, 2003; Ullrich et al., 2005) e sugere que os profissionais atribuem grande peso às contingências do ambiente organizacional no delineamento de seu futuro profissional.

O modelo estrutural indica ainda que expectativas mais favoráveis de futuro organizacional e de carreira vinculam-se a níveis maiores de comprometimento organizacional afetivo. Parece intuitivo supor que o vínculo com a organização decorra essencialmente das experiências passadas ou das atuais vivências dos indivíduos no trabalho. Este estudo descortinou que as expectativas sobre futuro também atuam na produção desse vínculo.

As análises apontaram, igualmente, que quanto mais favoráveis forem as expectativas de carreira, menor será a intenção de rotatividade, contribuindo neste sentido para além de comprometimento organizacional, o mais consistente preditor dessa variável (Meyer et al., 2002). A relação negativa e moderada entre futuro na carreira e intenção de rotatividade/desligamento foi identificada previamente (Chay \& Aryee, 1999; Chen et al., 2011). Os resultados endossaram esse padrão, contudo, expandiram a literatura ao conceituar 
o futuro na carreira por meio de expectativas, medi-lo com um instrumento mais abrangente e testá-lo em um modelo que contava com comprometimento organizacional.

Ao se avaliar possíveis moderadores, cumpre sublinhar o efeito de expectativas de carreira em intenção de rotatividade, que tende a ser mais robusto nas organizações privadas do que nas públicas. Nestas últimas, a intenção de sair/permanecer na organização parece menos dependente do futuro na carreira, possivelmente em função da influência do apreço pela estabilidade e da construção de vínculos relacionais de longo prazo. No setor privado, a relação com a organização tende a ser mais transacional e pragmática: logo, a intenção de rotatividade sofreria efeito mais direto das expectativas de carreira, que refletem crenças sobre futuras contrapartidas obtidas junto à organização.

Ressalta-se também que, no grupo com média/baixa orientação para o futuro, o efeito positivo das expectativas de carreira em comprometimento organizacional afetivo é maior do que no grupo com alta orientação para o futuro (a rigor, neste último grupo, o efeito foi nulo). Embora a moderação fosse prevista, esperava-se o efeito fosse maior no grupo com alta orientação para o futuro. A interpretação dos dados faculta possível explicação para a inversão. Indivíduos com alta orientação para o futuro planejam/organizam o futuro cuidadosamente, de modo que provavelmente atribuem conquistas futuras na carreira aos seus próprios méritos/esforços (e não à organização). Destarte, sentem-se menos imersos no mecanismo de troca social com a organização e menos obrigados a retribuir na forma de comprometimento (por isso, o efeito é quase nulo). Indivíduos com média/baixa orientação para o futuro planejam e se esforçam menos para obter um porvir favorável na carreira. Este passaria então a ser interpretado mais como fruto das políticas/práticas organizacionais do que como resultado de esforço/planejamento pessoal, exigindo assim mais reciprocidade (na forma de comprometimento) na relação com a organização. 
Esta pesquisa contribui para a literatura, primeiramente, ao valorizar a dimensão temporal na compreensão da dinâmica indivíduo-organização, abordagem ainda residual na academia (George \& Jones, 2000; Lee \& Liebenau, 1999; Sonnentag, 2012). Em especial, explicita o entrelaçamento do presente com o futuro na predição de comprometimento organizacional afetivo e intenção de rotatividade. Nesse sentido, expectativas favoráveis para a carreira e para o ambiente organizacional (futuro positivo antecipado) parecem retroagir temporalmente sobre aquelas variáveis, estimulando nos profissionais vínculos mais profundos com a organização, como uma forma de contrapartida.

Do ponto de vista prático, os resultados sugerem que a gestão de recursos humanos deve atentar para as crenças de seus profissionais não apenas sobre o próprio futuro, mas também sobre o futuro da organização. Em um mercado de trabalho com grande disputa por talentos, a existência de expectativas favoráveis (seja para si mesmo e/ou para a organização) pode garantir a retenção de bons quadros para a organização e a elevação do comprometimento. Ainda que a intenção de rotatividade nem sempre se traduza em efetivo desligamento, certamente aumenta o risco de evasão de profissionais para o mercado. Nessa linha, torna-se relevante, por exemplo, aferir por meio de pesquisas institucionais como estão as expectativas e investir em práticas capazes de fomentar expectativas positivas, como a criação de trilhas de carreiras (futuro profissional) e a comunicação adequada dos planos de negócios e visão da organização (futuro organizacional).

Entre as limitações da pesquisa, sublinha-se a não aleatoriedade da amostra, a impossibilidade de derivar relações causais entre as variáveis e o uso exclusivo de medidas de autorrelato, potencialmente influenciadas por vieses como a desejabilidade social. Destaca-se ainda que o modelo não incluiu variáveis provavelmente importantes na predição de comprometimento organizacional e intenção de rotatividade (como percepção de alternativas de emprego em outras organizações e orientação de carreira sem fronteiras). Estas poderiam 
ser usadas como variáveis de controle no modelo. Não foi possível também incluir o efetivo desligamento como variável. Além de ser um dado confidencial na maioria das organizações, sua inclusão no modelo exigiria um desenho longitudinal, opção difícil dada a premissa de não identificação dos respondentes. Pesquisas futuras podem incluir tais variáveis no modelo e assumir desenho longitudinal, oportunizando testes mais abrangentes e complexos.

A relação com o futuro marca a subjetividade humana de diversas formas. No mundo organizacional, pouco se sabe sobre o modo como as expectativas influenciam o momento atual dos profissionais. Mesmo com suas limitações, espera-se que este artigo abra veredas para novas pesquisas neste instigante (e pouco explorado) campo de estudos. 


\section{Referências}

Bandura, A. (1977). Self-efficacy: Toward a unifying theory of behavioral change. Psychological Review, 84, 191-215.

Bastos, A. V. (1994). Comprometimento organizacional: seus antecedentes em distintos setores da administração e grupos ocupacionais. Temas em Psicologia, 1, 73-90.

Bastos, A. V. \& Borges-Andrade, J. E. (2002). Comprometimento com o trabalho: padrões em diferentes contextos organizacionais. Revista de Administração de Empresas, 42, 31 41.

Bastos, A. V., Rodrigues, A., Moscon, D., Silva, E. \& Pinho, A. (2013). Comprometimento no trabalho: fundamentos para gestão de pessoas. In L. Borges \& M. Mourão (Orgs.). $O$ trabalho e as organizações (pp. 279-310). Porto Alegre: Artmed.

Blau, P. (1964). Exchange and power in social life. New York: John Wiley.

Boros, S. \& Curseu, P. (2013). Is it here where I belong? An integrative model of turnover intentions. Journal of Applied Social Psychology. 43, 1553-1562.

Byrne, B. (2010). Structural equation modeling with AMOS. New York: Taylor \& Francis.

Chay, Y. \& Aryee, S. (1999). Potential moderating influence of career growth opportunities on careerist orientation and work attitudes: Evidence of the protean career era in Singapore. Journal of Organizational Behavior, 20(5), 613-623.

Chen, G., Ployhart, R., Cooper-Thomas, H., Anderson, N., \& Bliese, P. (2011). The power of momentum: A new model of dynamic relationships between job satisfaction change and turnover intentions. Academy of Management Journal, 54, 159-181.

Chiu, W. (2002). Do types of economic ownership matter in getting employees to commit? An exploratory study in the People's Republic of China. International Journal of Human Resource Management, 13, 865-882. 
Crawshaw, J., van Dick, R., \& Brodbeck, F. C. (2012). Opportunity, fair process and relationship value: career development as a driver of proactive work behaviour. Human Resource Management Journal, 22(1), 4-20.

Duarte, M. \& Silva, A. (2013). A reconstrução da carreira em ambientes de trabalho em transformação. Organizações \& Sociedade, 20, 699-715.

George J. \& Jones, G. (2000). The role of time in theory and theory building. Journal of Management, 26, 657-684.

Gouldner, A. (1960). The norm of reciprocity: A preliminary statement. American Sociological Review, 25, 161-178.

Hair, J., Black, W., Babin, B., Anderson, R. \& Tatham, R. (2010). Multivariate Data Analysis (sétima edição). Upper Saddle River, NJ: Prentice Hall.

Hall, R., Snell, A. \& Foust, M. (1999). Item parceling strategies in SEM: Investigating the subtle effects of unmodeled secondary constructs. Organizational Research Methods, 2, 233-256.

Kline, R. (2011). Principles and practice of structural equation modeling. New York: Guilford Press.

Kraimer, M., Seibert, S., Wayne, S., Liden, R., \& Bravo, J. (2011). Antecedents and outcomes of organizational support for development: The critical role of career opportunities. Journal of Applied Psychology, 96, 485-500.

Lawrence, B. \& Tolbert, P. (2007). Organizational demography and individual careers: structure, norms, and outcomes. In H. Gunz, \& M.A. Peiperl (Eds.). Handbook of Career Studies (pp. 399-421). Thousand Oaks, CA: Sage.

Lee, H. \& Liebenau, J. (1999). Time in organizational studies: towards a new research direction. Organization Studies, 20, 1035-1058.

Lewin, K. (1939). Field Theory and Experiment in Social Psychology: Concepts and Methods. The American Journal of Sociology, 44, 868-896. 
Magalhães, M. \& Bendassolli, P. (2013). Desenvolvimento de carreiras nas organizações. In L. Borges \& M. Mourão (Orgs.). O trabalho e as organizações (pp. 433-464). Porto Alegre: Artmed.

Margolis, S. \& Hansen, C. D. (2003). Visions to guide performance: a typology of multiple future organizational images. Performance Improvement Quarterly, 16(4), 40-58.

Menezes, I. \& Bastos, A. (2011). Comprometimento organizacional atitudinal: estudo empírico sobre a dimensionalidade do construto. Estudos de Psicologia (Campinas), 28, 463-474.

Meyer, J., Stanley, D., Herscovitch, L. \& Topolnytsky, L. (2002). Affective, Continuance, and Normative Commitment to the Organization: A Meta-analysis of Antecedents, Correlates and Consequences. Journal of Vocational Behavior, 61, 20-52.

Mitchell, T., Burch, T., \& Lee, T. (2014). The need to consider time, level, and trends: A turnover perspective. Journal of Organizational Behavior, 35(2), 296-300.

Mobley, W., Griffeth, R., Hand, H. \& Meglino, B. M. (1979). Review and conceptual analysis of the employee turnover process. Psychological Bulletin, 86, 493-522.

Mossholder, K. W., Settoon, R. P., Harris, S. G., \& Armenakis, A. A. (1995). Measuring emotion in open-ended survey responses: An application of textual data analysis. Journal of Management, 21(2), 335-355.

Oettingen, G. (2012). Future thought and behaviour change. European Review of Social Psychology, 23, 1-63.

Oettingen, G. \& Mayer, D. (2002). The motivating function of thinking about the future: expectations versus fantasies. Journal of Personality and Social Psychology, 83, 1198-1212.

Podsakoff, P., MacKenzie, S., Lee, J. \& Podsakoff, N. (2003). Common method biases in behavioral research: a critical review of the literature and recommended remedies. Journal of Applied Psychology, 88(5), 879-903. 
Poon, J. (2012). Distributive Justice, Procedural Justice, Affective Commitment, and Turnover Intention: A Mediation-Moderation Framework. Journal of Applied Social Psychology, 42, 1505-1532.

Prince, J. B. (2003). Career opportunity and organizational attachment in a blue-collar unionized environment. Journal of Vocational Behavior, 63(1), 136-150.

Richardson, H. A., Simmering, M. J., \& Sturman, M. C. (2009). A tale of three perspectives: Examining post hoc statistical techniques for detection and correction of common method variance. Organizational Research Methods, 12(4), 762-800.

Salles, D. \& Nogueira, M. (2006). Carreiras no serviço público federal: antigos dogmas, novas perspectivas. In M. Balassiano \& I. Costa (Orgs.). Gestão de Carreiras: Dilemas e Perspectivas (pp.134-149). Rio de Janeiro: Editora Atlas.

Sant'anna, L., Paschoal, T. \& Gosendo, E. (2012). Bem-estar no Trabalho: Relações com Estilos de Liderança e Suporte para Ascensão, Promoção e Salários. Revista de Administração Contemporânea, 16, 744-764.

Siqueira M., Gomide Jr., S., Oliveira, A. \& Filho, A. (2014). Intenção de rotatividade. In M. Siqueira (Org.). Novas Medidas do Comportamento Organizacional (pp. 209-216). Porto Alegre: Artmed.

Sonnentag, S. (2012). Time in organizational research: Catching up on a long neglected topic in order to improve theory. Organizational Psychology Review, 2(4), 361-368.

Souza, M. (2013). O uso do crédito pelo consumidor: percepções multifacetadas de um fenômeno intertemporal (Dissertação de Mestrado). Universidade de Brasília, Brasília.

Stroh, L., \& Reilly, A. (1997). Rekindling Organizational Loyalty: The Role of Career Mobility. Journal of Career Development, 24, 39-54. 
Ullrich, J., Wieseke, J., \& van Dick, R. (2005). Continuity and Change in Mergers and Acquisitions: A Social Identity Case Study of a German Industrial Merger. Journal of Management Studies, 42(8), 1549-1569.

Vasconcellos, V. \& Neiva, E. (2015a). Escala de Expectativas de Futuro Organizacional: Desenvolvimento e Evidências de Validade. Manuscrito em preparação para submissão. Vasconcellos, V. \& Neiva, E. (2015b). Escala de Expectativas de Carreira na Organização: Desenvolvimento e Evidências de Validade. Manuscrito em preparação para submissão. Vroom, V. H. (1964). Work and motivation. New York: Wiley.

Zimbardo, P. \& Boyd, J. (1999). Putting time in perspective: A valid, reliable individualdifferences metric. Journal of Personality and Social Psychology, 77(6), 1271-1288. 


\section{CONSIDERAÇÕES FINAIS}

A relação com o futuro perpassa a subjetividade humana e influencia a vida psíquica dos indivíduos. Tal influência adquire força ainda maior com o advento da Modernidade, época na qual o futuro, menos vinculado ao fatalismo da religião/tradição, surge como projeto aberto e farto de possibilidades, oportunidades e riscos. Especialmente nas últimas décadas, as transformações tecnológicas, econômicas e sociais delinearam um cenário dotado de alto grau de incerteza sobre como será o futuro.

O mundo do trabalho insere-se neste cenário de constante mutação e indefinição sobre o futuro. Contudo, a relação dos indivíduos com o futuro acaba sendo em larga escala ignorada ou tratada de forma inadequada em estudos acadêmicos sobre trabalho e organizações. A presente tese buscou, dentro de seus limites, compreender melhor a relação dos indivíduos com o futuro no contexto organizacional. Seu objetivo geral foi investigar variáveis que influenciam expectativas sobre a carreira na organização e sobre o futuro da própria organização, assim como identificar os efeitos dessas mesmas expectativas sobre outras variáveis no contexto organizacional.

Para alcançar tal objetivo, empreendeu-se uma série de pesquisas entrelaçadas e dispostas nos sete manuscritos que compõem esta tese. Os dois primeiros manuscritos analisaram a produção científica sobre futuro na carreira e futuro organizacional na perspectiva dos profissionais. Essas duas revisões indicaram que a literatura adota diferentes formas de projetar/representar/lidar com o futuro, mas que ambos os campos ainda estão em formação, sendo caracterizados por pesquisas isoladas e por construtos/instrumentos formulados sem grande aprofundamento conceitual ou psicométrico. No Brasil, investigações sobre esses dois tópicos são raras.

Os Manuscritos 3 e 4 apresentaram o desenvolvimento e forneceram evidências de validade da Escala de Expectativas de Carreira na Organização (EECO) e da Escala de 
Expectativas de Futuro Organizacional (EEFO). As duas escalas registraram boas qualidades psicométricas, estão adaptadas ao contexto brasileiro e são rapidamente aplicadas. Podem ser empregadas tanto na academia quanto nas organizações.

Por sinal, os manuscritos seguintes utilizaram tais escalas. O Manuscrito 5 testou o efeito de diversas variáveis que representam a atual situação de carreira do profissional em suas expectativas de carreira na organização (medida pela EECO). Os dados sugerem que indivíduos em cargos gerenciais, que participaram de práticas de desenvolvimento de carreira e com conquistas profissionais recentes detêm expectativas mais elevadas do que os demais indivíduos. Os efeitos de estágio de carreira, tempo de carreira na organização e sexo foram pequenos ou inexistentes. A partir de uma meta-análise de pequeno porte, este manuscrito forneceu ainda referências de resultados para o fator Conquistas Profissionais da EECO que podem ser utilizadas por profissionais de recursos humanos na interpretação de seus dados se utilizarem a escala para fins de diagnóstico.

Os dois últimos manuscritos relataram testes de modelos estruturais. Os resultados do Manuscrito 6 revelaram que bem-estar no trabalho (efeito direto), expectativas de futuro organizacional (efeito direto) e percepções de políticas/práticas de recursos humanos (efeito indireto) influenciam as expectativas de carreira na organização. Por fim, o Manuscrito 7 testou os dois tipos de expectativas no papel de variável antecedente. As expectativas de futuro organizacional mostraram capacidade preditiva diante de comprometimento organizacional afetivo, ao passo que as expectativas de carreira na organização, além de predizerem esta última variável, surgiram também como antecedentes de intenção de rotatividade.

Esse conjunto de manuscritos proporciona contribuições acadêmicas e práticas. As revisões de literatura geraram um retrato do estado atual das pesquisas nacionais e internacionais sobre futuro organizacional e na carreira, permitindo a identificação das 
possibilidades, das lacunas e do potencial de investigação desses campos. A tese forneceu ainda medidas confiáveis e válidas que podem ser empregadas livremente nas organizações para fins de diagnóstico e por outros pesquisadores em estudos na área de comportamento organizacional.

Por fim, os últimos manuscritos trazem evidências da relação entre as expectativas de futuro e variáveis-chave da vida organizacional. Esses resultados auxiliam a academia na compreensão da relação indivíduo-trabalho-organização, especialmente ao salientar a dimensão intertemporal que a perpassa, assim como podem ser aproveitados na formulação de políticas e práticas organizacionais com vistas a promover melhorias na gestão de recursos humanos. Assim, trata-se não apenas de suprir lacunas da literatura, mas também de sensibilizar as organizações para o papel da temporalidade no contexto organizacional e de fornecer subsídios para a discussão desse tópico.

Apesar de suas contribuições, é preciso considerar as limitações dos estudos relatados. Todos os estudos adotaram corte transversal e delineamento não experimental, o que impede o teste de relações causais entre as variáveis. Outra limitação concerne ao uso de medidas de autorrelato (que podem ser influenciadas por vieses como a desejabilidade social) e ao fato da EECO e da EEFO exigirem respondentes com pelo menos o nível médio de escolaridade. Ainda sobre limitações metodológicas, embora algumas amostras tenham sido geradas por listas aleatórias das organizações, outras não contaram com esse expediente, de forma que o recrutamento de respondentes ocorreu pela divulgação da pesquisa via e-mails e redes sociais. Ademais, conforme sugerido nos Manuscritos 5, 6 e 7, outras variáveis poderiam ser testadas como antecedentes e consequentes das expectativas de futuro organizacional e de carreira.

Essas limitações designam caminhos futuros de investigação. Sugere-se a utilização de pesquisas de corte longitudinal e com delineamento experimental ou quase experimental para 
conferir maior robustez aos resultados. O teste de variáveis aferidas por medidas objetivas no papel de antecedente ou consequente das expectativas também enriqueceria a compreensão do fenômeno. Por fim, a replicação da presente pesquisa em outros contextos organizacionais também deve constar na agenda de investigação, sendo especialmente importante acrescentar o teste de explicações rivais para as relações aqui reportadas.

Existe, por certo, vasto terreno a ser investigado sobre a relação dos indivíduos com o futuro na carreira e com o futuro de suas organizações. Esse terreno encontra-se praticamente inexplorado, especialmente no Brasil. A expectativa é que este trabalho contribua para pavimentar os caminhos dessa exploração. Afinal, essa tese nunca deixou de lançar seu olhar para o futuro. 